\title{
WRONG TURN IN CYBERSPACE: USING ICANN TO ROUTE AROUND THE APA AND THE CONSTITUTION
}

\author{
A. MiCHAEL FROOMKIN $\dagger$
}

\begin{abstract}
The Internet relies on an underlying centralized hierarchy built into the domain name system (DNS) to control the routing for the vast majority of Internet traffic. At its heart is a single data file, known as the "root." Control of the root provides singular power in cyberspace.
\end{abstract}

This Article first describes how the United States government found itself in control of the root. It then describes how, in an attempt

Copyright (C) 2000 by A. Michael Froomkin.

$\dagger \quad$ Professor, University of Miami School of Law. E-mail: froomkin@law.tm. Research and writing of this Article was supported by a Summer Grant from the University of Miami School of Law. Thank you to Karl Auerbach and Richard Sexton for technical information, to Tony Rutkowski for help with DNS history, to Jonathan Weinberg for a number of very helpful conversations, to all the members of the BWG+ mailing list for an education, to James Boyle for including me in this symposium, to Julie Dixson for research assistance, and especially to Caroline Bradley. Kind readers who helped me correct and improve drafts included Alan Davidson, John Hart Ely, Bret A. Fausett, Patrick Gudridge, David Johnson, David Post, Ellen Rony, Tony Rutkowski, Joe Sims, and Jonathan Weinberg. Remaining errors are my own unintentional contribution to further obfuscating ICANN's history.

Readers have a right to know that I participate in activities that touch on the subject of this Article. I served as a member of the so-called Panel of Experts that advised the World Intellectual Property Organization on its Domain Name Process. See infra note 13. Currently, I am a director of disputes.org, which, in partnership with eResolution.ca, is one of the dispute resolution providers accredited by ICANN. See Approved Providers for Uniform Domain Name Dispute Resolution Policy, at http://www.icann.org/udrp/approved-providers.htm (last visited Sept. 21, 2000) (providing a link to the eResolution website) (on file with the Duke Law Journal). I am also a co-founder of ICANNWatch.org, a group founded to increase awareness of ICANN's activities. The views expressed in this article are my own and should not be attributed to either disputes.org or ICANNWatch.org.

An earlier version of this paper was delivered in Durham, N.C., on March 3, 2000. Unless otherwise noted, this Article aims to reflect technical and legal developments as of October $1,2000$. 
to meet concerns that the United States could so dominate an Internet chokepoint, the U.S. Department of Commerce (DoC) summoned into being the Internet Corporation for Assigned Names and Numbers (ICANN), a formally private nonprofit California corporation. DoC then signed contracts with ICANN in order to clothe it with most of the U.S. government's power over the DNS, and convinced other parties to recognize ICANN's authority. ICANN then took regulatory actions that the U.S. Department of Commerce was unable or unwilling to make itself, including the imposition on all registrants of Internet addresses of an idiosyncratic set of arbitration rules and procedures that benefit third-party trademark holders.

Professor Froomkin then argues that the use of ICANN to regulate in the stead of an executive agency violates fundamental values and policies designed to ensure democratic control over the use of government power, and sets a precedent that risks being expanded into other regulatory activities. He argues that DoC's use of ICANN to make rules either violates the APA's requirement for notice and comment in rulemaking and judicial review, or it violates the Constitution's nondelegation doctrine. Professor Froomkin reviews possible alternatives to ICANN, and ultimately proposes a decentralized structure in which the namespace of the DNS is spread out over a transnational group of "policy partners" with DoC.

\section{TABLE OF CONTENTS}

Introduction 20

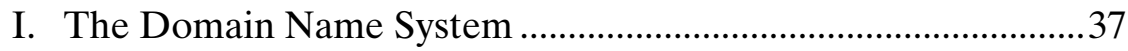

A. Domain Names and Their Uses ............................................37

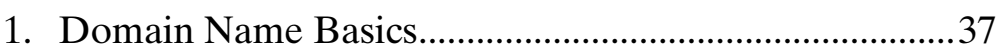

2. The Registration Hierarchy ............................................41

3. The Domain Name Resolution Hierarchy ......................42

B. The Source and Import of Control of the Legacy Root.

II. The DNS: A Contractual History...............................................50

A. Before ICANN .....................................................................

1. Early Days (1972-94) ......................................................51

2. The NSF-NSI Cooperative Agreement (1993-95)..........57

3. The TM Community Awakens ......................................59

4. PGP Media Lawsuit (1997) .............................................66

5. The Road to the White Paper (1997-98) .........................62

B. Contractual Basis of ICANN's Authority (October 1998-present) 
1. ICANN Formed (October 1998) …...................................72

2. ICANN Opens Shop \& DoC-ICANN Memorandum of Understanding (November 1998) .....82

3. ICANN Takeover of the IANA Function (1999) ..........85

4. ICANN's Search for Revenue .......................................87

5. The Tripartite Agreements (November 1999)...............89

III. DoC's Relationship with ICANN Is Illegal ..............................93

A. ICANN Is Engaged in Policymaking.....................................99

B. DoC's Relationship with ICANN ......................................105

1. DoC's Continuing Control over the Legacy Root .......106

2. Nature of DoC's Authority to Review ICANN's

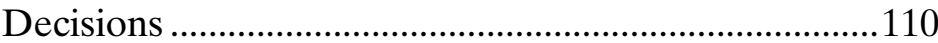

3. The State Actor Question ............................................113

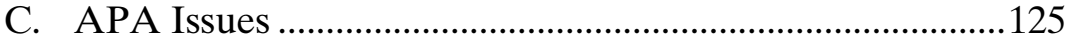

1. Do APA Exceptions Apply? .......................................126

2. Consequences of APA.................................................129

3. Is ICANN an "Advisory Committee"? ........................138

D. Constitutional Issues...........................................................141

1. Origins and Purpose of the Nondelegation

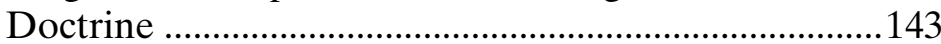

2. Modern Reception of Private Nondelegation

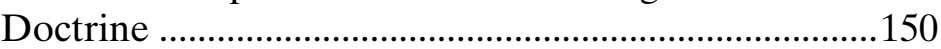

E. Due Process Issues....................................................................153

F. Structural Failures/Self-Dealing ........................................160

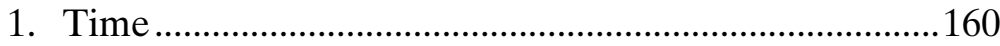

2. Money ................................................................................. 161

IV. Reforming the U.S. DNS Policy ...............................................165

A. The Policy Problem ............................................................166

B. ICANN Sets a Terrible Precedent ........................................168

C. A Better DNS Policy is Within Our Grasp........................171

1. Limit ICANN to Technical Policymaking?..................171

2. Full Privatization? ..............................................................174

3. Give the DNS to an International Body?......................176

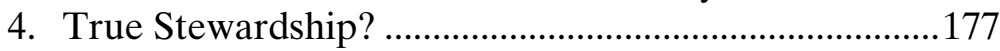


The availability of judicial review is the necessary condition, psychologically if not logically, of a system of administrative power which purports to be legitimate, or legally valid.

LOUIS L. JAFFE ${ }^{1}$

\section{INTRODUCTION}

The United States government is managing a critical portion of the Internet's infrastructure in violation of the Administrative Procedures Act (APA) and the Constitution. For almost two years, the Internet Corporation for Assigned Names and Numbers (ICANN) has been making domain name policy under contract with the Department of Commerce (DoC). ${ }^{2}$ ICANN is formally a private nonprofit California corporation created, in response to a summoning by U.S. government officials, to take regulatory actions that DoC was unable or unwilling to take directly. If the U.S. government is laundering its policymaking through ICANN, it violates the APA; if ICANN is, in fact, independent, then the federal government's decision to have ICANN manage a resource of such importance and to allow-indeed, require-it to enforce regulatory conditions on users of that resource violates the nondelegation doctrine of the U.S. Constitution. In either case, the relationship violates basic norms of due process and public policy designed to ensure that federal power is exercised responsibly.

Despite being famously decentralized and un-hierarchical, ${ }^{3}$ the Internet relies on an underlying centralized hierarchy built into the domain name system (DNS). Domain names (such as "www.law.miami.edu") are the unique identifiers that people depend on to route e-mail, find web pages, and connect to other Internet resources. ${ }^{4}$ The need to enforce uniqueness, that is, to prevent two people from attempting to use the exact same domain name, creates a need for some sort of body to monitor or allocate naming. However,

1. Judicial Control of Administrative ACtion 320 (1965).

2. See infra Part II.B. DoC recently extended these contracts. See infra note 47.

3. See generally A. Michael Froomkin, The Internet as a Source of Regulatory Arbitrage, in BORDERS IN CYBERSPACE: INFORMATION POLICY AND THE GLOBAL INFORMATION INFRASTRUCTURE 129 (Brian Kahin \& Charles Nesson eds., 1997) (explaining "the Internet's resistance to centralized control"), available at http://www.law.miami.edu/ froomkin/articles/ arbitr.htm. But see infra note 709 and accompanying text (discussing centralizing tendencies).

4. See infra Part I.A for a fuller explanation of the functioning of the DNS. 
control over the DNS confers substantial power over the Internet. Whoever controls the DNS decides what new families of "top-level" domain names can exist (e.g., new suffixes like .xxx or .union) and how names and essential routing numbers will be assigned to websites and other Internet resources. ${ }^{5}$ The power to create is also the power to destroy, and the power to destroy carries in its train the power to attach conditions to the use of a domain name. ${ }^{6}$ Currently, this power is used to require domain name registrants to publish their addresses and telephone numbers on a worldwide readable list and to agree that any trademark holder in the world aggrieved by their registration can demand arbitration regarding ownership of the name under an eccentric set of rules and standards. In theory, the power conferred by control of the DNS could be used to enforce many kinds of regulation of the Internet; it could, for example, be used to impose content controls on the World Wide Web (WWW), although there are no signs that anyone intends this at present.

Without meaning to at first, the United States government found itself controlling this unique Internet chokepoint. ${ }^{7}$ When the Internet was small, the DNS was run by a combination of volunteers, the Na-

5. See ICANN Fact Sheet, at http://www.icann.org/general/fact-sheet.htm (last modified Mar. 25, 2000) (on file with the Duke Law Journal). In addition to giving ICANN effective control over the DNS, DoC gave ICANN the authority to make critical decisions relating to Internet Protocol (IP) numbers. See id. In the long run, control over IP numbers is likely to be more important than control over the DNS. The Internet as we know it could function without domain names. It could function, albeit differently, with radically different systems for allocating domain names. It cannot function without a system for the unique allocation of IP numbers. Furthermore, the demand for IP numbers is likely to increase exponentially as designers begin to put IP numbers on everything found in the office or home-even the foods found in a "smart fridge." See A. Michael Froomkin, The Death of Privacy, 52 STAN. L. REV. 1461, 1493-94 (2000). This Article nevertheless concentrates on the short-term DNS issues, because they are much clearer. ICANN has yet to take any substantial decisions relating to the allocation of IP numbers.

6. See Jonathan Zittrain, ICANN: Between the Public and the Private: Comments Before Congress, 14 BERKELEY TECH. L.J. 1071, 1073 (1999) (noting that control of .com could facilitate the control of content).

7. Reviewing the "research done and steps taken" to avoid Y2K disruptions of the Internet, one report noted:

Due to its fundamental design assumption of a singly rooted hierarchical namespace, the domain name system (DNS) comprises one of the few (logical) single points of failure within the Internet. More specifically, the root of the Internet namespace is held in 13 geographically distributed root name servers operated by nine independent organizations. In a worst case scenario, loss of all 13 of the root name servers would result in significant disruption to Internet operation as name to address translation (and vice versa) would no longer function.

David Conrad et al., Root Nameserver Year 2000 Status, at http://www.icann.org/committees/ dns-root/y2k-statement.htm (last modified July 15, 1999) (on file with the Duke Law Journal). 
tional Science Foundation (NSF), and U.S. government civilian and military contractors and grant recipients. ${ }^{8}$ As the paymaster for these contractors, the U.S. government became the de facto ruler of the DNS, although it barely exercised-and for a long time may not in any real sense have been aware of-its power. The Internet's exponential growth placed strains on the somewhat ad hoc system for managing the DNS, and what had been primarily technical issues became political, legal, and economic problems that attracted high-level official attention. ${ }^{9}$ In particular, as attractive domain names in .com began to become scarce, ${ }^{10}$ disputes over attractive names became increasingly common, ${ }^{11}$ and pressure mounted for the creation of new "top-level" domain suffixes such as .shop or .web. Although technically trivial to implement, ${ }^{12}$ the proposals ran into intense counter-

8. See generally Vint Cerf, A Brief History of the Internet and Related Networks, Internet Society, at http://www.isoc.org/internet-history/cerf.html (July 1995) (documenting the creation and growth of the Internet) (on file with the Duke Law Journal); Barry M. Leiner et al., A Brief History of the Internet, Internet Society, at http://www.isoc.org/internet-history/brief.html (last visited Aug. 17, 2000) (reviewing the origin and fundamental ideas behind the Internet) (on file with the Duke Law Journal).

9. See infra Parts II.A.3-5. Even if the individuals responsible for managing the government's support of the networks that would grow into the Internet may have understood the implications of their work, there is no sign that this understanding extended to higher-level officials.

10. In 1998, NSI registered almost two million new names. See Michele Masterson, NSI Registers Almost 2 Million Web Addresses in 1999, INTERNET NEWS.COM, II 1 (Jan. 12, 1999), at http://www.internetnews.com/bus-news/article/0,2171,3_24221,00.html (on file with the Duke Law Journal). The growing importance of domain names led to speculative registration and hoarding. By April 1999, Wired News found that fewer than 2,000 of the 25,000 most common English words remained to be registered. See Declan McCullagh, Domain Name List is Dwindling, WIRED News, If 3 (Apr. 14, 1999), at http://www.wired.com/news/ technology/0,1282,19117,00.html (on file with the Duke Law Journal). Many of the most attractive names had been taken years earlier. See ELLEN RONY \& PETER RONY, THE DOMAIN NAME HANDBOOK 26, 31-32 (1998) (noting that many popular domain names are no longer available).

11. The first high-profile disputes were in 1994, over kaplan.com and mtv.com. See generally RONY \& RONY, supra note 10 (tracing the history of these disputes).

12. Karl Auerbach has suggested that the smallest technically-mandated upper level for the number of gTLDs might be as high as a million. See Posting of Karl Auerbach, karl@CaveBear.com, to wg-c@dnso.org (Dec. 15, 1999), Domain Name Supporting Organization, http://www.dnso.org/wgroups/wg-c/Arc01/msg00195.html (on file with the Duke Law Jour$n a l)$. On October 10, 2000, Mr. Auerbach was elected as the North American representative to the ICANN board. See Vote for Region 5 Director-North America, at http://www.election.com/ us/icann/region5.html (last visited Oct. 12, 2000) (announcing Auerbach's election) (on file with the Duke Law Journal). Others with long experience in DNS matters apparently agree. See Email from Paul Vixie, BIND 8 Primary Author, to Eric Brunner (Dec. 15, 1999) ("A million names under '? isn't fundamentally harder to write code or operate computers for than are a million names under 'COM.'”), Domain Name Server Organization, http://www.dnso.org/ 
pressure from intellectual property rights holders who already faced mounting problems with cybersquatters-speculators who registered domain names corresponding to trademarks and held them for profit. ${ }^{13}$ Meanwhile, foreign governments, notably the European Union, began to express understandable concern about the United States' control of a critical element of a global communication and commercial resource on which they foresaw their economies and societies becoming ever-more dependent. ${ }^{14}$

wgroups/wg-c/Arc01/msg00203.html (on file with the Duke Law Journal). Peter Deutsch has performed tests using the .com file as a Top-Level Domain (TLD) and found that it works. Indeed, he argues that this is not surprising, as there is no technical difference between the TLD file and a second-level domain file. See E-mail from Peter Deutsch, Engineering Manager, Cisco Systems, to Professor A. Michael Froomkin, University of Miami School of Law (Sept. 26, 2000) (on file with the Duke Law Journal). There are currently about sixteen million registrations in .com, suggesting that the maximum number of TLDs may be very high. See Quickstats, at http://www.dotcom.com/facts/quickstats.html (last visited Sept. 29, 2000) (reporting twenty million registrations, of which $80 \%$ are in .com) (on file with the Duke Law Journal).

Some experts worry, however, that a very large number of new TLDs might affect DNS response time. See, e.g., E-mail from Paul V. Mockapetris, BIND Author, to Paul Vixie, BIND 8 Primary Author, \& Eric Brunner (Dec. 15, 1999) (querying whether one million new TLDs would impose performance costs on DNS), Domain Name Server Organization, http://www.dnso.org/wgroups/wg-c/Arc01/msg00202.html (on file with the Duke Law Journal).

13. See, e.g., The Management of Internet Names and Addresses: Intellectual Property Issues-Final Report of the WIPO Internet Domain Name Process, II 23, World Intellectual Property Organization, at http://wipo2.int/process1/report/finalreport.html (last visited Aug. 17, 2000) (noting the existence of "a number of predatory and parasitical practices that have been adopted by some ... includ[ing] the deliberate, bad faith registration as domain names of wellknown and other trademarks in the hope of being able to sell the domain names to the owners of those marks") (on file with the Duke Law Journal) [hereinafter Domain Name Process]. WIPO's Final Report set out many of the ideas later incorporated into ICANN's Uniform Dispute Resolution Policy (UDRP). I disagreed with substantial portions of that final report and said so in A. Michael Froomkin, A Commentary on WIPO's The Management of Internet Names and Addresses: Intellectual Property Issues, at http://www.law.miami.edu/ amf/commentary.pdf (last visited Sept. 21, 2000) (listing the author's critiques of the report) (on file with the Duke Law Journal) [hereinafter Froomkin, A Commentary on WIPO's Management]. I was also a member of the so-called "small drafting committee" that advised ICANN on the UDRP, see Second Staff Report on Implementation Documents for the Uniform Dispute Resolution Policy, § 2.4, at http://www.icann.org/udrp/udrp-second-staff-report-24oct99.htm (Oct. 24, 1999) (on file with the Duke Law Journal) [hereinafter Second Staff Report], although I have my differences with it as well. See A. Michael Froomkin, Comments on ICANN Uniform Dispute Policy: A Catalog of Critical Process Failures; Progress on Substance; More Work Needed, at http://www.law.miami.edu/ amf/icann-udp.htm (Oct. 13, 1999) (noting that while this draft is "unquestionably an improvement .... this may say as much about the sad state of the predecessor draft as about the virtues of the current document") (on file with the Duke Law Journal) [hereinafter Froomkin, A Catalog of Process Failures].

14. See Angela Proffitt, Drop the Government, Keep the Law: New International Body for Domain Name Assignment Can Learn from United States Trademark Experience, 19 LOY. L.A. ENT. L.J. 601, 608 (1999) (noting the concerns of the European Union, the Australian government, and others that the United States had "too much control over the DNS"). 
As the DNS issue, and especially the relationship between domain names and trademarks, grew in importance, the conflicting pressures on the federal government for action grew as well. In June 1998, DoC and an interagency task force headed by Presidential Senior Adviser Ira Magaziner responded with the Statement of Policy on the Privatization of Internet Domain Name System, known as the DNS White Paper. ${ }^{15}$ Abandoning earlier hopes of issuing a substantive rule, which requires statutory authorization and is subject to judicial review, the policy statement instead set out goals that the administration thought could be achieved without rulemaking. Embracing the rhetoric of privatization, the DNS White Paper called for the creation of a private nonprofit corporation to take over the DNS and institute various reforms. ${ }^{16}$ Shortly thereafter, an international group incorporated ICANN as a private nonprofit California corporation, and, after some negotiation, DoC lent ICANN much of its authority over management of the DNS.

In its first two years of life, ICANN has made a number of decisions with potentially long-term effects. Of necessity, much of ICANN's energy has been devoted to the process of setting up its own, somewhat ornate, internal structures ${ }^{17}$ and procedures. The formal structures in place at this writing give overwhelming weight to corporate voices, tempered only by the power of the board to reject their suggestions. The board remains composed of the nine original unelected directors, supplemented by nine selected by so-called constituency groups, who in turn are selected by ICANN. Internet users and individual domain name registrants remain unrepresented at the board level, although ICANN is in the process of organizing a limited representation for the public. ${ }^{18}$

Almost as soon as it was in place, the ICANN board undertook major decisions, beginning with the agenda set out in the White $\mathrm{Pa}$ per. ICANN pushed Network Solutions, Inc. (NSI), the monopoly registry and dominant registrar, to allow more competition among

15. Management of Internet Names and Addresses, 63 Fed. Reg. 31,741 (1998), http://www.ntia.doc.gov/ntiahome/domainname/6_5_98dns.htm (on file with the Duke Law Journal) [hereinafter White Paper].

16. See id. at 31,744 .

17. For a simplified view of the mind-boggling complexity of ICANN's internal structures, circa September 1999, see fig. 1, supra pp. 185-86.

18. See infra Part II.B.2 (describing ICANN's move to limit the legal import and effect of elections for at-large board seats). 
registrars. ${ }^{19}$ ICANN also instituted mandatory arbitration of trademark claims. ICANN's "Uniform Dispute Resolution Policy" (UDRP) requires every registrant in .com, .org, or .net to agree to arbitration before ICANN-selected arbitration providers if any trademark owners anywhere in the world feel aggrieved by their registration of a term similar to that trademark. ${ }^{20}$

As a result of this policy, registrants are now subject to an idiosyncratic set of arbitration rules and procedures that benefit thirdparty trademark holders at the expense of registrants and do not necessarily conform to U.S. trademark law. ${ }^{21}$ ICANN also chose to keep in place and step up enforcement of some policies that it inherited, notably NSI's anti-privacy rule requiring that every registrant of a domain name agree to have his name, address, e-mail, and telephone number placed in a database readable by any Internet user in the world. ${ }^{22}$

Since ostensibly handing the policy baton to ICANN, DoC has treated these key decisions regarding the DNS as if they were either matters of policy outside the rulemaking strictures of the Administrative Procedure Act, as if they were matters of contract, or as if ICANN were an arms-length private body exercising autonomous choices that could take effect spontaneously, without DoC's participation or responsibility. ${ }^{23}$ DoC has, thus, made, or acquiesced in ICANN's making, some of the most important decisions relating to the near-term future of the Internet via research contracts rather than agency adjudication or rulemaking, thus evading notice, comment, due process, and judicial review. Government outsourcing and privatization often is premised on the theory that private enterprise can

19. A "registrar" is a firm that contracts with clients ("registrants") to collect their information and payment in order to make a definitive and unique entry into a database containing all domain names registered in a top-level domain (TLD). This database is maintained by a "registry." Top-level domains are sometimes grouped into "generic TLDs" (gTLDs), most of which are currently three- or four-letter transnational domains, and "country code TLDs" (ccTLDs) which are currently two-letter TLDs, most of which exist to serve a national population. See infra Part I.A.1.

20. See Uniform Domain-Name Dispute Resolution Policy, at http://www.icann.org/udrp/ udrp-policy-24oct99.htm (Oct. 24, 1999) (defining, for example, the scope of applicable disputes, as well as evidentiary and response requirements) (on file with the Duke Law Journal) [hereinafter $U D R P]$.

21. See infra notes 342-68 and accompanying text; see also Christopher R. Perry, Note, Trademarks As Commodities: The Famous Roadblock To Applying Trademark Dilution Law In Cyberspace, 32 CONN. L. REV. 1127, 1155-57 (2000) (noting the numerous criticisms of UDRP).

22. See infra note 98.

23. See infra Part II.B.1. 
provide some goods and services more efficiently than the public sector. ${ }^{24}$ DoC's reliance on ICANN is different from the classic model of privatization, because rather than privatizing a revenue-generating function, the government is "privatizing" a policy-generating function. Furthermore, the "privatization" is subject to sufficient strings to make ICANN's actions fairly chargeable to the government. Although the ICANN-DoC contracts speak of cooperation and research, some of the most significant outputs from ICANN are government regulation in all but name. It is time to call them what they are.

However one chooses to characterize the U.S. government's interest in the root file or the DNS as a whole, there is little debate that (1) DoC derives at least part of whatever authority it has from its ability to instruct a U.S. government contractor, NSI, regarding the content of the root file, ${ }^{25}$ and (2) whatever authority ICANN holds at present emanates from, and remains subject to, DoC's ultimate authority. ${ }^{26}$ The U.S. government's continuing control of the DNS has legal consequences that have not been well understood by participants in what have come to be called the "DNS wars," ${ }^{27}$ and were ignored in a recent General Accounting Office (GAO) study that examined DoC's role in ICANN's creation. ${ }^{28}$ Chief among these legal

24. See generally Al Gore, Creating a GOVERnMENT That WORKS BetTer \& COSTS LESS (1993) (arguing that agencies should adopt strategies that make private businesses competitive). But see generally A. Michael Froomkin, Reinventing the Government Corporation, 1995 U. ILL. L. REV. 543 (1995) (suggesting that reforms to increase accountability should be a prerequisite to the proliferation of federal government corporations), available at http://www.law.miami.edu/ froomkin/articles/reinvent.htm (on file with the Duke Law Journal).

25. See infra note 82 .

26. See infra Part III.B (discussing the ICANN-DoC relationship).

27. On the DNS wars, see Craig Simon, Overview of the DNS Controversy, at http://www.flywheel.com/ircw/overview.html (last modified Sept. 14, 2000) (providing historical background and the author's analytical approach to the DNS controversy) (on file with the Duke Law Journal).

28. The GAO's recent report, see Letter from Robert P. Murphy, General Counsel, General Accounting Office, to Sen. Judd Gregg, Chairman, United States Senate Subcommittee on Commerce, Justice, State, and the Judiciary 25 (July 7, 2000), http://www.gao.gov/new.items/ og00033.pdf (on file with the Duke Law Journal) [hereinafter GAO Report], deals only with the issues surrounding the establishment of ICANN, and DoC's authority to enter into contracts with it. The GAO's conclusions in this report that no laws were violated when ICANN was established, see id. at 12, are most likely correct. The GAO's conclusion that DoC had the authority to contract with ICANN may also be technically correct, although to reach that conclusion the GAO had to rely on the text of the agreements and largely ignored their substance and implications. See id. What matters most, legally, is DoC's (not ICANN's) performance during the life of those agreements, as that is where the legal violation lies. 
consequences is that to the extent that DoC relies on ICANN to regulate in its stead-and this reliance appears to be quite substantial-DoC's relationship with ICANN violates fundamental U.S. policies that are designed to ensure democratic control over the use of government power. DoC's relationship with ICANN is, therefore, illegal.

Depending on the precise nature of the DoC-ICANN relationship, not all of which is public, DoC's use of ICANN to run the DNS violates the APA and/or the U.S. Constitution. On the one hand, DoC may retain substantial control, either directly or by review, over ICANN's policy decisions. In that case, DoC's use of ICANN to make rules violates the APA. On the other hand, if DoC has ceded temporary policy control to ICANN, that violates the Constitution's nondelegation doctrine.

There is substantial evidence, discussed below, that DoC has directly instructed ICANN on policy matters. Furthermore, as ICANN is utterly dependent on DoC for ICANN's continuing authority, funding, and, indeed, its reason for being, it would be reasonable to conclude that the corporation is currently so captive that all of ICANN's decisions can fairly be charged to the government. If so, the DNS has not, in fact, been privatized at all, even temporarily. At least in cases where ICANN does what DoC tells it to do, and arguably in all cases, DoC's use of a private corporation to implement policy decisions represents an end run around the APA and the Constitution. To the extent that DoC launders its policy choices through a cat's paw, the public's right to notice and meaningful comment; to accountable decisionmaking; to due process; and to protection against arbitrary and capricious policy choices, self-dealing, or ex parte proceedings are all attenuated or eliminated; so, too, is the prospect of any meaningful judicial review. The result is precisely the type of illegitimate agency decisionmaking that modern administrative law claims to be most anxious to prevent. ${ }^{29}$

If, on the other hand, ICANN is making its policy decisions independently of DoC, as ICANN's partisans tend to argue, then even a partial transfer of DoC's policymaking authority over the DNS violates an even more fundamental public policy against the arbitrary

29. See generally Jody Freeman, The Private Role in Public Governance, 75 N.Y.U. L. REV. 543 (2000) (reconceptualizing administrative decisionmaking as a series of negotiations between public and private actors); Richard B. Stewart, The Reformation of American Administrative Law, 88 HARV. L. REV. 1667 (1975) (examining the problem of agency discretion). 
exercise of public power, the constitutional doctrine prohibiting the delegation of public power to private groups. ${ }^{30}$ Most famously expounded in two pre-New Deal cases, Carter v. Carter Coal Co. ${ }^{31}$ and A.L.A. Schechter Poultry Corp. v. United States, ${ }^{32}$ the private nondelegation doctrine focuses on the dangers of arbitrariness, lack of due process, and self-dealing when private parties are given the use of public power without the shackles of administrative procedure. ${ }^{33}$ The doctrine stems from a long tradition of seeking to ensure that public power is exercised in a manner that makes it both formally and, insofar as possible, actually accountable to elected officials, and through them-we hope-to the electorate. This concern for proper sources and exercise of public authority promotes both the rule of law and accountability. $^{34}$

The ICANN issue is unique in a number of ways. Modern federal cases implicating the nondelegation doctrine are quite rare; the Supreme Court does not seem to have considered the issue in the context of a delegation to a private group since the New Deal, and the lower court cases are few and often very technical. In any event, nondelegation cases usually involve a contested statute. ${ }^{35}$ The issue then is whether Congress's attempt to vest power in an agency or a private body is constitutional. In the case of ICANN, there is no statute. Congress at no time determined that the DNS should be privatized, or, indeed, legislated anything about national DNS policy. Instead, DoC itself chose to delegate the DNS functions to ICANN, relying on its general authority to enter into contracts. ICANN is also a very unusual corporation. There are many government contractors, both profit-making and nonprofit. But it is unusual for a nonprofit corpo-

30. See Carter v. Carter Coal Co., 298 U.S. 238, 311 (1936) (condemning delegation to a private group as the worst type of legislative delegation); $c f$. Texas Boll Weevil Eradication Found. v. Lewellen, 952 S.W.2d 454, 465 (Tex. 1997) (applying a balancing test to determine the invalidity, under the Texas Constitution, of a legislative delegation to a private entity).

31. 298 U.S. 238 (1936).

32. 295 U.S. 495 (1935).

33. See Carter Coal, 298 U.S. at 311; Schechter Poultry, 295 U.S. at 537. The private nondelegation doctrine should not be confused with its more famous constitutional cousin, the public nondelegation doctrine. Long thought to have been in desuetude, but now revived, the public nondelegation doctrine imposes a particularity requirement on delegations of congressional authority to federal agencies. See infra notes 564-69 and accompanying text.

34. See infra notes 569-71 and accompanying text.

35. See, e.g., Carter Coal, 298 U.S. at 239, 295 (holding that the empowerment of a national commission through the Bituminous Coal Conservation Act of 1935 is beyond the powers of Congress). 
ration to be created for the express purpose of taking over a government regulatory function.

There is a danger, however, that ICANN may not be unique for long. One administration spokesperson has already suggested that ICANN should be a model for regulation of other Internet-related issues such as accreditation standards for distance learning and ecommerce over business-to-business "closed" networks. ${ }^{36}$ The specter of a series of ICANN clones in the United States or in cyberspace should give one pause, because ICANN is a very bad model, one that undermines the procedural values that motivate both the APA and the Due Process Clause of the Constitution. ${ }^{37}$

DoC's reliance on ICANN has (1) reduced public participation in decisionmaking over public issues, (2) vested key decisionmaking power in an essentially unaccountable private body that many feel has already abused its authority in at least small ways and is indisputably capable of abusing it in big ways, and (3) nearly (but, as argued below, not quite) eliminated the possibilities for judicial review of critical decisions regarding the DNS. So far, ICANN appears to be accountable to no one except DoC itself, a department with a strong vested interest in declaring its DNS "privatization" policy to be a success.

Democratic theory suggests that the absence of accountability tends to breed arbitrariness and self-dealing. ${ }^{38}$ In addition to avoiding governmental accountability mechanisms, ICANN lacks much of the accountability normally found in corporations and in nonprofits. Or-

36. See Brian Krebs, Regulators Would Do Well to Mimic ICANN-White House, at http://www.newsbytes.com/pubNews/00/148011.html (Apr. 25, 2000) (summarizing a speech by DoC General Counsel Andrew Pincus arguing that " $[\mathrm{t}]$ he federal government could put an end to its numerous Internet regulatory headaches if it approached industry with the same type of cooperation shown... under the aegis of ICANN") (on file with the Duke Law Journal). Cf. Masanobu Katoh, ICANN-A Model for International Organizations in the 21st Century, at http://www.mkatoh.net/speech/icann_katoh072000-e.ppt (July 2000) (archiving PowerPoint slides from a speech made by ICANN board member-elect arguing that ICANN could be a model for global rulemaking in the twenty-first century) (on file with the Duke Law Journal).

37. See infra Part III.C-E; see also Kenneth M. Casebeer, The Empty State and Nobody's Market: The Political Economy of Non-Responsibility and the Judicial Disappearing of the Civil Rights Movement, 54 U. MiAmI L. REV. 247, 255 (2000):

More and more governance is carried out by delegation to private institutions, by subsidy, by tax incentive or disincentive, by private enforcement, by the nod and the wink, or by intentional inaction. All such law is not State or government action subject to the responsibilities of Constitutional rights or enforceable limits.

38. See, e.g., Rebecca L. Brown, Accountability, Liberty, and the Constitution, 98 Colum. L. REV. 531, 533, 565 (1998) (discussing the role of accountability in the design of U.S. political institutions). 
dinary corporations have shareholders and competitors. ICANN does not because it is nonprofit and has a unique relationship with the Department of Commerce. Many nonprofit organizations have members who can challenge corporate misbehavior. ICANN has taken steps to ensure that its "members" are denied such legal redress under California law. ${ }^{39}$ All but the wealthiest nonprofits are constrained by needing to raise funds; ICANN faced such constraints in its early days, but it has now leveraged its control over the legacy root into promises of contributions from the registrars that have agreed to accept ICANN's authority over them in exchange for the ability to sell registrations in .com, .org and .net, and from NSI, the dominant registrar and monopoly .com/.org/.net registry, ${ }^{40}$ which agreed to pay $\$ 2.25$ million to ICANN this year as part of agreements hammered out with DoC and ICANN. ${ }^{41}$ The result is a body that, to date, has been subject to minimal accountability. Only DoC (and, in one special set of cases, NSI or registrars ${ }^{42}$ ) currently has the power to hold ICANN account-

39. More than 158,000 Internet users "joined" ICANN as "members," and an unknown number of others were unable to join, as ICANN's computers-programmed to handle only 10,000 applications-were overwhelmed. See ICANN At-Large Membership Registration Exceeds 158,000 Internet Users Worldwide, at http://www.icann.org/announcements/icannpr31jul00.htm (July 31, 2000) (on file with the Duke Law Journal) [hereinafter ICANN Membership Registration]. ICANN first sought to perpetuate its insulation from legal challenge by its membership by eliminating direct election of directors, and only reinstated direct election under pressure. See Jonathan Weinberg, ICANN and the Problem of Legitimacy, 50 DUKE L.J. 187, 246 (2000); Comments of Common Cause and the Center for Democracy and Technology on Proposed Revisions to ICANN Bylaws on At-large Membership, Center For Democracy and Technology, at http://www.cdt.org/dns/icann/000709comments.shtml (July 9, 2000) (on file with the Duke Law Journal) [hereinafter Comments of Common Cause]. ICANN then revised its bylaws to state that the people filling out a "membership" form on the ICANN website in order to vote for five (down from nine) at-large ICANN directors are not in fact "members" under California law. See ICANN Bylaws, art. II, § 1, at http://www.icann.org/general/archivebylaws/bylaws-16jul00.htm (July 16, 2000) (on file with the Duke Law Journal):

The Corporation shall not have members as defined in the California Nonprofit Public Benefit Corporation Law (CNPBCL), notwithstanding the use of the term "Member" in these bylaws, in a selection plan adopted by board resolution, or in any other action of the board. Instead, the Corporation shall allow individuals (described in these bylaws as "Members") to participate in the activities of the Corporation as described in this Article II and in a selection plan adopted by board resolution, and only to the extent set forth in this Article II and in a selection plan adopted by board resolution.

40. See infra notes 315-25 and accompanying text.

41. See infra note 320 and accompanying text; see also March 2000 ICANN Meeting in Cairo: ICANN Budget for 2000-2001 Fiscal Year, § II, at http://www.icann.org/financials/cairofy00-01-budget-issue.htm (Mar. 6, 2000) (reporting an estimate of NSI's payments) (on file with the Duke Law Journal) [hereinafter 2000-01 Budget].

42. In the Registry Agreement, approved November 4, 1999, NSI reserved the right to challenge new ICANN policies as not being based on a consensus. See ICANN-NSI Registry 
able. NSI currently has no incentive to use its limited power, and DoC has nothing to complain of so long as ICANN is executing the instructions set out in the White Paper. The accountability gap will get worse if DoC gives full control of the DNS to ICANN. ${ }^{43}$ But it should be

Agreement, § 1, at http://www.icann.org/nsi/nsi-registry-agreement-04nov99.htm (Nov. 4, 1999) (on file with the Duke Law Journal). In its agreement with registrars, approved November 4, 1999, ICANN also promised registrars that they would have 15 days to challenge major decisions by lodging a challenge with an independent review panel. See Registrar Accreditation Agreement, § I.B, at http://www.icann.org/nsi/icann-raa-04nov99.htm (Nov. 4, 1999) (on file with the Duke Law Journal). On March 10, 2000, ICANN adopted its Independent Review Policy. See Independent Review Policy, § 1, at http://www.icann.org/indreview/policy.htm (Mar. 10, 2000) (on file with the Duke Law Journal). However, as of this writing, ICANN has yet to appoint any Panel members.

43. Whether and under what circumstances DoC would turn over the root to ICANN has been the subject of somewhat contradictory pronouncements. In the White Paper, DoC stated, "The U.S. Government would prefer that this transition be complete before the year 2000. To the extent that the new corporation is established and operationally stable, September 30, 2000 is intended to be, and remains, an 'outside' date." White Paper, supra note 15, at 31,744. More recently, DoC assured Congress that it intends to retain its rights over the DNS:

The Department of Commerce has no intention of transferring control over the root system to ICANN at this time [July 8, 1999].... If and when the Department of Commerce transfers operational responsibility for the authoritative root server for the root server system to ICANN, an [sic] separate contract would be required to obligate ICANN to operate the authoritative root under the direction of the United States government.

Letter from Andrew J. Pincus, DoC General Counsel, to Rep. Tom Bliley, Chairman, United States House Committee on Commerce (July 8, 1999), National Telecommunications and Information Administration, http://www.ntia.doc.gov/ntiahome/domainname/blileyrsp.htm (on file with the Duke Law Journal).

Meanwhile, or at best slightly later, DoC apparently assured the European Union that it intends to give ICANN full control over the DNS by October 2000:

[T]he U.S. Department of Commerce has repeatedly reassured the Commission that it is still their intention to withdraw from the control of these Internet infrastructure functions and complete the transfer to ICANN by October 2000.... The Commission has confirmed to the US authorities that these remaining powers retained by the United States DoC regarding ICANN should be effectively divested, as foreseen in the US White Paper.

Commission of the European Communities, Communication from the Commission to the Council and the European Parliament: The Organization and Management of the Internet International and European Policy Issues 1998-2000, at 14 (Apr. 7, 2000) (emphasis added), Information Society Promotion Office, http://www.ispo.cec.be/eif/InternetPoliciesSite/Organisation/ com(2000)202EN.pdf (on file with the Duke Law Journal). Recently, DoC assured the GAO that "it has no current plans to transfer policy authority for the authoritative root server to ICANN, nor has it developed a scenario or set of circumstances under which such control would be transferred." GAO Report, supra note 28, at 30. ICANN meanwhile stated on June 30, 2000, that "[s]ince it appears that all of the continuing tasks under the joint project may not be completed by the current termination date of the MOU, the MOU should be extended until all the conditions required to complete full transition to ICANN are accomplished." Second Status Report Under ICANN/US Government Memorandum of Understanding (30 June 2000), § D.4, at http://www.icann.org/general/statusreport-30jun00.htm (June 30, 2000) (on file with the Duke Law Journal) [hereinafter Second Status Report]; see also infra note 89 and accompanying text 
noted that opinions may differ as to whether DoC could legally give away its interest in DNS to ICANN without an act of Congress. It is likewise unclear what precisely "giving away control" would consist of beyond DoC's interest in its contracts with the maintainer of the root, since the most important part of anyone's "control" over the root is publishing data that other parties, many of whom are independent of the government, choose to rely on. ${ }^{44}$

Part I of this Article describes the domain name system and its central role in the smooth functioning of the Internet as we know it today. The DNS is a hierarchical system in an otherwise relatively decentralized Internet. Section A explains what a domain name is, what domain names do, and how domain names are assigned and acquired. Section B explains the technical source of control over the DNS and why this control over the DNS system is so important.

Part II of the Article lays out the convoluted legal and contractual history of the DNS in order to establish the foundation for the legal argument in the third part. Part II thus describes the growing formalization of DNS regulation and the increasingly conscious intervention of the U.S. government in DNS policymaking. What began as small operation, below the policy radar, affecting only a small number of computers, grew in importance as the Internet grew and as the number of attractive names remaining to be registered in .com shrank. Existing arrangements came under increasing strain as conflicts over names, especially between trademark holders and registrants, grew. Where there had been uncertainty for many years as to precisely where authority over the root might reside, by 1998 the U.S. government had defeated an attempt to redirect the root and amended its contract with NSI to make the government's supremacy clear. Power, however, brought responsibility and increased controversy. The debate over the addition of new top-level domains to the root brought matters to a head and triggered active intervention by DoC and an interagency group headed by Presidential Senior Adviser

(describing the ICANN board resolution seeking to take direct control of the root and to sign contracts with other root server operators).

44. The GAO recently described DoC's authority to effect a hypothetical transfer as "unclear." See GAO Report, supra note 28, at 25. If the U.S. government's interest is a property right, or an intellectual property right, then DoC would need statutory authority to give it away under the Property Clause of the Constitution. See U.S. CONST. art. IV, § 3, cl. 2 ("The Congress shall have power to dispose of and make all needful Rules and Regulations respecting the Territory or other Property belonging to the United States ...."); GAO Report, supra note 28, at 26 n. 43 ; cf. supra note 43 (listing DoC's varying accounts regarding whether it intended to give up control of the root). 
Ira Magaziner. Their policy review culminated in the White Paper, which called for an entity like ICANN to take over the management of the DNS.

Part III of this Article offers a legal analysis concentrating on the federal government's role in DNS policymaking. How ICANN perceives itself is of only minor relevance to the legality of DoC's reliance on it. The central questions concern: (1) the nature of ICANN's actions and (2) the nature of DoC's response to ICANN's actions. ICANN does something that is either is "standard setting" or is something more, such as "policymaking" or "rulemaking." Determining whether ICANN does "policy" requires a fairly detailed excursion into ICANN's and the DNS's history and contributes mightily to the length of this Article. But this is a critical issue, because if ICANN is engaged in mere standard setting, then there is no APA or constitutional issue; however, if ICANN is doing something more than mere standard setting, then the nature of DoC's response to ICANN's actions is legally significant.

If ICANN is engaged in policymaking, and if DoC is reviewing these decisions and retaining the authority to countermand them, then DoC's adoption of or approval of ICANN's regulatory and policy decisions are subject to the APA. One could argue as to whether DoC's approval is an informal adjudication under the $\mathrm{APA},{ }^{45}$ or whether due to its overwhelming influence over ICANN and due to its adopting ICANN's rules, DoC is engaged in rulemaking without proper notice and comment. In either case, however, the APA has been violated.

If, on the other hand, ICANN is engaged in policymaking and DoC does not retain the power to countermand ICANN's decisions, then DoC has delegated rulemaking and policymaking power to ICANN. This probably violates the APA, since it was done without proper rulemaking; regardless of the applicability of the APA, it violates the Due Process Clause and the nondelegation doctrine of the U.S. Constitution, as well as basic public policy norms designed to hold agencies and officials accountable for their use of public power.

Since ICANN's board and staff operate largely in secret, it is difficult for outsiders to know how much influence DoC has over ICANN's

45. This would require some kind of notice to affected parties, and in many cases, might also require a written decision of some sort. See 5 U.S.C. § 555(e) (1994) (requiring an agency to issue a written decision if an interested person has filed a written application, petition, or other request in connection with an agency proceeding). 
decisionmaking. As a result, the statutory and constitutional arguments in this Article are presented in the alternative. The two arguments are very closely related, however, in that both rely on legal doctrines designed to promote accountability and prevent the arbitrary exercise of government power.

My analysis is substantially different from both DoC's and ICANN's accounts of their roles and their relationship. DoC's account of its relationship with ICANN relies on what I shall call the private party story and the standard-setting story. The private party story relies on ICANN's status as a California nonprofit corporation. Government agencies have to observe due process, and many rules about openness, even-handedness, and especially advance notice, not least of which are the procedures set out in the Administrative Procedure Act. If they fail to observe these requirements, they are subject to judicial review. Because ICANN is (formally) a private corporation, it does not face similar obligations. It is beyond argument that private parties are almost never subject to the APA. ${ }^{46}$

In fact, as detailed below, ICANN's relationship to DoC is nothing like the arms-length relationship suggested by the private party story. Although ICANN is private, it is no ordinary corporation, and its relationship with DoC is highly unusual. ICANN is totally beholden to DoC for its creation, its initial policies, and especially DoC's loan of control over the root. This control over the root is the sole basis of ICANN's relevance, power, and financing, and DoC can take it away on 120 days' notice, a right that persists even after the recent renewal of ICANN's contract. ${ }^{47}$ More than anything, ICANN

46. One important exception is when they are state actors. See infra Part III.B.3. Another exception is when they serve as advisory committees under the Federal Advisory Committee Act, which is codified within the APA. See infra Part III.C.3.

47. ICANN's hold on the DNS was due to expire on September 30, 2000. See Memorandum of Understanding, Dept. of Commerce and ICANN, at http://www.icann.org/general/icannmou-25nov98.htm (Nov. 25, 1998) (on file with the Duke Law Journal) [hereinafter Memorandum of Understanding]. On September 4, 2000, ICANN announced that following ICANN's submission on June 30, 2000, of a second status report under the memorandum, see Second Status Report, supra note 43, the U.S. government agreed to extend ICANN's hold on the DNS for one year, or less "if ICANN and the U.S. government agree that the work under the MOU has been completed." Announcement: ICANN and U.S. Government Agree to Extend Agreements, at http://www.icann.org/announcements/icann-pr04sep00.htm (Sept. 4, 2000) (on file with the Duke Law Journal) [hereinafter Announcement]. This extension affected both the ICANNDoC MoU of November 25, 1998, see Memorandum of Understanding, supra, and ICANN's Cooperative Research and Development Agreement, see Cooperative Research \& Development Agreement, at http://www.icann.org/committees/dns-root/crada.htm (last visited Aug. 18, 2000) (on file with the Duke Law Journal) [hereinafter CRADA]. In addition, ICANN reported that 
seeks to achieve permanent and, perhaps, irrevocable control of the root when the current memorandum of understanding (MoU) expires. DoC has some control over ICANN through the stick of the MoU, but the real control comes from the carrot. ICANN's ability to retain or expand its control over the root is entirely at DoC's discretion.

The standard-setting story focuses on what ICANN does. In this story, ICANN does only "technical coordination" relating to the DNS. ICANN does not do "policy"; if there was any policy to be done (DoC is a little vague on this), it was done in the White Papera statement of policy. And ICANN most certainly does not do "regulation" or "governance." ICANN is at most implementing the key pieces of the White Paper policy: privatization, Internet stability, increasing competition, bottom-up coordination. To the extent that ICANN might be making decisions that have impacts on third parties, this is merely setting standards, not making policy, and it is well settled that the government can rely on private groups to set standards. ${ }^{48}$

There is no question that contractors can administer a federally owned resource, such as the snack bar in a federal building. Moreover, the United States has created a number of federal government corporations, mostly to undertake commercial activities; some are private, a few have mixed ownership, but all have federal charters and direct congressional authorization. ${ }^{49}$ While the federal use of state-

DoC extended ICANN's no-fee contract to run the Internet Assigned Number Authority (IANA): "the IANA contract extension results from ICANN's acceptance of a new provision in the contract allowing the U.S. Government unilaterally to extend the period of performance by up to six months." Announcement, supra.

In taking this decision to extend ICANN's tenure, DoC appears to have sought no public comment, giving the public no notice that it was considering an extension. Nor were there any calls for competing bids. Furthermore, as of October 1, 2000, no announcement of the ICANN extension appears at the website devoted to ICANN matters, http://www.ntia.doc.gov/ ntiahome/domainname/domainnamehome.htm (last visited Oct. 1, 2000) (on file with the Duke Law Journal), nor is there a press release on the NTIA press site, http://www.ntia.doc.gov/ ntiahome/press/pressindex.htm (last visited Oct. 1, 2000) (on file with the Duke Law Journal).

48. Courts are generally in agreement that, at least following the appropriate rulemaking or adjudication, the federal government may rely on expert technical judgments of private groups, for example, letting Underwriters Laboratories determine which electrical goods are properly wired. See, e.g., A.L.A. Schechter Poultry Corp. v. United States, 295 U.S. 495, 537 (1935) (suggesting that "matters of a more or less technical nature" could be delegated to private parties). An example of such delegation is Saint Louis, Iron Mountain, \& S. Ry. Co. v. Taylor, 210 U.S. 281, 286-87 (1908) (upholding delegation of authority to private railroad association to fix mandatory height for drawbars on railroad cars).

49. See generally Froomkin, supra note 24 (surveying charters of and rules applicable to existing federal government corporations). 
chartered corporations to undertake federal tasks is rare, and usually criticized, ${ }^{50}$ if it were true that ICANN was limited to "technical coordination," that would rebut the claim of an unconstitutional delegation of power. In fact, as detailed below, the standard-setting story ignores reality. While some of what ICANN does can fairly be characterized as standard setting, key decisions would certainly have been rulemaking if done directly by DoC and remain regulatory even when conducted by its proxy. ${ }^{51}$

Having said what this Article is about, a few words about what it is not about may also be in order. Opinions differ-radically-as to the wisdom of ICANN's early decisions, decisions with important worldwide consequences. ${ }^{52}$ Opinions also differ as the adequacy of ICANN's decisionmaking procedures. And many legitimate questions have been raised about ICANN's ability or willingness to follow its own rules. ${ }^{53}$ Whether ICANN is good or bad for the Internet and whether the U.S. government should have such a potentially dominant role over a critical Internet resource are also important questions. This Article is not, however, primarily concerned with any of these questions. Nor is it an analysis of the legality of actions taken by ICANN's officers, directors, or employees. In particular, this Article does not discuss whether ICANN's actions comply with the requirements of California law regarding nonprofit corporations. Despite their importance, all of these issues will appear only tangentially insofar as they are relevant to the central, if perhaps parochial, question: whether a U.S. administrative agency is, or should be, allowed to call into being a private corporation and then lend it sufficient control over a government resource so that the corporation can use that con-

50. The Federal Asset Disposition Administration (FADA) was established as a Colorado corporation by the Federal Home Loan Bank Board; the GAO later opined that the agency lacked congressional authority to establish a corporation. See 1988 Op. Comp. Gen. B-226708.3 (1988) (concluding that the Federal Home Loan Bank Board "acted improperly" by establishing FADA and that FADA employees are not federal employees because they fail to satisfy criteria in 5 U.S.C. $\$ 2105$ (a) (1994), despite being "engaged in the performance of federal functions"); 134 CONG. REC. E1185 (1988) (remarks of Rep. Kanjorski) (alleging that FADA was established to evade pay caps, personnel ceilings, and "budgetary and legal constraints"); see also Harold Seidman, The Quasi World of the Federal Government, BROOKINGS ReV., Summer 1988, at 23, 26 (summarizing the controversy over FADA). ICANN differs from FADA because DoC did not actually create ICANN itself. See GAO Report, supra note 28, at 12-14.

51. See infra note 474 and accompanying text.

52. For continuing coverage of these issues, see ICANNWATCH, at http://www.icannwatch.org (last visited Aug. 17, 2000) (on file with the Duke Law Journal).

53. See, e.g., Bret Fausett, Want to Create a Secret Committee?, at http://www.lextext.com/ 21days.html (last visited Aug. 17, 2000) (on file with the Duke Law Journal). 
trol effectively to make policy decisions that the agency cannot—or dares not-make itself.

Although focused on DoC's actions, this Article has implications for ICANN. If the government's actions in relation to ICANN are illegal or unconstitutional, then several-but perhaps not all-of ICANN's policy decisions are either void or voidable, and DoC might reasonably be enjoined from further collaboration with ICANN in other than carefully delineated areas. Some of these implications for ICANN, and for the Internet, are canvassed in Part IV.

\section{The Domain NAME SYSTEM}

As a result of its hierarchical design, Internet custom, and the prevalence of one program, the domain name system has become a uniquely hierarchical system in an otherwise relatively decentralized Internet. Section A of this part explains how this control is exercised; in order to do so, it sets out what a domain name is, what domain names do for the smooth functioning of the Internet, and how domain names are assigned and acquired. Section B of this part explains why control over the DNS system matters.

\section{A. Domain Names and Their Uses ${ }^{54}$}

1. Domain Name Basics. Domain names are the alphanumeric text strings to the right of an "@" in an e-mail address, or immediately following the two slashes in a World Wide Web address. By practice and convention, domain names can be mapped to a thirty-two-bit number consisting of four octets (sets of eight binary digits) that specifies a network address and a host ID on a TCP/IP network. These are the "Internet protocol" (IP - not to be confused with "intellectual property") numbers-the numbers that play a critical role in addressing all communications over the Internet, including email and World Wide Web traffic. ${ }^{55}$ They have justly been called the

54. There are only so many ways to set out basic technical information. The next nine paragraphs borrow heavily from A. Michael Froomkin, Semi-Private International Rulemaking: Lessons Learned from the WIPO Domain Name Process, in Regulating THE Global INFORMATION SOCIETY (Christopher T. Mardsen ed., forthcoming 2000), available at http://www.law.miami.edu/ froomkin/articles/tprc99.pdf (on file with the Duke Law Journal).

55. See P. Mockapetris, Request for Comments (RFC) 1034, Domain Names-Concepts and Facilities 29, Internet Engineering Task Force, at http://www.ietf.org/rfc/rfc1034.txt (Nov. 1987) (on file with the Duke Law Journal). 
"human-friendly address of a computer." Their potential "friendliness" is also the source of legal and commercial disputes: businesses have come to view their domain names as an important identifier, even a brand. And as both businesses and users increasingly have come to view domain names as having connotations that map to the world outside the Internet, rather than as arbitrary identifiers, conflicts, often involving claims of trademark infringement or unfair competition, have become more frequent. ${ }^{57}$

The Internet works the way it does because it is able to route information quickly from one machine to another. IP numbers provide the identifying information that allows an e-mail to find its destination or allows a request for a web page to reach the right computer across the Internet. Until recently ${ }^{58}$ web page accesses, unlike e-mail, always could be achieved with an IP number. Thus, for example, http://www.law.miami.edu was equivalent to http://129.171.187.10. However, e-mail to froomkin@129.171.187.10 will not inevitably reach me-or anyone else. (On most systems, however, e-mail to froomkin@[129.171.187.10] will reach me. But it is not inevitable or easy to type.) Because IP numbers are hard for people to remember, the designers of the Internet introduced easier alphanumeric domain names as mnemonics. When a user types an alphanumeric Uniform Resource Locator (URL) into a web browser, the host computer must "resolve" the domain name-that is, translate it into an IP number. ${ }^{59}$ Both domain names and IP numbers are ordinarily unique (subject to minor exceptions if resources are interchangeable). Using domain names also increases portability-since numbers can be arbitrarily assigned to names, the names can stay constant even when the resources to which they refer change. The system by which these unique domain names and IP numbers are allocated and domain names resolved to IP numbers is a critical function on the Internet. Each of the thirteen legacy root name servers handles millions of

56. Domain Name Process, supra note 13.

57. See id.

58. More recently, so-called "name-based virtual hosting" introduced the possibility of operating unrelated web servers, identified by different domain names, but with a single IP address. See R. Fielding et al., RFC 2616, Hypertext Transfer Protocol-HTTP/1.1, USC Information Sciences Institute, at http://www.isi.edu/in-notes/rfc2616.txt $\$ 5.2$ (June 1999) (on file with the Duke Law Journal).

59. See Neil Randall, How DNS Servers Work, PC MAG., Sept. 24, 1996, at 217; Neil Randall, What Happens When You Click, PC MAG., Oct. 22, 1996, at 245. 
DNS queries a day, ${ }^{60}$ and uncounted millions more are handled downstream by ISPs and others who cache the most frequently requested domain names to IP mappings.

Currently, the large majority of domain names for Internet resources intended to be used by the public have a relationship to two organized hierarchies. (Internet-based resources for private use, such as intranets, can be organized differently.) The first, very visible hierarchy relates to naming conventions for domain names and constrains how domain names are allocated. The second, and largely invisible, hierarchy determines the ways in which domain names are resolved into the IP numbers that actually make Internet communication possible. The two hierarchies are closely related but not identical.

Domain naming conventions treat a domain name as having three parts: in the address www.miami.edu, for example, "edu," the rightmost part, is the "top-level domain" or "TLD," while "miami" is the second-level domain (SLD), and any other parts are lumped together as third-or-higher-level domains. Domain names are just conventions, and a core part of the current dispute over them arises from the conflict over whether new TLDs should be added to the so-called "legacy root" - the most widely used, and thus most authoritative, list of which TLDs will actually map to IP numbers. It should be noted that in addition to the "legacy root" TLDs discussed in this Article, there are a large number of "alternate" TLDs that are not acknowledged by the majority of domain name servers. ${ }^{61}$ There is no technical bar to their existence, and anyone who knows how to tell his software to use an alternate domain name server can access both the "legacy root" and whatever alternate TLDs are supported by that name server. Thus, for example, choosing to get domain name services from 205.189.73.102 and 24.226.37.241 makes it possible to resolve http://lighting.faq, where a legacy DNS would only return an error message.

The legacy root is currently made up of 244 two-letter country code TLDs (ccTLDs), seven three-letter generic TLDs (gTLDs), and

60. See, e.g., F.root-servers.net, Internet Software Consortium, at http://www.isc.org/ services/public/F-root-server.html (last visited Aug. 17, 2000) (reporting that "F answers more than 260 million DNS queries per day, making it one of the busiest DNS servers in the world. In fact, it is often the busiest root nameserver on the Internet") (on file with the Duke Law Journal).

61. See Rony \& RonY, supra note 10, at 513-72 (describing the "Alterweb"). 
one four-letter TLD (.arpa). ${ }^{62}$ The 244 ccTLDs are almost all derived from the International Organization for Standardization's ISO Standard $3166 .^{63}$ Not every ccTLD is necessarily controlled by the government that has sovereignty over the territory associated with that country code, however. This is likely to be an area of increasing controversy, as (some) governments argue that the ccTLD associated with "their" two-letter ISO 3166 country code is somehow an appurtenance of sovereignty. ${ }^{64}$ The ccTLDs sometimes have rules that make registration difficult or even next to impossible; as a result, the gTLDs, and especially .com, have the lion's share of the registrations. Three gTLDs are open to anyone who can afford to pay for a registration: .com, .org, and .net. Other gTLDs impose additional criteria for registration: .mil (U.S. military), ${ }^{65}$.gov (U.S. government) ${ }^{66}$.int (international organizations), .edu (institutions of higher education, mostly U.S.-based), and .arpa. ${ }^{67}$ Domains registered in ccTLDs and gTLDs are equally accessible from any computer on the Internet.

62. A list of the ccTLDs, gTLDs, and their registries (NICs) appears at TLD Registries, World Internetworking Alliance, at http://www.wia.org/database/DNS_registries.htm (last visited Aug. 19, 2000) (on file with the Duke Law Journal).

63. See ISO 3166-1:1997 Codes for the Representation of Names of Countries and Their Subdivisions-Part I: Country Codes, Deutsches Institut für Normung, at http://www.din.de/ gremien/nas/nabd/iso3166ma/codlstp1/en_listpl.html (June 23, 2000) (on file with the Duke Law Journal). The ISO, a private standards body, has created these codes for computer information systems processing purposes. It is not a treaty organization. See Frequently Asked Questions, International Organization for Standardization, at $\mathrm{http} / / / \mathrm{www}$. iso.ch/infoe/faq.htm (last modified Nov. 29, 1999) (on file with the Duke Law Journal).

64. See Communique of the Government Advisory Committee, Berkman Center for Internet and Society, at http://cyber.law.harvard.edu/icann/santiago/archive/GAC-Comminuque-

mtg3.html (last modified Aug. 24, 1999) (asserting that "delegation of a ccTLD Registry is subject to the ultimate authority of the relevant public authority or government") (on file with the Duke Law Journal).

65. Delegation of the .mil domain is under the authority of the DDN NIC. See D. Engebretson \& R. Plzak, RFC 1956, Registration in the MIL Domain 1, USC Information Sciences Institute, at http://www.isi.edu/in-notes/rfc1956.txt (June 1996) (on file with the Duke Law Journal).

66. Delegation of the .gov TLD is under the authority of the U.S. Federal Networking Council (FNC). See FNC, RFC 1816, U.S. Government Internet Domain Names 1, USC Information Sciences Institute, at http://www.isi.edu/in-notes/rfc1816.txt (Aug. 1995) (on file with the Duke Law Journal).

67. The .arpa domain is used for all reverse IP lookups and is about to be expanded to include other infrastructure functions. See, e.g., P. Faltstrom, E.164 Number and DNS draft-ietf-enum-e164-dns-03, Internet Engineering Task Force, at http://www.ietf.org/internetdrafts/draft-ietf-enum-e164-dns-03.txt (last visited Aug. 18, 2000) (proposing a method of using the DNS for storage of telephone numbers, relying on domain e164.arpa) (on file with the Duke Law Journal). 
2. The Registration Hierarchy. The registration side of the current DNS architecture is arranged hierarchically to ensure that each domain name is unique. At least prior to the recent introduction of a "shared registry" system, ${ }^{68}$ which seems to have introduced some at least transitory uncertainty about whether the master list of second-level domain names is authoritative, a master file of the registrations in each TLD was held by a single registry. ${ }^{69}$ In theory, and ignoring software glitches, having a single registry ensures that once a name is allocated to one person, it cannot simultaneously be assigned to a different person. End-users seeking to obtain a unique domain name must obtain one from a registrar. ${ }^{70} \mathrm{~A}$ registrar can be the registry or it can be a separate entity that has an agreement with the registry for the TLD in which the domain name will appear. Before issuing a registration, the registrar queries the registry's database to make certain the name is available. If it is, it marks it as taken, and (currently) associates various contact details provided by the registrant with the record. ${ }^{71}$

While one can imagine other possible system architectures, the current domain name system requires that each domain name be "unique" in the sense that it be managed by a single registrant rather than in the sense that it be associated with a single IP number. The registrant may associate the domain name with varying IP numbers if that will produce a desired result. For example, a busy website might have several servers, each with its own IP number, that take turns serving requests directed to a single domain name. ${ }^{72}$ In a different

68. The shared registry is a communal data pool made up of the registration data for the gTLDs collected by all ICANN-approved registries and maintained by the NSI registry. See Network Solutions, Glossary of Terms, VeriSign Global Registry Services, at http://www.nsiregistry.com/glossary/gt3.html\#shresy (last visited Aug. 17, 2000) (on file with the Duke Law Journal).

69. See Network Solutions, Shared Registration System, VeriSign Global Registry Services, at http://www.nsiregistry.com/affairs/SRS_Overview_02.pdf (last visited Sept. 21, 2000) (on file with the Duke Law Journal); Registrar Accreditation Agreement, supra note 42.

70. See supra note 19.

71. See Network Solutions, supra note 69; Registrar Accreditation Agreement, supra note 42.

72. For example, anyone with access to the "nslookup" command on a unix-based machine connected to the Internet can confirm that google.com has been associated with 64.209.200.100 and 64.209.200.101 rather than with just one IP number, as is commonly the case. Similarly, anyone able to access CNAME records can see that www.yahoo.com maps into a CNAME (i.e., an alias) that, in turn, maps into five distinct address records:

www.yahoo.com. 23h59m18s IN CNAME www.yahoo.akadns.net.

www.yahoo.akadns.net. 4m19s IN A 204.71.202.160 
Internet, many computers controlled by different people might answer to http://www.law.tm. In that world, users who entered that URL, or clicked on a link to it, would either be playing a roulette game with unpredictable results, or they would have to pass through some sort of gateway or query system so their requests could be routed to the right place. (One can spin more complex stories involving intelligent agents and artificial intelligences that seek to predict user preferences, but this only changes the odds in the roulette game.) Such a system would probably be time-consuming and frustrating, especially as the number of users sharing popular names grew. In any case, it would not be compatible with today's e-mail and other noninteractive communications mechanisms. ${ }^{73}$

3. The Domain Name Resolution Hierarchy. The name resolution side of the domain name system is an interdependent, distributed, hierarchical database. ${ }^{74}$ At the top of the hierarchy lies a single data file that contains the list of the machines that have the master lists of registrations in each TLD. This is the "root zone," or "root," also sometimes known as the "legacy root." Although there is no technical obstacle to anyone maintaining a TLD that is not listed in the legacy root, these "alternate" TLDs can only be resolved by users whose machines, or Internet service providers (ISPs) as the case may be, use a domain name server that includes this additional data or knows where to find it. A combination of consensus, lack of knowledge, and inertia among the people running the machines that administer domain name lookups means that domain names in TLDs outside the legacy root, e.g., http://lightning.faq, cannot be accessed by the large majority of people who use the Internet, unless they do some tinkering with obscure parts of their browser settings. ${ }^{75}$

www.yahoo.akadns.net. 4m19s IN A 204.71.200.74

www.yahoo.akadns.net. 4m19s IN A 204.71.200.75

www.yahoo.akadns.net. 4m19s IN A 204.71.200.67

www.yahoo.akadns.net. 4m19s IN A 204.71 .200 .68

73. For a more strident view that the root must be unique, see generally Brian Carpenter, IAB Technical Comment on the Unique DNS Root, at http://www.iab.org/iab/IAB-TechnicalComment.txt (last visited Oct. 10, 2000) (on file with the Duke Law Journal).

74. See RONY \& RonY, supra note 10 , at $60-61$.

75. Cf. How To Use New Domain Names, Open Root Server Confederation, at http://support.open-rsc.org/How_To/ (last visited Aug. 17, 2000) (explaining how to access new domain names not yet recognized by an ISP) (on file with the Duke Law Journal). 
Domain names are resolved by sending queries to a set of databases linked hierarchically. The query starts at the bottom, at the name server selected by the user or her ISP. A name server is a network service that enables clients to name resources or objects and share this information with other objects in the network. ${ }^{76}$ If the data is not in the name server, the query works its way up the chain until it can be resolved. At the top of the chain is the root zone file maintained in parallel on thirteen different computers. ${ }^{77}$ These thirteen machines, currently identified by letters from A-M, contain a copy of the list of the TLD servers that have the full databases of registered names and their associated IP numbers. (To confuse matters, some of these machines have both a copy of the root zone file and secondlevel domain registration data for one or more TLDs.) Each TLD has a registry that has the authoritative master copy of the second-level domain names registered for that TLD, and the root zone file tells domain name resolving programs where to find them.

\section{B. The Source and Import of Control of the Legacy Root}

The heart of the DNS controversy is actually very simple. At issue is who should control a single small file of computer data kept in Herndon, Virginia, ${ }^{78}$ and how the power flowing from control of that file should be exercised. This "root" file or "root zone" file is the authoritative list of top-level domain names. For each name it gives the Internet address of the computer that has the authoritative list of who has registered domain names in that top-level domain (TLD). Currently there are 252 TLDs and associated addresses in the file. ${ }^{79}$ The data is authoritative because the right people use it-it is the file from which the thirteen computers known as the legacy root name

76. See Chris Peckham, Comp.protocols.tcp-ip.domains Frequently Asked Questions, at http://www.intac.com/ cdp/cptd-faq/ (last visited Aug. 18, 2000) (on file with the Duke Law Journal).

77. See Paul Albitz \& Cricket LiU, DNS ANd BIND 27 (3d ed. 1998).

78. See Conrad et al., supra note 7 :

The root of the Internet name space consists of a single file, the root zone file, which describes the delegations of the top-level domains and the associated records necessitated by the DNS protocol to implement those delegations. Currently, this file is maintained by Network Solutions, Incorporated of Herndon, Virginia, and is made available to the 12 secondary servers from the primary a.root-server.net. Change control of this file is held by the IANA with changes, typically modifications of the name servers for top-level domains, being made approximately once or twice a week.

79. See supra note 62 and accompanying text (discussing 244 ccTLds and 8 gTLDs). 
servers get their data. ${ }^{80}$ And they, in turn, are authoritative because almost every computer on the Internet gets its data from one of those root servers, or from a cached downstream copy of their data. This Internet monoculture is the result of the ubiquity of a single DNS program called BIND. ${ }^{81}$ BIND comes pre-configured to get data from one of the thirteen legacy root name servers, and few users or domain name service providers ever change the setting.

Thus, any discussion of the U.S. government's, or anybody else's, authority and control over the DNS occurs in the shadow of the peculiar fact that "control" does not work in a way familiar to lawyers. The United States does not "own" the entire DNS, although it has contracts with key players and owns a minority of the root servers. Most domain resolution functions take place on privately owned machines that may get their DNS data from other private machines, or from foreign machines, or from U.S. government contractors. The U.S. government's interest in the DNS indeed can be characterized in different ways. It could be argued that the U.S. government's control is ephemeral, since the only reason the root file matters is that the root server operators choose to get their base DNS data from it and that almost all other Internet users choose to get their root data from the thirteen legacy root servers.

Alternately, it could be argued that the U.S. government "owns" the root file that sits at the top of the DNS hierarchy, since the file is managed by NSI, under U.S. government contract. Indeed, in 1998, DoC amended its contract with NSI to make explicit DoC's power to decide what gets listed in the root file. ${ }^{82}$ Yet, although DoC clearly controls the content of the file, the government's power over the root seems to sound more in contract than in property. Indeed, it is difficult to say that the U.S. government's interest is a traditional chattel

80. A list of the root servers and their physical locations appears in Conrad et al., supra note 7, at Appendix A.

81. See ISC BIND, Internet Software Consortium, at http://www.isc.org/products/BIND/ (last visited Aug. 18, 2000) (noting that the "BIND DNS Server is used on the vast majority of name serving machines on the Internet") (on file with the Duke Law Journal).

82. Cooperative Agreement No. NCR-9218742, Amendment 11, http://www.networksolutions.com/legal/internic/cooperative-agreement/amendment11.html (Oct. 6, 1998) (on file with the Duke Law Journal) [hereinafter Amendment 11]:

While NSI continues to operate the primary root server, it shall request written direction from an authorized USG official before making or rejecting any modifications, additions or deletions to the root zone file. Such direction will be provided within ten (10) working days and it may instruct NSI to process any such changes directed by NewCo when submitted to NSI in conformity with written procedures established by NewCo and recognized by the USG. 
property right, since NSI owns the machine on which the root file resides. Nor is it easy to characterize DoC's interest as an intellectual property right. Although the root shares with domain names the property that it is a pointer to something, ${ }^{83}$ it is just a small file of data. The root file lacks sufficient originality to be copyrightable, nor is it the sort of collection likely to be entitled to a compilation copyright. Furthermore, if the root file belongs to the government, and it is continually published, then under the 1976 Copyright Act, it is a "work" not subject to copyright. ${ }^{84}$

Whatever control DoC enjoys over the content of the root file remains meaningful only so long as other participants in the DNSand especially the twelve other root servers ${ }^{85}$ at the next level of the hierarchy-continue to rely on a U.S. government-controlled root server as their source of the master DNS root file. As long as the United States retains its control of the root file, however, the danger that the twelve root server operators will choose to get their data from elsewhere seems very remote for four reasons: First, of the twelve root servers that draw data directly from the "A" root server at the top of the DNS hierarchy, seven currently are owned by the U.S. government or operated by its contractors. Only three of the servers are located outside the United States. ${ }^{86}$ Any move by the non-

83. In Network Solutions, Inc. v. Umbro Int'l, Inc., 529 S.E.2d 80 (Va. 2000), the supreme court of Virginia held that a registrant's interest in a domain name-an interest that is quite similar to DoC's interest in the root file-was merely contractual and hence could not be garnished. See id. at 80 . On the other hand, Congress recently passed the Anticybersquatting Consumer Protection Act, Pub. L. No. 106-43 § 3(a)(2), 5, 113 Stat. 218, 220 (1999), which authorizes in rem actions against domain names. Since in rem proceedings are traditionally used to attach property, this argues that domain names are property. The Umbro court, however, was completely unpersuaded by this reasoning, see Umbro, 529 S.E.2d at $86 \mathrm{n} .12$, as it was by Network Solutions, Inc.'s concession at trial that domain names are a form of intangible personal property. See id. at 86.

84. 17 U.S.C. $§ 105$ (1994) ("Copyright protection under this title is not available for any work of the United States Government ....").

85. There are 13 root servers, but as one of them also has the root file, there are actually only 12 at the next level of the hierarchy.

86. The "E," "G," and "H" root servers are operated by U.S. government agencies. The "A," "B," and "L" root servers are operated by U.S. government contractors. Only the "I," "K," and "M" root servers are operated in other countries (Sweden, the United Kingdom, and Japan, respectively). See Conrad et al., supra note 7, at Appendix A. Of the non-federalgovernmental U.S.-based servers, "C" is operated by psi.net, "D" by the University of Maryland, and "F" by the Internet Software Consortium (the group that publishes BIND, see supra note 81 ). The authoritative list at ftp://ftp.rs.internic.net/domain/named.root reports that the " $\mathrm{J}$ " root server is "temporarily housed at NSI (InterNIC)." Id. Other sources, however, report that the status of the "J" root server remains to be determined. See, e.g., Conrad et al., supra note 7; Jun Murai, Root Server System Advisory Committee, Presentation to ICANN Public Meeting, 
U.S. or even non-U.S. government root servers to choose a new source for the master file would be certain to split the root, because the U.S. servers would not follow suit. Second, the old Internet hands who manage key parts of the infrastructure such as the root servers have a very great aversion to anything that looks as if it might split the root. ${ }^{87}$ Third, the ur-lord of the DNS, the late Jon Postel, apparently tried to redirect the root from the "A" server and was intimidated into withdrawing the attempt. ${ }^{88}$ If Postel could not do it, it is unlikely that others could today. And, fourth, ICANN is currently seeking to move the root file to its own server and to negotiate direct agreements with the other root server operators, which could make the whole issue moot by reducing their independence from ICANN. ${ }^{89}$ If DoC were to choose not to renew its contracts with ICANN at some point in the future, then DoC or its designee as ICANN's successor presumably would become the beneficiary of any agreements ICANN had concluded with the root server operators. ${ }^{90}$ Ironically, in this scenario, the "privatization" of the DNS proposed in the White Paper could lead ultimately lead to tighter U.S. government control over the DNS.

Control of the root potentially confers substantial economic and political power. The root determines which TLDs are visible to the vast majority of Internet users. The most naked exercise of this power involves deciding what data is contained in the single data file that comprises the root. Given current Internet architecture and customs,

Yokohama, Japan, slide 6, Berkman Center for Internet and Society, at http://cyber.law.harvard. edu/icann/yokohama/archive/presentations/murai-071500/index.html (July 15, 2000) (on file with the Duke Law Journal).

87. The exemplar of this view is Carpenter, supra note 73.

88. See infra notes 171-75 and accompanying text.

89. See Preliminary Report: Meeting of the ICANN Board in Yokohama, Res. 00.59-00.62, at http://icann.org/minutes/prelim-report-16jul00.htm (July 16, 2000) (on file with the Duke Law Journal) [hereinafter Yokohama Report]. The ICANN board also authorized ICANN's president "to negotiate agreements or amendments of agreements with the United States Department of Commerce providing for the Corporation to assume responsibility for maintaining the root-zone file and establishing appropriate arrangements for approval of root-zone modifications, such agreements to be presented to the Board for approval or ratification." Id.

90. See ICANN/DOC Memorandum of Understanding, Amendment 1, at http://www.icann.org/nsi/amend1-jpamou-04nov99.htm (Nov. 4, 1999) ("If DOC withdraws its recognition of ICANN or any successor entity by terminating this MOU, ICANN agrees that it will assign to DOC any rights that ICANN has in all existing contracts with registries and registrars.") (on file with the Duke Law Journal) [hereinafter Memorandum of Understanding, Amendment 1]. The agreement speaks only of "registries" and "registrars," not of "root servers," but the root servers should be considered "registries" (of registries) for this purpose. 
the data in that file determines which gTLDs the vast majority of Internet users can access. ${ }^{91}$

People who register Internet domain names do so in hopes that anyone in the worldwide network will be able to reach them. It may be that they wish their websites to be visible around the world, or it may be that they want to get e-mail, or to engage in two-way chat. Whatever the application, a domain name that cannot be resolved into an IP number ${ }^{92}$ by the vast majority of users is of very limited value on the Internet. Similarly, registrars selling domain name registrations understand that only domain names that "work" in the sense of being part of the global network carry much value. The ability to list a registration in a registry that is part of the "legacy" root is thus of paramount importance to a registrar. Similarly, every registry knows that its database of domain name to IP mappings is of limited value if no one can find it. Registries thus need to be listed in the root or they (and all the domains they list) become effectively invisible. As only being listed in the legacy root currently provides visibility for a TLD and the domains listed in it, control of the root creates powerful leverage.

The power to add TLDs to the legacy root has implications for intellectual property rights, consumer choice, competition, the ease of political discourse, and e-commerce generally. It even has implications for nation-building and international law. The root authority can add the top-level domain of any nation or pretender to nationhood; it can create gTLDs such as .shop or .biz in minutes, and within a day or so the results of these decisions automatically echo around the world. For example, when Palestinians wanted to have .ps created as a country code, they first persuaded the keepers of the ISO country code list to add .ps. Since the current policy for determining which "countries" should be listed in the root relies on this list, once the Internet Assigned Numbers Authority (IANA) ${ }^{93}$ determined that the ISO 3166-1 list had been amended to include .ps as a code for "Palestine," it certified that .ps should be added to the root and announced that it was accepting an application from a Palestinian academic to run the new

91. See id.

92. See supra Part I.A (describing the function of IP numbers).

93. As discussed further below, IANA is, if not the government, at least a government contractor. See infra Part II.B.3. 
.ps domain. ${ }^{94}$ At some subsequent point, the Department of Commerce must have approved the change in writing, since its agreement with NSI requires written confirmation for all changes to the root. ${ }^{95}$ Although at this writing .ps does not appear to be accepting applications for second-level domain names, the ccTLD is listed in the root. ${ }^{96}$

The power to create is also, at least temporarily, the power to destroy. Because the servers in the DNS chain regularly refresh their cached data from the servers above them in the chain, the root server's decision to remove a nation's TLD from the web could make it effectively inaccessible to everyone who did not have alternate means of turning a domain name into an IP number. Delisting would severely limit the victim's Internet communications-at least until the managers of other DNS servers in the world manually reinserted the deleted data in their copies of the root. Thus, control over the DNS confers substantial economic and political power. Since both civilian and military infrastructures in many nations are becoming increasingly dependent on the existence of the Internet, the ability to

94. See IANA Report on Request for Delegation of the .ps Top-Level Domain, at http://www.icann.org/general/ps-report-22mar00.htm (Mar. 22, 2000) (on file with the Duke Law Journal). The report stated:

the United Nations Statistics Division notified the ISO 3166 Maintenance Agency that it had included "Occupied Palestinian Territory" on the United Nations list of Standard Country and Area Codes for Statistical Use. On 30 September 1999, the ISO 3166 Maintenance Agency announced that effective 1 October 1999 it was adding the alpha-2 code "ps" to the ISO 3166-1 list to designate "Occupied Palestinian Territory."

Id.

95. See supra note 82 (quoting the relevant portion of Amendment 11).

96. On May 22, 2000, a command of "dig@a.root-servers.net. ps. ns" from "spitfire.law.miami.edu" produced the following response indicating that ps is part of the "A" root server's database:

; $<<>>$ DiG $8.2<<>>$ @a.root-servers.net.ps.ns

; (1 server found)

; res options: init recurs defnam dnsrch

; got answer:

;; ->>HEADER<<- opcode: QUERY, status: NOERROR, id: 6

; flags: qr rd; QUERY: 1, ANSWER: 3, AUTHORITY: 0, ADDITIONAL: 3

; QUERY SECTION:

;ps, type = NS, class $=$ IN

; ANSWER SECTION:

ps. 2D IN NSNS.LEB.NET.

ps. 2D IN NSNS.DOLEH.COM.

ps. 2D IN NSPAPPSRV.PAPP.UNDP.ORG.

;; ADDITIONAL SECTION:

NS.LEB.NET. 2D IN A 206.127.55.2

NS.DOLEH.COM. 2D IN A 204.255.25.63 
disrupt an enemy's communications might be a strategic asset in wartime. $^{97}$

However, even if it could be effective, this ploy would work at most once, because, were the U.S. to use the root for strategic advantage, all root servers located abroad would undoubtedly stop mirroring the data served from the U.S. immediately, even if it split the root.

A more subtle, but already commonplace, use of the root authority involves putting contractual conditions on access to the root. ICANN has imposed a number of conditions on registrars and commercial gTLD (but not ccTLD) registries on a take-it-or-bedelisted basis. For example, ICANN not only forbids anonymous registrations; it also forbids the Internet equivalent of an unlisted telephone number. Under ICANN's contractually imposed regulations, which continue the practices it inherited from NSI, every registrant of a domain name in a gTLD must consent to worldwide publication of her name, telephone number and address. ${ }^{98}$ Unlike NSI, however, ICANN provides for rigorous enforcement of this rule, since under ICANN's mandatory arbitration policy, the Uniform Domain Name Dispute Resolution Policy, a domain name registration in "bad faith" is a key ground for transferring a domain from a registrant to a trademark holder, ${ }^{99}$ and failing to provide accurate contact details is evidence of bad faith. ${ }^{100}$ The addition of the UDRP is a radical change: under ICANN, every registrant in a gTLD must agree to a third-party beneficiary arbitration clause. Anyone anywhere who

97. While it would be easy to remove a country code from the root, the effects would only be felt as the data file was copied and echoed around the Internet-a process that would take time. A nation that became aware of the danger could ensure that its servers used a nonpolluted cache or, if it was too late, should be able to repair the damage in no more time than it took to cause it. Furthermore, removing a ccTLD from the root would be effective only if a country were dependent on it. If Ruritania primarily uses domains in the .rr domain, then it might suffer when they are not responding; if, on the other hand, Ruritanian institutions are heavy users of .com, .org, and .net, any attempt to disrupt Ruritanian communications via the DNS must identify its registrations in each of the registries for those domains, which is a more complex task and involves securing the cooperation of the registries.

98. See Registrar Accreditation Agreement, supra note 42, §§ II.E-F.

99. See UDRP, supra note 20.

100. See, e.g., McNeil Consumer Brands Inc. v. Mirweb Solutions, Case No. D2000-0612 (WIPO Aug. 3, 2000) ("The Respondent has provided incomplete contact information in its domain name registration and has on the face of it taken steps to conceal its true identity by 'vesting' the ownership of the 'tylenol.org' domain name in a series of internet entities."), available at http://arbiter.wipo.int/domains/decisions/html/d2000-0612.html (last visited Aug. 18, 2000) (on file with the Duke Law Journal). 
believes that the registration or use of the domain name infringes a trademark or service mark can invoke this clause to force arbitration before one of a list of ICANN-approved arbitration service providers paid for and selected by the complainant. ${ }^{101}$

\section{THE DNS: A CONTRACTUAL HISTORY}

The U.S. government did not plan to be in charge of a critical Internet chokepoint. Its control of the root was, more than anything, accidental. The United States has not at all times acted as if it was pleased with this good fortune and has worked assiduously to divest itself of this asset on the grounds that it was more properly controlled by the private sector and/or the global community. What follows is primarily a legal and contractual history of the key relationships that have defined ICANN's authority. ${ }^{102}$

One aspect of the legal history and pre-history of ICANN deserves special mention before embarking on a detailed contractual history. Like the story of Sherlock Holmes's dog that did not bark in the night, the ICANN story contains a telling absence. The ICANN story lacks a statute. At no time has Congress ever authorized ICANN or the "privatization" of the DNS. DoC has relied on its general statutory authority to manage and to seek to "privatize" the DNS. ${ }^{103}$ As a result, the critical legal documents are all contracts,

101. See UDRP, supra note 20.

102. It, therefore, leaves out many of the most interesting and juicy political machinations, and particularly slights a number of fascinating, but failed, initiatives to reorganize domain name policy. For full accounts, see RONY \& RONY, supra note 10, at 89-136; Craig Simon, Internet Governance Goes Global, in INTERNATIONAL RELATIONS IN A CONSTRUCTED WORLD 147, 160-65 (Vendulka Kubálková et al. eds., 1998); Craig Simon, Roots of Power: The Rise of Dot Com and the Decline of the Nation State (2000) (placing the history of the "DNS War" in the context of modern social thought) (unpublished manuscript, on file with the Duke Law Journal); Gordon Cook, Secret Meeting Shows ICANN-IBM Dependence, THE COOK REPORT ON INTERNET (Jan. 2000) (criticizing ICANN's "agenda of control" as well as the role several individuals have had in the development of ICANN's current position as registrar), at http://cookreport.com/icannoverall.shtml (on file with the Duke Law Journal); Milton Mueller, ICANN and Internet Governance: Sorting Through the Debris of "Self-Regulation," 1 INFO 497 (1999) (arguing that the Clinton administration's guiding principle of "industry self-regulation" only "served to obscure the policy issues raised by the historic transition" and that the government, ironically, retains "“policy authority" over the DNS root indefinitely"), at http://www.icannwatch.org/archives/muell.pdf (on file with the Duke Law Journal); Ellen Rony \& Peter Rony, Domain Name System in Congress and US Govt., at http://www.domainhandbook.com/congress.html (last visited Aug. 18, 2000) (cataloguing agreements between the government, ICANN and others) (on file with the Duke Law Journal).

103. See infra notes 325-30. 
memoranda of understanding, or other bilateral agreements either between DoC and contractors, or among government contractors.

Compared to an ordinary legislative history, the contractual history described below is complex, sometimes confusing, rich in acronyms, and at times perhaps a little boring. Yet the legal underpinnings of the current DNS cannot be understood without a slog through it. The contractual history makes clear that the origins of the DNS and its management were informal, and only a small part of larger projects. When the Internet was small, the issues that now loom large were of little importance and attracted almost no attention. As the Internet, and especially its perceived commercial importance, grew, so too did the conflict over the rules to be applied to the DNS. Whatever doubt there may have been about the U.S. government's authority seems to have been resolved by mid-1997, when NSF decisively exercised its authority. ${ }^{104}$ Policy control then passed to an interagency working group headed by Ira Magaziner, and to the Department of Commerce, which issued a critical policy document, the DNS "White Paper." 105 Although as a mere policy statement the White Paper did not have the force of law, major parts of its policies were quickly implemented, notably the creation of ICANN and the institution of a new domain name dispute policy that sought to meet the concerns of trademark holders.

\section{A. Before ICANN}

1. Early Days (1972-94). The U.S. government came to control the DNS system because the DNS came into the hands of people whose work on it was funded by government grants. By the time the grantees sought to break free of government control, it was too late.

The idea of giving internetworked computers easily remembered names dates back at least to $1971 .^{106}$ Peggy Karp, one of the early authors and editors of the Internet standards, ${ }^{107}$ and the author of the

104. See infra notes 139-43.

105. See supra note 15.

106. See Peggy Karp, RFC 226, Standardization of Host Mnemonics 1, USC Information Sciences Institute, at http://www.isi.edu/in-notes/rfc226.txt (Sept. 20,1971) (providing host name mnemonics so that users would not be required to know the "idiosyncrasies of each list") (on file with the Duke Law Journal).

107. See Richard W. Watson, RFC 101, Notes on the Network Working Group Meeting 1, USC Information Sciences Institute, at http://www.isi.edu/in-notes/rfc101.txt (Feb. 23, 1971) 
first request for comments (RFC) on host names, prepared the first hosts.txt file (the predecessor of the modern "root" file) and turned it over to the Stanford Research Institute (SRI) in early 1972. For the next fourteen years, the hosts.txt file was maintained by the SRI Network Information Center (NIC), then the Defense Data Network (DDN) NIC, and then the Defense Information Systems Agency (DISA) NIC. ${ }^{108}$ Internet pioneer Paul Mockapetris wrote the specification for the original implementation of the DNS we have today, ${ }^{109}$ but the transition to it took several years. Meanwhile, maintenance and administration of the system remained the responsibility of the SRI NIC for DISA. ${ }^{110}$ During this period, the SRI NIC not only hosted the root file, but also served as the domain name registrar and registry for most gTLDs.

While the SRI NIC provided the machines and mechanics, starting about 1977, ${ }^{111}$ the day-to-day responsibility for coordinating changes in standards and policy fell to a UCLA graduate student, Jon Postel, who was funded by a U.S. Department of Defense grant. ${ }^{112}$ Postel, who had started coordinating other Internet protocols as early as $1972,{ }^{113}$ took on the task of assigning IP numbers, and (at some

(noting that Peggy Karp was summarizing the first 100 Internet standards documents) (on file with the Duke Law Journal).

108. See S. Williamson \& L. Nobile, RFC 1261, Transition of NIC Services, Internet Engineering Task Force, at http://www.ietf.org/rfc/rfc1261.txt (Sept. 1991) (noting the role of DISA in the transition of NIC from SRI) (on file with the Duke Law Journal).

109. See P. Mockapetris, RFC 882, Domain Names-Concepts and Facilities, Internet Engineering Task Force, at http://www.ietf.org/rfc/rfc0882.txt (Nov. 1983) (describing the "conceptual framework of the domain system and some uses") (on file with the Duke Law Journal); P. Mockapetris, RFC 883, Domain Names: Implementation and Specification, Internet Engineering Task Force, at http://www.ietf.org/rfc/rfc0883.txt (Nov. 1983) (discussing "the implementation of domain name servers and resolvers ... and ... the use of domain names in the context of existing mail systems and other network software") (on file with the Duke Law Journal); P. Mockapetris, RFC 973, Domain System Changes and Observations, Internet Engineering Task Force, at http://www.ietf.org/rfc/rfc0973.txt (Jan. 1986) (updating Domain Name Specifications RFC 882 and RFC 883, suggesting some operational guidelines, and discussing "some experiences and problem areas in the present system") (on file with the Duke Law Journal).

110. See Robert H. Zakon, Hobbes’ Internet Timeline v5.1, §§ 1981, 1985, Internet Society, at http://www.isoc.org/guest/zakon/Internet/History/HIT.html (last visited Sept. 20, 2000) (on file with the Duke Law Journal).

111. See A.M. Rutkowski, History of Supporting Internet Names and Numbers, World Internetworking Alliance, at http://www.wia.org/pub/identifiers/identifier_management.gif (last visited Sept. 20, 2000) (on file with the Duke Law Journal).

112. See White Paper, supra note 15, at 31,741.

113. See Jon Postel, RFC 349, Proposed Standard Socket Numbers, USC Information Sciences Institute, at http://www.isi.edu/in-notes/rfc349.txt (May 30, 1972) (proposing the assign- 
point) protocol values for domain names. Thus, Postel, working through the evolving consensus procedures for setting Internet standards, decided which gTLDs and ccTLDs would be created and personally selected the people who would be empowered to register names in ccTLDs. When, after receiving his Ph.D., Dr. Postel moved to the University of Southern California's Information Sciences Institute, he took these functions with him. ${ }^{114}$

In October 1983, Postel and his colleague, Joyce Reynolds, authored RFC 920, "an official policy statement" of the Internet Architecture Board (a private Internet standards body) ${ }^{115}$ and the Defense Advanced Research Projects Agency (DARPA). ${ }^{116}$ This official policy of the government and the Internet standards body defined most of the TLDs in use to this day. ${ }^{117}$

In 1985, DISA formally gave the responsibility for managing the expansion of the namespace to the Information Sciences Institute (ISI) at USC. ${ }^{118}$ As early as 1974 , ISI had begun to manage some other RFC administrative activities. At some later point, perhaps December $1988,{ }^{119}$ ISI reorganized. ISI, led by Postel, began operating the DNS and other RFC operational activities under the rubric of the Internet Assigned Numbers Authority, ${ }^{120}$ pursuant to authority delegated from the U.S. Department of Defense. ${ }^{121}$

ment of official socket numbers for use by standard protocols) (on file with the Duke Law Journal).

114. See, e.g., News Release, University of Southern California, Internet Pioneer Jon Postel Dies at 55 (Oct. 19, 1998) (describing Postel's work and accomplishments while at USC), http://www.usc.edu/dept/News_Service/releases/stories/35680.html (on file with the Duke Law Journal).

115. On the history of the IAB, see Internet [Architecture] [Activities] Board: Known History, World Internetworking Alliance, at http://www.wia.org/pub/iab-history.htm (Nov. 4, 1998) (on file with the Duke Law Journal).

116. See J. Postel \& J. Reynolds, RFC 920, Domain Requirements 1, Internet Engineering Task Force, at http://www.ietf.org/rfc/rfc0920.txt (Oct. 1984) (on file with the Duke Law Journal).

117. RFC 920 defined .com, .gov, .edu, .mil, .org, and the ccTLDs. See id. at 2; see also RonY \& RONY, supra note 10, at 113-16 (calling RFC 920 "historic").

118. See Zakon, supra note $110, \S 1985$.

119. See id. § 1988.

120. See Pincus, supra note 43; Zakon, supra note 110, § 1988.

121. See The Role of the Internet Assigned Numbers Authority (IANA), Internet Society, at http://www.isoc.org/isoc/media/releases/iana.shtml (Jan. 16, 1998) (on file with the Duke Law Journal):

The IANA is the name for the function for the allocation and assignment of various identifiers needed for the operation of the Internet, which function was assigned by DARPA to the Information Sciences Institute (ISI) of the University of Southern California pursuant to contracts between DARPA and ISI. Under the DARPA con- 
In 1986, DISA began allowing some offshore DARPA research centers to perform some DNS registration functions, the first of which was University College, London, for a UK domain. Later, it allowed a research facility in Amsterdam to manage some IP address blocs under the rubric RIPE. The government contracts for these activities remained with ISI, of which IANA was an unincorporated administrative unit. IANA's funding came from Department of Defense grants to USC. ${ }^{122}$ Although for a time IANA claimed to have a charter from the Internet Society (ISOC) and the Federal Networking Council, it was at all relevant times a government contractor. ${ }^{123}$

Between 1972 and 1994, Dr. Postel and (starting in the late 1980s) IANA ${ }^{124}$ documented their procedures in a set of requests for comments, which were adopted by the Internet Engineering Task Force (IETF). ${ }^{125}$ The IETF is an independent, unincorporated, international standards body of continually floating membership. Although RFCs are nonbinding, they are widely recognized as the critical Internet standards documents and often have enormous influence. ${ }^{126}$ Thus, for example, in RFC 349, Postel, still a graduate student, wrote presciently, "I propose that there be a czar (me?) who hands

tracts, ISI (through the IANA function) has the discretionary authority to delegate portions of this function, and has delegated that portion of the responsibility concerning some aspects of numeric network and autonomous system identifiers to an Internet Numbers Registry (IR), previously performed by SRI International and currently performed by NSI. See RFC 1174 and Section H.1., NSF Solicitation for Network Information Services Manager for NSFnet and the NREN ("ISI (as the IANA) ha[s] delegated to the DISA NIC (currently NSI) the registration of users for the Internet").

122. See Pincus, supra note 43 .

123. See RONY \& RONY, supra note 10 , at 123.

124. The first RFC reference to IANA is in December 1988, in Internet Architecture Board, RFC 1083, IAB Official Protocol Standards 1, Internet Engineering Task Force, at http://www.ietf.org/rfc/rfc1083.txt (Dec. 1988) (on file with the Duke Law Journal); see also U.S. DOD [Internet] Assigned Numbers [Authority], Network Information Centers (NICs), Contractors, and Activities: Known Detailed History, World Internetworking Alliance, at http://www.wia.org/pub/iana.html (last visited Aug. 17, 2000) (on file with the Duke Law Journal). The first RFC by IANA staff appears to be J. Postel \& J. Reynolds, RFC 1060, Assigned Numbers, Internet Engineering Task Force, at http://www.ietf.org/rfc/rfc1060.txt (Mar. 1990) (on file with the Duke Law Journal).

125. See generally RFCs 1700, 1340, 1060, 1010, 990, 960, 943, 923, 900, 870, 820, 790, 776, $770,762,758,755,750,739,604,503,433$, and 349 , available by number, title, author or other identifier at Finding and Retrieving RFCs from the RFC Editor Site, Internet Society, at http://www.rfc-editor.org/rfc.html (last visited Aug. 17, 2000) (on file with the Duke Law Journal).

126. See generally A. Michael Froomkin, Habermas@discourse.net: Towards a Critical Theory of Cyberspace (forthcoming 2000), available at http://www.discourse.net (on file with the Duke Law Journal). 
out official socket numbers for use by standard protocols. This czar should also keep track of and publish a list of those socket numbers where host specific services can be obtained. I further suggest that the initial allocation be as follows ...."127 By the time of his death in 1998, by all accounts Jon Postel and his colleague Joyce Reynolds were not only socket czars, but Internet names and numbers czars.

In 1990, DISA recompeted the NIC contract, which was won by Government Systems Inc. (GSI), ${ }^{128}$ who then subcontracted the entire operation to Network Solutions, Inc. NSI started operating the NIC early in 1992. By then, DISA had concluded that the continued growth of the Internet and the introduction of new programs such as the National Research and Educational Network (NREN) meant that the funding and management of the non-military part of the Internet's administration belonged outside the Department of Defense. ${ }^{129}$ NSF had already begun funding cooperative private-sector Internet research and development in 1986 and continued to do so on an increasingly large scale until $1995 .{ }^{130}$ Unlike the Department of Defense, NSF provided grants to the private sector and entered into "cooperative agreements" to undertake the needed work with the "technology transfer" expectation that anything developed could eventually be undertaken and owned entirely by the grantee. ${ }^{131}$

In 1994, Dr. Postel authored RFC 1591, Domain Name System Structure and Delegation, ${ }^{132}$ in which he described his policies and procedures for assigning domain names. Several issues which are fraught

127. Postel, supra note 113, at 1.

128. See S. Williamson \& L. Nobile, RFC 1261, Transition of NIC Services 1, Internet Engineering Task Force, at http://www.ietf.org/rfc/rfc1261.txt (Sept. 1991) (announcing the transfer of NIC to GSI) (on file with the Duke Law Journal).

129. See E-mail from Anthony M. Rutkowski, Director, Center for Next Generation Internet, to Professor A. Michael Froomkin, University of Miami School of Law (May 27, 2000) (on file with the Duke Law Journal).

130. See Dan L. Burk, Federalism in Cyberspace, 28 CONN. L. REV. 1095, 1099 (1996).

131. On cooperative agreements, see Thomas N. Bulleit, Jr., Public-Private Partnerships in Biomedical Research: Resolving Conflicts of Interest Arising Under the Federal Technology Transfer Act of 1986, 4 J.L. \& HEALTH 1 (1989/1990) (describing cooperative agreements between private industry and scientists in federal laboratories); Brett Frishmann, Innovations and Institutions: Rethinking the Economics of U.S. Science and Technology Policy, 24 VT. L. REV. 347, 391-92 (2000) (proposing a framework for the coordination of U.S. science and technology policy); Nathan A. Adams, IV, Comment, Monkey See, Monkey Do: Imitating Japan's Industrial Policy in the United States, 31 TEX. INT'L L.J. 527 passim (1996) (contrasting the Japanese and American technology approaches).

132. J. Postel, RFC 1591, Domain Name System Structure and Delegation, Internet Engineering Task Force, at http://www.ietf.org/rfc/rfc1591.txt (Mar. 1994) (on file with the Duke Law Journal). 
with controversy today took only a paragraph or two to explain in 1994. Thus, for example, RFC 1591 described relatively lightweight procedures for creating new top-level domains-an issue that has more recently consumed years of debate without the creation of any new gTLDs. Since establishing the basic system of gTLDs and ccTLDs, Postel and IANA had created a small number of additional ccTLDs and a few limited-use gTLDs, but no gTLDs for general use. By 1994, the demand for names in the gTLD space was still very small; the explosion in demand did not begin until at least two years later. ${ }^{133}$ RFC 1591 also described how one qualified to manage a ccTLD. It set up a rule of first-come, first-served so long as one had decent Internet connectivity, acted fairly, and was accepted by the user community. Cases in which a ccTLD manager lost the confidence of his users were to be resolved by negotiation among the squabbling parties. ${ }^{134}$ As for what is a country name, and who has the right to a domain name that resembles a trademark, RFC 1591 said only this:

1) Names and Trademarks

In case of a dispute between domain name registrants as to the rights to a particular name, the registration authority shall have no role or responsibility other than to provide the contact information to both parties.

The registration of a domain name does not have any Trademark status. It is up to the requestor to be sure he is not violating anyone else's Trademark. ${ }^{135}$

Later in 1994, Postel and Reynolds offered in RFC 1700 a new account of IANA's status. ${ }^{136}$ In this new formulation, IANA was "the central coordinator for the assignment of unique parameter values for Internet protocols. The IANA is chartered by the Internet Society (ISOC) and the Federal Network Council (FNC) to act as the clearinghouse to assign and coordinate the use of numerous Internet pro-

133. Even by February 1996, there were fewer than 300,000 domain names registered with NSI, of which 232,004 were in .com. See Registration Services, Performance Measures for February, 1996, at http://www.networksolutions.com/legal/internic/coop-stats/feb96.html (last visited Aug. 20, 2000) (on file with the Duke Law Journal).

134. See Postel, supra note 132.

135. Id. $\S 4$. The document also stated a simple policy on ccTLDs: "The IANA is not in the business of deciding what is and what is not a country." $I d$.

136. See J. Reynolds \& J. Postel, RFC 1700, Assigned Numbers, Internet Engineering Task Force, at http://www.ietf.org/rfc/rfc1700.txt (Oct. 1994) (on file with the Duke Law Journal). 
tocol parameters." ${ }^{137}$ The difficulty with this new formula, as the authors of the Domain Name Handbook point out, is that IANA existed long before ISOC, and ISOC was neither capable of chartering it, nor had actually attempted to do so. ${ }^{138}$

If nothing else, it seems safe to say that by 1994 the authority for DNS policy was somewhat muddled. The entry of a new player would confuse matters further.

2. The NSF-NSI Cooperative Agreement (1993-95). In 1993, about a year before Jon Postel issued RFC 1591, the National Science Foundation replaced the Department of Defense as the funding source for the NIC. ${ }^{139}$ It engaged Network Solutions, Inc. to take over the domain name registration services for the non-military Internet, a function that NSF estimated would require it to spend around \$1 million per year. ${ }^{140}$ NSI thus ran the computers that held the root zone, was responsible for the mechanics of inserting new TLDs into the root (although not for deciding which, if any, should be included), and also took on the function of day-to-day assignment of secondlevel domain names in .com, .org and .net on a first-come, first-served basis. The NSF-NSI "Cooperative Agreement" "141 gave NSI a monopoly over .com registrations that it would ultimately build into a multi-billion dollar business; the monopoly originally was scheduled to expire in September $1998 .^{142}$

The agreement gave NSI operational control of the DNS but, as in the predecessor agreement between DISA and GSI, required NSI to follow the policy directions of IANA. Article 3 of that agreement required NSI to "provide registration services in accordance with the provisions of RFC 1174." "143 In turn, RFC 1174 stated that IANA had "discretionary authority to delegate [responsibility] with respect to

137. Id.

138. See Rony \& Rony, supra note 10, at 122-23.

139. See Stuart D. Levi et al., The Domain Name System \& Trademarks, in THIRD ANNUAL INTERNET LAW INSTITUTE 449, 454-55 (1999).

140. See Mueller, supra note 102, at 500 .

141. NSF Cooperative Agreement No. NCR-9218742, at http://www.networksolutions.com/ legal/internic/cooperative-agreement/agreement.html (Jan. 1, 1993) (on file with the Duke Law Journal).

142. See id. art. 7.

143. Id. art. 3(c). 
numeric network and autonomous system identifiers." ${ }^{144}$ RFC 1591 soon amplified RFC 1174, although since it was only an "informational" RFC, it arguably was not binding on NSI. RFC 1591 describes IANA as "the overall authority for the IP Addresses, the Domain Names, and many other parameters, used in the Internet." ${ }^{145}$ Since the paymaster for IANA remained the U.S. Department of Defense, the effect of this provision was to ensure that policy control of the root remained in the hands of people closely tied to the U.S. government, and especially the military, even while daily functions such as secondlevel domain name registration services were moving into NSF's, and through them NSI's, hands.

The profit potential of the domain name registration business soon grew. In September 1995, NSF agreed to amend the Cooperative Agreement to allow NSI to charge user fees of $\$ 50$ per year for domain names. ${ }^{146}$ IANA, still working under Department of Defense contracts, remained in charge of fundamental policymaking, but NSI's control over the mechanics of registration allowed it to, and perhaps even operationally required it to, make decisions that had policy im-

144. Vint Cerf, RFC 1174, IAB Recommended Policy on Distributing Internet Identifier Assignment and IAB Recommended Policy Change to Internet "Connected" Status, USC Information Sciences Institute, at http://www.isi.edu/in-notes/rfc1174.txt (last visited Aug. 20, 2000) (on file with the Duke Law Journal).

145. Postel, supra note 132.

146. See NSI-NSF Cooperative Agreement, Amendment 4, at http://www.networksolutions.com/legal/internic/cooperative-agreement/amendment4.html (Sept. 13, 1995) (on file with the Duke Law Journal). NSI kept only $\$ 70$ of the $\$ 100$ two-year fee. The other $\$ 30$ went to a special government fund for the enhancement of the "Intellectual Infrastructure" of the Internet. Congress retroactively authorized this tax (or fee). See Thomas v. Network Solutions, Inc., 176 F.3d 500, 505-06 (D.C. Cir. 1999).

As NSF prepared to change its policy on fees, Science Applications International Corporation (SAIC), a major defense contractor, acquired NSI. See Laura Pearlman, Truth, Justice and the Dot-Com Wars, AM. LAW., Mar. 31, 2000, http://www.lawnewsnetwork.com/practice/ techlaw/news/A20216-2000Mar31.html (on file with the Duke Law Journal). Tony Rutkowski recalls that the idea of charging for domain names long pre-dated the 1995 acquisition of NSI by SAIC:

Consonant with NSF's technology transfer concept in the original 1992 RFP, it was always contemplated that charges would exist. Some of the proposals actually contemplated full-scale immediate charges. However, at first, NSF was reluctant to require it after the award to NSI. However, it became almost immediately obvious to the review team (of which I was a part), that charges would be needed to provide sufficient money to do the with the scaling registrations. In addition, almost every country NIC was already charging, and the "free" registration was causing enormous problems from parties that would just come and register tens of thousands of names.

E-mail from Anthony M. Rutkowski, Director for Center for Next Generation Internet, to Professor A. Michael Froomkin, University of Miami School of Law (May 27, 2000) (on file with the Duke Law Journal). 
plications. The most controversial of these was undoubtedly NSI's frequently amended "dispute policy." Although the details varied from version to version, in essence the policy provided that any person proffering a trademark on a word identical to another person's domain name registration could have the registration put "on hold"frozen so that it would no longer resolve to an IP number and was, thus, of no practical use. ${ }^{147}$ The dispute policy greatly benefited NSI, as it nearly eliminated its exposure to lawsuits by trademark owners, who tended to be better financed and better represented than nontrademark-owning registrants.

3. The TM Community Awakens. NSI had reason to fear lawsuits. The Internet's explosive growth fueled a land-rush mentality for domain names, especially in the .com domain. In response to the growing demand for new gTLDs, Dr. Postel had endorsed creating a large number of new gTLDs as early as November $1995 .{ }^{148}$ Postel's own plan involved creating 150 new TLDs in the first year alone. ${ }^{149}$ But already the trademark problem threatened to dominate any debate over the creation of new TLDs, and Postel's plan, like his earlier proposal $^{150}$ to de-link IANA from the U.S. government and

147. See, e.g., NSI Domain Name Dispute Policy, § 9, Communications Media Center at New York Law School, at http://www.cmcnyls.edu/Misc/NSIDNRP3.HTM (Feb. 25, 1998) (describing the process by which NSI would turn off a registrant's domain name upon request by a holder of a trademark in the same character string whose registration date preceded the domain name's registration unless the registrant also had a valid trademark in that character string) (on file with the Duke Law Journal). On the NSI dispute policies, see generally Carl Oppedahl, Analysis and Suggestions Regarding NSI Domain Name Trademark Dispute Policy, 7 ForDHAM INTELL. PROP. MEDIA \& ENT. L.J. 73 (1996) (describing the role of NSI as the primary domain name registration authority); Carl Oppedahl, Remedies in Domain Name Lawsuits: How is a Domain Name Like a Cow?, 15 J. MARSHALL J. COMPUTER \& INFO. L. 437 (1997) (evaluating the NSI dispute policy).

148. Postel endorsed the October 1995 plan to have ISOC take over IANA that was floated by Professor Lawrence Landweber. Landweber later served as an intermediary who helped recruit ICANN board members. To view the text of the October 1995 proposal, see Lawrence Landweber, DNS Proposal, at http://dns.vrx.net/news/by_date/old/1995/Nov/isocplan.html (Oct. 1,1995) (on file with the Duke Law Journal).

149. See Jon Postel, New Registries and the Delegation of International Top Level Domains, Draft-postel-iana-itld-admin-02.txt, § 5.6, at http://www.newdom.com/archive/draft-postel-ianaitld-admin-02.txt (last visited Aug. 20, 2000) (on file with the Duke Law Journal).

150. See Jon Postel, IANA Charter Draft to ISOC Board of Trustees, World Internetworking Alliance, at http://www.wia.org/pub/postel-iana-draft1.htm (July 20, 1994) (offering the first draft of a proposed IANA charter) (on file with the Duke Law Journal). 
find other backing such as the Internet Society, failed to garner sufficient support. ${ }^{151}$

In compliance with NSF's directive to encourage use of the Internet, and in keeping with the growing .com mentality of wanting to do everything immediately, NSI allowed registrants a long grace period; even after NSI started charging $\$ 100$ for two-year domain name registrations, NSI waited thirty days before sending a bill, and then gave additional time to pay, creating a long float. ${ }^{152}$ As there was no limit to the number of names a person could register, name speculators quickly understood that they could register names and attempt to seek buyers for them without risking any capital. ${ }^{153}$ While some speculators sought common words with multiple possible uses, a few others-who became known as cybersquatters-registered thousands of names that corresponded to the trademarks of companies that had not yet found the Internet and then sought to resell (or, some would say, ransom) the name to those companies. Since the Lanham Act requires commercial use before a court will find trademark infringement, it seemed more than arguable that mere registration, without use, was legal, and that the brokers/cybersquatters had found a costless way to profit. ${ }^{154}$

Much of early cybersquatting law was defined by one of the most active cybersquatters, Dennis Toeppen. By 1996, in Intermatic Inc. $v$. Toeppen ${ }^{155}$ the first court had held that registering domain names in order to offer them for sale to a firm of that same name constituted an actionable commercial use of that name under the Federal Trademark Dilution Act. ${ }^{156}$ The Ninth Circuit later essentially adopted this reasoning in the landmark 1998 case of Panavision International $v$.

151. The story behind this is complex and well beyond the scope of this Article. For a vivid account, see Mueller, supra note 102, at 501. For a timeline, see Simon, supra note 27.

152. See Todd Spangler, NSI Adopts Prepayment Model, ZDNeT InTER@CTIVE WeEK ONLINE (July 22, 1999) (noting the change from the 30-day policy to payment in advance), at http://www.zdnet.com/intweek/stories/news/0,4164,2298737,00.html (on file with the Duke Law Journal).

153. For a survey of the law and equities of name speculation, see generally Jessica Litman, The DNS Wars: Trademarks and the Internet Domain Name System, 4 J. SMALL \& EMERGING BUS. L. 149 (2000).

154. See id. at $154-55$

155. 947 F. Supp. 1227, 1237-40 (N.D. Ill. 1996).

156. The Act provides: "The owner of a famous mark shall be entitled... to an injunction against another person's commercial use in commerce of a mark or trade name, if such use begins after the mark has become famous and causes dilution of the distinctive quality of the mark ...."15 U.S.C. $\$ 1125(c)$ (1994). 
Toeppen. ${ }^{157}$ The specter of illegality, however, did not stop the cybersquatters, as they could still exploit the settlement value of cases: they put no money down, or just the cost of a registration, which was $\$ 100$ or less, and could negotiate for sums up to the filing costs, attorney's fees, and value of management time, which usually added up to at least a few thousand dollars. ${ }^{158}$

4. PGP Media Lawsuit (1997). By 1997, it was evident that domain names would be valuable, and that NSI had a valuable franchise. Other firms sought to become registries and to establish parallel top-level domains. Some set up alternate roots, ${ }^{159}$ while others sought to force their way into the legacy root. One of the most persistent was PGP Media (later, Name.Space), a firm that in March 1997 wrote to NSI requesting that NSI add to the root zone file some 530 gTLDs that PGP Media alleged it had claimed. NSI argued that it lacked the authority to add entries to the root zone and referred Name.Space's request to IANA. PGP Media responded by filing a complaint alleging antitrust violations against NSI, with IANA named as a nonparty co-conspirator. As the Second Circuit summarized it:

NSI then wrote to Dr. Jon Postel at IANA on March 27, 1997, informing him of this lawsuit and seeking to confirm NSI's understanding that it could make changes to the root zone file only at the direction of IANA. IANA responded on April 4, 1997 by denying that IANA had any authority over NSI's operations, and stating that IANA also had no authority to establish any new gTLDs in the absence of an Internet community consensus. Therefore, NSI wrote to NSF on June 10, 1997 describing the events that had transpired to date, and requesting authority to begin accepting applications for new gTLDs pursuant to a registration procedure.

157. 141 F.3d 1316, 1325 (9th Cir. 1998).

158. See Jeffrey J. Look, The Virtual Wild, Wild West (WWW): Intellectual Property Issues In Cyberspace-Trademarks, Service Marks, Copyrights, and Domain Names, 22 U. ARK. LiTTLE RocK L.J. 49, 64 (1999) (noting that cybersquatters know "it will often cost a company much more to litigate this issue rather than pay a ransom of a few thousand dollars"); see also Panavision Int'l, 141 F.3d at 1319 (describing Toeppen's \$13,000 demand for panavision.com).

159. See, e.g., Towards Fair, Open, Technically Sound Global Internet Policy, Open Root Server Confederation, at http://www.open-rsc.org (last visited Sept. 18, 2000) ("[W]e feel the DNS should have new TLD's added to it.") (on file with the Duke Law Journal); Chris Oakes, When Dot Com Isn't Enough, WIRED NEWs (Sept. 1, 1999) (describing super-root and other initiatives), at http://wirednews.com/news/print/0,1294,21507,00.html (on file with the Duke Law Journal).

160. Name.Space, Inc. v. Network Solutions, Inc., 202 F.3d 573, 579 (2d Cir. 2000). 
NSF officially rejected NSI's proposal on June 25, 1997, and explicitly requested that NSI add no new TLDs to the root zone file pending the conclusion of an internal review of DNS policy, an order it confirmed the next month. Name.Space responded by amending its complaint to include NSF, although that part of the case became moot after ICANN was formed. ${ }^{161}$ Although Name.Space ultimately lost on all counts, ${ }^{162}$ the maneuvering did have important consequences. IANA disclaimed authority over NSI and asserted only an equivocal authority over the root, the ability to act on the basis of consensus. In contrast, NSF demonstrated control over NSI and thus, in effect, over the root zone file.

5. The Road to the White Paper (1997-98). As the Internet grew, and as commercial considerations began to loom larger, the U.S. government's control of the root began to be a magnet for controversy. Foreign governments began to question why the United States should control a critical component of a global network, and firms all over the world began to complain about the uneasy overlap between domain names and trademarks. ${ }^{163}$ In July 1997, in response to these growing domestic and international concerns regarding the future of the DNS, President Clinton directed the Secretary of Commerce to privatize the DNS. ${ }^{164}$ On July 2, 1997, the Department

161. See id. at 580 .

162. See id. at 588.

163. As the White Paper itself noted, "An increasing percentage of Internet users reside outside of the U.S., and those stakeholders want to participate in Internet coordination." White Paper, supra note 15, at 31,742. An example of an effort sparked in part by foreign concerns over the United States' domination of the DNS was the International Ad Hoc Committee, which united ISOC, IANA, WIPO, and the ITU, among others, and produced a proposal for DNS governance. See Establishment of a Memorandum of Understanding of the Generic Top Level Domain Name Space of the Internet Domain Name System ( $g T L D-M o U)$, International Ad Hoc Committee, at http://www.iahc.org./gTLD-MoU.html (Feb. 28, 1997) (on file with the Duke Law Journal).

164. See Name.Space, 202 F.3d at 577; Improvement of Technical Management of Internet Names and Addresses, 63 Fed. Reg. 8825, 8827 (1998) [hereinafter Green Paper]. By the time NSF formally transferred to DoC the responsibility for administering the NSI Cooperative Agreement on September 8, 1998, see Name.Space, 202 F.3d at 579, DoC had been taking an increasingly major role in U.S. Internet policy for more than a year. The transfer may not have been unrelated to the NSF Appropriations Act of 1999, which prohibited NSF from expending any funds to support DNS administration. See Departments of Veteran Affairs and Housing and Urban Development, and Independent Agencies Appropriations Act, Pub. L. No. 105-276, 112 Stat. 2461, 2505 (1998) (declaring that "none of the funds ... may be obligated or expended by the National Science Foundation to enter into or extend a grant, contract, or cooperative agreement for the support of administering the domain name and numbering system of the Internet"). Within a month of the transfer, J. Beckwith Burr, then the Acting Associate Ad- 
of Commerce issued a request for comments on DNS administration, on behalf of an interagency working group headed by Ira Magaziner. ${ }^{165}$ Magaziner's reputation had suffered from his responsibility for the debacle of President Clinton's national health care initiative, and commentators speculated that he saw his role in Internet policymaking as a chance to do some repair work. ${ }^{166}$ Magaziner was also influential in crafting the administration's policy statement on e-commerce. ${ }^{167}$

Agencies commonly issue requests for comments as a first step towards figuring out whether (and how) to regulate. While not all such requests result in a notice of proposed rulemaking (NPRM), an NPRM is a routine next step. An NPRM is a formal notice, published in the Federal Register, in which an agency sets out a proposed rule. In informal rulemaking under the APA, an NPRM is subject to public comment, after which the agency can either abandon the rule, substantially revise it and issue a fresh NPRM, or issue it, perhaps with minor changes.

On January 30, 1998, Magaziner and DoC published their proposal for the reform of DNS administration. ${ }^{168}$ This document became

ministrator for International Affairs at DoC's National Telecommunications and Information Administration (NTIA), became NSI's Program Officer, the person in charge of administering the Cooperative Agreement. See NSI-Cooperative Agreement No. NCR-9218742, Amendment 10, at http://www.networksolutions.com/legal/internic/cooperative-agreement/

amendment10.html (Oct. 1, 1998) (listing Burr as the Federal Program Officer) (on file with the Duke Law Journal).

165. See Request for Comments on the Registration and Administration of Internet Domain Names, 62 Fed. Reg. 35,896, 35,896 (1997).

166. See, e.g., John Simons, In Cyberspace, Nobody Knows You're Ira: For Magaziner, There's Life After Health Care, U.S. NEws ONLINE (June 16, 1997) (suggesting that Magaziner could redeem himself if his commercial ground rules are adopted by other countries), at http://www.usnews.com/usnews/issue/970616/16ira.htm (on file with the Duke Law Journal).

167. William J. Clinton \& Albert Gore, JR., A Framework FOR Global ELECTRONIC COMMERCE 1 (1997) (discussing the need for a set of globally recognized commercial law rules, a "'Uniform Commercial Code' for Electronic Commerce"), available at http://www.iitf.nist.gov/eleccomm/ecomm.htm (on file with the Duke Law Journal). This document is known as the "e-commerce White Paper" and is sometimes confused with the later "DNS White Paper" discussed in this Article. See supra note 15. For a wide-ranging critique of the e-commerce White Paper, see Symposium, The Legal and Policy Framework for Global Electronic Commerce: A Progress Report, 14 BERKELEY TECH. L.J. 502 (1999).

168. See White Paper, supra note 15, at 31,741; Green Paper, supra note 164, at 8825. 
known as the Green Paper, ${ }^{169}$ but in bureaucratic form it was just an ordinary NPRM proposing an informal rule.

Just before Magaziner published the Green Paper on the World Wide Web, ${ }^{170}$ an incident occurred that demonstrated the fragility of the existing, somewhat informal, understandings about DNS authority and control. On January 28, 1998, Jon Postel-who may have been aware of the likely content of the Green Paper $^{171}$ - sent an e-mail requesting that the root servers not controlled by NSI or the U.S. government start pointing to his server "B" rather than server " $A$ " for the authoritative data on the root. ${ }^{172}$ Postel's "B" server continued to mirror the data in "A," so in the short term this shift would have changed nothing; in the longer term it would have enabled him to control the root and thus single-handedly create new TLDs. Most of the other root servers complied. ${ }^{173}$ To his detractors, Postel was attempting a power grab, a single-handed hijack of the Internet, or even threatening to split the root, creating the dreaded possibility of inconsistent databases. ${ }^{174}$ (Recall that inconsistent data is bad because it means that which IP resolves when one types in a domain name might depend on which database - effectively which Internet—one might be connected to.) When Ira Magaziner heard of what Postel would later diplomatically call a "test," Magaziner instructed Postel to return to the status quo. Postel did so, and the "test" was over. ${ }^{175}$ Magaziner

169. "Green paper" is a British locution for a "government document that proposes and invites discussion on approaches to a problem." Merriam-Webster Online: WWWebster Dictionary, at http://www.m-w.com/cgi-bin/dictionary.htm (1997) (on file with the Duke Law Journal).

170. The Green Paper's web publication of January 30, 1998, preceded the official February 20, 1998, publication date in the Federal Register. See White Paper, supra note 15, at 31,741.

171. See Magaziner Continues to Build Consensus for Domain Name Solution, at http://www.iperdome.com/releases/980127.htm (Jan. 27, 1998) (describing various January 1998 meetings between Magaziner and interested parties and disclosing before its January 30, 1998, publication the likely features of the Green Paper) (on file with the Duke Law Journal).

172. See Craig Simon, The Technical Construction of Globalism: Internet Governance and the DNS Crisis, at http:www.flywheel.com/ircw/dnsdraft.html (last visited Aug. 19, 2000) (on file with the Duke Law Journal).

173. See Kenneth Cukier, Testing Times for Net Guardians, 199 COMMUNICATIONS WeEK INT'L 1, IIII 4-7 (Feb. 16, 1998) (outlining Postel's "test" and the response of the other root servers), at http://www.totaltele.com/cwi/199/199news11.html (on file with the Duke Law Journal).

174. See Simon, supra note 172 ("Critics charged he had 'hijacked' the root.").

175. See id. Postel's letter to the other root server operators read as follows:

Hello.

As the Internet develops there are transitions in the management arrangements. The time has come to take a small step in one of those transitions. At some point on down the road it will be appropriate for the root domain to be edited and published directly by the IANA. 
was later quoted as saying that he told Postel that redirection could result in criminal charges, ${ }^{176}$ although it is unclear what statute would apply.

The Green Paper mapped out an ambitious course of action for U.S. domain name policy, the details of which can be elided since the rulemaking was abandoned in the face of the opposition it engendered. The Green Paper remains noteworthy, however, for its account of why DoC felt it had the power to make rules about the DNS at all, given the absence of direct congressional authorization. The Green Paper listed five sources of DoC's statutory authority for this proposed rulemaking: ${ }^{177}$ (1) the general mission statement of DoC for the promotion of U.S. commerce, ${ }^{178}$ (2) DoC's National Telecommunications and Information Administration's (NTIA) power to coordinate telecommunications activities and assist in the formation of policies ${ }^{179}$ (3) NTIA's authority to "develop and set forth telecommunications policies"; ${ }^{180}$ (4) NTIA's power to conduct studies and make rec-

As a small step in this direction we would like to have the secondaries for the root domain pull the root zone (by zone transfer) directly from IANA's own name server.

This is "DNSROOT.IANA.ORG" with address 198.32.1.98. The data in this root zone will be an exact copy of the root zone currently available on the A.ROOT-SERVERS.NET machine. There is no change being made at this time in the policies or procedures for making changes to the root zone.

This applies to the root zone only. If you provide secomdary [sic] service for any other zones, including TLD zones, you should continue to obtain those zones in the way and from the sources you have been.

-jon.

Id. (quoting Jon Postel).

176. See Cook, supra note 102 ("Ira asserted that he had assured Postel that disobedience would result in criminal charges being filed against him.").

177. See Green Paper, supra note 164, at 8826.

178. See 15 U.S.C. $§ 1512$ (1994):

It shall be the province and duty of said Department to foster, promote, and develop the foreign and domestic commerce, the mining, manufacturing, and fishery industries of the United States; and to this end it shall be vested with jurisdiction and control of the departments, bureaus, offices, and branches of the public service hereinafter specified, and with such other powers and duties as may be prescribed by law.

179. See 47 U.S.C. $\$ 902($ b)(2)(H) (1994) (giving NTIA "[t]he authority to provide for the coordination of the telecommunications activities of the executive branch and assist in the formulation of policies and standards for those activities, including (but not limited to) considerations of interoperability, privacy, security, spectrum use, and emergency readiness"). Note that this does not in itself include any rulemaking power.

180. Id. § 902(b)(2)(I) (giving NTIA "authority to develop and set forth telecommunications policies pertaining to the Nation's economic and technological advancement and to the regulation of the telecommunications industry"). This also does not include any rulemaking power: the power to "develop and set forth" policy is not the power to promulgate it or to make rules. 
ommendations; ${ }^{181}$ and (5) NTIA's authority to "issue such regulations as may be necessary to carry out" its functions. ${ }^{182}$ Finding rulemaking authority in any of the above for giving ICANN even temporary control of the DNS in these statutes would be, to put it gently, a stretch. NTIA has the authority to conduct studies, to coordinate and formulate policy, and to make recommendations. It does not have independent rulemaking authority, and the congressional grant of power to act as a think tank cannot be leveraged into rulemaking power via DoC's general authority to make regulations "as may be necessary to carry out the functions assigned under this chapter" ${ }^{183}$ when none of those functions involved regulating rather than studying or recommending.

As it happened, however, the question of DoC's or NTIA's rulemaking authority became moot, since the Green Paper foundered on politics. The Green Paper encountered substantial opposition, ${ }^{184}$ and it became clear that DNS regulation was too controversial for consensus, or even a politically satisfying compromise. DoC and Ira Magaziner's interagency group abandoned their effort to issue a final rule, and instead, in June 1998, they issued a nonbinding statement of policy that became known as the DNS White Paper. ${ }^{185}$ Whether or not DoC had the authority to issue a rule ceding even temporary control of the DNS, it never purported to do so. Unlike substantive rules, statements of policy are not subject to notice and comment under the APA,${ }^{186}$ because they are not a final decision as to citizen's rights or

181. See id. $\S 902(\mathrm{~b})(2)(\mathrm{M})$ (giving NTIA "[t]he authority to conduct studies and make recommendations concerning the impact of the convergence of computer and communications technology"). Again, this does not give NTIA rulemaking power.

182. Id. § 904(c)(1).

183. Id. §904(c)(1). Rulemaking is also strikingly absent among the activities described on NTIA's web page. See NTIA Information, National Telecommunications and Information Administration, at http://www.ntia.doc.gov/ntiahome/aboutntia.htm (last visited Aug. 19, 2000) (on file with the Duke Law Journal).

184. See, e.g., Developments in the Law-The Law of Cyberspace, 112 HARV. L. REV. 1574, 1666-67 (1999) (summarizing the domestic objections of trademark holders and others); Official Comments on the Green Paper (Technical Management of Internet Names and Addresses) from the Internet Council of Registrars (CORE), at http://corenic.org/documents/official.htm (last visited Aug. 17, 2000) (stating the objections of an association of non-U.S. registrars) (on file with the Duke Law Journal); RIPE CENTR Response to Green Paper from U.S. Government, Council of European National Top-Level Domain Registries, at http://www.centr.org/docs/ statements/greenpaper.html (Mar. 13, 1998) (providing a response from non-U.S. registries) (on file with the Duke Law Journal).

185. See White Paper, supra note 15.

186. See 5 U.S.C. $§ 553(b)(A)(1994)$. 
duties. A statement of policy is intended to guide officials and inform the public, ${ }^{187}$ but officials remain required to exercise their discretion when applying the policy, and citizens remain free to challenge each decision on a case-by-case basis.

Like the Green Paper before it, the White Paper framed the basic "Principles for a New System" as "stability, competition, private bottom-up coordination, and representation": ${ }^{188}$

1. Stability.... During the transition and thereafter, the stability of the Internet should be the first priority of any DNS management system....

2. Competition.... Where possible, market mechanisms that support competition and consumer choice should drive the management of the Internet because they will lower costs, promote innovation, encourage diversity, and enhance user choice and satisfaction.

3. Private Sector, Bottom-Up Coordination.... A private coordinating process is likely to be more flexible than government and to move rapidly enough to meet the changing needs of the Internet and of Internet users. The private process should, as far as possible, reflect the bottom-up governance that has characterized development of the Internet to date.

4. Representation.... Management structures should reflect the functional and geographic diversity of the Internet and its users. Mechanisms should be established to ensure international participation in decision making. ${ }^{189}$

The White Paper called for a private entity to appear spontaneously and take over the DNS because "overall policy guidance and control of the TLDs and the Internet root server system should be

187. The Supreme Court defines a statement of policy as "'statements issued by an agency to advise the public prospectively of the manner in which the agency proposes to exercise a discretionary power." Chrysler Corp. v. Brown, 441 U.S. 281, 302 n.31 (1979) (quoting ATTORNEY General's Manual on the Administrative Procedure ACt 30 n.3 (1947)); see also J.E.M. Broad. Co. v. FCC, 22 F.3d 320 (D.C. Cir. 1994) (holding that an FCC rule change was not subject to the APA's notice-and-comment requirement because it was a procedural change); cf. Robert A. Anthony, Interpretive Rules, Policy Statements, Guidances, Manuals, and the Like-Should Federal Agencies Use Them to Bind the Public?, 41 DUKE L.J. 1311 (1992) (arguing that, in general, agencies should not use interpretive rules and policy statements to bind the public, either as a legal matter or as a practical matter).

188. White Paper, supra note 15 , at 31,743 .

189. Id. at 31,749 . 
vested in a single organization that is representative of Internet users around the globe." into agreement with

a new, not-for-profit corporation formed by private sector Internet stakeholders to administer policy for the Internet name and address system. Under such agreement(s) or understanding(s), the new corporation would undertake various responsibilities for the administration of the domain name system now performed by or on behalf of the U.S. Government or by third parties under arrangements or agreements with the U.S. Government. ${ }^{191}$

As a result, "[t]he U.S. Government should end its role in the Internet number and name address system."

The statement of policy went on to describe in a fairly detailed way what this new hoped-for corporation should look like, and how it should work. "NewCo" (as it came to be known) "should be headquartered in the United States, and incorporated in the U.S. as a notfor-profit corporation. It should, however, have a board of directors from around the world." ${ }^{, 193}$ It should take over the existing IANA staff, and it should have the authority to "[s]et policy for and direct allocation of IP number blocks to regional Internet number registries" and "[o]versee operation of the authoritative Internet root server system" "194 plus "[o]versee policy for determining the circumstances under which new TLDs are added to the root system" while coordinating "the assignment of other Internet technical parameters as needed." 195

The White Paper also prescribed a structure for NewCo's board of directors, which it said "should be balanced to equitably represent the interests of IP number registries, domain name registries, domain name registrars, the technical community, Internet service providers (ISPs), and Internet users (commercial, not-for-profit, and individuals) from around the world." ${ }^{, 196} \mathrm{NewCo}$ would start with an interim

\footnotetext{
190. Id.

191. Id.

192. Id.

193. Id. at 31,750. While the White Paper itself does not use the name "NewCo," the use of the term by DoC to describe the entity called for in the White Paper dates at least from Amendment 11, supra note 82, in August 2000.

194. White Paper, supra note 15 , at 31,749 .

195. Id.

196. Id. at 31,750 .
} 
board that would serve for a fixed period until the board of directors was elected, but interim board members would "not themselves serve ... for a fixed period thereafter." ${ }^{197}$ Government officials would be forbidden to serve on the board. The interim board would "develop policies for the addition of TLDs, and establish the qualifications for domain name registries and domain name registrars within the system." 198

The White Paper further detailed the internal functioning of NewCo, stating it should be
governed on the basis of a sound and transparent decision-making process, which protects against capture by a self-interested fac- tion .... The new corporation could rely on separate, diverse, and robust name and number councils responsible for developing, re- viewing, and recommending for the board's approval policy related to matters within each council's competence. Such councils, if devel- oped, should also abide by rules and decision-making processes that are sound, transparent, protect against capture by a self-interested party and provide an open process for the presentation of petitions for consideration. ${ }^{199}$

Not only did the White Paper explain the structure of NewCo, but it was able to "anticipate that the policies established by the new corporation would" require specified information about domain name registrants to be included in all registry databases and freely available on the Internet in order to allow trademark holders to "contact a domain name registrant when a conflict arises between a trademark holder and a domain name holder." several other policies, including requiring registrants to pay fees at the time of registration, and requiring them to "agree to submit infringing domain names to the authority of a court of law in the jurisdiction in which the registry, registry database, registrar, or the ' $\mathrm{A}$ ' root servers are located." ${ }^{201}$ Furthermore, DoC recommended that registrants be required to agree "that in cases involving cyberpiracy or cybersquatting (as opposed to conflicts between legitimate competing rights holders), they would submit to and be bound by alternative dispute resolution systems identified by the new corporation for

$\begin{array}{ll}\text { 197. } & I d . \\ \text { 198. } & I d . \\ \text { 199. } & I d . \\ \text { 200. } & \text { Id } . \\ \text { 201. } & \text { Id }\end{array}$


the purpose of resolving those conflicts." ${ }^{202}$ And similarly, registrants would be required to agree to "processes adopted by the new corporation that exclude, either pro-actively or retroactively, certain famous trademarks from being used as domain names (in one or more TLDs) except by the designated trademark holder."203

In order to achieve these ends, the statement of policy committed the U.S. to a "[r]amp down" of its existing agreements with NSI that would require it to take actions to promote competition ${ }^{204}$-although in practice the "ramp down" probably meant extending existing agreements rather than simply allowing them to end, as NSF earlier suggested. ${ }^{205}$ Further, DoC pledged to require NSI to "recognize the role of the new corporation to establish and implement DNS policy and to establish terms (including licensing terms) applicable to new and existing gTLDs and registries under which registries, registrars and gTLDs are permitted to operate." ${ }^{206}$ In other words, NewCo would become NSI's regulator in all but name.

\section{B. Contractual Basis of ICANN's Authority (October 1998-present)}

The Department of Commerce's statement of policy in the White Paper was formally nonbinding, but it was no less effective for that. Shortly following what, in legal terms, was no more than a pious hope for competitive bidding, an entity that looked a great deal like NewCo materialized under the imprimatur of Jon Postel, the man most identified with IANA and the existing domain name system. This was of course no coincidence: The whole point of the White Paper had been to find a more formal structure for DNS management that left it in Postel's capable hands - and could be presented as a pro-Internet, deregulatory victory for the Clinton administration (and Ira Magaziner). ICANN exists because the Department of Commerce called for it to exist.

Once ICANN was formed, it owed its purpose, power, and relevance to the Department of Commerce. Without Jon Postel, no one would ever have paid any attention to anything ICANN said, had not DoC designated ICANN as NewCo. ICANN derives its power from

\footnotetext{
202. Id.

203. Id. at 31,751 .

204. Id.

205. See Simon, supra note 172 (noting that the NSF announced in 1997 that it did not plan to renew its cooperative agreement with NSI).

206. White Paper, supra note 15 , at 31,751 .
} 
contracts with DoC and acts as DoC's agent for DNS matters. DoC could, if it wished, terminate its relationship with ICANN and choose another body to perform all of ICANN's functions. Thus, whatever the legal formalities, DoC is the "but for" cause of ICANN's relevance, indeed its very existence, and the fundamental source of ICANN's powers. Nevertheless, subsection 1 below argues that because the formation was kept at arms' length, ICANN's creation did not violate the Government Corporation Control Act, the statute designed to prevent agencies from creating private corporations to do their will. Similarly, because DoC's relationship with ICANN is contractual, it probably complies with the letter of the Federal Advisory Committee Act.

Whatever the intentions may have been in early 1998, by early 1999 ICANN had adopted a Byzantine structure that privileged some interests, primarily corporate and commercial. The structure disadvantaged end-users and the firms that had expended resources to set up alternate registries. ${ }^{207}$ Would-be registrars, on the other hand, benefited, as ICANN recognized them as one of the seven "stakeholder" interest groups entitled to preferential recognition in the ICANN structure..$^{208}$ One of the many oddities of the ICANN gerrymander of the Domain Name Supporting Organization (DNSO) is that future registrars were allowed to enter the registrars' constituency and vote before they were accredited by ICANN, but future registries were not. The first board members, selected for their lack of experience with the DNS wars, nevertheless proceeded to make fundamental decisions that affected the legal rights of all registrants in the three open gTLDs, and perhaps all Internet users. They also sought to impose fees on various participants in the DNS hierarchy and gutted the influence that non-corporate domain name registrants might have over the composition of subsequent boards.

207. End-users and individual domain name registrants had no representation in the original ICANN structure, and ICANN fought hard to prevent direct elections in which they could participate. See, e.g., Comments of Common Cause, supra note 39 (objecting to ICANN's plans to revise its bylaws) (on file with the Duke Law Journal); ICANN's Global Elections: On the Internet, for the Internet, Common Cause and Center for Democracy and Technology, at http://www.cdt.org/dns/icann/study/icannstudy.pdf (Mar. 2000) (recommending reforms to the election process and listing concerns about ICANN proposals) (on file with the Duke Law Journal)

208. See Weinberg, supra note 39, at 238 \& n.261. ICANN would soon make opening NSI's virtual monopoly of the registration business to increased competition a priority, further benefiting entrants to the registration business. 
The road to these results was anything but direct. It was the result of a tripartite struggle between NSI, ICANN and DoC. From its inception, ICANN embarked on a series of moves designed to raise revenue and to solidify its authority. Its first order of business was to become recognized as NewCo, its next to take over IANA's role in DNS administration. Last but not least, ICANN needed to get NSI to recognize its authority. Only when DoC had pressured a very reluctant NSI to recognize ICANN's authority-at the price of extending NSI's monopoly over the .com registry business for years to come ${ }^{209}-$ was ICANN able to ensure that the policies it had adopted, such as the UDRP's mandatory arbitration rules, would affect every registrant in the commercial gTLDs. Indeed, each major step required intervention from DoC.

1. ICANN Formed (October 1998). After the publication of the White Paper, Postel and his lawyer, Jones Day partner Joe Sims, incorporated ICANN and set out to write bylaws that would be close enough to DoC's requirements for ICANN to be accepted as NewCo while preserving substantial freedom of action for the ICANN board. ${ }^{210}$ The ICANN drafting and board recruitment efforts operated behind closed doors, but it benefitted from the imprimatur and prestige of Jon Postel. ${ }^{211}$ Postel was intended to be the chief technical officer of ICANN, ${ }^{212}$ and the interim board was designed to be composed of worthies who would be recognized as neutrals and would lend their prestige and neutrality to legitimate his decisions. ${ }^{213}$

209. See Simon, supra note 172.

210. Joe Sims reports that after Jon Postel died, he considered ICANN to be his client, "fully realizing it was incorporeal." Once ICANN was formed, the board hired him as its counsel. Contrary to the account in Gordon Cook, New IANA Formation Ending Amidst Uncertainty, Congressional Inquiry of Magaziner \& the Death of Jon Postel, THE COOK REPORT ON INTERNET (Oct. 27, 1998), at http://www.cookreport.com/whorules.shtml (on file with the Duke Law Journal), Mr. Sims was never retained by USC. See E-mail from Joe Sims, former Counsel, ICANN, to Professor A. Michael Froomkin, University of Miami School of Law (Sept. 10, 2000) (on file with the Duke Law Journal).

211. Postel broadly endorsed the White Paper approach. See Framework for Discussion 1, Internet Assigned Numbers Authority, at http://www.iana.org/discussion.html (last visited Aug. 17, 2000) (on file with the Duke Law Journal).

212. See Gina Paik \& P-R Stark, The Debate over Internet Governance: Fred Baker, § IV.a, Berkman Center for Internet and Society, at http://cyber.law.harvard.edu/is99/governance/ baker.html (last visited Aug. 17, 2000) (on file with the Duke Law Journal).

213. See Mueller, supra note 102, at 507 (characterizing the emphasis on non-partisanship as "a ruse"). Joe Sims describes the process of choosing the board as follows:

[Jon Postel] came to the conclusion that it would be silly and counter-productive to

have an initial board made up of the combatants because the likelihood was that they 
(Recall that Postel's previous attempt to add TLDs to the root had been shelved due to protests, leading to questions about who had the authority to make DNS policy. ${ }^{214}$ ) An important part of the interim board members' function as neutrals would be to agree on how their successors should be selected. The decision to choose neutrals meant that the board members had to be chosen for their lack of involvement in the DNS wars, and this, in turn, meant that the first set of board members had little direct technical expertise relating to the DNS, although some had extensive technical background in other technologies. ${ }^{215}$ The exemplar of both of these characteristics was the person ICANN would elect to head its board: Esther Dyson. Already well-known as a magazine publisher, venture capitalist, and Internet guru, Dyson was a highly respected name in most of the Internet community. She did not, however, have much experience in DNS matters. ${ }^{216}$ Lack of experience, however, seemed a minor issue since Postel would be the CTO, and he was acknowledged to be a trusted, if not revered, figure by almost everyone interested in DNS policy. But Jon Postel died suddenly on October 16, 1998, just as plans to form ICANN were near completion. ${ }^{217}$ With Postel's death, ICANN

\footnotetext{
would continue their combat on the board and so he determined that the initial board ought to be people who were not active combatants in the wars leading up to the creation of ICANN. So that was the one unilateral decision that was made. So we cut out all the active combatants that people had recommended, and that left us with you know a fairly long list of people who had not been active combatants. And with those we asked everybody who we could find to give us their reactions to them. Do you know this person? Do you like this person? Are they any good? Would they be interested, etc. So over time winnowed the list down to a manageable number and started approaching people and got turned down by a number of people. And had a number of other people say they were willing to do that and finally, I think actually the day before the ICANN proposal was turned into the Department of Commerce, got our last person to agree to be on the initial board and put forth a slate, and again with the notion that (this was Jon's belief) this group of people would attract consensus support from the internet community.
}

Paik \& Stark, supra note 212, § IV.d; see also Todd Spangler, Interim ICANN Board to Redraft Bylaws, ZDNET INTER@CTIVE WEEK ONLINE (Oct. 28, 1998) (quoting an anonymous U.S. government official as supporting the selection of neutrals for the board), at http://www.zdnet.com/intweek/stories/news/0,4164,2156478,00.html (on file with the Duke Law Journal).

214. See supra note 151 and accompanying text.

215. For a revealing first-person account of the lack of background in the DNS of the initial ICANN board members, see ICANN Public Meeting Transcript 7, Berkman Center for Internet and Society, at http://cyber.law.harvard.edu/icann/cambridge-1198/archive/transintro.html (Nov. 14, 1998) (on file with the Duke Law Journal).

216. See id.

217. See Internet Society (ISOC) All About ISOC: Jon Postel, Internet Society, at http://www.isoc.org/postel/iana.shtml (last visited Aug. 17, 2000) (on file with the Duke Law Journal). 
lost the figure on which its legitimacy and trust had been based before it was even officially incorporated.

Following the lead of the White Paper, which called for NewCo to have "the functional and geographic diversity of the Internet and its users," ${ }^{218}$ ICANN adopted a frankly corporatist structure. This structure, however, was unduly complex-as a glance at the simplified (!) diagram in Figure 1 (pp. 185-86) demonstrates; programmers may recognize the symptoms of a code base run wild. Moreover, not only was ICANN frankly corporatist, ${ }^{219}$ but some "stakeholders" were far more equal than others. The Domain Name Supporting Organization and its parent body, the Names Council, appeared to be the places where issues such as new gTLDs and anti-cybersquatting policies would be thrashed out. ICANN declared that the DNSO would have seven "constituencies," 220 each of which would elect three delegates to the Names Council, which, in turn, would ultimately elect three ICANN board members who would sit with the initial, self-selected board. ${ }^{221}$ As the DNSO constituencies often overlapped, a single firm could simultaneously be a member of up to four constituencies. ${ }^{222}$ In

218. White Paper, supra note 15 , at 31,749 .

219. ICANN's decision to reflect (some) user interests by functional groupings in the ASO, PSO, and especially DNSO, comes out of the corporatist tradition in which "interested groups have been given authoritative powers of determination, usually in conjunction with a public administrative agency." Louis L. Jaffe, Law Making by Private Groups, 51 HARV. L. REV. 201, 234 (1937); see also Organizing InTERESTS In WeStern Europe: Pluralism, CORPORATISM, AND THE TRANSFORMATION OF POLITICS passim (Suzanne Berger ed., 1981) (describing oldstyle corporatism based on representation of and sovereignty by socioeconomic interest groups); Arthur F.P. Wasenberg, Neo-Corporatism and the Quest for Control: The Cuckoo Game, in PATTERNS OF CORPORATIST POLICY-MAKING 83, 84-85 (Gerhard Lehmbruch \& Philippe C. Schmitter eds., 1982) (noting that "corporatism should be considered as a conflict-displacing, rather than as a conflict-resolving, device").

220. The seven constituencies are: ccTLD registries; commercial and business entities; gTLD registries; ISP and connectivity providers; noncommercial domain name holders; registrars; and trademark, other intellectual property, and anti-counterfeiting interests. See About DNSO, Domain Name Supporting Organization, at http://www.dnso.org/dnso/aboutdnso.html (last visited Aug. 17, 2000) (on file with the Duke Law Journal).

221. See id.

222. The right firm could join (1) commercial and business entities; (2) ISP and connectivity providers; (3) registrars; and (4) trademark, other intellectual property, and anti-counterfeiting interests. See By-Laws of the Intellectual Property Constituency, § III, Intellectual Property Constituency, at http://ipc.songbird.com/IPC_Bylaws_dec_15_correct.htm (Nov. 30, 1999) (on file with the Duke Law Journal); Commercial and Business Entities Constituency Charter, § II.A, Business Constituency Domain Name Supporting Organization, at http://www. bcdnso.org/Charter.htm (Oct. 25, 1999) (on file with the Duke Law Journal); The DNSO Registrar Constituency, § II, Domain Name Supporting Organization, at http://www.dnso.org/ 
contrast, none of the DNSO constituencies offered voting membership to individual domain name registrants, not to mention ordinary Internet users. Furthermore, ICANN decided that the public's role, the number of directors the public could elect, and the public's influence over directors that it might elect, should be reduced well below the level contemplated in the White Paper.

a. ICANN and the GCCA. Despite the tradition of openness that dominates most Internet standards processes, ${ }^{223}$ ICANN was founded in secret. The secrecy led to enormous ill-will and suspicion in the Internet community and to at least two formal inquiries, one by a House Committee and one by the General Accounting Office. ${ }^{224}$ The inquiries were motivated, in part, by an understandable suspicion that administration officials might have done more than simply call for NewCo to be created. Any participation by the federal government in ICANN's formation beyond general cheerleading would probably have violated the Government Corporation Control Act (GCCA). However, most of the board members appear to have been recruited either by European Union officials or by Joe Sims, Postel's lawyer and later ICANN's. ${ }^{225}$ Although ICANN organizers

constituency/registrars/Registrars.Articles.html (last visited Aug. 17, 2000) (on file with the Duke Law Journal); ISPs and Connectivity Providers, How to Become a Member, Domain Name Supporting Organization, at http://www.dnso.org/constituency/ispcp/membership.html (last visited Aug. 17, 2000) (on file with the Duke Law Journal).

223. See generally Froomkin, supra note 126 (discussing the informal, decentralized nature of the Internet standard-setting process).

224. The GAO investigation was requested by H.R. CONF. REP. NO. 106-479, accompanying the Consolidated Appropriations Act for fiscal year 2000 (which incorporates the fiscal year 2000 appropriation for the Department of Commerce). The General Accounting Office was asked to review the relationship between ICANN and the Department of Commerce. See generally GAO Report, supra note 28. A transcript of the House Subcommittee on Oversight and Investigations' July 22, 1999, hearing Domain Name System Privatization: Is ICANN Out of Control? is available at http://comnotes.house.gov/cchear/hearings106.nsf (last visited Aug. 18, 2000) (on file with the Duke Law Journal).

225. Mr. Sims signed the DoC-ICANN MoU in November 1998, after Dr. Postel had died, as ICANN's counsel. See Memorandum of Understanding, supra note 47. Mr. Sims describes his relationship with the U.S. government as follows:

[W] hile I have no specific recollections, I'm sure we discussed ... the Board recruitment process from time to time. Of course, we solicited recommendations from [the U.S. government] as we did from many others; got relatively little useful input, but did get some recommendations (from non-US governments) that were useful inputs.... [W] did not seek the approval of any government of any individual or the final slate, but we certainly listened to their views as we did to others offered.

E-mail from Joe Sims, former Counsel, ICANN, to Professor A. Michael Froomkin, University of Miami School of Law (May 19, 2000) (on file with the Duke Law Journal). 
briefed U.S. government officials from time to time, and Magaziner himself had a hand in recruiting Esther Dyson, these officials's participation probably did not violate the GCCA. ${ }^{226}$ It may be an indictment of the GCCA, but by simply describing what needed to be done rather than doing it itself, the government remained sufficiently at arms' length to satisfy the formal requirements of the law. Only Magaziner's recruitment of Dyson crossed this line, and that alone was probably not enough to taint the entire enterprise.

DoC is not the first agency to seek to use the corporate form or to create a private corporation to achieve desired ends. ${ }^{227}$ The Government Corporation Control Act ${ }^{228}$ is Congress's most comprehensive modern attempt to define when and how federal officials may create and use private corporations for public purposes. Congress enacted the GCCA in response to a plethora of federally owned and mixed-ownership federal government corporations ${ }^{229}$ and attendant inconsistent accounting standards and a general lack of federal control and accountability. ${ }^{230}$ Section 9102 of the GCCA prohibits the creation or acquisition of corporations by the executive branch "to act as an agency" without specific legal authorization. ${ }^{231}$

In one of the few cases interpreting section 9102 of the GCCA or discussing when a federal agency may shepherd a state corporation

226. See GAO Report, supra note 28, at 12-13 (concluding that the GCCA was not violated). Magaziner's role is mentioned in ICANN's response to the United States House Committee on Commerce's inquiry about ICANN's role in the possible privatization of the DNS. See ICANN-Response to Chairman Bliley, § 4.4, at http://www.icann.org/correspondence/blileyresponse-08july99.htm (July 8, 1999) (on file with the Duke Law Journal).

227. See Froomkin, supra note 24, at 560 (discussing the greater independence enjoyed by FGCs). One perhaps extreme example is Lt. Col. Oliver North's plan to create a "stand-alone" entity that would channel funds from foreign governments to the Contras and elsewhere. The plan contemplated the creation of a covert self-financing, federally owned corporation with a state charter, in order that its activities would be immune from congressional interference or control. See H.R. REP. NO. 100-433, at 332 (1987).

228. 31 U.S.C. $\$ \S 9101-10$ (1994).

229. See Lebron v. National R.R. Passenger Corp., 513 U.S. 374, 387-90 (1995) (describing the necessity for the regulatory provisions of the GCCA). At the end of the Second World War, the United States had 63 wholly-owned and 38 partly-owned FGCs, as well as 19 non-corporate credit agencies and hundreds of military-run enterprises. See ANNMARIE HAUCK WALSH, THE PUBLIC'S BusINESS 29 (1978).

230. See Oliver Peter Field, Government Corporations: A Proposal, 48 HARV. L. REv. 775, 781-82 (1935) (describing the problems caused by the wide variation among then-existing corporations).

231. 31 U.S.C. $\S 9102$ ("An agency may establish or acquire a corporation to act as an agency only by or under a law of the United States specifically authorizing the action."). 
into being, the Supreme Court in Lebron v. National Railroad Passenger Corp. observed that the GCCA

was evidently intended to restrict the creation of all Government-controlled policy-implementing corporations, and not just some of them. And the companion provision that swept away many of the extant corporations said that no wholly owned government corporation created under state law could continue "as an agency or instrumentality of the United States," § 304(b), 59 Stat. 602. Once again, that was evidently meant to eliminate policy-implementing government ownership of all state corporations, and not just some of them. ${ }^{232}$

While only dicta, this comment in Lebron underlines the point that the GCCA was a strong policy statement by Congress against what had become a common agency practice of creating or acquiring corporations to conduct public business.

The only other reported case to discuss section 9102, Varicon International v. Office of Personnel Management, ${ }^{233}$ involves facts that more closely resemble ICANN. The Office of Personnel Management (OPM) decided to privatize the office that conducts background investigations of executive branch applicants and employees for security clearance purposes. It produced a privatization plan that called for an employee-owned company to be created with which OPM would contract to perform the background investigations previously performed by the Investigations Service. As part of the privatization plan, the new company offered employment to all OPM personnel displaced by the privatization plan. OPM then awarded a sole-source contract for information services to this employee-owned company. Plaintiffs, who had previously contracted with OPM for similar work, sought to enjoin operation of the contract. ${ }^{234}$

In the course of denying the application for an injunction on several grounds, the district court noted a number of facts about the U.S. Investigation Services (USIS) that persuaded it to distinguish Lebron: (1) no USIS employees were employed by the government; (2) the government had no control over the USIS board of directors, management, or employees, except as provided for in the contract; (3) the government did not and would not own any USIS stock; (4) the gov-

232. Lebron, 513 U.S. at 396.

233. 934 F. Supp. 440 (D.D.C. 1996).

234. See id. at 442. 
ernment appointed none of USIS's directors; and (5) the government had no obligation to pay USIS except as provided under the contract in payment for service performed under the contract. ${ }^{235}$ The district court therefore concluded that USIS was "a private corporation which was awarded a government contract, and not a corporation which is acting as a federal agency." ${ }^{236}$ All these factors, except perhaps the second, apply to ICANN as well. The second factor is debatable, since DoC control over the root gives it extraordinary leverage over ICANN. However, even if we assume OPM was the only possible buyer of USIS's services (an issue the court did not address), there are still differences between the USIS/OPM relationship and the ICANN/DoC relationships: USIS was a contractor performing a service for money; ICANN is not paid by DoC but rather gets income from third parties over whom DoC gave ICANN power. ${ }^{237}$ Most of ICANN's contracts are research agreements rather than ordinary procurement agreements, and the "procurement" is for zero dollars. Finally, there is no way that USIS's services to OPM could be described as regulatory.

The nature of ICANN's services to DoC is particularly important, as can be seen from an analogous distinction involving Defense Department Federally Funded Research Development Centers (FFRDCs). The Acting Comptroller General opined in 1992 that agencies could establish FFRDCs in universities and other nonprofits pursuant to existing statutory authority without violating section 9102. ${ }^{238}$ Even FFRDCs that received all of their funding from the government did not, therefore, become "a corporation established or acquired to act as an agency. ${ }^{239}$ The Comptroller General noted, however, that "agencies are prohibited from awarding FFRDC contracts to perform work of a policy, decisionmaking or managerial nature which is the direct responsibility of agency officials." 240

On the other hand, even when a corporation provides no policymaking services, an agency may still lack the authority to create it. The General Counsel of the GAO opined in 1998 that the Federal Communications Commission exceeded its authority under 47 U.S.C.

235. See id. at 447.

236. Id.

237. See infra notes 294-96 and accompanying text.

238. See Letter from Milton J. Socolor, Comptroller General of the United States (Acting), to Sen. David Pryor, 71 Comp. Gen. 155, 157 (Jan. 17, 1992), available at 1992 WL 18518.

239. Id.

240. Id. 
$\S 254(\mathrm{~h})$ when the FCC directed the incorporation of two Delaware corporations. Section 254(h) authorized the FCC to provide service support benefits to certain schools, libraries, and rural health care providers, but did not specify how the FCC should do this. ${ }^{241}$ The FCC appointed the National Exchange Carrier Association (NECA) to administer its programs, then directed it to create "an independently functioning not-for-profit subsidiary" to temporarily administer some programs. ${ }^{242}$ The FCC also directed NECA to create "two unaffiliated, not-for-profit corporations to be designated the Schools and Libraries Corporation and the Rural Health Care Corporation.... NECA was directed to incorporate the corporations under the laws of Delaware and to take such steps as are necessary ... to make the corporations independent." ${ }^{243}$ These new entities would take up some of the support functions. The certificate of incorporation for the new entities stated that their purposes were defined in FCC regulations. Those regulations stated that the boards and CEOs were to be selected or approved by the FCC Chair. ${ }^{244}$

The FCC first argued that it had the authority to create the two corporations pursuant to its general authority, ${ }^{245}$ but the GAO's General Counsel was unpersuaded, stating that "we recognize the breadth of [the general authority but] the provision is constrained by the later passage of the Government Corporation Control Act." 246 The FCC ultimately agreed with this statutory analysis, but then argued that the GCCA still did not apply since NECA, not the FCC, established or acquired the two corporations. The General Counsel dismissed this fiction, stating that the GCCA "prohibits an agency from creating or causing creation of a corporation to carry out government programs without explicit statutory authorization.",247

Nevertheless, the ICANN case is different from the case of the Schools and Libraries and the Rural Health Care corporations.

241. See In re Hon. Ted Stevens, B-278820, 1998 WL 465124, at *2 (Comp. Gen. Feb. 10, 1998) (reviewing the FCC's implementation of section 254(h) of the Communications Act).

242. Id.

243. Id.

244. See id. at*3.

245. The FCC relied on 47 U.S.C. § 154(i) (1994), which states that "[t]he Commission may perform any and all acts, make such rules and regulations, and issue such orders, not inconsistent with this chapter, as may be necessary in the execution of its functions." Id.

246. Id.

247. Id. (emphasis added). In general, " [ $[\mathrm{t}] \mathrm{he}$ committee does not consider the practices of chartering wholly owned Government corporations without prior authorization . . . under State charters to be desirable."' Id. (quoting H.R. REP. No. 79-856, at 11 (1945)). 
ICANN is more independent and its creation was substantially more arms-length than the FCC's captive corporations. Neither of those made even a pretense of independence, and their top officers were subject to FCC approval. ${ }^{248}$ As a formal matter, and one suspects in reality also, ICANN is more independent.

Thus, DoC's decision to publish the White Paper as a formally nonbinding policy statement appears to be a successful end-run around the GCCA-which suggests that the GCCA may need amendment. ${ }^{249}$ By calling for NewCo to form spontaneously, ${ }^{250}$ government officials avoided directly "creating" the corporation.

b. Amendment 11: NSI Preserves Its Monopoly (October 1998). While Postel and Sims were selecting directors for the ICANNto-be, NSI was working to preserve and extend its monopoly of both domain name registry services and registrar services, a goal that seemed to leave little room either for ICANN or for increased competition in the domain name business. NSI's right to register domain names, an increasingly remunerative activity, was due to expire on March 31, 1998, although it could be extended by the U.S. government. ${ }^{251}$ Ordinarily, that should have given the U.S. government enormous leverage over its contractor. The picture was clouded, however, by an anomaly in the drafting of the NSI-NSF agreements, exacerbated by an amendment proposed by NSI in 1995, that created an arguable case that NSI had some sort of right to own the database of registrants. NSI claimed variously that it had no obligation to turn over the data linking registrants to domain names, or that it could keep a copy even if its MoU expired-with the implicit threat that it might go into business on its own, setting up an alternate root. ${ }^{252}$ NSI used its intellectual property claim, and the very significant threat of truly privatizing the root, plus its unique experience in managing the

\footnotetext{
248. See id.

249. For related suggestions regarding reform of the GCCA, see generally Froomkin, supra note 24 .

250. See supra notes 190-91 and accompanying text.

251. See Simon, supra note 172.

252. See, e.g., David S. Hilzenrath, Network Solutions Dropped as Registrar of Internet Domains, WASH. POST, Apr. 24, 1997, at E1 (noting the contention by NSI that it could continue to administer .com even if NSF ended its contractual relationship).
} 
ever-growing and ever-more-important .com domain, as leverage to negotiate an extension of its contract on favorable terms. ${ }^{253}$

Amendment 11 (agreed to on October 7, 1998) extended the DoC-NSI MoU to September 30, 2000, and punted the question of intellectual property, ${ }^{254}$ but imposed on NSI an obligation to design a "shared registry" system that would allow other, competing registrars to sell registrations that would be reflected in the legacy root. ${ }^{255}$ This extension agreement also paved the way for a separation of NSI's registry and registrar functions, with the registry entitled to charge all registrars a fixed fee, to be determined later, for its services. ${ }^{256}$ NSI further promised to give the U.S. government a copy of the secondlevel registration data, something it had not admitted was already due in the previous agreement. ${ }^{257}$ Critically, NSI also promised to make no changes to the root without written authorization from DoC. ${ }^{258}$

Perhaps the most significant part of Amendment 11 was that DoC extracted promises from NSI regarding what would happen "as the USG transitions DNS responsibilities to NewCo." 259 The agreement stated that as NewCo took over, "corresponding obligations under the Cooperative Agreement as amended will be terminated and, as appropriate, covered in a contract between NSI and NewCo." In other words, NewCo would more or less step into DoC's shoes, and NSI would accept it as policy master of the legacy root: "NSI acknowledges that NewCo will have the authority, consistent with the

253. See, e.g., Rajiv Chandrasekaran, Commerce Threatens to Weaken NSI's Grip; Internet Address Manager Warned, WASH. POST, July 10, 1999, at E1 (noting NSI's claims to continued rights to .com, .org and .net).

254. "[E]xcept as otherwise expressly provided herein, nothing in this paragraph is intended to alter any intellectual property rights of the USG or NSI established in the Cooperative Agreement." Amendment 11, supra note 82.

255. The contract neglected to require that the SRS be open source, which created opportunities for NSI to use nondisclosure clauses to its benefit.

256. See Amendment 11, supra note 82 . DoC and NSI later agreed to a fee of $\$ 9$ per year per second-level domain, for at least four years, extendable to eight in some circumstances. See Amendment to Financial Assistance Award 1 (May 6, 1999), at http://www.networksolutions.com/legal/internic/cooperativeagreement/amendment13coverpage. pdf (on file with the Duke Law Journal); NSI-Cooperative Agreement No. NCR-9218742, Amendment 13, at http://www.networksolutions.com/legal/internic/cooperative-agreement/ amendment13.html (last visited Aug. 17, 2000) (on file with the Duke Law Journal).

257. See Amendment 11, supra note 82.

258. See id. (quoting the relevant clause).

259. Id. The Agreement continued: "For purposes of this agreement, NewCo is the not-for-profit corporation described in the Statement of Policy and recognized by the USG in accordance with the provisions of the Statement of Policy for so long as the USG continues its recognition of NewCo." Id. 
provisions of the Statement of Policy and the agreement between the USG and NewCo, to carry out NewCo's Responsibilities. ${ }^{260}$ NSI also promised that once DoC selected NewCo, NSI would appoint ten persons chosen by NewCo to help design the shared registry system, create a testing environment to help new registrars selected by NewCo exercise their software, give NewCo technical assistance on request, and enter into a contract with $\mathrm{NewCo}{ }^{261}$

2. ICANN Opens Shop \& DoC-ICANN Memorandum of Understanding (November 1998). From the moment of its formation on October 26, 1998, ICANN faced obstacles and opposition. The secret selection of the initial board, combined with (depending who you asked) the collapse of, sabotage of, or end-run, around popular alternatives created hard feelings. ${ }^{262}$ ICANN's only potential source of income was to require one or more classes of Internet users to pay it, but neither registrants, NSI, nor the other registries seemed anxious to do so. Meanwhile, ICANN had to choose between, on the one hand, establishing the full set of governance structures articulated in the White Paper, including widespread representation, and, on the other hand, trying to rush decisions to a conclusion so that ICANN would have tangible achievements. The requirement to elect half the board from the at-large membership of the new entity implied requirements for a global membership and some means to run a reasonable worldwide election among a group whose parameters had yet to be defined. And, worst of all, Jon Postel's death robbed the organization of its intellectual center, its chief source of technical knowhow, much of its institutional memory, and a good part of its legitimacy.

ICANN's first priority was to formalize its relationship with DoC and to have DoC recognize it as the NewCo contemplated in the White Paper. Recognition as NewCo would then trigger NSI's duties under Amendment 11. So long as NSI refused to recognize ICANN, its authority was limited at best. ICANN, however, was not the only

\footnotetext{
260. Id.

261. See id.

262. See Niall McKay, Critics Decry New Net Government, Wired News (Oct. 8, 1998), at http://www.wirednews.com/news/politics/0,1283,15482,00.html (on file with the Duke Law Jour$n a l)$.
} 
body seeking to be NewCo. ${ }^{263}$ In retrospect, however, it seems clear that the ICANN proposal had the inside track from the start. ${ }^{264}$

The existence of an alternative to ICANN's proposals did have one effect, however: It highlighted ways in which the original draft of the ICANN articles and bylaws differed from the more inclusive and representative structures envisioned by the White Paper's call for "bottom up" decisionmaking and "representation." The Department of Commerce was sufficiently concerned about the lack of end-user representation in the original ICANN structure to demand changes. While ICANN created what appeared to be an expanded role for a "general assembly" of registrants that would be part of the DNSO, this group had no influence on the Names Council, and thus none on the ICANN board-not surprisingly, it never amounted to anything. And the concessions concerning election of at-large directors by a public membership were later undermined. ${ }^{265}$

DoC also queried ICANN regarding its membership, financial accountability, transparency, conflicts of interest policy, geographic diversity, and its policy on ccTLDs. ${ }^{266}$ ICANN responded by revising its articles of incorporation ${ }^{267}$ and making substantial changes to its bylaws to accommodate these criticisms. ${ }^{268}$ Changes included the addition of an anodyne policy on conflicts of interest and the promise to

263. Notably, a competing proposal had grown out of a series of public meetings hosted by self-organized groups called the Internet Forum on the White Paper (IFWP) and the Boston Working Group (BWG). See Boston Working Group, Letter of Submission, National Telecommunications and Information Administration, at http://www.ntia.doc.gov/ntiahome/

domainname/proposals/bosgrp/submission-letter.html (Sept. 28, 1998) (on file with the Duke

Law Journal).

264. See Mueller, supra note 102, at 506-07.

265. See supra notes 39, 207.

266. See Letter from J. Beckwith Burr, Associate Administrator (Acting), National Telecommunications and Information Administration, to Herb Schorr, Executive Director, USC Information Sciences Institute (Oct. 20, 1998), National Telecommunications and Information Administration, http://www.ntia.doc.gov/ntiahome/press/icann102098.htm (on file with the Duke Law Journal).

267. See Articles of Incorporation (As Revised), at http://www.icann.org/general/articles.htm (Nov. 21, 1998) (on file with the Duke Law Journal).

268. See NTIA Reviewing ICANN November 6 Submission, National Telecommunications and Information Administration, at http://www.ntia.doc.gov/ntiahome/press/ICANN111098.htm (Nov. 10, 1998) (on file with the Duke Law Journal). The complete set of proposed and frequently amended bylaws are now available from Ellen Rony's excellent ICANN bylaws web page. See Ellen Rony, ICANN: Announcements, Bylaws, Board and Budget, at http://www. domainhandbook.com/icann1.html\#bylaws (last visited Aug. 17, 2000) (on file with the Duke Law Journal). 
publish board minutes of secret board meetings quickly and regularly - a promise later honored in the breach.

On November 25, 1998, DoC signed a memorandum of understanding with ICANN (the DoC-ICANN MoU), ${ }^{269}$ although it did not (yet) formally recognize ICANN as NewCo. This MoU is one of the three pillars of ICANN's authority. In it, DoC and ICANN agreed to "jointly design, develop, and test the mechanisms, methods, and procedures that should be in place and the steps necessary to transition management responsibility for DNS functions now performed by, or on behalf of, the U.S. Government to a private-sector not-for-profit entity" in order to prepare the ground for the transition of DNS management to ICANN. ${ }^{270}$ The "DNS management functions" covered included "[e]stablishment of policy for and direction of the allocation of IP number blocks," as well as oversight of both "the operation of the authoritative root server system" and "the policy for determining the circumstances under which new top-level domains would be added to the root system," plus any other agreed activities "necessary to coordinate the specified DNS management functions." White Paper, the DoC-ICANN MoU also listed four principles by which the parties "will abide": stability of the Internet; competition; private, bottom-up coordination; and representation. ${ }^{272}$ The MoU explained "private bottom-up coordination" as meaning that the agreement would

result in the design, development, and testing of a private coordinating process that is flexible and able to move rapidly enough to meet the changing needs of the Internet and of Internet users.... [and] foster the development of a private sector management system that, as far as possible, reflects a system of bottom-up management. ${ }^{273}$

On its face, the document conveys no direct authority, only the power to make a study of how the DNS would be privatized in the future. In fact, however, the DoC-ICANN MoU conveyed very significant authority, because the means by which ICANN would "study" the future privatization of the DNS was by acting as if the DNS were already privatized. As DoC later explained to a House Committee,

269. See Memorandum of Understanding, supra note 47.

270. Id. § II.B.

271. Id.

272. Id. § II.C.

273. $I d$. 
ICANN's responsibility under the [MoU] is to act as the not-for-profit entity contemplated in the White Paper, and to demonstrate whether such an entity can implement the goals of the White Paper. If it cannot, Government involvement in DNS management would likely need to be extended until such time as a reliable mechanism can be established to meet those goals. The Department does not oversee ICANN's daily operations. The Department's general oversight authority is broad, and, if necessary, the Department could terminate the agreement and ICANN's role in this aspect of DNS management with 120 days notice. ${ }^{274}$

In other words, in order to "demonstrate" ICANN's future authority, the DoC-ICANN MoU provided that ICANN would take on the task of exercising that authority immediately.

The authority DoC granted to ICANN in the November 1998 DoC-ICANN MoU was sweeping but (formally) only temporary. The agreement placed ICANN on a short leash, ending on September 30, 2000 , or after 120 days' notice. ${ }^{275}$ Thus, if ICANN failed to perform as DoC "anticipate[d]" 276 it could lose its reason for being or be replaced. On the other hand, if, as appears to be the case, ICANN did what DoC desired, then it could reasonably have hoped to be given full control of the DNS at the end of this "transitional" agreement. ${ }^{277}$ ICANN had every incentive to be DoC's cat's paw and risked all if DoC was unhappy with its actions.

3. ICANN Takeover of the IANA Function (1999). In the ICANN-DoC MoU, the parties agreed that ICANN would study the privatization of the DNS by doing it. However, IANA, a separate government contractor, was already doing the job that ICANN proposed to privatize. Thus, DoC needed another agreement to allow ICANN to take over "the IANA function"-although it sometimes seemed as if ICANN simply was taking over IANA. (Indeed, ICANN is now headquartered in Marina Del Rey, California, in the same office building tower that long housed IANA.) In June 1999, the parties signed a Cooperative Research and Development Agreement $(\mathrm{CRADA})^{278}$ by which DoC (acting via NIST and NTIA) engaged

\footnotetext{
274. Pincus, supra note 43.

275. See Memorandum of Understanding, supra note 47, § VII.

276. See supra note 47 and accompanying text.

277. See supra notes 204-06 and accompanying text.

278. A CRADA is usually an agreement in which, as the United States Geological Survey explained:
} 
ICANN to study how to improve the IANA functions; like the ICANN-DoC MoU, this new agreement appears to include having ICANN perform the function during the study. ${ }^{279}$

ICANN had already moved to secure a relationship with IANA. About six months before the CRADA, ICANN agreed with USC (which was still the government contractor for the IANA function) that ICANN should take over IANA's role. ${ }^{280}$ USC transferred some of IANA's assets and personnel to ICANN, and ICANN agreed to pay IANA's bills. ${ }^{281}$ In practical terms, ICANN's takeover of the DNS may date to this agreement. DoC had not agreed to the transfer, but within weeks, DoC remedied the gap by announcing that it intended to issue a sole source contract to ICANN for the IANA function on the grounds that ICANN was the only responsible source available. ${ }^{282}$ DoC duly issued a purchase order to ICANN for IANA services, a purchase order that has a price of zero dollars but allows ICANN to establish and collect fees from third parties, subject to review by DoC, so long as the fees reflect the actual cost of providing the service. $^{283}$

Thus, in addition to the MoU, another part of the legal basis for ICANN's management of the DNS became the fact that ICANN

[t]he collaborating partner agrees to provide funds, personnel, services, facilities, equipment or other resources needed to conduct a specific research or development effort while the Federal government agrees to provide similar resources but not funds directly to the partner.... The CRADA vehicle provides incentives that can help speed the commercialization of Federally-developed technology, making it an excellent technology transfer tool.

What Is a CRADA?, United States Geological Survey, at http://www.usgs.gov/tech-transfer/ what-crada.html (last modified May 23, 1997) (on file with the Duke Law Journal).

279. See CRADA, supra note 47. The CRADA was signed in June 1999. See GAO Report, supra note 28 , at 17.

280. A copy of what appears to be this agreement, dated January 1, 1999, appears as Appendix 21 to ICANN's application for tax-exempt status. See Form 1023 (Appendix 21), at http://www.icann.org/financials/tax/us/appendix-21.htm (last modified Sept. 4, 2000) (on file with the Duke Law Journal); see also Form 1023 (Appendix 19), at http:/www.icann.org/financials/ tax/us/appendix-19.htm (last modified Sept. 4, 2000) (detailing a loanout agreement for two employees) (on file with the Duke Law Journal). For an account of the IANA transition, see Gordon Cook, Paris DNSO Draft Gathers Wide Support, THE COOK REPORT ON INTERNET (Mar. 1999), at http://www.cookreport.com/07.12.shtml (on file with the Duke Law Journal).

281. See Cook, supra note 280.

282. See GAO Report, supra note 28 , at 18.

283. See Contract Between ICANN and the United States Government for Performance of the IANA Function, at http://www.icann.org/general/icann-contract-09feb00.htm (last visited Sept. 21, 2000) (showing a copy of the purchase order) (on file with the Duke Law Journal). According to an ICANN press release dated September 4, 2000, the purchase order was extended for one year. See Announcement, supra note 47. 
stands in the shoes of IANA while it studies how to improve IANA and how to privatize IANA's functions.

4. ICANN's Search for Revenue. If getting recognized as NewCo was ICANN's first order of business, the search for revenue was an only slightly lower priority. The White Paper had proposed that NewCo be supported by "stakeholders," including registrars and registries. NSI, however, did not accept ICANN as NewCo and was unwilling to make payments; since NSI was the monopoly registrar and would continue to be the dominant registry in the gTLDs, this left few alternatives with any assets. ICANN had no assets other than its agreements with DoC and a considerable fund of goodwill.

Thus, in February 1999, ICANN proposed that registrars should pay it $\$ 1$ for every domain name registration and re-registration. This proposal met with intense criticism, caused a congressional hearing, and prompted DoC to send ICANN a letter objecting to the fee. ${ }^{284}$ Within two weeks of receiving DoC's letter, ICANN dropped its proposal for the $\$ 1 \mathrm{fee},{ }^{285}$ even though ICANN CEO Mike Roberts described the organization as "broke." 286 Since NSI had most of the gTLD registrations, it would have paid the largest fee to ICANN. When ICANN proposed the $\$ 1$ fee, however, NSI had yet to recognize its authority, so the pressure from Congress advanced its agenda of keeping ICANN weak.

Although ICANN received a number of $\$ 10,000-\$ 25,000$ donations, primarily from telecommunications and Internet businesses, ${ }^{287}$

284. See Letter from J. Beckwith Burr, DoC, to Esther Dyson \& Mike Roberts, ICANN (July 8, 1999), http://www.icann.org/correspondence/doc-to-icann-08july99.htm (on file with the Duke Law Journal); see also Pincus Testimony, National Telecommunications and Information Administration, at http://www.ntia.doc.gov/ntiahome/congress/pincus19990722.htm (last visited Aug. 18, 2000) (calling for the elimination of the fee and for the adoption of a financing method "in accordance with the representative, bottom-up process called for in the White Paper") (on file with the Duke Law Journal).

285. See Letter from Esther Dyson, Interim Chair, ICANN, to J. Beckwith Burr, DoC (July 19, 1999), http://www.icann.org/correspondence/icann-to-doc-19july99.htm (on file with the Duke Law Journal); see also Maura Ginty, ICANN Drops Registrar Fee, at http://www.internetnews.com/bus-news/print/0,3_164621,00.html (July 20, 1999) ("Bowing to protests against the controversial move, ICANN has deferred its proposed $\$ 1$ per-year, perdomain registrar fee program.") (on file with the Duke Law Journal).

286. See Courtney Macavinta, ICANN Running Out of Money, CNET NEws (July 7, 1999), at http://news.cnet.com/news/0-1005-200-344529.html?sas.mail (on file with the Duke Law Journal).

287. See List of ICANN Contributors, at http://www.icann.org/contributors.htm (last visited Aug. 18, 2000) (on file with the Duke Law Journal). 
these were far less than its expenses. ${ }^{288}$ In August 1999, ICANN sent out desperate messages seeking funding to IBM and MCI. ${ }^{289}$ On September 24, 1999, IBM pledged an unconditional contribution of $\$ 100,000$ to ICANN. ${ }^{290}$ ICANN also negotiated unsecured loans on favorable interest terms from four large e-commerce companies with interests in domain name policy. ${ }^{291}$

Although the loans were described as being for one year, as of this writing at least the four listed above appear to be outstanding, and ICANN's budget does not include a line item for repayment. ${ }^{292}$ ICANN's money troubles continued even after DoC persuaded NSI to recognize it as NewCo and to make a $\$ 1$ million payment immediately plus pledge about $\$ 2$ million per year. ${ }^{293}$ ICANN has a contract with DoC that allows it to levy user fees at cost for its performance of the IANA function, but that agreement was not signed until February 2000 , and DoC estimates the costs at under $\$ 10,000 .^{294}$

As of this writing, ICANN is trying to levy about $\$ 1.5$ million per year from ccTLD registries, ${ }^{295}$ but a large number have protested on the grounds that they have no contract with ICANN and no obliga-

288. See Macavinta, supra note 286.

289. See Gordon Cook, Follow the Money, THE COOK REPORT ON INTERnET (Sept. 1, 1999), at http://dns.vrx.net/news/by_date/1999/Sep/cook1.html (on file with the Duke Law Journal).

290. See Letter from John R. Patrick, Vice President of Internet Technology, IBM, to Esther Dyson, Interim Chair, ICANN (Sept. 24, 1999), http://www.icann.org/correspondence/ ibm-letter-24sept99.htm (on file with the Duke Law Journal).

291. ICANN's web page currently acknowledges receiving loans of $\$ 150,000$ from Cisco Systems, Inc., \$500,000 from MCI Worldcom Corp., $\$ 175,000$ from 3Com Corp., and \$175,000 from Deutsche Telekom. See Loan Agreement Information, at http://www.icann.org/general/ loaninfo.htm (last modified Feb. 1, 2000) (on file with the Duke Law Journal). The interest rate is not disclosed. See Financial Statements, at http://www.icann.org/financials/financial-report-fye30jun99.htm (June 30, 1999) (noting $\$ 800,000$ in loans) (on file with the Duke Law Journal); 2000-01 Budget, supra note 41 (noting that "[d]uring the summer of 1999, unsecured loans were obtained by the corporation in the total amount of $\$ 1.025$ million"); I Think ICANN: Loan Keeps Group Afloat, THE STANDARD (Aug. 20, 1999) (stating that ICANN would receive up to $\$ 1$ million from IBM and MCI and that ICANN had $\$ 800,000$ in debt), at http://www.thestandard.net/article/display/0,1151,6020,00.html (on file with the Duke Law Jour$n a l)$.

292. See 9-Month Financial Report for Period Ending 31 March 2000, at http://www.icann.org/financials/financial-report-fpe-31mar00.htm (last modified Feb. 14, 2000) (on file with the Duke Law Journal) [hereinafter 9-Month Financial Report].

293. See infra note 320 and accompanying text.

294. See GAO Report, supra note 28, at 19.

295. See Task Force on Funding_Draft Final Report, at http://www.icann.org/tff/finalreport-draft-30oct99.htm (Oct. 30,1999) (on file with the Duke Law Journal). 
tion to pay. ${ }^{296}$ Registries in some third world nations have also complained that ICANN's levies were calculated arbitrarily, without notice or their participation, and that they discriminate against registries that choose to offer free domain names to their nationals. ${ }^{297}$

5. The Tripartite Agreements (November 1999). Agreements to agree are notoriously hard to enforce, and NSI's promise in Amendment 11 to make agreements with NewCo fit this pattern. Although DoC had signed an MoU with ICANN in November 1998, ICANN's teething troubles kept DoC from officially recognizing ICANN as "NewCo" until February 26, 1999. ${ }^{298}$ Even after this designation, the negotiations with NSI dragged on. By recognizing ICANN, NSI risked losing much of its autonomy. By not recognizing ICANN, NSI kept its grip on the registry and a predominant share of .com registrations-plus the leverage the threat to go it alone gave NSI over DoC. Furthermore, NSI must have known that ICANN had two powerful incentives to secure NSI's cooperation: without it, ICANN risked becoming a paper tiger; and, without a cash infusion from NSI, ICANN had no reliable source of funding. ${ }^{299}$ ICANN clearly saw NSI as the chief obstacle to its success. ${ }^{300}$

But for pressure from DoC, it is possible that NSI would never have reached a final agreement with ICANN; it had little incentive to do so quickly. The pressure from DoC was, however, intense, and NSI's contract would eventually expire. Thus, in early November 1999 - a year after DoC signed its first agreement with ICANN—the

296. See, e.g., Jeri Clausing, European Domain Operators Refuse to Pay Bills, CyBERTIMES (June 7, 2000) (describing ICANN's attempt to bill country code management organizations and those organizations' refusals to acknowledge ICANN's invoices), at http://www.nytimes.com/ library/tech/00/06/cyber/articles/07domain.html (on file with the Duke Law Journal).

297. See, e.g., Jay Fenello, ICANN's ccTLD Tax, Matrix Information and Directory Services, Inc., at http://www.mids.org/mn/1006/za.html (June 2000) (on file with the Duke Law Journal); see also Clausing, supra note 296 (characterizing the proposed Internet address tax as representative of the sometimes-misguided leadership of ICANN).

298. See Letter from J. Beckwith Burr, Associate Administrator (Acting), NTIA, to David Graves, Director, Business Affairs, Network Solutions, Inc. (Feb. 26, 1999), National Telecommunications and Information Administration, http://www.ntia.doc.gov/ntiahome/domainname/ icannnewco.htm (on file with the Duke Law Journal).

299. See 9-Month Financial Report, supra note 292.

300. See, e.g., Letter from Esther Dyson, Interim Chair, ICANN, to Ralph Nader, Founder, Center for Study of Responsive Law, \& James Love, Director, Consumer Project on Technology 1 (June 15, 1999) (commenting that "NSI has apparently concluded that its interests [in maintaining a monopoly on providing DNS services] are not consistent with ICANN's success"), http://www.icann.org/chairman-response.htm (on file with the Duke Law Journal). 
three parties signed a set of triangular agreements by which NSI agreed with DoC to make agreements with ICANN that would give ICANN near-total control over the root and de facto control over the contractual terms that would govern every registrant's access to domain names in the open gTLDs: .com, .org, and .net.

The DoC-NSI Agreement. In Amendment 19 to the DoC-NSI Cooperative Agreement, DoC agreed to extend NSI's contract for at least four more years and possibly more. ${ }^{301}$ DoC also agreed to ensure that NSI's root remained the authoritative root. ${ }^{302}$ NSI agreed to recognize ICANN as $\mathrm{NewCo}^{303}$ and to sign the ICANN Registry Agreement and the ICANN Registrar Accreditation Agreement. ${ }^{304}$ Furthermore, NSI agreed that if it were to violate those agreements and ICANN were to terminate it for cause, DoC could similarly terminate NSI. ${ }^{305}$ This threat ensured NSI's good behavior. NSI also promised to accept registrations only from ICANN-accredited registrars. ${ }^{306}$ The consequences of this promise were as significant as anything else in the tripartite set of agreements. With this promise, ICANN acquired the power, through the Registry Agreement, to impose any conditions it chose on registrants. Since no registrant could be listed in the legacy root without going through an ICANN registrar, and ICANN now acquired the power to determine what conditions the registrar would impose on registrants, the effect was to acquire contractual leverage over anyone wanting a functional domain name. ${ }^{307}$ Significantly, NSI, perhaps the only party capable of deploying an alternate root with instant worldwide acceptance, also gave up its option of creating such a competitor, agreeing with DoC that "[i]n the interest of the smooth, reliable and consistent functioning of the Internet, for so long as the Cooperative Agreement is in effect, NSI agrees not to deploy alternative DNS root server systems.",308

\footnotetext{
301. See DoC-NSI Cooperative Agreement, Amendment 19, § I.B.10 (Nov. 4, 1999), http://www.icann.org/nsi/coopagmt-amend19-04nov99.htm (on file with the Duke Law Journal) [hereinafter Amendment 19].

302. See id. § I.B.4.A.

303. See id. § I.B.1.

304. See id. §1.B.2.A.

305. See id. § I.B.2.C.

306. See id. §1.B.2.E.

307. Alternate root domain names "function" in the sense of working for those who use a machine that knows how to find them; they do not "function" in the sense of allowing any but a tiny minority of Internet users to access an Internet resource via the domain name. See supra note 61 and accompanying text.

308. Amendment 19, supra note 301, § I.B.4.E.
} 
The ICANN-DoC Agreement. DoC and ICANN amended their MoU of November 25, $1998,{ }^{309}$ to underline DoC's authority over ICANN and, thus, provide NSI assurances that ICANN would not attempt to disadvantage NSI relative to its new registrar competitors nor attempt to alter its privileged position as registry. DoC not only approved the revised Registry Agreement, ${ }^{310}$ but ICANN further promised DoC that ICANN would not amend the Registry Agreement without DoC's prior approval. ${ }^{311}$ ICANN also promised not to make agreements with a successor registry without DoC's approval ${ }^{312}$ and to follow DoC's lead if it chose to replace NSI with a new registry. ${ }^{313}$ And, as if to make clear beyond peradventure that ICANN was DoC's agent for DNS matters, ICANN agreed that "[i]f DOC withdraws its recognition of ICANN or any successor entity by terminating this MOU, ICANN agrees that it will assign to DOC any rights that ICANN has in all existing contracts with registries and registrars." ${ }^{314}$

The NSI-ICANN Agreements. In the Registry Agreement, ${ }^{315}$ NSI agreed to become the official ICANN registry but extracted substantial limits on ICANN's ability to exercise regulatory powers. ${ }^{316}$ NSI agreed to accept ICANN's revised Registrar Accreditation Agreement $^{317}$ and, in an ICANN-NSI Registrar Transition Agreement, ${ }^{318}$ to become an ICANN-accredited registrar. ${ }^{319}$ NSI-as-registrar agreed to pay ICANN $\$ 1$ million immediately and up to $\$ 2$ million per year thereafter. ${ }^{320}$ NSI also revised its Registrar License Agreement ${ }^{321}$ governing NSI-as-registry's relationship with other registrars. In a critical part of the new agreement, NSI-as-registry required all registrars to

\footnotetext{
309. See supra notes 47, 269 and accompanying text.

310. See ICANN-NSI Registry Agreement, supra note 42.

311. See Memorandum of Understanding, Amendment 1, supra note 90.

312. See id.

313. See id.

314. Id.

315. ICANN-NSI Registry Agreement, supra note 42.

316. See id.

317. Id.

318. ICANN-NSI Registrar Transition Agreement, at http://www.icann.org/nsi/icann-nsitransition-04nov99.htm (Nov. 4, 1999) (on file with the Duke Law Journal).

319. See id. §1.

320. See id. $\$ 4$.

321. NSI-Registrar License and Agreement, at http://www.icann.org/nsi/nsi-rla-04nov99.htm (Nov. 4, 1999) (on file with the Duke Law Journal). Among other things, this agreement limited the terms of users' registrations to 10 years. See id. $\S 2.3$.
} 
have an ICANN-approved domain name dispute policy and to enforce it on their registrants. ${ }^{322}$ Registrars also had to promise to pay NSI $\$ 9$ per year per registration for the first two years of a registration and $\$ 6$ per year thereafter. ${ }^{323}$ Unlike earlier MoU's, this one included an explicit disclaimer of any intent to create third-party beneficiaries. ${ }^{324}$

At this point, ICANN's day-to-day control of the DNS was complete, subject to two rather important constraints explored in the next section: DoC stated that it retained "policy control" over the DNS, and the MoU and the sole-source contracts were due to expire late in the year 2000 .

What authority did DoC have to lend ICANN its authority over the DNS, even temporarily? According to the MoU itself, that authority came from five sources. Two of these sources had been cited to justify the proposed rulemaking in the Green Paper: DoC's general authority "to foster, promote, and develop ... foreign and domestic commerce" ${ }^{, 325}$ and NTIA's authority to coordinate telecommunications activities and "assist in the formulation of policies and standards. ${ }^{326}$ Three were new. First, there was the White Paper itself, which as a mere policy statement could not provide the authority. ${ }^{327}$ DoC also cited a presidential directive, based on an earlier product of

322. The agreement reads:

Registrar shall have developed and employ in its domain name registration business an electronic or paper registration agreement, including a domain name dispute policy, a copy of which is attached to this Agreement as Exhibit A (which may be amended from time to time by Registrar, provided a copy is furnished to the Registry three (3) business days in advance of any such amendment), to be entered into by Registrar with each SLD holder as a condition of registration. Registrar shall include terms in its agreement with each SLD holder that are consistent with Registrar's duties to NSI hereunder.

Id. $\S 2.7$.

323. See id. $\$ 5.2$.

324. See id. § 6.2. While it might appear that the mutual promises to follow the relevant RFCs made registrants third-party beneficiaries of the earlier NSI-NSF agreement, the two courts that have examined the issue have been singularly unpersuaded. See Beverly v. Network Solutions, Inc., No. C-98-0337-VRW, 1998 WL 320829, at *6 (N.D. Cal. June 12, 1998) (holding as a matter of federal common law that the NSI-NSF agreement evinced insufficient evidence of an intent to create a third-party benefit); Oppedahl \& Larson v. Network Solutions, Inc., 3 F. Supp. 2d 1147, 1159 (D. Colo. 1998) (same). The prime beneficiary from the addition of the disclaimer to the MoU was NSI itself. Section 6.2 removed any danger that a subsequent court might view the third-party beneficiary in a way that could impose liability on NSI.

325. 15 U.S.C. $\S 1512$ (1994).

326. 47 U.S.C. $\$ 902(b)(2)(H)(1994)$.

327. See Vietnam Veterans of Am. v. Secretary of the Navy, 843 F.2d 528, 537 (D.C. Cir. 1988) (“A binding policy is an oxymoron."). 
Ira Magaziner's interagency task force, which instructed the Secretary of Commerce to transition DNS management to the private sector. ${ }^{328}$ Most substantively, DoC relied on its Joint Project Authority, which allows DoC to enter into "joint projects" with "nonprofit organizations, research organizations, or public organizations . . . on matters of mutual interest, the cost of which shall be apportioned equitably. ${ }^{, 329}$ Indeed, ICANN is nonprofit, both DoC and ICANN wanted ICANN to have the authority, and no money changed hands, thus formally satisfying these requirements, if not perhaps in a way that Congress might have anticipated.

The formal satisfaction of these contracting requirements perhaps explains why the General Accounting Office recently concluded that DoC had the authority to enter into its contracts with ICANN. ${ }^{330}$ Indeed, the problem with DoC's relationship with ICANN has little to do with the wording of the agreements and only a little to do with their substance. Rather, the problem is something that the GAO excluded from its terms of reference-how DoC itself has directed and reacted to ICANN's performance of the contracts.

\section{DOC'S RELATIONSHIP WITH ICANN IS ILLEGAL}

A person suffering legal wrong because of agency action ... is entitled to judicial review thereof. ${ }^{331}$

Pinning down the exact nature of DoC's relationship with ICANN is difficult, perhaps because a studied ambiguity on a few key points serves the interests of both parties. This part begins by arguing that at least some of ICANN's activities pursuant to its agreements with DoC are governmental in nature and most properly characterized as policymaking or regulation. The subsequent sections examine the different possible legal characterizations of DoC's relationship with ICANN in light of the contractual history set out in Part II above and ICANN's performance of its contracts. Each of these sections also discusses the legal consequences of that characterization.

328. See Presidential Memorandum on Electronic Commerce, 33 WeEKLY COMP. PreS. Doc. 1006, 1008 (1997) ("I direct the Secretary of Commerce to support efforts to make the governance of the domain name system private and competitive and to create a contractually based self-regulatory regime that deals with potential conflicts between domain name usage and trademark laws on a global basis.").

329. 15 U.S.C. $§ 1525$ (1994).

330. See GAO Report, supra note 28 , at 15-19.

331. 5 U.S.C. $\$ 702$ (1994). 
The Department of Commerce seeks to paint its relationship with ICANN as a normal relationship it might have with any contractor; call this the private party story. Similarly, ICANN argues that it neither regulates nor makes policy but just sets technical standards; call this the standard-setting story. It has long been accepted that the government may delegate technical "standard setting" to private parties-at least so long as the government retains a supervisory role. Indeed, some of what ICANN does, or plans to do, can legitimately be described as standard setting, and if ICANN were limited to those functions, DoC's reliance on ICANN would not be illegal so long as it retained the right to review-and if necessary countermandICANN's decisions.

In fact, however, ICANN's effects on third parties' legal rights are so sweeping that functionally DoC has outsourced policymaking and regulatory functions to ICANN. As explained below, ICANN's imposition of arbitration on domain name registrants clearly rises to the level of regulation and policymaking. ${ }^{332}$ The question then is whether ICANN regulates as DoC's proxy-the state actor question. If ICANN is a state actor, its regulatory acts are directly chargeable to DoC, and need to comply with the Administrative Procedures Act. If, on the other hand, ICANN is not a state actor, but is acting independently, then one question is whether ICANN is subject to the Federal Advisory Committee Act. A more important question is whether DoC retains the right to approve or countermand ICANN's decisions. If DoC has forfeited this right, the issue is whether this grant of public power to a private group violates the Due Process Clause or the nondelegation doctrine. Conversely, if DoC retains the right to review ICANN's policy decisions, the issue is again whether DoC's review complies with the APA.

\section{A. ICANN Is Engaged in Policymaking}

Both ICANN and DoC deny that ICANN is engaged in either regulation or governance. Instead they proffer the standard-setting view, in which ICANN is engaged in nothing more than routine stan-

332. It is also, arguably, bad policy. See Harry T. Edwards, Where Are We Heading with Mandatory Arbitration of Statutory Claims in Employment?, 16 GA. ST. U. L. REV. 293, 295 (1999) (warning that "[w]hen public laws are enforced in the private fora . . . we have no assurance that the underlying public interests are fully satisfied"). 
dard setting or perhaps technical coordination. ${ }^{333}$ Thus, ICANN maintains that it "has no statutory or regulatory 'authority' of any kind.",334 It has, it says, "only the power of the consensus that it represents," since root servers not run by or under contract to the U.S. government could at any time choose to point to a different root, albeit at the cost of causing the very fragmentation most root server operators oppose. ${ }^{335}$ ICANN argues that only "the willingness of members of the Internet community to participate in and abide by the consensus development process that is at the heart of ICANN",336 makes people do what it says, not coercion or regulation. As Esther Dyson put it,

The White Paper articulates no Internet governance role for ICANN, and the Initial Board shares that (negative) view. Therefore, ICANN does not "aspire to address" any Internet governance issues; in effect, it governs the plumbing, not the people. It has a very limited mandate to administer certain (largely technical) aspects of the Internet infrastructure in general and the Domain Name System in particular. ${ }^{337}$

The standard-setting view seeks to take advantage of a long line of cases accepting delegations of near-regulatory power to private technical, agricultural, mechanical, or scientific groups. Since the New Deal, Congress has enacted a number of programs that rely on delegations to private groups. Although some state courts have been very aggressive about striking down legislative innovations of this type, the federal courts have been generally lenient. ${ }^{338}$ Thus, for example, numbers of agricultural and industrial marketing boards have survived federal judicial review. ${ }^{339}$ Each of those delegations, however, resulted directly from a congressional enactment, and each provided at least

333. DoC calls ICANN's job “coordination." White Paper, supra note 15, at 31,744 ("[U]nder the Green Paper proposal, the U.S. Government would gradually transfer these coordination functions to the new corporation ... with the goal of having the new corporation carry out operational responsibility by October 1998.").

334. Letter from ICANN to Rep. Tom Bliley, Chairman, United States House Committee on Commerce (July 8, 1999), http://www.icann.org/correspondence/bliley-response-o8july99.htm (on file with the Duke Law Journal).

335. Id.

336. Id.

337. Dyson, supra note 300 , at 1 .

338. See Harold I. Abramson, A Fifth Branch of Government: The Private Regulators and Their Constitutionality, 16 Hastings Const. L.Q. 165, 193 (1989).

339. See George W. Liebmann, Delegation to Private Parties in American Constitutional Law, 50 IND. L.J. 650, 709-10 (1975). 
some role for public officials' oversight. ${ }^{340}$ They therefore provide, at best, very limited guidance when a dubious delegation occurs solely at an agency's behest.

To the extent that ICANN really is engaged in mere technical standard setting - the Internet equivalent of deciding how insulated a wire must be to be safe-the standard-setting story has merit. The assignment of IP numbers, the maintenance of unique protocol numbers for various Internet functions-these and other semi-ministerial tasks are indeed just standard setting, although ICANN's agreement with the IETF seems to make ICANN little more than a rubber stamp for a significant fraction of these tasks. ${ }^{341}$ Yet both ICANN's conduct and the various agreements it has entered into reveal that a substantial fraction of ICANN's activities go far beyond the setting of technical standards. Choosing TLDs on the basis of social utility from among multiple technically qualified providers, fixing the business models of registrars, enforcing dispute resolution procedures on millions of unwilling business and consumers, accrediting dispute resolution providers, writing substantive and procedural rules for the disputes-not one of these tasks is "technical" standard setting in any routinely meaningful sense of the word.

The most glaring example of ICANN's policymaking to date is surely its promulgation of the Uniform Dispute Resolution Policy (UDRP) following the lead set out in the White Paper. The White Paper identified cybersquatting as a major problem that would need to be attended to by NewCo, and called for the UN's World Intellectual Property Organization (WIPO) to provide NewCo with an advisory report on what might be done. ${ }^{342}$ WIPO duly produced a lengthy report. ${ }^{343}$ ICANN referred the question of the arbitration of cybersquatting cases to a "working group." ICANN's working groups are supposed to be open to all, but the Chair of the Working Group excluded several opponents of mandatory arbitration from voting, although everyone remained allowed to comment. ${ }^{344}$ The Working Group's report was then forwarded to the ICANN Names Council, which is supposed to assess whether there is a consensus for the re-

340. See id. at 701-04.

341. See infra notes 371-72 and accompanying text.

342. White Paper, supra note 15, at 31,747.

343. See Domain Name Process, supra note 13.

344. See Froomkin, A Catalog of Process Failures, supra note 13. 
port. It did not, choosing instead to air its own views on the matter. ${ }^{345}$ After a period of public comment, the ICANN board next took up the issue. Finding that there were a number of unresolved issues, the board convened an ad hoc committee, dubbed the "small drafting committee," that met in secret to advise the staff on changes to the proposed policy, some but by no means all of which the staff accepted. ${ }^{346}$ The board then adopted the staff's final recommendations.

By adopting these rules, ICANN imposed on all current and future registrants in .com, .org, and .net a requirement that they agree to a third-party beneficiary clause in favor of any person, anywhere, who believes that the registrant's domain name registration infringed the complainant's trademark right. This clause was not optional: pursuant to the Registrar Agreement, ICANN required domain registrars to include this clause in every registration contract and to modify existing contracts with their customers, ${ }^{347}$ and, pursuant to the Registry Agreement, ICANN required NSI to agree to refuse to list registrations from any registrar who failed to do so. ${ }^{348}$

The UDRP offers a great deal to trademark registrants seeking to claim domain names from registrants, as the proceeding can cost under $\$ 1000^{349}$ and runs on a fast track, with each side (ordinarily) en-

345. See id.

346. See Second Staff Report, supra note 13, §§ 2.1-2.4.

347. See Registrar Accreditation Agreement, supra note 42, § II.K. ("In the event that ICANN adopts a policy or procedure for resolution of disputes concerning SLD names that by its terms applies to Registrar, Registrar shall adhere to the policy or procedure.").

348. This is different from imposing conditions on government contractors via procurement, see generally Lars Noah, Administrative Arm-Twisting in the Shadow of Congressional Delegations of Authority, 1997 WIS. L. REV. 873 (evaluating the various informal mechanisms that federal regulators use to evade the substantive limitations on their agency's delegated authority, and arguing that greater agency self-restraint and congressional oversight are the only realistic mechanisms for curbing overreaching by those regulators), because whatever one may think of the constitutional status of contractual conditions, the policy choice to embed the condition in the contract has been made directly by the executive branch, not delegated to a private body, and the condition applies directly to the contractor, rather than empowering it to make rules affecting relations between third parties.

349. Actual costs vary among the providers and also depend on whether the arbitration uses a one-person or three-person panel. Costs run between $\$ 750$ and $\$ 4500$ for one disputed domain name. See CPR Supplemental Rules to ICANN's Rules for Uniform Domain Name Dispute Resolution Policy, $\$ 12$, CPR Institute for Dispute Resolution, at http://www.cpradr.org/ ICANN_RulesAndFees.htm (last modified Sept. 15, 2000) (noting that the fee for one panelist is $\$ 2000$ and the fee for three panelists is $\$ 4500$ ) (on file with the Duke Law Journal); Schedule of Fees, $\S 1$, eResolution Consortium, at http://www.eresolution.ca/services/dnd/schedule.htm (Oct. 2, 2000) (noting that the fee for one panelist is $\$ 750$ and the fee for three panelists is \$2200) (on file with the Duke Law Journal); Schedule of Fees, National Arbitration Forum Dispute Resolution for Domain Names, at http://www.arbforum.com/domains/domain-fees.html 
tering only exhibits and one short pleading and no live witnesses or arguments. But the UDRP reduces registrants' legal rights in at least three ways. ${ }^{350}$

First, complainants choose the arbitral tribunal from a small list of approved providers maintained by ICANN, ${ }^{351}$ which gives the providers an economic incentive to compete by being "complainantfriendly." ${ }^{, 352}$ The first fruits of this competition can be seen in the decision of one of the competing providers — not the one I am affiliated with-to offer plaintiffs a chance to file an extra brief after the ordinary close of pleadings for $\$ 150 .^{353}$ Respondents have no say in which provider will manage the case, and no peremptory challenges to block arbitrators whom they may fear are biased. Respondents can, however, pick one member of a three-person panel-at their own expense if the complainant opted for a single panelist and the respondent decides three are needed. ${ }^{354}$ The choice of the provider determines who

(Dec. 23, 1999) (noting that the fee for one panelist is $\$ 750$ and the fee for three panelists is \$2250) (on file with the Duke Law Journal); Schedule of Fees Under the ICANN Policy, World Intellectual Property Organization, at http://arbiter.wipo.int/domains/fees/index.html (Aug. 15, 2000) (noting that the fee for one panelist is $\$ 1500$ and that the fee for three panelists is $\$ 3000$ ) (on file with the Duke Law Journal).

350. I can imagine only two benefits to registrants: (1) an innocent registrant who would have been sued in court might find an arbitration cheaper to defend (a gain thoroughly overcome by the increased number of filings resulting from the lower cost of arbitration to plaintiffs); and (2) a registrant whose name was on "hold" by NSI might be better off because, as a result of the imposition of the UDRP, his name is no longer on "hold."

351. There are currently four approved providers. See Approved Providers for Uniform Domain Name Dispute Resolution Policy, at http://www.icann.org/udrp/approved-providers.htm (last modified May 21, 2000) (on file with the Duke Law Journal) [hereinafter Approved Providers]. Readers are reminded that I am involved in organizing one of the providers. To the extent that I am arguing the whole structure is illegitimate, though, this is surely an argument against interest.

352. See Letter from Professor A. Michael Froomkin, University of Miami School of Law, \& Professor David G. Post, Temple University School of Law, to ICANN Board of Directors 1 (Jan. 26, 2000), available at http://www.icannwatch.org/archives/essays/950296910.shtml (last modified Feb. 11, 2000) (on file with the Duke Law Journal).

353. See National Arbitration Forum Dispute Resolution for Domain Names, Supplemental Rules, Rule 7, at http://www.arbforum.com/domains/domain-rules.html (Oct. 24, 1999) ("A party may submit additional written statements and documents to The Forum and the opposing party(s) not later than five (5) calendar days after the date the Response is submitted or the last date the Response was due to be submitted to the Forum, whichever occurs first.") (on file with the Duke Law Journal). Although couched in neutral terms allowing either party to avail itself of the supplemental brief, it is obvious that a provision allowing either party to file a supplemental brief five days after the defendant's response is designed to favor plaintiffs.

354. See Rules for Uniform Domain Name Dispute Resolution Policy, § 6(c), at http://www.icann.org/udrp/udrp-rules-24oct99.htm (Oct. 24, 1999) (on file with the Duke Law Journal) [hereinafter UDRP Rules]. A sole arbitrator is at the complainant's expense, see id. 
will be the arbitrators. For one-person panels the arbitrator must come from the provider's lists, and for three-person panels, each side provides a list of choices for one arbitrator, and the provider picks the chair. ${ }^{355}$

Second, unlike court proceedings, the URDP does not require actual notice to defendants, only attempted notice for a relatively short period of time..$^{356}$ Proceedings normally take forty-five days or less. After the complainant selects an ICANN-approved dispute provider and files a complaint, the dispute provider has three days to check it for formal compliance and forward it to the respondent. ${ }^{357}$ The respondent has twenty days from the date this notice is sent (not received) to respond. ${ }^{358}$ The provider then ordinarily has five days to appoint the arbitrator(s). ${ }^{359}$ The panel then has fourteen days to make its decision. ${ }^{360}$ The provider has three more days to communicate the

$\S 6(\mathrm{~b})$, as are all three if the complainant opted for a three-person panel from the start. See id. $\S 6(\mathrm{c})$.

355. See id. $\S \S 6(\mathrm{~b})-(\mathrm{c}),(\mathrm{e})$. In my experience, however, complainants frequently propose arbitrators from the providers' lists. There is also a likelihood that an unsophisticated respondent will tend to ask the provider for the names of arbitrators if the respondent has no experience with the UDRP and has no other source of information on whom to propose. Furthermore, if a party fails to propose names, or the provider is unable to secure the services of a party-proposed arbitrator in five days, the provider names a substitute. Providers, thus, have a greater influence than is apparent from Rule 6(e), even in three-arbitrator panels.

356. ICANN does not require the Provider to achieve actual notice to domain name registrants. See UDRP Rules, supra note 354, § 2(a). Instead, the mere sending of all of the following suffices to trigger respondent's 20-day period to respond to a complaint:

(i) sending the complaint to all postal-mail and facsimile addresses (A) shown in the domain name's registration data in Registrar's Whois database for the registered domain-name holder, the technical contact, and the administrative contact and (B) supplied by Registrar to the Provider for the registration's billing contact; and

(ii) sending the complaint in electronic form (including annexes to the extent available in that form) by e-mail to:

(A) the e-mail addresses for those technical, administrative, and billing contacts;

(B) postmaster@<the contested domain name $>$; and

(C) if the domain name (or "www." followed by the domain name) resolves to an active web page (other than a generic page the Provider concludes is maintained by a registrar or ISP for parking domain-names registered by multiple domain-name holders), any e-mail address shown or e-mail links on that web page; and

(iii) sending the complaint to any address the Respondent has notified the Provider it prefers and, to the extent practicable, to all other addresses provided to the Provider by Complainant under Paragraph 3(b)(v).

Id.

357. See UDRP Rules, supra note $354, \S 4(a)$.

358. See id. §5(a).

359. See id. §6(b).

360. See id. §15(b). 
decision to the parties. ${ }^{361}$ If the respondent loses, he has ten days to file a challenge in a competent court, or the domain name is transferred to the complainant. ${ }^{362}$ It can be seen from this chronology that, barring exceptional circumstances, the longest a proceeding can take from filing of complaint to decision is forty-five days, with another ten days before a decision to transfer takes effect. The decision to forgo requiring actual notice in absolutely all cases is understandable, given the efforts that the sleaziest registrants make to hide their contact details in shady registrations. The short deadlines, on the other hand, are completely unfair. ${ }^{363}$ Defendants who happen to take a month's vacation without e-mail can lose their chance to explain why they should keep their domain name without ever knowing it was endangered.

Third, and most significantly, the consequences of the arbitration are highly asymmetric and discriminate against registrants. UDRP decisions are not "binding"; if the plaintiff loses, the arbitration does not preclude an attempt to bring the case in court. ${ }^{364}$ This alone is a desirable feature, because a summary procedure, in which each side has only one submission, and in which there is neither testimony, cross-examination, briefing, nor argument cannot by itself hope to make reliable credibility determinations or sort out complex competing claims. If the system by design can resolve only clear cases of trademark infringement, it follows that plaintiffs with more complex cases should lose but still be entitled to have their day in courtwhere sometimes they will deserve to prevail.

The unfairness comes in comparison to what happens if the defendant loses. First, the registrant now has to sue to keep the name, taking on the burden of proof, and possibly being subject to different courts, rules of procedure, language, and choice of law than if the trademark complaint had been forced into litigation where the registrant resides. ${ }^{365}$ Worse, under the UDRP, a defendant is given only ten days to file an action in a court with jurisdiction over the plaintiff-or in the jurisdiction where the registrar is located ${ }^{366}$ - to halt the transfer of the domain name. No injunction is required, as filing suf-

\footnotetext{
361. See id. §16(a).

362. See UDRP, supra note $20, \S 4(\mathrm{k})$.

363. See generally Froomkin, A Catalog of Process Failures, supra note 13.

364. See UDRP, supra note $20, \S 4(\mathrm{k})$.

365. See generally Froomkin, A Commentary on WIPO's Management, supra note 13.

366. See UDRP Rules, supra note $354, \S 3$ (b)(xiii).
} 
fices to stop the clock, but this still means that either the losing defendant must have hired and probably paid a lawyer in advance, or the loser will need to find representation in a great hurry. This contrasts very unfavorably with the position of the losing plaintiff, who has as much time as statutes of limitations or laches will allow. The rule has particularly harsh effects in legal systems that do not provide for amendment of pleadings as of right, or at all. ${ }^{367}$

DoC's, WIPO's, and ICANN's objective in promoting mandatory domain name arbitration was to produce a rapid, lightweight, and inexpensive process that would allow victims of cybersquatting to vindicate their rights far more cheaply and quickly that would be possible in most courts. ${ }^{368}$ To the extent that this reduced the settlement value of clearly meritless defenses by persons infringing trademarks online, this was surely a very laudable objective. But it was not in any sense "technical coordination" of the Internet. Rather, it represents a clear policy choice to sacrifice the interests of (some) domain name registrants in favor of (some) trademark registrants for the communal good. While this policy choice is surely one that a legislature could make, it is not at all evident that Congress has delegated power over trademark policy to DoC. And, even if this sort of policy choice is within DoC's mandate, there can be no grounds by which DoC could outsource policymaking discretion of this sort to ICANN.

The standard-setting story's defense that this is mere technical coordination is not credible. Technical issues are questions such as the bit size of data packets, the architecture of the root servers, or the number of new top-level domains that can safely be added to the root. Determining what sort of redundancy the DNS requires and investigating the Y2K reliability of the DNS also are technical questions. Changing the legal rights accruing to more than twenty million contracts of registration is not.

Although it is the clearest case of ICANN's non-technical regulation so far, the adoption of UDRP is not unique. As it prepares to add new TLDs to the root, ICANN will again venture outside of the technical arena. ICANN will choose from one to ten proposals for new TLDs from applications from potential registries who will pay a

367. See, e.g., Jorge A. VArgas, MexicAn LAW: A Treatise fOr Legal PRACTITIONERS AND INTERNATIONAL INVESTORS $\S 20.2$ (1998) (stating that, in Mexico, "[o]nce drafted, a complaint cannot be refiled").

368. Having participated in both the WIPO and ICANN processes, I can certainly testify to their views from personal experience. See also Froomkin, A Catalog of Process Failures, supra note 13 (criticizing an ICANN dispute resolution policy proposal). 
$\$ 50,000$ non-refundable application fee..$^{369}$ Some proposals may be rejected for not demonstrating sufficient technical abilities. If, as seems likely, there are more technically qualified applicants than ICANN is willing to grant a TLD, then ICANN plans to choose among the applicants on other criteria. Specifying minimum performance levels for new registries and registrars are technical matters indeed, but choosing among multiple competing, technically qualified, proposals to see which five or so should be added to the root based on the social value of the proposed name is not easily called technical coordination. As one astute commentator put it,

[T]he problems surrounding the domain name system have, up to now, largely been framed as technical standard problems, and the processes used to resolve these problems have accordingly been analogs to the technical standard-setting processes. This approach, however, fails to fully appreciate the fact that domain name problems are not purely technical problems, but public policy ones as well. Specifically, the domain name controversy raises difficult issues regarding the proper distribution of a limited resource (domain names), the allocation of authority to control such a resource, and the proper shape and structure of the Internet as a whole. Such questions are "public" in nature, to the extent that they affect all participants on the Internet and to the extent they involve distribution of a quasi-public resource. Moreover, they cannot be resolved solely by reference to a relatively neutral technical performance metric; in many cases, conflicting value judgments may be irreconcilable. Domain name problems are thus, in a number of ways, fundamentally unlike other technical standard problems. ${ }^{370}$

The line between what is sufficiently a question of expertise to be a matter of implementation of a more general policy and what constitutes making the policy is not always easy to draw. But the fuzziness

369. See New TLD Application Instructions, at http://www.icann.org/tlds/new-tldapplication-instructions-15aug00.htm (Aug. 15, 2000) (setting the $\$ 50,000$ fee and describing numerous other requirements for valid applications) (on file with the Duke Law Journal). The size of the fee, especially the fact that it is non-refundable, has been criticized as a de facto decision to price nonprofit groups and applicants wishing to provide free or low-cost domain names out of the game, since they are least likely to be able to buy a $\$ 50,000$ lottery ticket. See CyberFederalist No. 3: Why ICANN's Elections Matter, Computer Professionals for Social Responsibility, at http://www.cpsr.org/internetdemocracy/cyber-fed/Number_3.html (Aug. 26, 1999) (stating that hindering such potential applicants "may not have been the intent, but it is the effect") (on file with the Duke Law Journal).

370. Joseph P. Liu, Legitimacy and Authority in Internet Coordination: A Domain Name Case Study, 74 IND. L.J. 587, 604 (1999) (footnotes omitted). 
of a line at the margin should not blind us to the very real distinctions that can be drawn between clear cases. In any event, ICANN itself has proved that it understands the distinction between technical matters and policy judgment and that it can implement this distinction. Subsequent to ICANN's takeover of IANA, the IETF and ICANN signed a memorandum of understanding concerning technical work, in which ICANN promised that it would ensure IANA followed the RFCs, or in case of "doubt or in case of a technical dispute, IANA will seek and follow technical guidance" from a management committee of the IETF. ${ }^{371}$

This technical work MoU has one particularly striking feature. It carefully distinguishes between the standards work of the IETF, which ICANN agrees to be bound by, and policy matters, which ICANN reserves to itself: "Two particular assigned spaces present policy issues in addition to the technical considerations specified by the IETF: the assignment of domain names, and the assignment of IP address blocks. These policy issues are outside the scope of this MOU." "372 Indeed, the thread of "policy" runs throughout ICANN's own internal planning. ICANN's budget projections include provisions for both standards work and policymaking. In the policy area, we find that ICANN plans to "study, recommendations and implementation of policy decisions concerning domain names, trademarks and the related provisions of the WIPO study," and "study, recommendations and implementation of policy decisions concerning expansion of the Top-level Domain (TLD) name space." ${ }^{373}$ In the longer range, ICANN plans to "[p]rovide timely and responsive staff support to the policymaking activities of the Board, its Supporting Organization Councils and other advisory bodies as needed, including policy implementation, preparation of legal agreements, etc.,"374 and, among the specific priorities: "Complete Board policy-making and related implementation actions for gTLD registries and registrars; Complete Board policy-making and related implementation actions on revisions

371. IETF-ICANN Memorandum of Understanding Concerning the Technical Work of the Internet Assigned Numbers Authority, $\S 4$, at http://www.icann.org/general/ietf-icann-mou01mar00.htm (Mar. 10, 2000) (on file with the Duke Law Journal). Interestingly, this MoU defines "IANA" as "IANA-Internet Assigned Numbers Authority (a traditional name, used here to refer to the technical team making and publishing the assignments of Internet protocol technical parameters). The IANA technical team is now part of ICANN." Id.

372. Id. $§ 4.3$.

373. 2000-01 Budget, supra note 41, § IV.1.

374. Id. § IV.2.A. 
to ICP-1 dealing with delegation and administration of ccTLDs." ${ }^{375}$ All this policy work naturally requires a senior policy officer, and ICANN has one, in the person of one Andrew McLaughlin. ${ }^{376}$ It is also recruiting a policy analyst. ${ }^{377}$

Partisans of the private-party story might object that any claim that ICANN regulates or makes policy founders on the voluntary nature of the contract between a registrant and a registry. No one is forced to register a domain name, and if ICANN, or even DoC, imposes a term on those contracts that someone doesn't like, they can do without. That participation in the legacy DNS is, for all practical purposes, the only way to get a unique domain name that has real utility is not relevant, the argument goes, because having a domain name is an option, not a necessity. This attempt to set a "luxury" test on the government's (or the government's agents') power to impose conditions on the public is misguided. Even in Thomas v. Network Solutions, Inc. ${ }^{378}$ where the district court held that NSI's domain name registrations fees were not an illegal tax because the fees were paid "pursuant to a voluntary contract between private parties," the court recognized that this principle has limits. ${ }^{379}$ True, the district court rejected the argument that the fees were not really voluntary at all because "NSF, a government agency, has stacked the system so that users are forced to contract with NSI to receive the services they need," ${ }^{380}$ but its reasoning is instructive. The district court held that "a contract is not involuntary because it flows from a monopoly, even if

375. Id. § IV.2.B. In addition, ICANN itself once admitted that it was making policy. In its 1999 status report to DoC, ICANN complained that NSI was refusing to bow to ICANN's "policy authority." Status Report to the Department of Commerce, § IV, at http://www.icann.org/ statusreport-15june99.htm (June 15, 1999) (on file with the Duke Law Journal) [hereinafter Status Report]. Similarly, Amendment 11 and the NTIA's report to the House Commerce Committee both speak of policy decisions that ICANN will be called upon to make. See Pincus, supra note 43 ("Under Amendment 11, NewCo's Responsibilities specifically include the establishment and implementation of DNS policy and the terms, including licensing terms, applicable to new and existing gTLDs and registries under which registries, registrars and gTLDs are permitted to operate." (paraphrasing White Paper, supra note 15, at 31,751)).

376. See ICANN Officers: Andrew McLaughlin, at http://www.icann.org/biog/mclaughlin. htm (last visited Aug. 19, 2000) (on file with the Duke Law Journal).

377. See 2000-01 Budget, supra note 41, § V (5)(a) (including the position, then vacant, in ICANN's organization plan).

378. 2 F. Supp. 2d 22 (D.D.C. 1998), aff'd on other grounds, 176 F.3d 500 (D.C. Cir. 1999). The plaintiffs did not pursue the illegal tax issue before the court of appeals. See Thomas v. Network Solutions, Inc., 176 F.3d 506, 506 n.8 (D.C. Cir. 1999).

379. Network Solutions, Inc., 2 F. Supp. 2d at 35-36.

380. Id. at 35 . 
the government (or its agent) holds that monopoly, as long as the monopolist is merely servicing an existing need, and not ... creat[ing] the need itself." $" 381$ The contrast with the UDRP could not be more clear.

Unlike the federally provided electricity in Yosemite Park and Curry Co. v. United States, ${ }^{382}$ the case on which the Thomas court relied, the party to the contract - the registrants-have no need or desire for the UDRP or for the arbitration services provided by ICANN-approved suppliers. The need for the UDRP was felt by third parties only, and it therefore would not be reflected in the contract between the registrant and the registrar "even if the government were not involved"- thus it cannot be said to be "merely servicing ... [a] need. $" 383$

The claim that ICANN is exercising governmental regulatory functions is not new. The EU Commission noted that "even within their narrowly defined remit, it is already the case that ICANN and the [Governmental Advisory Committee] are taking decisions of a kind that governments would, in other contexts, expect to take themselves in the framework of international organizations." ${ }^{384}$ Not only is ICANN making regulatory choices for the whole DNS, but the structure of the contracts set up by DoC make ICANN into the regulator of the registries and even the registrars. In particular, ICANN is now NSI's regulator. Amendment 19 to the DoC-NSI agreement states that NSI recognizes ICANN as NewCo. As a result, DoC's "[s]upervision $[\mathrm{u}]$ nder [c]ooperative [a]greement [g]oes [m]ostly [d]ormant" ${ }^{385}$ as most NSI obligations to DoC become satisfied by compliance with NSI's agreement with ICANN or with the ICANNdrafted registrar agreement.

\section{B. DoC's Relationship with ICANN}

DoC's relationship with ICANN is defined by two sets of opposite claims that are hard, perhaps legally impossible, to reconcile. On the one hand, DoC retains ultimate control over the root, and enjoys

\footnotetext{
381. Id. at 35-36 (emphasis added).

382. 686 F.2d 925 (Ct. Cl. 1982).

383. Network Solutions, Inc., 2 F. Supp. $2 \mathrm{~d}$ at 36.

384. Commission of the European Communities, supra note 43, at 9.

385. Louis Touton, Outline of the ICANN/NSI/Department of Commerce Agreements, Presentation to European Commission Staff, slide 13, European Internet Forum, at http://www.ispo.cec.be/eif/InternetPoliciesSite/InternetGovernance/Presentations/EC-NSI_ Agreements/sld001.htm (Nov. 15, 1999) (on file with the Duke Law Journal).
} 
very substantial sources of leverage over ICANN, so much so that it almost amounts to de facto control. On the other hand, DoC committed itself to "privatizing" the governance of the DNS, and its statements and actions since are consistent with a desire to avoid being seen to control the DNS and with allowing ICANN maximum freedom of action.

This section examines DoC's continuing control over the legacy root and the implications of that control for DoC's current relationship with ICANN. In light of these factors, it then discusses whether ICANN is a state actor, whether DoC retains a right to review ICANN's decisions before they go into effect, and whether ICANN is an advisory committee to DoC. Two simple dichotomies lie at the heart of each of the these issues: is ICANN legally independent of DoC or under its influence; and, if ICANN is legally independent of DoC, has DoC given ICANN (temporary) license to make final decisions regarding the root, or has DoC retained a right of review? Opinions may differ as to the most correct answers to these questions given the facts set out above, but in the long run that makes no difference. Once one accepts that ICANN is doing something more than simply issuing technical standards, so long as one provides consistent answers to these questions, DoC's relationship with ICANN violates a legal rule, however one slices it.

1. DoC's Continuing Control over the Legacy Root. Despite ICANN's seeming ability to run the root, and its supervisory role over NSI, DoC maintains that the U.S. government, not ICANN, retains ultimate "policy control" over the root and that DoC has no current plans to let go of that authority. ${ }^{386}$

Certainly, until ICANN came along, the U.S. government's de facto control over the root was clear, if not often exercised. Examples include the original policy against registering multiple domain names, commercial uses, and a number of NSF policies directed to encourage use of the Internet, including making registration easy. ${ }^{387}$ The policy that domains could be reserved without payment ${ }^{388}$ has its origins in

386. See supra note 43 .

387. See, e.g., NSF9224-Network Information Services Manager(s) for NSFNET and NREN, National Science Foundation, at http://www.nsf.gov/pubs/stis1992/nsf9224/nsf9224.txt (Mar. 19, 1992) (describing contract requirements designed, inter alia, to make registration simple) (on file with the Duke Law Journal).

388. See RONY \& RonY, supra note 10, at 219. 
NSF's insistence that registration be easy. ${ }^{389}$ And NSF itself believed that domain names were subject to its control, and thus Congress's, noting that " $\mathrm{t}]$ he people, through their elected representatives, have historically exercised control over these internet addresses" and that "[g]overnment authority over internet addresses, which continues to be administered under federal awards, is a matter of historical fact., ${ }^{390}$ The Second Circuit had no trouble finding that NSF controlled new gTLDs and that NSI acted at its instruction. ${ }^{391}$

Similarly, although ICANN admits that domain name registrars and registries (i.e., NSI) are subservient to it, in that they must accept ICANN's conditions to be allowed to sell registrations and make entries in the legacy root, it says that DoC imposed this subservience. ICANN says it is only doing what the government tells it because the ICANN-DoC MoU requires ICANN "to accredit competitive registrars before they may access the .com, .org, and .net registries," and "the effect of this accreditation is governed by Amendment 11 of the Cooperative Agreement between NSI and the USG and the USG's inherent control over the operation of these registries. ${ }^{392}$ In other words, the real regulation, ICANN says, either happens elsewhere or happens only because the government makes ICANN do it.

In operational terms, DoC's authority over ICANN and the root rests on three elements: its agreements with NSI, its ability to hold a virtual sword of Damocles over ICANN, and its direct cooperation with and supervision of ICANN.

First, despite the network of agreements among ICANN, DoC and NSI, ICANN does not have the authority to create a new TLD without DoC's approval. NSI, which continues to physically operate

389. In an earlier age, the government exercised power over large segments of the network. For example, in setting policies for the ARPANET and the NSFNet, both precursor networks, the government limited traffic to various types of noncommercial uses. See generally Brian Kahin \& Bruce McConnell, Towards a Public Metanetwork: Interconnection, Leveraging, and Privatization of Government-Funded Networks in the United States, in PRIVATE NETWORKS Public OBJeCtives (Eli M. Noam \& Aine M. Nishuilleabhain eds., 1996) (comprehensively describing the government's role in the development of the Internet), available at http://www.columbia.edu/dlc/wp/citi/citi488.html (last visited Aug. 19, 2000) (on file with the Duke Law Journal).

390. Memorandum from W. Bordogna, Deputy Director (Acting), Office of the Inspector General, to the Inspector General (Apr. 17, 1997), Bureau of National Affairs, http://www.bn.acom/e-law/docs/nsfnsi.html (on file with the Duke Law Journal).

391. See Name.Space, Inc. v. Network Solutions, Inc., 202 F.3d 573, 583 (2d Cir. 2000).

392. Pincus, supra note 43. 
the root, remains obliged to secure written approval from DoC before adding any top-level domains to the root. ${ }^{393}$

Second, DoC's retention of the power to take control of the root away from ICANN is of enormous significance, as it forces ICANN to be exquisitely conscious of DoC's requirements. If ICANN fails to meet DoC's expectations, DoC can choose another body to replace ICANN ${ }^{394}$ All of the relevant agreements provide that if DoC recognizes another entity as "NewCo" in ICANN's place, then the obligations to ICANN in those agreements immediately terminate. ${ }^{395}$ The point bears repeating: ICANN's only reason for existence, and the sole source of its power over the DNS, is that the thirteen root servers treat it as authoritative, and that the government instructed NSI, another contractor, both to defer to ICANN on policy and to pay it money. The root servers recognize ICANN only because DoC signed an MoU with ICANN and announced that ICANN is the relevant authority. Were the U.S. government to transfer its recognition to another authority, the root servers would be under no more legal obligation to recognize that new authority than they were to recognize ICANN, but the move is all but certain..$^{396}$ So long as the root servers recognize ICANN's authority, ICANN is able to dictate contractual terms to registries and registrars who wish to be included in the legacy root. By dictating terms to registrars, ICANN can also enforce terms on registrants, since ICANN can (and does) require that registrars include standard terms in contracts with registrants.

Third, DoC and ICANN have a warm and cooperative relationship, although whether that relationship is best characterized as a partnership, master-servant, or self-regulatory body and supervising agency is hard to discern. Whatever the precise nature of the relationship, it certainly is not arms-length. In particular, it cannot reasonably

\footnotetext{
393. See Amendment 11, supra note 82 .

394. See Memorandum of Understanding, supra note 47, at 7; Memorandum of Understanding, Amendment 1, supra note 90.

395. Thus, for example, the Registry Agreement states:

In the event that, prior to the expiration or termination of this Agreement under Section 14 or 16(B), the United States Department of Commerce withdraws its recognition of ICANN as NewCo under the Statement of Policy pursuant to the procedures set forth in Section 5 of Amendment 1 (dated November 10, 1999) to the Memorandum of Understanding between ICANN and the Department of Commerce, this Agreement shall terminate.

ICANN-NSI Registry Agreement, supra note 42, § 24.

396. But see supra notes 89-90 and accompanying text (noting ICANN's effort to formalize relationships with root servers and speculating about the consequences).
} 
be characterized as DoC calling ICANN into being, signing an MoU with it to give it authority, and letting it go off on its own. ${ }^{397}$ Indeed, from the first, DoC planned to be heavily involved with ICANN on a continuing basis. Although DoC did not pay ICANN in the DoCICANN MoU (other than payment in kind by lending it the root), DoC promised to devote more than a quarter of a million dollars in staff time and expenses to monitoring and helping ICANN. DoC estimated that staff support alone would equal half-time dedication of four or five full-time employees. ${ }^{398}$ When first asked, a DoC official told a House Subcommittee that, “[t]he Department's general oversight under the joint project is limited to ensuring that ICANN's activities are in accordance with the joint project MOU, which in turn requires ICANN to perform its MOU tasks in accordance with the White Paper., ${ }^{399}$ But, when pressed for specifics, DoC admitted that it "consults" with ICANN before its major decisions, such as ICANN's proposal to charge a fee of $\$ 1$ per domain name..$^{400}$

DoC supported ICANN during its first thirteen months by pressuring its other contractor, NSI, to recognize ICANN. ${ }^{401}$ Indeed, DoC and ICANN closely coordinated a strategy designed to get NSI to accept a subordinate position as an ICANN-accredited registrar. Thus, for example, ICANN's June 1999 status report noted that

397. Consider, for example, ICANN's fulsome but accurate thanks to NTIA's Becky Burr: Along with her colleagues at the Department of Commerce, she played an essential facilitating role in not only the creation of ICANN, but also in its creation of contractual relationships with many of the important elements of the Internet community which have been and will be instrumental in its continued viability as an effective global, private sector, consensus creation body.

It would not be an overstatement to conclude that, without the enormous contributions of Becky Burr, ICANN would not be here today, or at a minimum would not have made the very significant progress that is reflected at this meeting. She could not have done it alone, but we could not have done what we have done without her tireless devotion to the objective of a viable and effective ICANN.

Yokohama Report, supra note 89, at 12-13.

398. See Memorandum of Understanding, supra note 47, at 7.

399. Pincus, supra note 43.

400. See id.; see also GAO Report, supra note 28, at 23 (discussing the cooperation between ICANN and DoC regarding the above-mentioned fee).

401. See, for example, DoC's statement that:

Network Solutions has indicated that it is not obligated to enter into a contract with ICANN because the Department of Commerce has not "recognized" ICANN by transferring authority over the authoritative root system to it. We find no merit in this argument. The Department of Commerce entered into a Memorandum of Understanding with ICANN on November 25, 1998. That MOU constitutes the Government's "recognition" of ICANN. We reiterated this point in a letter to Network Solutions on February 26, 1999.

Pincus, supra note 43. 
"DOC/ICANN" agreed that NSI should became an ICANNaccredited Registrar and "accept the policy authority of ICANN.",402 ICANN also complained that NSI was simultaneously taking part in ICANN's activities while funding ICANN's critics. Because ICANN and DoC were afraid that NSI might do something that "could have adverse implications for the short-run stability of the domain name system"-presumably the threat to operate an alternate root"ICANN and DOC are taking prudent steps necessary to be able to implement the White Paper objectives with or without the cooperation of NSI." ${ }^{403}$ The tripartite agreement signed in November 1999 would have been impossible without DoC's intervention and its willingness to stand as guarantor of the parties' good behavior. And DoC demanded, and got, NSI's promise not to compete with ICANN's root. ${ }^{404}$

Not surprisingly, given the dire consequences of angering DoC and DoC's close supervision/cooperation, ICANN's initial actions have closely tracked those contemplated by the White Paper. Indeed, in June 1999, ICANN itself boasted that the White Paper "principles formed the basis of the MOU, and have dictated ICANN's policy decisions to date. ${ }^{\$ 405}$

2. Nature of DoC's Authority to Review ICANN's Decisions. If there had been any doubts about the extent of the federal government's view of its authority over the root, those doubts were answered by NSF's assertion of authority in reaction to the PGP Media case. ${ }^{406}$ NSF transferred its authority to DoC. DoC then entered into a series of agreements with ICANN. Although it is clear that DoC's authority fully reverts to it in the event that it terminates the agreements or they lapse of their own accord, DoC's formal role during the life of the agreements is less transparent.

Other than requests for new entries to the root, which by Amendment 11 require explicit written authorization from DoC to $\mathrm{NSI},{ }^{407}$ there are no (publicly) defined procedures by which DoC reviews ICANN's work, nor are there any public procedures in place for determining whether ICANN's lease on the root deserves to be

\footnotetext{
402. Status Report, supra note $375, \S \mathrm{IV}$.

403. Id.

404. See id.

405. Id. § I.

406. See supra notes 160-62 and accompanying text.

407. See Amendment 11, supra note 82, at 8.
} 
renewed or made permanent. Nor does DoC publish its decisions regarding ICANN's regulatory activities. This contrasts with other regulatory agencies' relationships with self-regulatory organizations. In most other cases, an agency that relies on rules promulgated by a private or quasi-private body does so on the basis of a congressional direction and puts in place some sort of review before rubberstamping the output of self-regulation. The SEC, for example, engages in informal rulemaking, including full notice and comment and ultimate publication in the federal register, before accepting the rules of regulated exchanges. ${ }^{408}$

In addition to giving ICANN its initial marching orders in the White Paper-supplemented by the ICANN-DoC MoU, the CREDA, the IANA function contract, and the continuing informal contacts described above ${ }^{409}-$ DoC retains considerable authority to review and countermand ICANN's decisions. Indeed, this authority is so sweeping that as a practical, and, this subsection argues below, legal, matter, any decision of ICANN's other than truly technical matters ${ }^{410}$ is subject to DoC's approval. If this is the case, then ICANN's policy decisions take effect only because DoC has at least passively approved them.

The agreements between DoC and ICANN are either couched as cooperative agreements between equals, or, in the case of the IANA function, as procurement of a zero-cost service. In none of these agreements does DoC purport to give up any of its control over the root. As a matter of longstanding doctrine therefore, DoC's authority is unimpaired. As the Supreme Court explained in 1908,

The surrender, by contract, of a power of government, though in certain well-defined cases it may be made by legislative authority, is a very grave act, and the surrender itself, as well as the authority to make it, must be closely scrutinized. No other body than the supreme legislature... has the authority to make such a surrender, unless the authority is clearly delegated to it by the supreme legislature.... Specific authority for that purpose is required.... But for the very reason that such a contract has the effect of extinguishing

408. See, e.g., Order Approving Proposed Rule Change to Rescind Rules 5 and 6, the Exchange's Off-Board Trading Rules, and to Make Conforming Changes to Rules 25, 317, 900 and 959, 65 Fed. Reg. 36855 (June 12, 2000) (explaining the SEC's approval of a rule change to eliminate off-board trading restrictions); see also 15 U.S.C. $§ 780-3$ (1994) (granting the SEC considerable discretion in its regulation of registered securities associations).

409. See supra note 398-400 and accompanying text.

410. See infra notes 675-77 and accompanying text (discussing the definition of "technical"). 
pro tanto an undoubted power of government, both [the existence of the promise to cede an aspect of sovereignty] and the authority to make it must clearly and unmistakably appear, and all doubts must be resolved in favor of the continuance of the power. ${ }^{411}$

The insistence of the courts throughout this century on a clear surrender of authority makes it evident that, in its absence, DoC's power to make all forms of DNS policy is unimpaired. ${ }^{412}$ Indeed, I argue below that any surrender by DoC of its right to review all of ICANN's decisions would be a violation of the nondelegation doctrine of the Constitution.

Yet, for all DoC's unimpaired authority, the fact remains that most of the time when ICANN makes a decision other than to add a TLD to the root, DoC is officially silent. When DoC disagrees with a decision, such as the $\$ 1$ per domain name fee, DoC works by informal processes. ${ }^{413}$ Nevertheless, I argue below that because DoC has the authority to disapprove ICANN's decisions, its choice not to is reviewable under the APA, whether or not it is formally memorialized or even the subject of conscious choice. ${ }^{414}$ As the Ninth Circuit noted, this silence tells one little, because "nondisapproval requires neither publication and comment nor explicit findings. In fact, it does not guarantee any level of review whatsoever." ${ }^{415}$ As the APA defines "agency action" to include "the whole or a part of an agency rule, or-

411. Home Tel. \& Tel. Co. v. Los Angeles, 211 U.S. 265, 273 (1908); see also Chiglades Farm, Ltd. v. Butz, 485 F.2d 1125, 1134 (5th Cir. 1973) (upholding a celery marketing order on the basis that the Secretary of Agriculture retains ultimate authority over an industry committee composed of private producers); R.H. Johnson \& Co. v. SEC, 198 F.2d 690, 695 (2d Cir. 1952) (holding that the SEC did not unconstitutionally delegate powers to the National Association of Securities Dealers, because it retained power to approve or disapprove rules and to review disciplinary actions); National Park \& Conservation Ass'n v. Stanton, 54 F. Supp. 2d 7, 19 (D.D.C. 1999) ("Delegations by federal agencies to private parties are, however, valid so long as the federal agency or official retains final reviewing authority.").

412. See United States v. Cherokee Nation of Okla., 480 U.S. 700, 707 (1987) (refusing to imply a waiver of sovereign authority without unmistakable evidence of an intent to surrender that authority); Bowen v. Public Agencies Opposed to Soc. Sec. Entrapment, 477 U.S. 41, 52-53 (1986) (requiring a clear surrender of authority); Merrion v. Jicarilla Apache Tribe, 455 U.S. 130, 148 (1982) ("[S]overeign power, even when unexercised, is an enduring presence that governs all contracts subject to the sovereign's jurisdiction, and will remain intact unless surrendered in unmistakable terms.").

413. In the case of the $\$ 1$ fee, DoC, presumably having initially supported the charge, appears to have then changed its mind in the face of the Bliley committee hearing. DoC thus sent ICANN a letter outlining its concerns, and ICANN changed its policy. See Burr, supra note 284. The letter was not, however, even an informal adjudication reviewing ICANN's decision.

414. See infra notes 507-19 and accompanying text.

415. Wileman Bros. \& Elliott v. Giannini, 909 F.2d 332, 338 (9th Cir. 1990). 
der, license, sanction, relief, or the equivalent or denial thereof, or failure to act," ${ }^{416}$ it seems clear that "nondisapproval" is a form of agency action subject to review under APA section 706.

Arbitrary and capricious review is not searching, but neither is it toothless. Many of the decisions that DoC and ICANN are likely to make would survive it - if supported by an adequate record. Probably the single largest change that would be imposed by recognizing the applicability of section 706 is that it would force DoC to make a record justifying its decisions. However, some of ICANN's most arbitrary decisions would be unlikely to survive a section 706 challenge. For example, a rule that allows losing plaintiffs years to go to court for a second chance to acquire a contested domain name but gives losing defendants only ten days to file to retain what they believe to be their legal rights seems quite arbitrary, and might even violate the Due Process Clause or the Equal Protection Clause.

3. The State Actor Question. ICANN is currently able to take measures such as the UDRP because it is formally independent from DoC. ICANN is a California nonprofit corporation. It is not a federal agency. It has a board of directors, a staff, and a budget. As a formal matter there is no question that ICANN has independent legal existence and personality. Form, however, is not everything; substance matters. ${ }^{417}$ Given that DoC called for an ICANN to exist, clothed it with authority, persuaded other government contractors to enter into agreements with it (including the one with NSI that provides the bulk of ICANN's revenue), and has close and continuing contacts with ICANN, a strong, but not unassailable, case can be made that ICANN is a state actor. If ICANN is a state actor, then it

416. 5 U.S.C. $\$ 551(13)$ (1994).

417. As the Supreme Court stated in its ruling that Amtrak was subject to the First Amendment despite a clause in its federal corporate charter stating that it was not a government agency:

[Courts will determine what is] a Government entity for purposes of determining the constitutional rights of citizens affected by its actions. If Amtrak is, by its very nature, what the Constitution regards as the Government, congressional pronouncement that it is not such can no more relieve it of its First Amendment restrictions than a similar pronouncement could exempt the Federal Bureau of Investigation from the Fourth Amendment. The Constitution constrains governmental action "by whatever instruments or in whatever modes that action may be taken." 
must comply with due process. ${ }^{418}$ It is highly unlikely that the procedures used to impose the UDRP on domain name registrants would meet this standard, and it is even debatable whether the UDRP itself would do so.

The Supreme Court recently reviewed and restated the test for state action in a case that bears some similarity to DoC's reliance on ICANN's UDRP; the differences between the circumstances in that case and those surrounding the UDRP, however, are as instructive as the similarities. American Manufacturers Mutual Insurance Co. v. Sullivan ${ }^{419}$ concerned a section 1983 challenge to insurers' invocation of a Pennsylvania Workers' Compensation statute that allows insurers to withhold payments for disputed treatment pending a "utilization review" conducted by a private, state-regulated "utilization review organization" (URO). Insurers trigger the review by filing a short form with a state bureau, which then randomly selects a URO from its list of qualifying medical service providers. ${ }^{420}$ Applying for the review suspends the insurer's obligation to make payments, which resumes only if the URO finds the treatment justified, or, if the URO finds the treatment was not justified, if the worker wins an appeal to a state agency or, ultimately, a court. ${ }^{421}$ Plaintiff workers sued, arguing that the procedure deprives them of a due process pre-deprivation right to notice and a hearing. ${ }^{422}$ The Third Circuit held that the state's participation in the launching of the review, and its extensive regulation of the UROs and workers' compensation generally, made the insurers state actors when they used the UROs. ${ }^{423}$

Chief Justice Rehnquist, writing for the Court, held that there was no state action on the part of the insurers. He began by restating

\footnotetext{
418. See Goss v. Lopez, 419 U.S. 565, 572 (1975) (invalidating any state action that deprives a person of a protected life, liberty, or property interest without due process of law).

419. 526 U.S. 40 (1999).

420. See id. at 46.

421. See id. at 47.

422. See id. at 48. The URO procedure in force at the time of the lawsuit provided for notice to the employee that there was a challenge, but neglected to inform him or her that it could result in suspension of medical benefits during the pendency of the proceedings. It also lacked any means by which the employee could make representations to the URO, although the employee's medical provider did get an opportunity to explain the motivation behind the proposed course of treatment. See Sullivan v. Barnett, 139 F.3d 158, 164 (3d Cir. 1998), rev'd, 526 U.S. 40 (1999). After the Third Circuit's decision, the Pennsylvania state agency that managed the process changed the procedures to require fuller disclosure and also to allow employees the option of submitting a written statement. See Sullivan, 526 U.S. at 46 n.3.

423. See Sullivan, 526 U.S. at 48-49.
} 
the basic tests for state action. First, the " $[\mathrm{t}]$ he mere fact that a business is subject to state regulation does not by itself convert its action into that of the State." ${ }^{424}$ Thus, a private party

will not be held to constitutional standards unless "there is a sufficiently close nexus between the State and the challenged action of the regulated entity so that the action of the latter may be fairly treated as that of the State itself." Whether such a "close nexus" exists ... depends on whether the State "has exercised coercive power or has provided such significant encouragement, either overt or covert, that the choice must in law be deemed to be that of the State. ${ }^{425}$

On the facts of the Sullivan case, the Chief Justice found that there was an insufficient nexus, since by creating a right to apply to UROs the state was only providing "encouragement" to insurers rather than requiring them to use the URO procedure; similarly, the state did not seek to influence the outcomes of individual cases. Rather, all the state did was "enable" the procedure, and give legal effect to its outcome. ${ }^{426}$

In Sullivan, a section 1983 action, the plaintiffs were not challenging the validity of the Pennsylvania statute authorizing insurers to withhold payments if they prevailed before a URO, but rather were claiming that the action of the insurers, who initiated the URO review by filing a form, was itself state action. ICANN's imposition of the UDRP differs from Sullivan in who the actor is, what the action is, and who is acted upon; each of these differences suggests that the argument for state action in the case of ICANN is much stronger than in Sullivan.

Sullivan involved action in the shadow of a statute. In contrast, part of the problem with ICANN's somewhat similar imposition of the UDRP is precisely that there is no such statute: The Pennsylvania legislature imposed the UROs on workers by making their decisions legally effective; ICANN, not Congress, imposed the UDRP on registrants by requiring that all registrars include standard form thirdparty beneficiary clauses in their contracts. ${ }^{427}$ The Pennsylvania legis-

424. Id. at 52 (quoting Jackson v. Metropolitan Edison Co., 419 U.S. 345, 350 (1974)).

425. Id. (quoting Jackson, 419 U.S. at 350); see also Lugar v. Edmondson Oil Co., Inc., 457

U.S. 922, 937 (1982) (describing a two-part "fair attribution" analysis for the requisite nexus).

426. Sullivan, 526 U.S. at 53-54.

427. See UDRP, supra note 20. 
lature's action was classic, and procedurally legitimate, state action, ${ }^{428}$ the issue is whether the nexus between ICANN and DoC is sufficiently tight to compel the conclusion that ICANN stands in the shoes of the state (DoC) when it imposes the cognate requirement on registrars who must then impose it on registrants. ${ }^{429}$ The Sullivan case does suggest that if Congress were to create an arbitration regime for domain name disputes, then the actions of trademark holders in bringing complaints would not be state action, as indeed they most likely are not under the current regime. Nothing makes a trademark holder invoke the UDRP any more than Pennsylvania law made insurers apply to UROs. ${ }^{430}$

The ICANN problem differs from the Sullivan facts in ways that shape the state action analysis. The main problem with ICANN's UDRP is not the effect on trademark holders; it is ICANN's regulation of registrars and, through them, of registrants. Unlike trademark holders or Pennsylvania insurers, registrars and registrants subject to ICANN's rules do not have a choice about the UDRP. ICANN does not allow registrars to deviate from ICANN's mandatory terms in the contracts the registrars offer to their clients. ICANN requires registrars to make domain name registrants in .com, .org, and .net sign a third-party beneficiary agreement that can be invoked by any aggrieved party in the world. If Congress imposed these conditions through legislation, that would of course be procedurally legitimate state action; the procedures created by that legislation would have to conform to due process. Significantly, defendants in Sullivan changed

428. Cf. Sullivan, 526 U.S. at 53 (characterizing the Pennsylvania statute as a "a legislative decision not to intervene in a dispute").

429. In fact, however, the difference with Sullivan is even sharper, because if ICANN is DoC's agent it is violating the law as well as the Constitution. DoC would not have been able to impose the UDRP directly, because Congress has enacted a flat prohibition on such mandatory arbitration schemes in connection with federal programs. See infra notes 519-22 and accompanying text.

430. Conversely, in Sullivan, the Chief Justice suggested that due to the heavily regulated nature of the URO procedure, "the decision of a URO, like that of any judicial official, may properly be considered state action." Sullivan, 526 U.S. at 54. As ICANN, acting in conformity with the policy set out in the White Paper, has written both the substantive rules applied in the UDRP, see UDRP, supra note 20, and the bulk of the procedural rules that arbitration providers must observe, see UDRP Rules, supra note 354, it follows that if ICANN is a state actor then arguably dispute providers are state actors also. For an interesting discussion of the constitutional status of alternate dispute resolution, which suggests that ADR should, at least sometimes, be seen as part of the public provision of civil justice and hence subject to some due process constraints, see generally Richard C. Reuben, Constitutional Gravity: A Unitary Theory of Alternate Dispute Resolution and Public Civil Justice, 47 UCLA L. REV. 949 (2000). 
their procedures rather than appealing the Third Circuit's holding that elements of the Pennsylvania URO plan violated due process by providing inadequate notice and failing to give employees a chance to plead their case properly. ${ }^{431}$ Were Congress to attempt to impose a plan like the UDRP, similar questions would then be squarely presented for judicial review. In the case of existing DNS regulation, however, the state action issue must be decided first. The critical issue therefore concerns the purported nexus-whether when the government calls for an ICANN to impose requirements for it, and an ICANN duly appears and does so, ICANN's actions can fairly be charged to the government.

As Sullivan reminds us, determining whether governmental authority may dominate an activity to such an extent that its participants should be deemed to act with the authority of the government, and, as a result, be subject to constitutional constraints, ${ }^{432}$ is a critical question in state action cases ${ }^{433}$ and one that is primarily a question of fact. ${ }^{434}$ In Edmonson v. Leesville Concrete Co., ${ }^{435}$ the Supreme Court provided three factors to be weighed: first, "the extent to which the actor relies on governmental assistance and benefits"; 436 second, "whether the actor is performing a traditional governmental function"; ${ }^{437}$ and third, "whether the injury caused is aggravated in a unique way by the incidents of governmental authority."

These three tests suggest that ICANN is a state actor. First, ICANN depends very heavily on government assistance and benefits. ICANN would be irrelevant but for DoC having anointed it as

431. See Sullivan, 526 U.S. at 46 n.3.

432. See Edmonson v. Leesville Concrete Co., Inc., 500 U.S. 614, 622 (5th Cir. 1991). A private party's conduct is government action only if it has its source in the exercise of a right or privilege having its source in state authority. See Lugar v. Edmondson Oil Co., Inc., 457 U.S. 922, 939-41 (4th Cir. 1982).

433. See Sullivan, 526 U.S. at 51 ("Our approach to this latter question begins by identifying 'the specific conduct of which the plaintiff complains."') (quoting Blum v. Yaretsky, 457 U.S. 991, 1004 (1982)).

434. See Edmonson, 500 U.S. at 621.

435. Id.

436. Id. at 621 (citing Tulsa Prof. Collection Servs., Inc. v. Pope, 485 U.S. 478 (1988); Burton v. Wilmington Parking Auth., 365 U.S. 715 (1961)).

437. Id. (citing Terry v. Adams, 345 U.S. 461 (1953); Marsh v. Alabama, 326 U.S. 501 (1946); San Francisco Arts \& Athletics, Inc. v. United States Olympic Comm., 483 U.S. 522, 544-45 (1987)).

438. Id. at 622 (citing Shelley v. Kraemer, 334 U.S. 1 (1948)). For a discussion of these factors, see G. Sidney Buchanan, A Conceptual History of the State Action Doctrine: The Search for Governmental Responsibility (pt. 2), 34 Hous. L. REV. 665, 728-33, 756-64 (1997). 
NewCo and lent it control over the root. The second test focuses on the nature of the function being performed. DNS services have been a government function since the inception of the domain name system. The federal government's provision of root DNS services is thus unlike the provision of electricity in Jackson v. Metropolitan Edison Co. ${ }^{439}$ because (until ICANN) the DNS has been "exclusively the province of the state"- through the offices of the military and government contractors. But whether DNS services can be said to be a "traditionally" governmental function, given the relative youth of the Internet, is a little harder to say. In the Thomas case, the D.C. Circuit found the provision of registrar services too "recent and novel" to qualify. ${ }^{440}$ The idea of a hosts.txt file, the precursor of the modern DNS, goes back at least to $1971{ }^{441}$ the modern DNS dates from about $1983 .{ }^{442}$ Twenty years, or even thirty, may be a little short for a "tradition," even though it is an eternity in "Internet Years." ${ }^{443}$ But perhaps this approach mischaracterizes the problem. For it is not ICANN that provides registry and registrar services, nor even that maintains the zone file. Rather, ICANN is fundamentally engaged in a traditional, even quintessential, government function: regulation of service providers. The fact that the objects of that regulation are relatively new types of entities is of no moment-regulation is regulation. The application of the third test, whether the harm is aggravated in a unique

439. 419 U.S. 345 (1974)

440. Thomas v. Network Solutions, Inc., 176 F.3d 500, 511 (D.C. Cir. 1999). But see National A-1 Adver., Inc. v. Network Solutions, Inc., Civ. No. 99-0033-M, slip. op. at 28-30 (D.N.H. Sept. 28,2000 ) (suggesting that domain name registrar services might be "traditional" government services, despite the argument advanced in Thomas).

441. See supra note 106 and accompanying text.

442. See supra notes $115-17$ and accompanying text.

443. Internet years are commonly said to be like "dog years"- - moving seven times as fast as human years. See, e.g., Hal R. Varian, Economic Issues Facing the Internet, School of Information Management and Systems, at http://www.sims.berkeley.edu/ hal/Papers/econ-issuesinternet.html (Sept. 15, 1996) (on file with the Duke Law Journal).

The DNS is certainly unlike "traditional government functions," such as elections, that are reserved to the state by statute; if that element of legal compulsion is required for state action as suggested by Flagg Brothers and other cases prior to Lebron v. National Railroad Passenger Corp., see Flagg Bros., Inc. v. Brooks, 436 U.S. 149, 156-60 (1978) (stating that "very few" state functions are traditionally exclusively reserved to the state, such as elections and municipal functions); see also Terry v. Adams, 345 U.S. 461, $469-70$ (1953) (holding that a "white primary" held before a county election deprived minorities of the right to vote); Marsh v. Alabama, 326 U.S. 501, 507-08 (1946) (holding that a "company town" may not violate constitutional guarantees by claiming that it is not a state actor), then ICANN may not be a state actor. However, in Edmonson, the "Court has liberated itself from the bondage of the exclusivity test" applied in those earlier cases. Buchanan, supra note 438, at 760. 
way by the incidents of government authority, depends on the context in which a state actor claim would arise. The factor may weigh differently in a complaint about a (would-be) top-level domain, whose access to the root is directly controlled by DoC, as opposed to a secondlevel domain, where the influence of DoC's control of the root is exercised through the registrars.

The leading recent cases considering whether corporations with unusually close ties to the federal government should be considered state actors are Lebron v. National Railroad Passenger Corp. ${ }^{444}$ and San Francisco Arts \& Athletics, Inc. v. United States Olympic Committee. ${ }^{445}$ In Lebron, the Supreme Court held that Amtrak was a government actor on the basis of the direct federal control spelled out in Amtrak's federal charter. The Court reached this conclusion despite a statute pronouncing that Amtrak "will not be an agency or establishment of the United States government." ${ }^{, 446}$ Lebron thus stands for the proposition that in determining whether a corporation is a government actor, the Court will look at the substance of an entity's relationship with the government rather than relying on legal formalities. Indeed, as Justice Scalia wrote for the Court, "It surely cannot be that government, state or federal, is able to evade the most solemn obligations imposed in the Constitution by simply resorting to the corporate form.'

Nevertheless, exactly how much control the government must have over a corporation before the firm becomes a government actor remains open to debate. The government's control over Amtrak was direct and complete-the government appointed a majority of Amtrak's board-so the case serves only as an upper bound in determining what degree of state control suffices to make a corporation a federal actor. Similarly, San Francisco Arts \& Athletics provides only an example of a degree of control that is insufficient. Although the government provided part of the USOC's funding ${ }^{448}$ and gave it special trademark protection, the Supreme Court held that it was not a

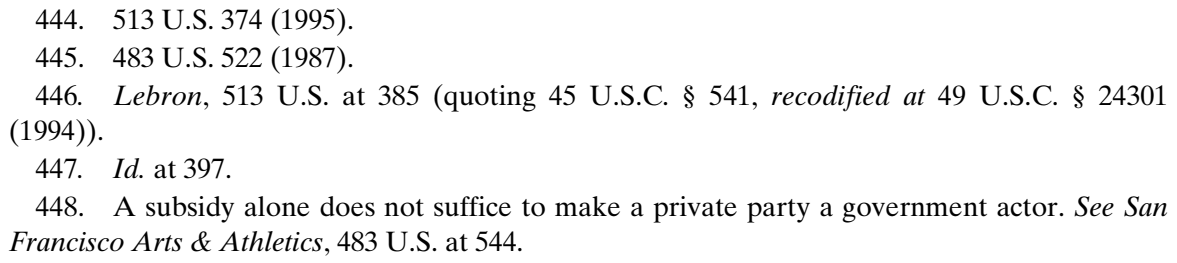


government actor. ${ }^{449}$ In reaching this conclusion, the Court offered a (perhaps overly) subtle distinction between a corporation that would be a government actor if it undertook a function that was "traditionally the exclusive prerogative" of the federal government, and the USOC, which merely "serves the public." ${ }^{450}$ More clearly, the Court noted that the USOC was not a government actor because the necessary element of government control was lacking. The United States, the Court stated, no more controlled the USOC than it did the Miss Universe pageant. ${ }^{451}$

To the extent that ICANN is executing the policies set out in the White Paper under pain of termination, ICANN very closely resembles a state actor. The White Paper is not, however, a particularly detailed document, and other than creating the UDRP, ICANN's main function is to make decisions that the federal government was politically unwilling or unable to make itself. ${ }^{452}$ The government's control over ICANN falls between the extremes of Amtrak and the USOC. On the one hand, there is no question that DoC lacks the formal control over ICANN that the Department of Transportation enjoys over Amtrak. The United States does not appoint any ICANN board members, and government officials' direct participation within the ICANN structure is limited to the Governmental Advisory Committee. On the other hand, as noted above, DoC has ICANN by the throat: it controls its major asset, all of ICANN's major contractual rights revert to the government if DoC pulls ICANN's plug, and so far at least DoC has kept ICANN on a short leash.

The case for ICANN being a state actor turns on the degree of instruction, and perhaps even continuing coordination, from DoC. As noted above, not only is there substantial evidence that ICANN is making policy and regulating, there is also substantial evidence that ICANN is doing so at the behest, tacit or overt, of the Department of Commerce. As we have seen, the ICANN-DoC MoU speaks of cooperation more than delegation; DoC not only initially enabled ICANN,

449. See id. at 543-44. In reaching the no-control finding, the Court quoted a district court's finding with approval, finding that there was no control based on the USOC's charter and the absence of any evidence of de facto control. See id. at 544 n.27 (quoting DeFrantz v. United States Olympic Comm., 492 F. Supp. 1181, 1194 (D.D.C.), aff'd, 701 F.2d 221 (D.C. Cir. 1980)).

450. Id. at 544 (quoting Rendell-Baker v. Kohn, 457 U.S. 830, 842 (1982)). Justice Brennan's dissent argued the USOC, in fact, did a traditionally governmental job-that of representing the United States to the outside world. See id. at 550 (Brennan, J., dissenting).

451. See id. at 545.

452. See supra Part II.A.5. 
but they both agreed contractually to stay in close communication with each other.

What makes ICANN different from Amtrak, and more like the USOC, is that ICANN's board is formally independent. The issue, therefore, is whether that formal independence is overcome by the totality of the relationship between ICANN and DoC. In making this determination, some guidance may be found in a recent Supreme Court decision considering a very similar issue in the context of an Establishment Clause claim. Establishment Clause jurisprudence is not identical to state action jurisprudence, ${ }^{453}$ although both lines of cases can require courts to consider whether the government should be held responsible for ostensibly private conduct. As the Establishment Clause can be violated by the appearance of endorsement of private religious speech as well as the actual support of it, ${ }^{454}$ a lower level of government control or sponsorship than would be required to find state action in other areas may suffice to trigger an Establishment Clause violation. Even with this caveat, the Supreme Court's recent decision in Santa Fe Independent School District v. Doe $e^{455}$ may be instructive. In Santa Fe, the defendant school district argued that student-led, student-initiated prayer at high school football games did not violate the Establishment Clause because it was private speech. ${ }^{456}$ The Supreme Court agreed with the distinction between public and private speech, but found the speech to be public because it was "authorized by a government policy and [took] place on government property at government-sponsored school-related events." ${ }^{457}$ Similarly, ICANN's management of the domain name system is authorized by government policy - the White Paper-and relies on its control over a federal resource, the root.

Various groups will ultimately elect ICANN's board. The intervention of an election-in which the U.S. government has no votesmight reasonably be considered to insulate ICANN's policymaking

453. For a discussion of the similarities between the two doctrines, see Alan E. Brownstein, Prayer and Religious Expression at High School Graduations: Constitutional Etiquette in a Pluralistic Society, NeXUS: A JOURNAL OF OPINION (forthcoming Spring 2000) (on file with the Duke Law Journal).

454. See Kathryn R. Williams, Recent Decision: Constitutional Law-Squeezing LemonCapitol Square Review \& Advisory Board v. Pinette, 115 S. Ct. 2440 (1995), 69 TEMP. L. Rev. 1609, 1614-15 (1996).

455. 120 S. Ct. 2266 (2000).

456. See id. at 2275. The Court contrasted a forum that is open to all with one where a single student is allowed to give invocations for the entire season. See id. at 2276.

457. Id. at 2275 . 
from state action. However, the Supreme Court has long held that "fundamental rights may not be submitted to vote; they depend on the outcome of no elections." ${ }^{458}$ The fundamental rights threatened by ICANN's activities are rights to property in domain names, the right to noninterference in contracts with registrars, rights to due process and, to the extent that domain names are or facilitate speech, First Amendment rights.

In Santa Fe, the Supreme Court was unimpressed by the use of a free election as a defense against an Establishment Clause claim and held that it did not prevent the elected person's conduct from being fairly charged to the government. Although the Establishment Clause context does not automatically translate to other forms of state action, the Court's reasoning and language is at least suggestive. The Court noted in Santa Fe that "the majoritarian process implemented by the District guarantees, by definition, that minority candidates will never prevail and that their views will be effectively silenced." Court seemed particularly concerned that in choosing to let students vote to elect a designated prayer leader, the school district knew full well which sort of opinion-the Christian prayers they had previously offered themselves-would prevail, if not necessarily exactly who would speak or what they would say. ${ }^{460}$ The parallel to ICANN is imperfect, but the Supreme Court's focus on the full context of the election provides a useful model. In approving ICANN, and in particular in requiring the corporatist constituency structure that privileges business and intellectual property owners at the expense of other domain name registrants, the government in effect rigged the game to ensure a predictable outcome. ${ }^{46}$

Whether the government chose to outsource policymaking from a noble desire to privatize and internationalize the root or for other reasons is of no legal relevance to the question of whether ICANN is a state actor. What matters most is the high degree of control and direction exercised over ICANN by DoC. It may be that some day the

458. Id. at 2276 (quoting West Virginia State Bd. of Educ. v. Barnette, 319 U.S. 624, 638 (1943)).

459. Id.

460. The Court seemed to believe that the school district used the election process as a sham to avoid earlier court decisions. See id. at 2282 ("We refuse to turn a blind eye to the context in which this policy arose ....").

461. See supra notes 218-22 and accompanying text. And, if there had been any doubt initially of the balance of power, there certainly can have been no doubt when the time came for DoC to decide whether to renew ICANN's hold on the root. See supra note 47. 
government will remove itself fully from DNS regulation. Until that day, however, ICANN arguably falls within the rule the Supreme Court summarized in NCAA $v$. Tarkanian: ${ }^{462}$ Private parties are state actors

if the State creates the legal framework governing the conduct; [or] if it delegates its authority to the private actor .... Thus, in the usual case we ask whether the State provided a mantle of authority that enhanced the power of the harm-causing individual actor. ${ }^{463}$

But for that "mantle of authority" DoC gave ICANN over the root, ICANN would be an irrelevance.

Furthermore, although the government does not directly pay ICANN, ICANN's ability to raise funds is entirely due to the government having lent ICANN a federal resource, the government's control over the root. ICANN's funds come from registries and registrars. Registrars pay to be accredited by ICANN so they can sell registrations that will be reflected in the legacy root. NSI, which was both registrar and registry, agreed to pay ICANN as part of the tripartite agreements. ${ }^{464}$ Moreover, ICANN may some day be able directly to charge registrants and ccTLD registries, and in each case its ability to compel payment will rely on whatever power it may have to control access to the legacy root. Thus, DoC's loan of control over the root is not only the sole basis of ICANN's relevance and power, but also of its income stream.

Courts also find state action when the private enterprise has multiple contacts with the government. Courts look to see if a "symbiotic relationship" ${ }^{465}$ between the public and private entities has been formed. Although the inquiry is highly contextual, ${ }^{466}$ the presence of government subsidies or aid is probative of state actor status. ${ }^{467}$ Indeed, ICANN does have a "symbiotic" relationship with DoC, and DoC has provided enormous aid to ICANN in lending it the root,

\footnotetext{
462. 488 U.S. 179 (1988).

463. Id. at 179 (citations omitted). But see San Francisco Arts \& Athletics, Inc. v. United States Olympic Comm., 483 U.S. 522, 543-45 (1987) (holding that neither the U.S. Olympic Committee's federal charter nor the fact that it represented the United States in international athletic competitions made it a state actor).

464. See supra Part II.B.5.

465. See, e.g., Rendell-Baker v. Kohn, 457 U.S. 830, 842-43 (1982) (finding no "symbiotic relationship" as related to employment decisions in the typical government contractor relationship, even when the contractor is highly regulated).

466. See Burton v. Wilmington Parking Auth., 365 U.S. 715, 722 (1961).

467. See J.K. v. Dillenberg, 836 F. Supp. 694, 698 (D. Ariz. 1993).
} 
anointing it as NewCo, and forcing NSI to come to terms with it. DoC's relationship with ICANN is different from a normal research contract in which the government defines the parameters of a study and a contractor provides information or expert analysis. ICANN is not simply thinking up new ways to manage the DNS, or providing DNS management services, or even engaged in standard setting for new technical protocols. Instead, it provides the service of making policy on new TLDs, policy on registration in existing TLDs, and policy regarding dispute resolution within gTLDs. Unlike a contractor that provides goods or implementation of a department's policy, ICANN is providing regulation services; most of the actual management of the DNS is, after all, conducted by NSI pursuant to the U.S. government's instructions, ${ }^{468}$ which now include doing what ICANN says. ${ }^{469}$

A number of court decisions have examined the federal government's relationship with corporations that provide expert advice on technical questions. Generally, these decisions hold that the corporations are to be identified with the government when the government acts as a rubber stamp, even if the government has retained a formal right to countermand their decisions. ${ }^{470}$ The publicly available evidence makes it difficult to discern the extent to which DoC actually reviews ICANN's decisions. We know that new entries to the root, such as .ps, require ratification by DoC; we know that DoC "consults" intensively with ICANN, and has the equivalent of at least two employees working full time on ICANN matters; and we know that in some cases, such as the proposed and abandoned $\$ 1$ domain name fee, DoC caused, or participated in causing, ICANN to change its

\footnotetext{
468. The Second Circuit recently held that NSI was "entitled to implied conduct-based immunity with respect to its refusal to add new gTLDs to the root zone file" because its refusal to add new TLDs was "compelled by the explicit terms of NSI's agreement with a government agency and by the government's policies regarding the proper administration of the DNS." Name.Space, Inc. v. Network Solutions, Inc., 202 F.3d 573, 582 (2d Cir. 2000).

469. There are limits to NSI's duty to obey. See supra note 42 and accompanying text.

470. For example, in Wheeling-Pittsburgh Steel Corp. v. Allied Tube \& Conduit Corp., 573 F. Supp. 833 (N.D. Ill. 1983), the court held that the National Fire Protection Association (NFPA) and Underwriters Laboratories (UL) were not private bodies but were governmental entities for Noerr-Pennington purposes, because the

wholehearted reliance upon the NFPA and UL by these governmental entities [had] resulted in a near complete delegation of governmental authority to these otherwise private entities. While the governmental bodies of course have retained the power to modify or reject the NFPA and UL recommendations, in practice they have relied completely on them.

Id. at 838 .
} 
mind. However, we also know that after calling for action against cybersquatters in the White Paper, DoC took no public role in ICANN's decision to impose the UDRP; thus, it is impossible to say how involved DoC was in formulating the decision, and what review, if any, took place at DoC after ICANN resolved to impose the UDRP on registrants. ${ }^{471}$

One thing, however, seems logically clear. Either DoC does not review ICANN decisions ${ }^{472}$ such as the decision to adopt UDRP or the coming decision as to which gTLDs to put in the root, or DoC does some sort of review. If DoC does no review, the case for calling ICANN a state actor is strong, since the body uses its control over a federal resource to affect the legal rights of citizens. On the other hand, if DoC does conduct a meaningful review, then its decisions to adopt or to allow ICANN's decisions and pronouncements to take legal effect are decisions subject to the APA.

\section{APA Issues}

[F]inal agency action for which there is no other adequate remedy in a court [is] subject to judicial review. ${ }^{473}$

When ICANN issues the UDRP or reiterates NSI's old rule that registrants must make their contact details world readable, or when it sets criteria for new gTLDs, it is doing things that prospectively affect large numbers of people. If a government agency did those things directly, we would call it "rulemaking" and require that it be carried out in compliance with the Administrative Procedure Act (APA). The agency would either have to hold one or more hearings and then issue an order with reasons or, more commonly, would have to proceed by notice and comment rulemaking. ${ }^{474}$

The APA defines a "rule" as "the whole or a part of an agency statement of general or particular applicability and future effect designed to implement, interpret, or prescribe law or policy or describing the organization, procedure, or practice requirements of an

471. See UDRP, supra note 20, § II.C.2.B.

472. Or, for this purpose, DoC subjects the decisions to minimal review of the rubber-stamp variety.

473. 5 U.S.C. $\$ 704$ (1994).

474. See id. §§551-57. 
agency." ${ }^{475}$ Unless Congress legislates otherwise, or one of the specified APA exceptions applies, agencies can only issue rules in compliance with the APA's procedural requirements, which include publishing a notice in the Federal Register, soliciting comments for at least thirty days, and responding meaningfully to public comment. ${ }^{476}$ In so doing, the agency would have to publish in the Federal Register the proposed rule with an explanation of why it is needed and why it is legal; solicit comments; issue a final rule that was predictable, or at least a logical outgrowth, from the proposed rule; and respond to all comments in a reasoned way.

1. Do APA Exceptions Apply? It might be argued that either of two APA exceptions apply to rulemaking regarding DoC's reliance on ICANN's activities. The rulemaking procedures set out in section 553 of the APA do not apply to agency actions relating to "public property, loans, grants, benefits, or contracts." ${ }^{477}$ It could be argued that DoC's agreements with ICANN are contracts; arguably, ${ }^{478}$ the DNS is "public property." If either exception applies, then DoC's rulemaking is exempt from notice and comment requirements, although the rules are still subject to review under the APA's section 706 , which instructs courts to overturn "arbitrary and capricious" agency decisions. ${ }^{479}$ In any case, neither argument for the inapplicability of section 553 should carry the day.

475. Id. § 551(4); see also Bowen v. Georgetown Univ. Hosp., 488 U.S. 204, 209 (1988) (holding that rulemaking, unlike adjudication, must be prospective rather then retrospective in the absence of clear congressional authorization to the contrary).

476. See 5 U.S.C. § 553; Chrysler Corp. v. Brown, 441 U.S. 281, 302-03, 315 (1979) (holding that only rules promulgated pursuant to congressionally granted quasi-legislative authority and in accordance with procedural requirements imposed by Congress have the force of law); Citizens to Preserve Overton Park, Inc. v. Volpe, 401 U.S. 402, 417 (1971) (holding that an agency must make a record consisting of formal findings when necessary to facilitate a full and prompt review of the agency's action); Professional Pilots Fed'n v. FAA, 118 F.3d 758, 763 (D.C. Cir. 1997) (holding that an opportunity to comment is meaningless unless the agency responds to significant points raised by the public); Home Box Office, Inc. v. FCC, 567 F.2d 9, 35 (D.C. Cir. 1977) (same); Portland Cement Ass'n v. Ruckelshaus, 486 F.2d 375, 393-94 (D.C. Cir. 1973) (same); cf. Anthony, supra note 187, at 1322-23 (enumerating six requirements for a valid legislative rule, chief of which is notice and comment).

477. 5 U.S.C. $\$ 553(a)(2)$. The agency must possess statutory authority to make the rules and intend by making the rule to use its authority. See Anthony, supra note 187, at 1322 (arguing that when agencies attempt to bind the public with nonlegislative documents, those agencies violate the APA)

478. See supra notes 82-84 and accompanying text.

479. See 5 U.S.C. $§ 706(2)(A)(1994)$. 
The courts have generally construed the contracts exception narrowly. ${ }^{480}$ The Senate Judiciary Committee report on its version of the APA noted "that the exceptions apply only 'to the extent' that the excepted subjects are directly involved." ${ }^{, 481}$ It is not at all evident that the ICANN-DoC $\mathrm{MoU}^{482}$ is a "contract" within the meaning of section 553. ${ }^{483}$ However, even if the creation of DoC's relationship with ICANN is covered by the contracts exception to section 553, the APA may still apply to DoC's subsequent actions. The decision to choose ICANN to be NewCo appears to be an informal adjudication. Subsequent decisions taken by ICANN would be rulemaking if taken directly by the government and have their effect only because of government action giving ICANN control over the root. More importantly, the use of ICANN to make prospective decisions affecting third parties during the life of the contract should fall under the APA, or the contracts exception will make increasingly large parts of the APA a dead letter.

480. See, e.g., American Hosp. Ass'n v. Bowen, 834 F.2d 1037, 1044 (D.C. Cir. 1987) ("In light of the obvious importance of these policy goals of maximum participation and full information, we have consistently declined to allow the exceptions itemized in $\S 553$ to swallow the APA's well-intentioned directive."); Rainbow Valley Citrus Corp. v. Federal Crop Ins. Corp., 506 F.2d 467, 469 (9th Cir. 1974) (noting that the public contracts exception exists because it would be unreasonable to require agencies to publish Federal Register notices and hold hearings every time they entered into, rescinded, or cancelled a government contract). But see National Wildlife Fed'n v. Snow, 561 F.2d 227, 231-32 (D.C. Cir. 1976) (suggesting a broad reach for exceptions). See generally Construction and Application of 5 USCS $\S 553($ a)(2), Exempting from Administrative Procedure Act's Rulemaking Requirements Matters Relating to Agency Management or Personnel or to Public Property, Loans, Grants, Benefits or Contracts, 41 A.L.R. FED. 926 (1979 \& Supp. 1999) (collecting cases construing the contracts exception).

481. S. REP. NO. 79-752, at 13 (1945).

482. Note that a MoU between two agencies clearly does fall under the "procedural" exception to section 553. See, e.g., Emerson Elec. Co. v. Schlesinger, 609 F.2d 898, 904 (8th Cir. 1979) (excepting certain agencies from the notice and comment provisions of section 553).

483. On the other hand, the CRADA, see supra note 47, may be: it certainly is not the case that agencies must comply with section 553 before entering into a CRADA. See Kurt M. Rylander, Scanwell Plus: Challenging the Propriety of a Federal Agency's Decision to Use a Federal Grant and Cooperative Agreement, 28 PUB. CONST. L.J. 69, 73 (1998):

[W] hile the administration and performance of contracts for property and services are subject to the FAR and its supplements, and to the claim and appeal procedures of the Contract Disputes Act (CDA) [41 U.S.C. $\S \S 601-13$ ], federal grants and cooperative agreements are subject only to informal OMB advisories and agency regulations. Further, because the CDA is inapplicable to grants and cooperative agreements, no claim or appeal rights exist for termination, breach, or other claim events related to the performance of a grant or cooperative agreement. Thus, the classification of a government agreement as either a grant or cooperative agreement on the one hand or a contract for property or services on the other plays a significant role in the definition of contractor rights and government obligations. 
The GAO recently opined that the APA did not apply to the establishment of ICANN because DoC did not cause ICANN to be established, did not materially participate in the selection of its board, and because the White Paper was vague on the trademark policy NewCo should adopt. ${ }^{484}$ Even if this last point is not completely accurate-it was pretty clear what WIPO would say about cybersquatting-it is possible to agree with the GAO that ICANN was created independently of DoC and yet believe that the APA applies to DoC's decision to enter into various agreements with ICANN. And, even if one does not believe that the APA applies to DoC's decision to enter in the CRADA and the MoU with ICANN, one may still accept that the APA applies to DoC's reliance on ICANN when that reliance amounts to rulemaking. To the extent that DoC is using its ongoing relationship with ICANN to make rules that affect third-party registrants of domain names, the contract exception of the APA does not, and should not, apply. DoC is not immunized from APA review because it used a contract to lend a corporation control over the root, especially when it is working so closely with that corporation.

Nor is DoC's approval of or acquiescence in policymaking and regulation by ICANN covered by the public property exception to section 553. First, it is not at all clear that the government "owns" the DNS, or even the root; most likely it does not have an exclusive property interest in that root zone data file, if only because the U.S. government does not hold copyrights in its published information. ${ }^{485} \mathrm{No}$ tably, DoC did not attempt to rely on the public property exception theory in either the Green Paper or in the White Paper. DoC issued the Green Paper as an ordinary notice of preliminary rulemaking, ${ }^{486}$ and it issued the White Paper as a Policy Statement. ${ }^{487}$ If DoC had believed that the public property exception allowed it to avoid the APA's rulemaking requirements, it would surely have mentioned this somewhere. Second, even if the government's interest in the root is proprietary, it is not evident that the public property exception was intended to or should apply to the disposition of an intangible intellectual property-like asset. More fundamentally, although more

\footnotetext{
484. See GAO Report, supra note 28, at 9-12.

485. If the data is property, it is intangible property; it cannot be trademarked or patented; it is public, so it is not a trade secret, leaving copyright, which the government does not have in its published work. See supra notes 83-84 and accompanying text (discussing whether the root is government property).

486. See supra notes $170-72$ and accompanying text.

487. See supra notes $185-88$ and accompanying text.
} 
broadly construed than the contracts exception, the public property exception applies to matters "relating to" public property, not ancillary matters in which control of public property is leveraged to achieve ends that have nothing to do with the sound management of the property itself. ${ }^{488}$

2. Consequences of the APA. The heart of the APA is its provision for judicial review of administrative decisions. Regardless of whether APA section 553 applies, if APA section 706 applies it allows judicial review of DoC's adoption of, or acquiescence in, ICANN's actions.

a. The founding agreements with ICANN. Although the GAO may have thought otherwise, ${ }^{489}$ there is a strong argument that the APA applies to DoC's decision to enter into, or to extend, the ICANN-DoC MoU, to the CRADA, and to the zero-cost purchase order by which ICANN took over the IANA function. DoC would no doubt argue that the APA does not apply to any DoC relations with ICANN, much less ICANN's actions, because, in its view, DoC's only actions-other than approving or disapproving additions to the root $^{490}$ - consist of entering into MoUs or (costless!) procurements with ICANN. Indeed, as a general matter, the public does not have a right under the APA to complain about the letting of a contract, the entry of a CRADA, or the signing of an MoU. The primary reason for this absence of a right to sue is lack of standing: In the ordinary case, a member of the public lacks the sort of direct personal injury that would give her standing to complain. To have standing, a plaintiff must have a concrete and actual or imminent injury fairly traceable to the conduct of the defendant, which would be redressed by a ruling against the defendant. ${ }^{491}$ Furthermore, the plaintiff must be within the

488. See Susan L. Chapin, Comment, If You Build It They Will Come: Concession Reform in the National Parks, 33 LAND \& WATER L. REV. 33, 54 (1998). But see generally Wilderness Pub. Rights Fund v. Kleppe, 608 F.2d 1250 (9th Cir. 1979) (holding that the Secretary of the Interior's 1972 freezing and apportioning of use of the Colorado River was excepted from section 553).

489. The GAO's report examined DoC's authority to create ICANN and opined that the authority existed. GAO did not comment on the reasonableness of DoC's exercise of this authority, nor on the ability of third parties to challenge the exercise of that authority. See GAO Report, supra note 28, at 2 (stating the questions it addressed). Presumably, however, if the GAO thought that DoC's actions were unreasonable it would have said so.

490. See supra note 82 .

491. See Lujan v. Defenders of Wildlife, 504 U.S. 555, 560-61 (1992); see also Animal Legal Defense Fund v. Glickman, 154 F.3d 426, 431 (D.C. Cir. 1998) (defining the standing test). 
"zone of interests" sought to be protected by the statute or constitutional provision on which they base their claim. ${ }^{492}$ But, "for a plaintiff's interests to be arguably within the 'zone of interests' to be protected by a statute, there does not have to be an indication of congressional purpose to benefit the would-be plaintiff." "493 Instead, the focus is "on those who in practice can be expected to police the interests that the statute protects." ${ }^{, 44}$

Indeed, at least two courts have found that non-signatories to CRADAs may have a right of action if harmed by them. In Chemical Service, Inc. v. Environmental Monitoring Systems LaboratoryCincinnati, ${ }^{495}$ the Third Circuit held that a competitor to a private laboratory had standing to challenge provisions of a CRADA that it claimed should have been issued under ordinary procurement laws because "Congress did not intend that a CRADA be used to substitute for a procurement contract or cooperative agreement." ${ }^{, 46}$ The court also unanimously held that a related Memorandum of Understanding (MoU) between a division of the EPA and a firm was "final agency action" for APA purposes. ${ }^{497}$ Agency action though it might be, a majority then held that the plaintiffs nonetheless lacked standing to challenge it in court because there was no statute relating to the subject matter of the MoU, and a claim of a competitive disadvantage caused by the MoU was outside the zone of interests Congress had sought to protect in the Federal Technology Transfer Act, or in any other statute the court thought might be relevant. ${ }^{498}$ The dissenting judge argued, persuasively, that competitors did have standing to claim that an agency's actions pursuant to an MoU were arbitrary and capricious, because the agency's actions were allegedly "an arbitrary and capricious implementation of [its] regulatory program," ${ }^{499}$ and

492. See National Credit Union Admin. v. First Nat'l Bank \& Trust Co., 522 U.S. 479, 491 (1998) (holding that standing is precluded only "if the plaintiff's interests are . . marginally related to or inconsistent with the purposes implicit in the statute") (quoting Clarke v. Securities Indus. Ass'n, 479 U.S. 388, 399 (1987)); see also Association of Data Processing Serv. Org. v. Camp, 397 U.S. 150, 153 (1970) (holding that there is standing when "the interest sought to be protected by the complainant is arguably within the zone of interests to be protected or regulated by the statute or constitutional guarantee in question").

493. National Credit Union, 522 U.S. at 492 (quoting Clarke, 479 U.S. at 399-400).

494. Mova Pharm. Corp. v. Shalala, 140 F.3d 1060, 1075 (D.C. Cir. 1998).

495. 12 F.3d 1256, 1265 (3d Cir. 1993).

496. Id.

497. Id. at 1267 .

498. See id. at 1267-68.

499. Id. at 1269 (Stapelton, J., concurring and dissenting). 
participants in the program were within the zone of interests for standing purposes when they sought to challenge the approval of competing and allegedly non-conforming products. ${ }^{500}$

If there is no evidence that Congress wished to have a CRADA used as an end-run around the procurement laws, there is even less evidence that Congress ever contemplated a CRADA being used to make rules without conforming to the APA. Furthermore, the case for finding that persons whose property or contract rights have been affected by the actions of ICANN under its MoU with DoC have standing to challenge the $\mathrm{MoU}$ is much stronger than the competitive injury theory rejected by the majority in Chemical Service. Suppose one accepts the majority's theory that absent a statute there is no right to complain that the government is improperly aiding a competitor. Domain name registrants unhappy with ICANN's policies are not competitors; they are persons with an interest in their domain names that is protected by the Due Process Clause if it is an interest in a contract, and by the Takings Clause if it is a property interest. Because their claim is fundamentally grounded on their constitutional right to have those contract and property rights interfered with by government only according to law, they are within the zone of interest of the Constitution and thus have standing to bring an APA claim.

A more recent case, Edmonds Institute v. Babbitt, ${ }^{501}$ is an even better parallel to the ICANN situation. In Edmonds Institute, plaintiff environmentalists challenged a CRADA between Yellowstone National Park and Diversa Corp., a firm of private bio-harvesters. The plaintiffs were in no sense competitors with Diversa, but instead were users of the resources (Yellowstone) that the private firm would be using. The district court held that the plaintiffs had constitutional standing to attack the CRADA authorizing Diversa to conduct bioharvesting of minute quantities of micro-organisms from Yellowstone because "[t]he bottom line is that the plaintiffs in this case claim an injury to their aesthetic and recreational interests from Diversa's activities conducted pursuant to the Yellowstone-Diversa CRADA., ${ }^{, 52}$ The injury to plaintiffs' aesthetic interests in enjoying Yellowstone free from the bio-harvesters' footprints is surely a harm smaller then ICANN's threat to domain name holders' interest in domain names, whether one characterizes that as a property interest or a due process

500. See id. (Stapleton, J., concurring and dissenting).

501. 42 F. Supp. $2 d 1$ (D.D.C. 1999).

502. Id. at 13 . 
interest in the quiet enjoyment of registrants' contractual relations with registrars.

Furthermore, and of most direct relevance to ICANN, the Edmonds court held that Yellowstone's CRADA with Diversa Corp. was "final agency action" under the $\mathrm{APA}^{503}$ and, thus, subject to review under the "arbitrary and capricious" and "abuse of discretion and otherwise not in accordance with law" standards of the APA. ${ }^{504}$ The court noted that the Yellowstone-Diversa CRADA cited the Federal Technology Transfer Act (FTTA) ${ }^{505}$

as its legal basis, apparently taking the view... that Yellowstone National Park is itself a federal "laboratory."... When viewed in terms of recent cases interpreting the "zone of interest" requirement, it is not unreasonable to find that those who use federal laboratories "in practice can be expected to police the interests protected" by the FTTA. ${ }^{506}$

Whether one views the analogous DNS "laboratory" as the entire domain name system, or merely the root zone file itself, the fact remains that all users of the DNS are more directly affected by ICANN's actions than visitors to Yellowstone were by Diversa Corp's harvesting activities. In the case of DoC's contracts with ICANN, it is only non-parties to the agreement, and especially those persons excluded from the new governance arrangements, who can be expected to police it.

b. ICANN's on-going regulations. DoC has an obligation to make its general and prospective rules in compliance with the rulemaking provisions of the APA. ${ }^{507}$ This it demonstrably has failed to do. Therefore, rules of a general, nontechnical, and prospective nature, such as the UDRP, that DoC enacts via ICANN are not valid. ${ }^{508}$ And even if a section 553 exception did apply, this does not release the agency from its obligation to publish rules intended to

\footnotetext{
503. Id. at 15 ("The defendants have not argued that the Yellowstone-Diversa CRADA does not constitute final agency action reviewable under the APA, nor could they.").

504. Id. at 15 (citing Administrative Procedure Act, $\S 1,5$ U.S.C. $\S \S 702,706$ (1994)).

505. 15 U.S.C. $\$ \$ 3701-17$ (1994).

506. Edmonds Institute, 42 F. Supp. at 14.

507. Assuming, of course, that the APA section 553 exceptions do not apply. See supra Part III.C.1.

508. See 5 U.S.C. $\S 706(2)(D)(1994)$.
} 
bind the public, ${ }^{509}$ nor does it insulate the rule from judicial review under APA section $706 .^{510}$

ICANN's DoC-granted control of the root allows it to make decisions with substantial impacts on domain name holders. To date, the decision with the most significant direct effects on domain name holders and would-be registrants is the imposition of the UDRP; the most significant upcoming decision will be its selection of a small number of new gTLDs for introduction into the legacy root. These two decisions, one past, one in the near future, well illustrate the role of the APA relating to the review of ICANN's decisions. In the case of the UDRP, there was no overt and public act by DoC endorsing or enforcing ICANN's rule. As far as one can tell, DoC approved of the URDP, but it took no formal action at the time as if to promulgate or approve it, although arguably, DoC's subsequent decision to renew its agreements with ICANN is an implicit approval of ICANN's actions. At the time, though, DoC's official role was acquiescence. In contrast, although DoC has taken no official stance while ICANN has produced various complex rules and conditions and set a non-refundable $\$ 50,000$ fee per application for applicants wishing to run new gTLDs, ${ }^{511}$ when the time comes to enter new TLDs into the root, DoC will have to approve it rather than just acquiesce.

If a federal agency chooses to adopt a decision by an outside body as its own, it might proceed by rule or adjudication. ${ }^{512}$ Whether the agency acts by rulemaking or makes the rule via adjudication, the critical point is that the agency retains a right of review. ${ }^{513}$ In any case,

509. See id. §552(2).

510. Rules are ordinarily subject to review under the "arbitrary, capricious" standard. 5 U.S.C. $\S 706(2)(A)$.

511. For application forms and instructions, see TLD Application Process: Information for Applicants, at http://www.icann.org/tlds/tld-application-process.htm (last modified Aug. 15, 2000) (on file with the Duke Law Journal).

512. In SEC v. Chenery Corp., 332 U.S. 194 (1947) (Chenery II), the Supreme Court held that agencies empowered to act by both rule and adjudication may choose either. See id. at 203. It reaffirmed that view in NLRB v. Bell Aerospace Co., 416 U.S. 267, 294 (1974). See generally Russell L. Weaver, Chenery II: A Forty-year Retrospective, 40 ADMIN. L. REV. 161, 163-73 (1988), for a discussion of lingering uncertainties about the exact extent of agencies' power to make rules via adjudication.

513. Even a survey of legislative delegations offered as part of an argument that the executive's powers were being eroded and shared with outsiders found no delegations to private groups, other than in highly technical matters, that lacked review by a federal official before the rules went into effect. See Harold J. Krent, Fragmenting the Unitary Executive: Congressional Delegations of Administrative Authority Outside the Federal Government, 85 Nw. U. L. REV. 62 , 86-90, 95-101 (1990). The one potentially significant counter-example cited by Professor Krent, 
if the proceeding is prospective and general in nature, it is rulemaking for due process purposes, regardless of the form the agency may have chosen to use. ${ }^{514}$ If a federal agency were to attempt to adopt the UDRP directly, it would clearly be a rule, because it is prospective. On the other hand, the selection of one or more applicants for new gTLDs over others, although it has a prospective component, has elements of both rulemaking and adjudication. To the extent that the consequences of selection prospectively affect all users of the Internet, it is in the nature of rulemaking; to the extent that some applicants are licensed and others are not, it has elements of adjudicating "competing claims to a valuable privilege," which provides additional due process protections to the interested parties. ${ }^{51}$

The fact that most of DoC's decisions, such as allowing the UDRP to take effect, happen on the nod does not preclude review, although regulation by acquiescence imposes special problems for judicial review. ${ }^{516}$ Indeed, a silent record implicates all the process and review problems that were supposed to have been put to rest with Citizens to Preserve Overton Park, Inc. v. Volpe, ${ }^{517}$ as there is no evidence at all of reasoned decisionmaking. ${ }^{518}$

that of the Metropolitan Washington Airports Act of 1986, see id. at 89-90, was subsequently declared unconstitutional. See Metropolitan Washington Airports Auth. v. Citizens for Abatement of Aircraft Noise, Inc., 501 U.S. 252, 255 (1991).

514. See Bi-Metallic Inv. Co. v. State Bd. of Equalization, 239 U.S. 441, 445 (1915). The Due Process Clause provides far less protection to persons subject to agency proceedings in the nature of a rulemaking (prospective, general) than it does to persons subject to agency proceedings in the nature of an adjudication (targeted, personal, and with some element of retrospectivity). Compare id., with Londoner v. Denver, 210 U.S. 373, 385-86 (1908):

[D]ue process of law requires that at some stage of the proceedings before the tax becomes irrevocably fixed, the taxpayer shall have an opportunity to be heard, of which he must have notice, either personal, by publication, or by a law fixing the time and place of the hearing.

515. See Action for Children's Television v. FCC, 564 F.2d 458, 477 (D.C. Cir. 1977) (holding that ex parte contacts are prohibited when an agency is deciding "competing claims to a valuable privilege" because "at that point ... the potential for unfair advantage outweighs the practical burdens ... that such a judicially conceived rule would place upon administrators").

516. See Wileman Bros. \& Elliott, Inc. v. Giannini, 909 F.2d 332, 337-38 (9th Cir. 1990):

The mere fact of [the agency's] failure to disapprove, however, does not legitimize otherwise anticompetitive conduct.... [T]here is no affirmative process of non-disapproval which can be relied upon fairly to evaluate a committee's regulations. ... [N]on-disapproval is equally consistent with lack of knowledge or neglect as it is with assent.

517. 401 U.S. 402, 420 (1971) (holding-in the context of review of agency adjudicationthat courts require an administrative record in order to determine the propriety of an agency's action).

518. Cf. Action Alliance v. Heckler, 789 F.2d 931, 937 (D.C. Cir. 1986) (holding that a private interest group had standing to challenge an agency's decision not to issue findings because 
The case of the UDRP demonstrates in particularly stark terms why agencies should not be allowed to end-run the APA by giving control of public property to a corporation with tacit, much less written, instructions to that corporation that it use that control to make policy. If an agency sought to impose, as part of a government program, UDRP-like mandatory third-party beneficiary clauses that created arbitration rights for any aggrieved trademark holder, it would face significant obstacles. First, it would be subject to the ordinary procedural duties of the APA and to due process requirements. In the special case of the UDRP, however, the agency also would have to comply with the strictures of the Administrative Dispute Resolution Act (ADRA), ${ }^{519}$ which applies to "the resolution of an issue in controversy that relates to an administrative program" $" 520$ and imposes severe constraints on an agency's use of arbitration instead of ordinary formal or informal adjudication to resolve an "issue in controversy.",521

If the UDRP were subject to ADRA, then the program would be illegal, because "[a]n agency may not require any person to consent to arbitration as a condition of entering into a contract or obtaining a benefit ${ }^{, 522}$ - and domain name registrants must agree to be subject to the UDRP as a condition of being allowed to appear in the legacy root. Indeed, it is a nice question whether DNS regulation as conducted by ICANN pursuant to its agreements with DoC is currently "an administrative program" that decides "issues in controversy" that are "material to a decision concerning an administrative program of an agency" and "between persons who would be substantially affected by the decision"- and is therefore already subject to ADRA. ${ }^{523}$ ADRA defines the term "administrative program" as "includ[ing] a Federal function which involves protection of the public interest and

of the resultant injury to the group's function of informing the public); National Park \& Conservation Ass'n v. Stanton, 54 F. Supp. 2d 7, 13 (D.D.C. 1999) (recognizing the "informational injury" of having a matter privatized so as to not be subject to the APA).

519. 5 U.S.C. $\$ \$ 571-83$ (1994). On the ADRA, see generally Cynthia B. Dauber, The Ties That Do Not Bind: Nonbinding Arbitration in Federal Administrative Agencies, 9 ADMIN. L.J. AM. U. 165 (1995).

520. 5 U.S.C. $\$ 572(a)$.

521. An "issue in controversy" is defined as "an issue which is material to a decision concerning an administrative program of an agency, and with which there is disagreement" either "between an agency and persons who would be substantially affected by the decision" or "between persons who would be substantially affected by the decision." Id. $\S 571(8)(\mathrm{A})-(\mathrm{B}) ; c f$. In re Grand Jury Subpoena Dated December 17, 1996, 148 F.3d 487, 491 (5th Cir. 1998).

522. 5 U.S.C. $\$ 575(\mathrm{a})(3)$.

523. 5 U.S.C. $\$ 571(8)(B)$. 
the determination of rights, privileges, and obligations of private persons through rule making, adjudication, licensing, or investigation, as those terms are used in [sections 551-59 of the APA]., ${ }^{, 524}$ If ICANN acts as DoC's agent or is a state actor, ICANN's administration of the DNS and the UDRP could easily be characterized as one that "involves protection of the public interest," and as instantiating one of the expansive list of federal functions in ADRA.

Regardless of the ADRA issue, ICANN's arbitration system would have little chance of surviving ordinary "arbitrary and capricious" review under the APA, because it denies respondents minimal levels of fair procedure that participants would be entitled to expect from the U.S. government. As noted above, three aspects of the UDRP are particularly troubling: (1) the incentive for providers to compete to be "complainant friendly"; (2) its failure to require actual notice combined with the short time period permitted for responses; and (3) the asymmetric consequences of a decision. An agency rule that sought to impose an adjudicatory system with any of these features on U.S. citizens would surely be found to be arbitrary and capricious, if not an outright denial of due process.

First, and most importantly, due process requires an impartial tribunal, ${ }^{525}$ but the UDRP creates a system in which the impartiality of the tribunal could reasonably be questioned. The arbitration providers have an incentive to compete to provide complainant-friendly lists of arbitrators, ${ }^{526}$ and questions have already been raised about whether one or more of the providers are biased in favor of the complainants. ${ }^{527}$ Whether or not allowing the plaintiff to choose the provider is a violation of due process, ${ }^{528}$ it is arbitrary and capricious to design such an obvious vulnerability into the system.

Second, ICANN's arbitration rules-which all ICANN approved arbitration providers are required to follow-do not require that respondents receive actual notice of a complaint. ${ }^{529}$ While a system that

524. Id. §571(2).

525. See Ward v. Monroeville, 409 U.S. 57, 60 (1972); Tumey v. Ohio, 273 U.S. 510, 523 (1927).

526. See supra notes 351-54 and accompanying text.

527. See, e.g., Brian Livingston, Groups Cite Bias in Domain Name Arbitration, CNET NEws (July 7, 2000), at http://www.news.com/Perspectives/Column/0,176,459,00.html (on file with the Duke Law Journal).

528. A mere likelihood of bias, without actual bias, may not violate due process. See, e.g., Aetna Life Ins. Co. v. Lavoie, 475 U.S. 813, 820-21 (1986).

529. See supra note 356 and accompanying text. 
provides for substituted service is consistent with due process, minimal due process requires serious attempts to achieve actual notice before proceeding with the substitute. ${ }^{530}$ A related problem arises because the time allowed for a response is so short. ${ }^{531}$ In theory, both complainant and respondent each only get to file one set of papers with the arbitral tribunal. But the complainant gets to work on his pleading as long as he wishes, collect the relevant exhibits, and file when it suits him. The respondent has to answer in twenty days or essentially forfeit the case. What is more, the twenty-day clock to file a response starts ticking as soon as notice is mailed and e-mailed. Other than extraordinary cases, which are entirely at the discretion of the arbitrator, there is no procedure to provide extensions of time to a respondent who receives the notice late. ${ }^{532}$ While this schedule might be reasonable for business-to-business arbitration, it clearly is not reasonable in all situations; indeed, it is inconsistent with due process for a system in which many respondents will be ordinary people-people who take vacations without laptops or do not routinely read their email. ${ }^{533}$ The opportunity to be heard is fundamental to due process. ${ }^{534}$ The UDRP does not ensure that basic right.

Third, the system imposes asymmetric burdens on the losing parties. A losing complainant is free to file in whatever court would have heard the complaint before the UDRP decision and at a time of his choosing. A losing respondent has ten days to file a complaint in a forum that may be far from home. ${ }^{535}$ Not only is the time to file very

530. On e-mail service, see generally Rachel Cantor, Comment, Internet Service of Process: A Constitutionally Adequate Alternative?, 66 U. CHI. L. REV. 943 (1999) (arguing that Internet service is often constitutionally adequate and that rules governing service should permit Internet service); Frank Conley, Comment, :-) Service with a Smiley: The Effect of E-mail and Other Electronic Communications on Service of Process, 11 TEMP. INT'L \& COMP. L.J. 407 (1997) (arguing that e-mail is an efficient means to serve process).

531. See supra notes 357-64 and accompanying text.

532. See supra note 356 and accompanying text.

533. In contrast, the Federal Rules of Civil Procedure allow a defendant 20 days to answer, starting from the date of actual service of a complaint, see FED. R. CIV. P. 12(a)(1)(A); but if the defendant waives formal service, accepting mail service, for example, she has 60 days to answer. See FED. R. CIV. P. 4(d). Defendants outside the United States get 90 days. See id. A mailed request for waiver under Rule 4(d) not only includes a copy of the complaint but also a prepaid means for compliance, and it allows at least 30 days for the waiver to be returned. See id. What is more, extensions for good cause are not unusual.

534. See Mullane v. Central Hanover Bank \& Trust Co., 339 U.S. 306, 314 (1950).

535. Presumably, the complainant can be sued where he resides. In addition, complainants must agree to the jurisdiction of a court either where the complainant resides, or where the registrar is located. See UDRP, supra note $20, \S 3(\mathrm{~b})$ (xiii). 
short, but the reversal of the roles of plaintiff and defendant shifts the burden of proof. In international cases, the shift may also involve changes in language, procedure, and choice of law. ${ }^{536}$

Each of these flaws alone would probably suffice to doom the UDRP if subjected to review under APA section 706; their cumulative effect would be devastating.

3. Is ICANN an "Advisory Committee"? Suppose, contrary to the argument set out above, that ICANN is not a state actor. To the extent that ICANN does not in fact have the regulatory authority to make its decisions self-executing, but must have them reviewed and, as in the case of new gTLDs, implemented by DoC, then ICANN's role strongly resembles an advisory committee to a federal agency. ${ }^{537}$

The Federal Advisory Committee Act (FACA) imposes strict procedural requirements on advisory committees. If ICANN is subject to FACA, then it has been in continuing violation, since ICANN was neither established pursuant to FACA, ${ }^{538}$ nor has it conducted itself with the notice and openness that FACA requires. ${ }^{539}$ Under FACA, a U.S. government officer must call and chair every meeting of an advisory committee. ${ }^{540}$ In contrast, ICANN's charter excludes officials of all governments. ${ }^{541}$ FACA requires open meetings; the

536. See Froomkin, A Commentary on WIPO's Management, supra note 13.

537. An "advisory committee" is "utilized" whenever the President or a federal official turns to

a committee or other group composed in whole or in part of other than full-time officers or employees of the Federal Government with an established existence outside the agency seeking its advice which the President or agency official(s) adopts, such as through institutional arrangements, as a preferred source from which to obtain advice or recommendations on a specific issue or policy within the scope of his or her responsibilities in the same manner as that individual would obtain advice or recommendations from an established advisory committee.

41 C.F.R. § 101-6.1003 (1999). This sounds suspiciously like ICANN.

538. The Federal Advisory Committee Act, 5 U.S.C. app. 2 9 (1994), sets out prerequisites for the establishment of advisory committees, including a formal finding by an agency head or the President that the committee is needed, and publication of a detailed statement of purpose and modes of function in the Federal Register.

539. FACA states that "[e]ach advisory committee meeting shall be open to the public," and that "timely notice of each such meeting shall be published in the Federal Register, and the Administrator shall prescribe regulations to provide for other types of public notice to insure that all interested persons are notified of such meeting prior thereto." It also requires public access to detailed minutes. Id. $\S \S 10(\mathrm{a})(1)-(2)$.

540. See id. $\S \S 10(\mathrm{e})-(\mathrm{f})$.

541. ICANN's bylaws do not allow government officials to sit on the board of directors. See ICANN Amended Bylaws, art. V, § 5, at http://www.icann.org/general/bylaws.htm (July 16, 2000) (on file with the Duke Law Journal). Governments, however, do have a special advisory 
ICANN board has taken many of its key decisions in closed meetings. If FACA applies, decisions taken by DoC in reliance on ICANN are invalid, and ICANN would have to make some dramatic changes to its rules of procedure and bylaws. There are, however, substantial reasons to question whether FACA, as currently interpreted by the courts, would apply to ICANN.

FACA defines an advisory committee as "any committee, board, commission, council, conference, panel, task force, or other similar group ... which is ... established or utilized by one or more agencies ... in the interest of obtaining advice or recommendations for ... one or more agencies or officers of the Federal Government." ${ }^{542}$ That sounds a lot like ICANN, since the ICANN-DoC MoU indeed speaks of studying and advising. To the extent that DoC is adopting ICANN's decisions, overtly or by acquiescence, FACA may well apply; to the extent that ICANN directly executes policy as opposed to merely advising, it is not covered by FACA $^{543}$ (although those functions, in turn, raise nondelegation issues discussed below).

Even as regards ICANN's advisory role, however, one could debate whether ICANN is being "utilized" by DoC in the sense the term is used in FACA. ${ }^{544}$ In Public Citizen v. U.S. Department of Justice $^{545}$ the Supreme Court narrowly construed the word "utilize" in FACA. "Utilize," Justice Brennan said, "is a woolly verb"; read literally, it "would extend FACA's requirements to any group of two or more persons, or at least any formal organization, from which the President or an Executive agency seeks advice," a result Justice Brennan was certain Congress did not intend. ${ }^{54}$ Rejecting a FACA

role reserved for them. ICANN's Governmental Advisory Committee has a right to be consulted regarding any policy that will substantially affect the operation of the Internet or third parties. See id. art. VII, § 3 (referencing art. III, § 3 ).

542. 5 U.S.C. app. 2 \$3(2) (1994).

543. GSA regulations exclude from FACA coverage "[a]ny committee which is established to perform primarily operational as opposed to advisory functions. Operational functions are those specifically provided by law, such as making or implementing Government decisions or policy. An operational committee may be covered by the Act if it becomes primarily advisory in nature.” 41 C.F.R. § 101-6.1004(g) (1999).

544. See supra note 537. Under this definition, if DNS management and policy is currently a DoC responsibility, which it undeniably is, and if DoC has an "institutional arrangement" to use ICANN as a "preferred source" for advice or recommendations-which is a gentle way of describing the current relationship-then FACA should apply to ICANN.

545. 491 U.S. 440 (1989)

546. Id. at 452. Justice Kennedy's concurrence shears the wool off of the term "utilize," opting to adopt the plain meaning of the word for the purposes of legislative interpretation: 
challenge to the Department of Justice's use of a committee of the American Bar Association to advise the President on potential judicial nominees, Justice Brennan found in the legislative history "considerable evidence" that

Congress sought only to achieve compliance with FACA's more stringent requirements by advisory committees already covered by the Order and by Presidential advisory committees, and that the statute's "or utilized" phrase was intended to clarify that FACA applies to committees "established ... by" the Government in a generous sense of that term, encompassing groups formed indirectly by quasi-public organizations "for" public agencies as well as "by" such agencies themselves. ${ }^{547}$

If "utilize" is a woolly verb, then ICANN's facts are very shaggy. Whether the process in the White Paper that summoned ICANN into being, combined with the at least informal blessing by DoC of some of its prenatal organization, ${ }^{548}$ suffices to make ICANN a group formed indirectly by a quasi-public organization "for" an agency is one of those questions that could go either way.

Further complicating matters, the D.C. Circuit has held that FACA does not apply to government contractors. That might seem to let ICANN out of FACA, but here, too, the question is not straightforward. In Food Chemical News v. Young, ${ }^{549}$ Judge Ruth Bader Ginsburg relied on FACA's legislative history to find that FACA "does not apply to persons or organizations which have contractual relationships with Federal agencies." ${ }^{550}$ The alleged advisory committee in Food Chemical News was a panel of scientists assembled by a

We are told that "utilize" is "a woolly verb," and therefore we cannot be content to rely on what is described, with varying levels of animus, as a "literal reading," a "literalistic reading," and "a dictionary reading" of this word... . Reluctance to working with the basic meaning of words in a normal manner undermines the legal process. These cases demonstrate that reluctance of this sort leads instead to woolly judicial construction that mars the plain face of legislative enactments.

Id. at 469 (Kennedy, J., concurring).

547. Id. at 442.

548. See supra Part II.A.5.

549. 900 F.2d 328 (D.C. Cir. 1990).

550. Id. at 331 (citing H.R. CONF. REP. NO. 92-1403, at 2 (1972), reprinted in 1972 U.S.C.C.A.N. 3508, 3509; H.R. REP. No. 92-1017, at 4 (1972), reprinted in 1972 U.S.C.C.A.N. 3491, 3494 (stating that "advisory committee" does not include a contractor or consultant hired by an officer or agency of the federal government)); see also Tucson Rod \& Gun Club v. McGee, 25 F. Supp. 2d 1025, 1030 (D. Ariz. 1998) (citing the same House Reports as above to conclude that "the Court finds that this count should be dismissed ... because FACA does not apply to government contractors"). 
paid contractor. Judge Ginsburg said that as the contractor was merely a private organization working under contract to the government, it lacked the "quasi-public status" required by Public Citizen. As for the panel of scientists, it was managed by the contractor, rather than being managed by the government or by a "semiprivate entity the Federal Government helped bring into being." D.C. Circuit panel reiterated that contractors are outside FACA, although it also suggested that "even if 'utilization' does not require control in every instance, as where a committee is authorized by Congress and appointed and funded by an executive branch agency," FACA might apply if the agency "intended to use the Panel's guidelines as recommendations to formulate policy.",553

Again, therefore, the question is what weight to give which facts, and to what extent the facts outweigh the forms. Formally, ICANN is private, spontaneously generated, and a government contractor (even if no money changes hands in those contracts). In practice, it is making DNS policy at DoC's request, along lines mandated by DoC and either with DoC's cooperation or under its supervision. If the forms control, FACA will not apply. In substance, ICANN very much resembles an advisory committee-and FACA's requirements would probably cure many of the problems that most agitate ICANN's critics, especially issues of notice and secrecy.

\section{Constitutional Issues}

As we have seen, DoC's delegation to ICANN could be portrayed as somewhat metaphysical. There is a grain of truth to the sometimes-heard claim that whatever it is that DoC has to give ICANN is only the confidence reposed in it by the root server operators. Nothing stops the non-U.S. government servers from pointing their servers anywhere they choose-although since the U.S. government controls three of the thirteen root servers directly and several more indirectly, ${ }^{554}$ such a decision likely would produce a split in the root, and ultimately might lead to a divided Internet. ${ }^{555}$ Depending on how one chose to characterize it, DoC's delegation to ICANN of

\footnotetext{
551. See id.

552. Id. (quoting Public Citizen v. United States Dep’t of Justice, 491 U.S. 440, 463 (1989)).

553. Sofamor Danek Group, Inc. v. Gaus, 61 F.3d 929, 936 (D.C. Cir. 1995).

554. See supra note 86 and accompanying text.

555. See Cukier, supra note 173 (outlining Postel's test and the response to the test by the other root servers).
} 
power over the root could be described in ways ranging from the precatory to full-bore command and control, including:

- an announcement that inspires willing or altruistic compliance among the root servers; or

- an announcement that compels compliance among the root servers because they understand the network effects of sharing a single root; or

- a lease or loan of government property - the root file itself, or some intellectual property right to it; or

- the transfer of part of the government's interest in its contract with NSI; or

- the transfer of the power to regulate, with the root file being the means to enforce compliance.

However one chooses to characterize the delegation, it seems clear that control of the legacy root system undoubtedly confers power over domain name registrants and would-be registrants.

If $\mathrm{DoC}$ is neither regulating directly nor indirectly via a state actor, then DoC's delegation of the power to regulate violates the Constitution. A delegation of federal power to a private corporation differs from delegations to an agency. A private person-even a legal person-has independent powers. When the federal government delegates power to specific persons, it transfers power to a private group that is often small and unrepresentative or self-interested and presumptively less accountable to the public than are legislators who must face re-election or administrators who must report to the President. ${ }^{556}$

If DoC has handed this power over to ICANN, even on a temporary basis, without keeping the right to review its decisions, then that delegation violates the nondelegation doctrine and raises major due process concerns. These constitutional concerns are substantially

556. See, e.g., Cass R. Sunstein, Constitutionalism After the New Deal, 101 HARV. L. REV. 421, 447-48 (1987) (noting the frequent criticism that administrative agencies are insufficiently accountable to the electorate); Cass R. Sunstein, Interest Groups in American Public Law, 38 STAN. L. REV. 29, 60 (1985) ("[A]dministrative agencies exercise broad discretionary power with only intermittent control from the electorally accountable branches of the federal government. The danger is that private groups will co-opt the administrative process and exploit it to their advantage."). 
magnified by the absence of a clear congressional pronouncement authorizing the handing over, even on a trial basis, of policymaking authority over the root. The usual type of delegation to private persons that winds up in court originates in a statute. The ICANN case is unusual because Congress has made no such determination. Rather, the delegation from DoC is contractual. The case for the constitutionality of a delegation of public power to private persons is surely strongest when Congress determines that the delegation is necessary and proper to achieve a valid end, and the case is weaker when the delegation is the agency's independent action. ${ }^{557}$ Oddly, the GAOwhich focused on statutory issues to the exclusion of the constitutional ones-seems to have concluded the opposite, reasoning that because DoC had no statutory duty to manage the DNS, its "subdelegation" of the authority violated no congressional command. ${ }^{558}$ That analysis works at the statutory level when the issue is DoC's power to enter into contracts with ICANN; it does not work when the issue is delegations of dubious constitutional legitimacy.

1. Origins and Purpose of the Nondelegation Doctrine. The nondelegation doctrine has fallen out of favor. Notoriously used by a reactionary court to strike down elements of FDR's New Deal reforms, the constitutional doctrine preventing excessive delegations carries some heavy baggage. Since the famous "switch in time" that defanged FDR's Court-packing plan, the Supreme Court has upheld a legion of congressional delegations that suggest the pre-New Deal decisions are, at best, moribund. Any argument that seeks to invoke nondelegation principles must, therefore, do some heavy lifting. What follows seeks to take up that challenge by, first, demonstrating that the pre-New Deal decisions were animated by important constitutional values and were correct at least insofar as they placed limits on the delegation of public power to private parties. Second, it shows that, at least as regards the issue of constitutional limits on

557. See National Park \& Conservation Ass'n v. Stanton, 54 F. Supp. 2d 7, 14-15 (D.D.C. 1999) (holding that the plaintiffs stated a claim for unlawful subdelegation of statutory duty to a private group); Michael Ezra Fine, Rethinking the Nondelegation Doctrine, 62 B.U. L. REV. 257, 266 (1982) ("Congress may delegate 'administrative' power-the power to implement 'legislative' power. The nondelegation doctrine only requires that the legislature exercise its legislative power, and that the legislature control administrative power exercised by an agency.").

558. See GAO Report, supra note 28 , at $26 \&$ n. 41 ("Since it is a role not specifically required by statute, the Department was not delegating or transferring a statutory duty when it proposed to transition administrative control over the domain name system to a private entity."). 
delegations to private parties, the pre-New Deal cases remain valid today, both because they have never been overruled and, more importantly, because the principles on which they relied remain relevant and vital.

The nondelegation doctrine instantiates a fundamental public policy against the arbitrary exercise of public power. ${ }^{559}$ Most famously expounded in two pre-New Deal cases, Carter v. Carter Coal Co ${ }^{560}$ and A.L.A. Schechter Poultry Corp. v. United States ${ }^{561}$ the doctrine has two related but distinct forms: the public nondelegation doctrine, which constrains Congress's delegations to the executive, ${ }^{562}$ and the private nondelegation doctrine, which constrains Congress's delegations to nongovernmental actors. Carter Coal addresses the limits of the legislature's power to vest "lawmaking" power in private hands, an issue which had also arisen in Schechter Poultry. ${ }^{563}$

The better-known and recently revived ${ }^{564}$ public nondelegation doctrine embodies separation of powers concerns and limits Con-

559. See Carter v. Carter Coal Co., 298 U.S. 238, 311 (1936); cf. Texas Boll Weevil Eradication Found., Inc. v. Lewellen, 952 S.W.2d 454, 457 (Tex. 1997) (relying on the Texas Constitution to reach a similar result).

560. 298 U.S. 238 (1936).

561. 295 U.S. 495 (1935).

562. There are several early cases discussing the doctrine. See J.W. Hampton, Jr. \& Co. v. United States, 276 U.S. 394, 408 (1928) ("The true distinction . . is between the delegation of power to make the law, which necessarily involves a discretion as to what it shall be, and conferring an authority or discretion as to its execution, to be exercised under and in pursuance of the law. The first cannot be done; to the latter no objection can be made."); Field v. Clark, 143 U.S. 649, 692 (1892) ("That Congress cannot delegate legislative power to the President is a principle universally recognized as vital to the integrity and maintenance of the system of government ordained by the constitution."); The Aurora, 11 U.S. (7 Cranch) 382 passim (1813) (upholding a delegation to the President to determine "contingency").

563. See Schechter Poultry, 295 U.S. at 529-30 (addressing the question of whether Congress had established standards of legal obligation by enacting "codes of fair competition," thereby fulfilling its essential legislative function, or, by failing to enact such standards, had delegated this function to others).

564. See American Trucking Ass'ns, Inc. v. EPA, 175 F.3d 1027, 1034 (D.C. Cir.), modified in part and reh'g en banc denied, 195 F.3d 4 (D.C. Cir. 1999), cert. granted sub nom. Browner v. American Trucking Ass'ns, Inc., 120 S. Ct. 2003 (2000), and cert. granted sub nom. American Trucking Ass'ns, Inc. v. Browner, 120 S. Ct. 2193 (2000); see also Lisa Schultz Bressman, Essay, Schechter Poultry at the Millennium: A Delegation Doctrine for the Administrative State, 109 YALE L.J. 1399, 1415 (2000) ("The newly emerging delegation doctrine requires administrative agencies to issue rules containing reasonable limits on their discretion in exchange for broad grants of regulatory authority."). But see Cass Sunstein, Is the Clean Air Act Unconstitutional?, 98 MiCH. L. REV. 303, 380 (1999) ("The new nondelegation doctrine is a large mistake."); Cass R. Sunstein, Nondelegation Canons, 67 U. CHI. L. REV. 315, 316 (2000) (maintaining that the courts do not apply a single nondelegation doctrine, but rather a series of more specific variants); Mark Seidenfeld \& Jim Rossi, The False Promise of the "New" Nondelegation Doctrine 
gress's ability to make standardless delegations to administrative agencies by imposing a limited particularity requirement on delegations of congressional authority to federal agencies. ${ }^{565}$ Only government agencies in the executive branch may exercise executive powers. ${ }^{566}$ It follows that an agency that is responsible to Congress or to the courts may not execute the laws, ${ }^{567}$ and it goes almost without saying that even executive branch agencies may only exercise those powers delegated to them by Congress. ${ }^{568}$ The public nondelegation doctrine prevents Congress from surrendering a core part of its rolemaking certain fundamental policy choices-to the executive.

(Mar. 30, 2000) (maintaining that the doctrine hinders the rule of law), Social Science Research Network Electronic Library, http://papers.ssrn.com/paper. taf?abstract_id=214508 (on file with the Duke Law Journal).

565. See Schechter Poultry, 295 U.S. at 530 ("[W]e look to the statute to see whether Congress ... in authorizing 'codes of fair competition' has itself established the standards of legal obligation, thus performing its essential legislative function, or, by the failure to enact such standards, has attempted to transfer that function to others."); Panama Ref. Co. v. Ryan, 293 U.S. 388, 415 (1935) ("[T] he question whether that transportation shall be prohibited by law is obviously one of legislative policy. Accordingly, we look to the statute to see whether the Congress has ... set up a standard for the President's action."); J.W. Hampton, Jr. \& Co., 276 U.S. at 409 ("If Congress shall lay down by legislative act an intelligible principle to which the person or body authorized to fix such rates is directed to conform, such legislative action is not a forbidden delegation of legislative power."); Field, 143 U.S. at 692-93 ("Legislative power was exercised when Congress declared that the suspension should take effect upon a named contingency. What the President was required to do was simply in execution of the act of Congress.").

566. See Peter L. Strauss, The Place of Agencies in Government: Separation of Powers and the Fourth Branch, 84 COLUM. L. REV. 573, 618 (1984).

567. See Metropolitan Washington Airports Auth. v. Citizens for Abatement of Aircraft Noise, Inc., 501 U.S. 252, 276 (1991) ("If the power is executive, the Constitution does not permit an agent of Congress to exercise it."); Bowsher v. Synar, 478 U.S. 714, 726 (1986) (holding unconstitutional a statute vesting executive budget powers in an officer removable by Congress); INS v. Chadha, 462 U.S. 919, 952-59 (1983) (holding that the only means by which Congress may alter "the legal rights, duties and relations of persons" outside the legislative branch is by legislation and presentment to President). There are also a number of so-called "independent agencies," whose officers have some degree of insulation from removal without cause, although exactly how much is debated. Despite their name, however, independent agencies are part of the executive branch. Compare Steven G. Calabresi \& Kevin H. Rhodes, The Structural Constitution: Unitary Executive, Plural Judiciary, 105 HARV. L. REV. 1155, 1191 (1992) (comparing the Vesting Clauses in Article II and Article III of the Constitution and observing that the Article II Clause creates a unitary executive), with A. Michael Froomkin, The Imperial Presidency's New Vestments, 88 Nw. U. L. REV. 1346, 1372 (1994) (arguing that the text and structure of the Constitution allow Congress to insulate some inferior officers from the removal power of the President).

568. See 5 U.S.C. $\S 706(2)(C)(1994)$ (making agency action "in excess of statutory jurisdiction, authority, or limitations, or short of statutory right" unlawful); Bowen v. Georgetown Univ. Hosp., 488 U.S. 204, 208 (1988) ("It is axiomatic that an administrative agency's power to promulgate legislative regulations is limited to the authority delegated by Congress."). 
In contrast to the separation of powers concerns that animate the public nondelegation doctrine, the private nondelegation doctrine focuses on the dangers of arbitrariness, lack of due process, and selfdealing when private parties are given the use of public power without being subjected to the shackles of proper administrative procedure. Both doctrines stem from a long tradition of seeking to ensure that public power is exercised in a manner that makes it both formally and, insofar as possible, actually accountable to elected officials, and through them-we hope-to the electorate. ${ }^{569}$ This concern for proper sources and exercise of public authority promotes both the rule of law and accountability. ${ }^{570}$

Concern about delegations to private parties also has a long pedigree. In Eubank v. City of Richmond, ${ }^{571}$ the Supreme Court struck down an ordinance allowing owners of two-thirds of the properties on a street to make a zoning rule defining setbacks. The Court said this was unconstitutional because it gave one group of property owners the power "to virtually control and dispose of the proper rights of others" and lacked any "standard by which the power thus given is to be exercised." ${ }^{572}$ Similarly, in Washington $v$. Roberge ${ }^{573}$ the Court held that an ordinance requiring the prior approval of owners of two-thirds

569. See United States v. Robel, 389 U.S. 258, 276 (1967) (Brennan, J., concurring); Arizona v. California, 373 U.S. 546, 626 (1963) (Harlan, J., dissenting in part).

570. See Arizona, 373 U.S. at 626 (Harlan, J., dissenting in part):

[The nondelegation doctrine] insures that the fundamental policy decisions in our society will be made not by an appointed official but by the body immediately responsible to the people [and] prevents judicial review from becoming merely an exercise at large by providing the courts with some measure against which to judge the official action that has been challenged.

See also National Ass'n of Regulatory Util. Comm'rs v. FCC, 737 F.2d 1095, 1143 n.41 (D.C. Cir. 1984) ("[O]ne of the rationales against excessive delegation [is] the harm done thereby to principles of political accountability. Such harm is doubled in degree in the context of a transfer of authority from Congress to an agency and then from agency to private individuals."); Henry H. Perritt, Jr., International Administrative Law for the Internet: Mechanisms of Accountability, 51 ADMIN. L. REV. 871, 896-97 (1999) ("The core value embedded in the Delegation Doctrine is political accountability. Rules should be made only by those who are accountable to the people, and, equally important, rules that engender sufficient public opposition should be amenable to change."); David Schoenbrod, The Delegation Doctrine: Could the Court Give It Substance?, 83 MICH. L. REV. 1223, 1224 (1985) ("Unchecked delegation would undercut the legislature's accountability to the electorate and subject people to rule through ad hoc commands rather than democratically considered general laws."); David N. Wecht, Note, Breaking the Code of Deference: Judicial Review of Private Prisons, 96 YALE L.J. 815, 834 (1987) ("Privatization without retention of adequate control is inconsistent with the Court's own jurisprudence ....").

571. 226 U.S. 137 (1912).

572. Id. at $143-44$.

573. 278 U.S. $116(1928)$. 
of properties within 400 feet of a proposed home for the aged poor was a rule "uncontrolled by any standard or rule prescribed by legislative action." 574 This limited electorate, the Court noted, was "free to withhold consent for selfish reasons or arbitrarily." later, in City of Eastlake v. Forest City Enterprises, Inc. ${ }^{576}$ the Court upheld a city charter provision requiring proposed land-use changes to be ratified by $55 \%$ of the people voting at a city-wide referendum. ${ }^{577}$ Distinguishing the "standardless delegation of power" properly struck down in Eubank and Roberge, the Court stated that a citywide referendum was not a delegation of power because "[i]n establishing legislative bodies, the people can reserve to themselves power to deal directly with matters which might otherwise be assigned to the legislature." 57

The Schechter Poultry case involved both public and private delegation issues. The National Industrial Recovery Act set up a process by which trade or industrial associations could devise codes of fair competition and petition the President to make them binding on their trade or industry. (In the absence of such a request, the President could also promulgate codes himself. ${ }^{579}$ Trade associations and firms would select an "industry advisory committee"; this committee, in turn, would appoint a "code supervisor," subject to the approval of the Secretary of Agriculture and the Administrator for Industrial Recovery, with firms taxed to pay for him "proportionately upon the basis of volume of business, or such other factors as the advisory committee may deem equitable," subject again to federal review. ${ }^{580}$

The President was empowered to accept and enforce a trade or industrial code upon finding

(1) that such associations or groups "impose no inequitable restrictions on admission to membership therein and are truly representative," and (2) that such codes are not designed "to promote mo-

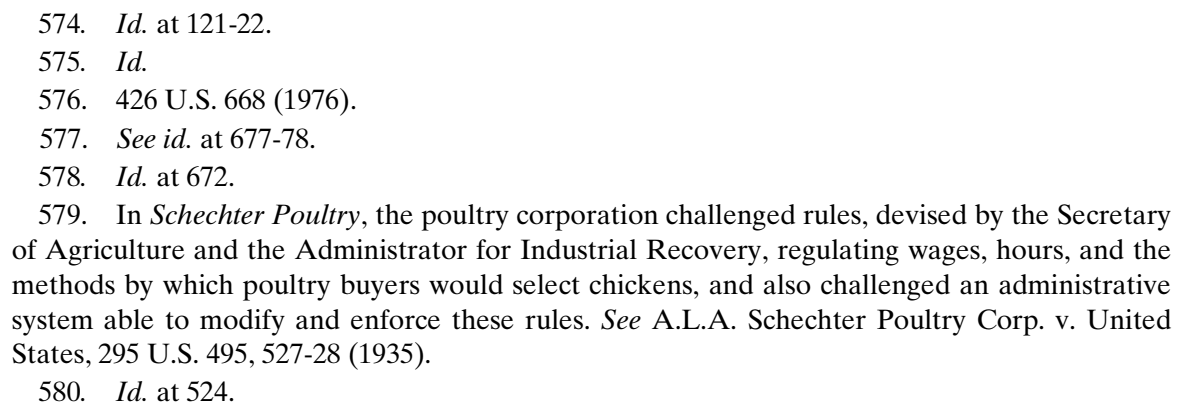

579. In Schechter Poultry, the poultry corporation challenged rules, devised by the Secretary of Agriculture and the Administrator for Industrial Recovery, regulating wages, hours, and the methods by which poultry buyers would select chickens, and also challenged an administrative system able to modify and enforce these rules. See A.L.A. Schechter Poultry Corp. v. United States, 295 U.S. 495, 527-28 (1935).

580. Id. at 524 . 
nopolies or to eliminate or oppress small enterprises and will not operate to discriminate against them, and will tend to effectuate the policy" [of the statute.]

The President could condition his approval on whatever provisions he thought necessary "for the protection of consumers, competitors, employees, and others, and in furtherance of the public interest." ${ }^{, 52}$ Violation of a duly approved code was a misdemeanor punishable by a fine of $\$ 500$ per day.

In response to the Schechters' challenge to the statute, the Supreme Court defined the issue as whether the statute adequately defined the authority delegated to the President or to trade associations. In both cases, the Supreme Court held, the standards that described the extent of the delegation were too vague to be constitutionally acceptable because they were sufficiently plastic to permit any rule. Citing its then-recent decision in Panama Refining v. Ryan, ${ }^{583}$ the Court said that such "virtually unfettered" delegations to the executive were unconstitutional $;{ }^{584}$ it then extended the Panama Refining ruling to apply to delegations to private groups also. Thus, the Supreme Court asked rhetorically whether

it be seriously contended that Congress could delegate its legislative authority to trade or industrial associations or groups so as to empower them to enact the laws they deem to be wise and beneficent for the rehabilitation and expansion of their trade or industries? ... The answer is obvious. Such a delegation ... is utterly inconsistent with the constitutional prerogatives and duties of Congress. ${ }^{585}$

In Carter v. Carter Coal, the Supreme Court struck down the Bituminous Coal Conservation Act of 1935 because it unconstitutionally delegated public power to private groups. ${ }^{586}$ The facts of Carter Coal eerily foreshadow the ICANN story-with the key differences that the Bituminous Coal Conservation Act was the direct and intentional result of a congressional enactment and that violators of the act might

581. Id. at 522-23 (quoting the National Industrial Recovery Act § 3, 48 Stat. 195, 196 (1933)).

582. Id. at 523 .

583. 293 U.S. 388 (1935).

584. Schechter Poultry, 295 U.S. at 542.

585. Id. at 537.

586. See Carter v. Carter Coal Co., 298 U.S. 238, 311 (1936). 
be subject to fiscal sanctions. ${ }^{587}$ Just as ICANN regulates the DNS on the basis of voluntary contractual agreements with private parties, so, too, the Coal Act relied on the "voluntary" acceptance by mine owners and operators of privately written codes of conduct that were created by each of twenty-three coal districts. The codes fixed maximum and minimum prices and rules relating to wages and working conditions. ${ }^{588}$ Congress gave the power to determine the content of the district's code to producers of more than two-thirds the annual national tonnage production for the preceding year; a majority of the mine workers employed in the district could fix the maximum hours of labor. ${ }^{589}$ Producers of more than two-thirds of the district annual tonnage during the preceding year and a majority of the miners shared the power to fix minimum wages for the district. "The effect," the Court concluded, "in respect of wages and hours, is to subject the dissentient minority, either of producers or miners or both, to the will of the stated majority ...." ${ }^{590}$ The coal boards' decisions went into effect directly, without review or intervention by the federal government.

The kicker in the Coal Act was that Congress set up a prohibitive "excise tax" on coal. ${ }^{591}$ Mine owners could only avoid the tax by "voluntarily" signing on to the codes of conduct. Furthermore, the Act required the U.S. government to buy coal only from mines that complied with a code and to impose the same requirement on all its contractors. ${ }^{592}$ Despite operating in what is now derided as a formalist era, the pre-New Deal Supreme Court made short work of this legal fiction of voluntariness, stating "[o]ne who does a thing in order to avoid a monetary penalty does not agree; he yields to compulsion precisely the same as though he did so to avoid a term in jail. ${ }^{, 933}$ Thus,

587. See Bituminous Coal Conservation Act of 1935, ch. 824, § 5(d), 49 Stat. 991, 1002-03 (authorizing treble damages), repealed by Act of Apr. 26, 1937, ch. 127, 50 Stat. 90. Another difference of some significance was that the Bituminous Coal Conservation Act created a direct right of action for persons aggrieved by the code. See Carter Coal, 298 U.S. at 340 n.7. No such right exists for persons aggrieved by ICANN's actions.

588. See Bituminous Coal Conservation Act of 1935, $\S 4$.

589. See id. $\S 1$.

590. Carter Coal, 298 U.S. at 311.

591. See Bituminous Coal Conservation Act of 1935, § 1; see also Carter Coal, 298 U.S. at 288-89 ("The exaction applies to all bituminous coal produced, whether it be sold, transported or consumed in interstate commerce, or transactions in respect of it be confined wholly to the limits of the state.").

592. See Carter Coal, 298 U.S. at 310.

593. Id. at 289. 
"[t]o 'accept,' in these circumstances, is not to exercise a choice, but to surrender to force." $" 594$

The consequences of refusing to submit to a privately drafted code were not penal; they were severe, but purely economic. Nevertheless, the Court excoriated the Coal Act as "legislative delegation in its most obnoxious form; for it is not even delegation to an official or an official body, presumptively disinterested, but to private persons whose interests may be and often are adverse to the interests of others in the same business." ${ }^{595}$ Chief Justice Hughes, writing separately, also faulted the Coal Act for violating the due process rights of mine owners and workers. ${ }^{596}$ Justice Cardozo, dissenting, defended the Coal Act by noting that it required the coal boards to act justly and equitably, to take account of market factors, and to avoid undue prejudice or preference between producers,${ }^{597}$ but these factors failed to sway the majority.

2. Modern Reception of the Private Nondelegation Doctrine. Since the New Deal, Schechter Poultry has been all but rejected as an authority, and both the Carter Coal doctrine and the standard nondelegation doctrine have been, at best, legal backwaters in the federal courts, ${ }^{598}$ although nondelegation survives, even flourishes, in the state courts. ${ }^{599}$ For years the public delegation doctrine bowed to the modern administrative state, which includes any number of congressional delegations of power to the executive that stretch the nondelegation doctrine almost beyond recognition. In decisions upholding these delegations, ranging from Yakus v. United States ${ }^{600}$ and Fahey v. Malone ${ }^{601}$ to Amalgamated Meat Cutters v. Connally, ${ }^{602}$ the federal courts' willingness to approve virtually any delegation

\footnotetext{
594. Id. at 311.

595. Id.

596. See id. at 318 (Hughes, C.J., concurring).

597. See id. at 333 (Cardozo, J., dissenting).

598. For a review of nondelegation decisions, see DAVID SCHOENBROD, POWER WITHOUT Responsibility: How Congress Abuses the People Through Delegation 25-46 (1993). 599. See infra notes $634-49$ and accompanying text.

600. 321 U.S. 414, 423 (1944) ("The Act is thus an exercise by Congress of its legislative power. In it Congress has stated the legislative objective, has prescribed the method of achieving that objective ... and has laid down standards to guide the administrative determination ....").

601. 332 U.S. 245, 249-56 (1947) (upholding a sweeping delegation to banking regulators).

602. 337 F. Supp. 737, 747 (D.D.C. 1971) (“[W]e cannot say that in the Act before us there is such an absence of standards that it would be impossible to ascertain whether the will of Congress has been obeyed.").
} 
prompted Justice Marshall to suggest that the nondelegation doctrine has been "abandoned by the Court for all practical purposes." While a number of cases cite nondelegation concerns as a reason to construe statutes narrowly, ${ }^{604}$ until the D.C. Circuit's recent, and very controversial, ${ }^{605}$ decision suggesting that an EPA regulation might be void on nondelegation grounds, ${ }^{606}$ the leading judicial suggestions that the classic nondelegation doctrine might not be dead were a concurring opinion by then-Justice Rehnquist ${ }^{607}$ and a dissent by Justice Scalia. ${ }^{608}$

Although it represents a separate, less-criticized doctrine than Schechter Poultry's public nondelegation doctrine, the private nondelegation doctrine of Carter Coal remains one of the decisions that prompted FDR's Court-packing proposal, and it found little favor in the federal courts after the "switch in time that saved nine." ${ }^{609}$ Parts of it-notably the suggestion that the Commerce Clause does not attach to mining because products only enter the stream of commerce after extraction-clearly have been repudiated. And, only a few years after Carter Coal, the Supreme Court limited the reach of the private nondelegation doctrine. In Currin v. Wallace ${ }^{610}$ the Court upheld a statute authorizing the Secretary of Agriculture to fix standards for the grading and weighing of tobacco. The statute also authorized the Secretary to designate tobacco auction markets that would be forbidden from selling tobacco unless it was described and measured according

603. Federal Power Comm'n v. New England Power Co., 415 U.S. 345, 352-53 (1974) (Marshall, J., concurring).

604. See, e.g., Mistretta v. United States, 488 U.S. 361, 373-74 (1989) (finding Congress's delegation of authority to a sentencing commission sufficiently specific to survive a nondelegation challenge); Kent v. Dulles, 357 U.S. 116, 129-30 (1958) (construing narrowly a statute delegating power to the executive regarding the issuance of passports). See generally Cass Sunstein, Law and Administration After Chevron, 90 COLUM. L. REV. 2071, 2110-12 (1990) (discussing the need for clear legislative statements when delegating authority to administrative agencies).

605. See Richard J. Pierce, Jr., The Inherent Limits on Judicial Control of Agency Discretion: The D.C. Circuit and the Nondelegation Doctrine, 52 ADMIN. L. REV. 63, 63-64 (2000) (describing how the American Trucking decision "shocked the world of administrative law").

606. See American Trucking Ass'ns, Inc. v. EPA, 175 F.3d 1027, 1034 (D.C. Cir.), modified in part and reh'g en banc denied, 195 F.3d 4 (D.C. Cir. 1999), cert. granted sub nom. Browner v. American Trucking Ass'ns, Inc., 120 S. Ct. 2003 (2000), and cert. granted sub nom. American Trucking Ass'ns, Inc. v. Browner, 120 S. Ct. 2193 (2000).

607. See Industrial Union Dep’t v. American Petroleum Inst., 448 U.S. 607, 686-87 (1980)

(Rehnquist, J., concurring).

608. See Peretz v. United States, 501 U.S. 923, 956 (1991) (Scalia, J., dissenting).

609. On the place of Carter Coal in the controversy, see Michael Ariens, A Thrice-told Tale, or Felix the Cat, 107 HARV. L. REV. 620, 626-27 (1994).

610. 306 U.S. 1 (1939). 
to the new national standards. An auction could be designated as a covered tobacco market only if two-thirds of the growers who had sold tobacco there the previous season approved of the designation. ${ }^{611}$ Plaintiffs attacked this vote as an unconstitutional delegation of power, but the Court rejected their nondelegation claim as "untenable." ${ }^{\circ 12}$ Because the authority for the entire regulatory scheme, including the requirement for the vote of approval, originated directly from Congress, and perhaps because the Secretary rather than private parties made the rules, the Court distinguished the vote from "a case where a group of producers may make the law and force it upon a minority or where a prohibition of an inoffensive and legitimate use of property is imposed not by the legislature but by other property owners."

Without a doubt, the ban against delegation to private parties has suffered erosion. ${ }^{614}$ This erosion is most visible at the state level ${ }^{615}$ but, like states, the federal government relies on private parties' decisions for a number of administrative matters. For example, the federal government relies on accreditation decisions made by private parties to make funding choices, ${ }^{616}$ although this reliance, and thus collaterally the underlying decision, is subject to basic due process review. ${ }^{617}$ The federal government also reviews and administers selfregulatory bodies. The best example of this sort of delegation is the regulation of exchanges, in which securities dealers write their own regulations, then submit them to the SEC for review. ${ }^{618}$ Once ap-

611. See id. at 6 .

612. Id. at 15 .

613. Id. at 15-16 (citations omitted). In United States v. Rock Royal Coop., 307 U.S. 533, 547 (1939), the Court rejected a challenge to a statute allowing the Secretary of Agriculture to fix prices for milk, after a two-thirds vote of producers. The two-thirds could be measured by numbers of producers or by volume of milk produced. See id. at 547-48. Citing Currin, the Supreme Court held that since Congress could have implemented the rule directly, and the rule was very specific, "it is permissible for [Congress] to provide for approval or disapproval in such way or manner as it may choose." Id. at 578.

614. The leading articles documenting this trend are Freeman, supra note 29; David M. Lawrence, Private Exercise of Governmental Power, 61 IND. L.J. 647, 689-94 (1986) (describing the extent of delegation to private parties); and Liebmann, supra note 339, at 717-18 (concluding that there is a wide scope of such delegation).

615. See generally Abramson, supra note 338; Liebmann, supra note 339.

616. See, e.g., 20 U.S.C. $\S \S 403(b)(5)$ (codifying the National Defense Education Act of 1958), 751(f)(5) (providing grants and loans for construction of academic facilities) (1994).

617. See Marjorie Webster Jr. College, Inc. v. Middle States Ass'n of Colleges \& Secondary Sch., Inc., 432 F.2d 650, 658 (D.C. Cir. 1970).

618. See 15 U.S.C. $\$ \S 78-83$ (1994); Liebmann, supra note 339, at 701. 
proved through ordinary notice and comment rulemaking, the securities dealers' rules take on the force of law.

\section{E. Due Process Issues}

Given its reception since the 1930s, it seems fair to ask if Carter Coal is still good law. ${ }^{619} \mathrm{~A}$ fair answer is that, while the federal courts have largely acquiesced to Congress's loaning out its legislative power to actors not conceived via Article I, the demand that this power be exercised with due process remains vital. ${ }^{620}$ The Carter Coal doctrine is known as a nondelegation doctrine, but in a way the name is misleading. Unlike the public nondelegation doctrine, which relies on the separation of powers to prevent Congress from making standardless delegations to administrative agencies, the Carter Coal doctrine forbidding delegation of public power to private groups is, in fact, rooted in a prohibition against self-interested regulation that sounds more in the Due Process Clause than in the separation of powers. The evil that the Carter Coal doctrine seeks to avoid is that of a private person being a judge or regulator, especially where there is a possible conflict of interest. ${ }^{61}$ The danger comes in its starkest form when some members of an industry are given the power to regulate their competitors, but is present whenever a judge or regulator lacks the neutrality due process demands. Viewed this way, it is not surprising that in Luxton v. North River Bridge ${ }^{622}$ the Supreme Court unanimously agreed that it was "beyond dispute" that Congress may give a private corporation the power of eminent domain, ${ }^{623}$ because a government-sponsored taking entitles the owner to just compensation-which can be secured

619. See Louis L. JafFe, Administrative Law, CASES And Materials 49 (1953) (querying whether the nondelegation doctrine is good law); Abramson, supra note 338, at 193 (arguing that the Court abandoned the private nondelegation doctrine after Carter Coal); Lawrence, supra note 613, at 672 (same); $c f$. JOHN HART ELY, DEMOCRACY AND DISTRUST 133 (1980) (noting that the decline of the nondelegation doctrine is "a case of death by association" with unpopular positions).

620. The Supreme Court's grant of certiorari in American Trucking, however, potentially puts all the nondelegation issues related to agencies' rulemaking powers back on the table-for the first time since the New Deal. See American Trucking Ass'ns, Inc. v. EPA, 175 F.3d 1027, 1033 (D.C. Cir.), modified in part and reh'g en banc denied, 195 F.3d 4 (D.C. Cir. 1999), cert. granted sub nom. Browner v. American Trucking Ass'ns, Inc., 120 S. Ct. 2003 (2000), and cert. granted sub nom. American Trucking Ass'ns, Inc. v. Browner, 120 S. Ct. 2193 (2000).

621. See Lawrence, supra note 614, at 659.

622. 153 U.S. 525 (1894).

623. Id. at 529-30. The corporation's charter required that it pay "proper compensation... ascertained according to the laws of the State" within which the property taken was located. Id. at 527 n.1. 
in court if necessary. Anyone harmed by self-dealing would have a full remedy.

The strongest argument for the continuing vitality-or, if need be, revival-of the Carter Coal doctrine is that undue delegations to private parties entrench a kind of officially sanctioned self-interested regulation that violates due process or equal protection. ${ }^{624}$ It was the self-interested regulation that the Carter Coal Court called the "most obnoxious form" of delegation. ${ }^{625}$ Several courts ${ }^{626}$ and commentators $^{627}$ have agreed that delegations to private groups are more troubling than those to public agencies because the accountability mecha-

624. See Carter v. Carter Coal Co., 298 U.S. 238, 311 (1936).

625. Id.

626. Delegations of administrative authority are suspect when they are made to private parties, particularly to entities whose objectivity may be questioned on grounds of conflict of interest. See, e.g., Carter Coal, 298 U.S. at 311 (holding that a statute that empowers large coal producers and miners to set maximum hours and minimum wages for themselves and for small coal producers and miners "is so clearly arbitrary, and so clearly a denial of rights safeguarded by the due process clause of the Fifth Amendment, that it is unnecessary to do more than refer to decisions of this court which foreclose the question"); Washington ex rel. Seattle Title Trust Co. v. Roberge, 278 U.S. 116, 122 (1928) (stating that the legislature may not hand de facto control over the regulatory process to private parties, "uncontrolled by any standard or rule," who are "not bound by any official duty, but are free to withhold consent for selfish reasons or arbitrarily"); General Elec. Co. v. New York State Dep’t of Labor, 936 F.2d 1448, 1455 (2d Cir. 1991) ("[A] legislative body may not constitutionally delegate to private parties the power to determine the nature of rights to property in which other individuals have a property interest, without supplying standards to guide the private parties' discretion."); Sierra Club v. Sigler, 695 F.2d 957, 963 n.3 (5th Cir. 1983) ("[A]n agency may not delegate its public duties to private entities, particularly private entities whose objectivity may be questioned on grounds of conflict of interest."); Schulz v. Milne, 849 F. Supp. 708, 712 (N.D. Cal. 1994) ("[T]he state may not constitutionally abdicate or surrender its power to regulate land-use to private individuals without supplying standards to govern the use of private discretion.”); Texas Boll Weevil Eradication Found. v. Lewellen, 952 S.W.2d 454, 475 (Tex. 1997) (striking down an act of the legislature authorizing the creation of the Official Cotton Growers' Boll Weevil Eradication Foundation as an overbroad delegation of power to private parties).

627. See, e.g., Jaffe, supra note 219, at 247-53 (discussing safeguards such as judicial review and delegations only to experts); Lawrence, supra note 614, at 689-94 (suggesting methods which should be available to hold private delegates accountable, such as public rights to damages and standards guiding the delegates); Liebmann, supra note 339, at 717-18 (questioning the mechanisms available to the public to check private delegates); Hans A. Linde, Structures and Terms of Consent: Delegation, Discretion, Separation of Powers, Representation, Participation, Accountability?, 20 CARDOZO L. REV. 823, 851 (1999):

Authority to make rules enforceable as public law may be delegated to regulatory or managerial agencies composed of interested private persons only with adequate standards capable of further review, and with clear direction that the persons are to use their knowledge to serve the public rather than private interests.... When governments authorize private entities to organize large territorial or institutional communities, that authority is subject to the applicable principles governing public policymaking in political communities. 
nisms are weaker or non-existent. Although modern ideas of how much can be delegated to public bodies have changed substantially in the last ninety years, the principle that specific legislative authority should be required to support an otherwise dubious delegation by contract remains as sensible today as ever.

Thus, even though the Supreme Court has not decided a case turning on the private nondelegation doctrine in sixty years, ${ }^{628}$ there is reason to believe that Carter Coal's fundamental limit on delegations of public power to private groups retains its validity. ${ }^{629}$ Admittedly, the formal clues are sparse. While never overturned ${ }^{630}$ post-Schechter Poultry Supreme Court commentary on Carter Coal is rare. ${ }^{631}$ Many legal scholars have argued that the doctrine is or should be dead, ${ }^{632}$ although others have argued that it retains or deserves vitality. ${ }^{633}$

But while the Supreme Court has had no modern opportunities to revisit the private nondelegation doctrine, the state courts have had that chance, and their treatment of the issue underlines the importance of the doctrine today. Perhaps the best example comes from Texas, where the state supreme court recently reaffirmed the impor-

628. Justice Scalia noted, in dissent, that

the limits of delegation "must be fixed according to common sense and the inherent necessities of the governmental co-ordination." Since Congress is no less endowed with common sense than we are, and better equipped to inform itself of the "necessities" of government; and since the factors bearing upon those necessities are both multifarious and (in the nonpartisan sense) highly political ... it is small wonder that we have almost never felt qualified to second-guess Congress regarding the permissible degree of policy judgment that can be left to those executing or applying the law.

Mistretta v. United States, 488 U.S. 361, 415-16 (1989) (Scalia, J., dissenting) (quoting J.W. Hampton, Jr. \& Co. v. United States, 276 U.S. 394, 406 (1928)).

629. "The one aspect of the nondelegation doctrine that the Supreme Court has never disavowed is that Congress cannot delegate lawmaking functions to purely private bodies." Mark Seidenfeld, Empowering Stakeholders: Limits on Collaboration as the Basis for Flexible Regulation, 41 WM. \& MARY L. REV. 411, 457 n.199 (2000).

630. Many decisions and dissents, most recently the four dissenting Justices in United States v. Morrison, 120 S. Ct. 1740 (2000), list Carter Coal as being one of several decisions that misunderstood the nature of the Commerce Clause because it distinguished "mining" from "commerce," but do not discuss the nondelegation issue. See id. at 1767 (Souter, J., dissenting).

631. In a concurring opinion, Justice Marshall quoted with approval Carter Coal's statement that, "'[I]n the very nature of things, one [private] person may not be entrusted with the power to regulate the business of another, and especially of a competitor. And a statute which attempts to confer such power undertakes an intolerable and unconstitutional interference with personal liberty and private property." "New Motor Vehicle Bd. of Cal. v. Orrin W. Fox Co., 439 U.S. 96, 125-26 (1978) (Marshall, J., concurring) (quoting Carter Coal, 298 U.S. at 311).

632. See Liebmann, supra note 339, at 716 ("[T] he nondelegation doctrine, in its commonly expressed form, is nonsense.").

633. See supra note 570. 
tance of the doctrine after a thorough and scholarly examination of the role of the private nondelegation doctrine.

The Texas Constitution does not permit occupation taxes on agricultural products. ${ }^{634}$ In order to have cotton growers pay for a Boll Weevil eradication campaign, the Texas legislature authorized the Texas Commissioner of Agriculture to certify a nonprofit organization representing cotton growers to create an "'Official Cotton Growers' Boll Weevil Eradication Foundation." "'635 The Foundation in turn would be empowered to propose geographic eradication zones and to conduct referenda in each zone to see if the cotton growers in it wished to become an "eradication zone." Zones that voted yes would elect a member to represent them on the Foundation's board. ${ }^{636}$ The Foundation then would set proposed assessments for eradication efforts, which the growers would have to approve by referendum. ${ }^{637} \mathrm{Al}-$ though its funding required a confirmatory referendum, the statute gave the Foundation broad powers, including the powers to decide what eradication program to pursue, to take on debt, to penalize late payers of assessments, to enter private property for eradication purposes, and even to require the destruction of uninfected cotton crops for nonpayment of assessments. ${ }^{638}$ Very soon after the legislature passed the statute, a nonprofit corporation formed "to allow a forum for discussion of problems and activities of mutual interest to the Texas Cotton Industry, ${ }^{, 39}$ which had lobbied for the statute, ${ }^{640}$ and pe-

634. See TEX. CONST. art. VIII, § 1(c). The Texas Constitution does allow “"representative associations of agricultural producers with authority to collect such refundable assessments on their product sales as may be approved by referenda of producers." Texas Boll Weevil Eradication Found., Inc. v. Lewellen, 952 S.W.2d 454, 459 (Tex. 1994) (quoting TEX. CONST. art. XVI, $\S 68$ ). The fees at issue in the Boll Weevil case were not refundable, so they did not come under this exception. See id. at 461.

635. Id. at 457 (quoting TEX. AGRIC. CODE $§ 74.103(a)$ ).

636. See id. (citing TEX. AGRIC. CODE $\$ 74.106$ ).

637. The Texas supreme court explained the system as follows:

$[\mathrm{O}]$ nce the initial zone has been created and the first board member elected, the growers of that zone must approve the assessment to fund the eradication at a subsequent referendum. Thereafter, the board is authorized to determine the assessment needed for each additional participating zone, which must be approved by the growers at a referendum. The Foundation may collect the assessment only if the assessment referendum passes. Approval of a zone and of the assessment each requires a vote of either two-thirds of the cotton growers in the zone or of those who farm more than one-half of the cotton acreage in the zone. The election of board members, on the other hand, requires only a plurality vote.

Id. at 457 (citations omitted).

638. See id. at 458.

639. Id. at 480-81 (Hecht, J., concurring in part and dissenting in part).

640. See id. at 482. 
titioned the Commissioner of Agriculture to be allowed to form the Foundation. Upon receiving that permission, the corporation created the Foundation, and-in seeming morphic resonance with ICANNimpaneled an initial board (even though the statute had no prevision for one) and began operations. Growers subjected to the Foundations assessment soon brought suit.

The court began its discussion of the constitutionality of the delegation to the Boll Weevil Foundation by noting that many delegations to private parties were "frequently necessary and desirable," such as the delegation of the power to marry or the decision to promulgate existing or future versions of industrial codes and professional standards. ${ }^{641}$ Nevertheless, the court warned, delegations to private parties create greater dangers of conflict of interest and, thus, deserve more searching scrutiny, than do delegations, however great, to public bodies. ${ }^{642}$

There being an absence of judicially crafted standards available to guide whether such delegations were permissible, the court decided to craft them. ${ }^{643}$ It decided, based on its review of federal and state precedent, and of academic writings, that there were eight key questions:

1. Are the private delegate's actions subject to meaningful review by a state agency or other branch of state government?

641. Id. at 469.

642. The court cautioned:

$[\mathrm{P}]$ rivate delegations clearly raise even more troubling constitutional issues than their public counterparts. On a practical basis, the private delegate may have a personal or pecuniary interest which is inconsistent with or repugnant to the public interest to be served. More fundamentally, the basic concept of democratic rule under a republican form of government is compromised when public powers are abandoned to those who are neither elected by the people, appointed by a public official or entity, nor employed by the government. Thus, we believe it axiomatic that courts should subject private delegations to a more searching scrutiny than their public counterparts.

Id. at 469 .

643. See id. at 470 . The court continued:

Unfortunately, scholars have concluded that these cases do not yet, when taken together, evince a coherent constitutional standard. When Professor Davis issued the second edition of his treatise, for example, he abandoned his earlier effort to analyze the state law on private delegations "because identifiable principles do not emerge." We thus begin our analysis with full recognition that, if the delegation at issue is to a private entity, we must craft our own criteria to judge its constitutionality.

Id. (quoting Kenneth Culp Davis, 1 Administrative LaW Treatise $§ 3.12$, at 196 (2d ed. 1978)). 
2. Are the persons affected by the private delegate's actions adequately represented in the decisionmaking process?

3. Is the private delegate's power limited to making rules, or does the delegate also apply the law to particular individuals?

4. Does the private delegate have a pecuniary or other personal interest that may conflict with his or her public function?

5. Is the private delegate empowered to define criminal acts or impose criminal sanctions?

6. Is the delegation narrow in duration, extent, and subject matter?

7. Does the private delegate possess special qualifications or training for the task delegated to it?

8. Has the Legislature provided sufficient standards to guide the private delegate in its work ? $^{644}$

The court did not, however, explain how these eight factors were to be weighed. Instead, it found five factors weighing against the delegation, one in favor, and two either neutral or severable. ${ }^{645}$ A concurring justice was more blunt; he described the Foundation as "little more than a posse: volunteers and private entities neither elected nor appointed, privately organized and supported by the majority of some small group, backed by law but without guidelines or supervision, wielding great power over people's lives and property but answering virtually to no one."

A subsequent decision suggested that the first and fourth factors are the most important. The importance of the first factor reflects the

644. Boll Weevil, 952 S.W.2d at 472. The court presented this eight-item list as a condensation of the scholarly attempts to formulate a set of tests found at DAVIS, supra note 643, at 196; Jaffe, supra note 219, at 247-53; Lawrence, supra note 614, at 686-94; and Liebmann, supra note 339, at 717-18. See Boll Weevil, 952 S.W.2d at 471-72.

645. See id. at 473-75. In Proctor v. Andrews, 972 S.W.2d 729, 735-38 (Tex. 1998), the Texas Supreme Court found seven factors favoring the delegation of the power and only one against, so it upheld a statute requiring cities to use neutral privately-appointed arbitrators in certain civil service disputes. In FM Properties Operating Co. v. City of Austin, 22 S.W.3d 868, 888 (Tex. 2000 ), the court held that a provision of the Texas Water Code, which allowed certain private landowners to create "water quality protection zones" in which they would be exempt from a number of environmental and land-use regulations, had unconstitutionally delegated legislative power to private landowners.

646. Boll Weevil, 952 S.W.2d at 479 (Hecht, J., concurring in part and dissenting in part). 
fact that "one of the central concerns in private delegations is the potential compromise of our "democratic rule under a republican form of government." ${ }^{647}$ The fourth factor gains pride of place because the nondelegation doctrine's "other central concern is the potential that the delegate may have a "personal or pecuniary interest [which is] inconsistent with or repugnant to the public interest to be served.'

While the post-New Deal federal judicial record is consistent with claims that Carter Coal may be a candidate for desuetude, these decisions of the Texas supreme court demonstrate that the principles that animated the private nondelegation doctrine remain valid and are, if anything, more relevant today than ever. ICANN is only an extreme example of a more general phenomenon in which suspicion of government and exaltation of the private sector have led to a general push for privatization. ${ }^{649}$ While privatization may be a more efficient way to produce goods and services, there is no reason to believe that privatized governance is preferable to a system in which government is elected by and responsible to the governed. Covert corporatism should not be confused with privatization. ${ }^{650}$

It remains the case that it is Congress's inalienable role to make "the important choices of social policy" power will be used. Giving private bodies or small groups of citizens the right to commandeer the power of the state to make decisions that affect neighbors, fellow citizens, competitors, or customers undermines democratic, or republican, government and creates a dangerous opportunity for self-interested regulation.

647. FM Properties Operating Co., 22 S.W.3d at 875 (quoting Boll Weevil, 952 S.W.2d at 469).

648. Id. (quoting Boll Weevil, 952 S.W.2d at 469).

649. See generally Freeman, supra note 29, at 543 (providing examples of private actors' roles in administrative contexts and arguing that there is neither a purely private realm, nor a purely public one).

650. Cf. Michael J. Astrue, Health Care Reform and the Constitutional Limits on Private Accreditation as an Alternative to Direct Government Regulation, 57 LAW \& CONTEMP. PROBS. 75, 81 (1994) (suggesting that the nondelegation doctrine may soon show new life in part because of increasing reliance on private policymaking intermediaries in government-sponsored health care systems).

651. Cf. Industrial Union Dep't v. American Petroleum Inst., 448 U.S. 607, 685 (1980) (Rehnquist, J., concurring) (describing the three vital functions served by the public nondelegation doctrine). 


\section{F. $\quad$ Structural Failures/Self-Dealing}

The White Paper's vision of NewCo, and especially ICANN's instantiation of it, proved be corporatist in form, but not in spirit, as substantial interest groups remained unrepresented while ICANN took critical decisions. Some "stakeholders" proved to be much better represented than others, and they used their initial dominance to entrench their position. Although the major cause of this dominance was ICANN's articles of incorporation and its bylaws, which institutionalized this over-representation, the favored "stakeholders" were able to entrench themselves by taking advantage of two factors: time and money.

1. Time. ICANN's structure taxes time as well as money. The profusion of constituencies, working groups, ad hoc committees, and the like means that only those with an enormous amount of time to devote to ICANN issues can stay abreast of every developing "consensus" policy. In practice, those who can afford to pay someone to represent them-predominantly commercial interests who hire lawyers or delegate managers to be their spokespersons-are able to dominate. Unorganized groups, such as users or small businesses, must rely on volunteers ${ }^{652}$ and tend to be outnumbered in committee. Thus, for example, ICANN's working group B announced a rough consensus for increased rights for trademark holders, above those already provided by the UDRP - a conclusion it based on a poll in which representatives of trademark owners cast more than half the votes. ${ }^{653}$ While trademark owners are important, and have legitimate interests, they do not make up half the current or future users of the Internet, nor of the U.S. population, nor any other group one would probably choose to poll to find "consensus" on DNS policies. Perhaps this result was not surprising, given that the working group was headed by the chair of the registrars' constituency-a group whose commercial interests required at least a few non-NSI dominated gTLDs in order to have new names to register and whose public

652. One exception to the general rule has been the Office of Advocacy of the U.S. Small Business Administration, which-once it learned of the process-argued vigorously to protect the interests of U.S. small businesses.

653. See Michael Palage, Working Group B Final Report, Domain Name Supporting Organization, at http://www.dnso.org/clubpublic/council/Arc03/msg00648.html (last visited Oct. 1, 2000) (on file with the Duke Law Journal). 
position was, therefore, often to make almost any concession needed to overcome opposition to the creation of new gTLDs. ${ }^{654}$

For an entity designed to make rules relating to the Internet, ICANN and its subsidiaries seem oddly dependent on attendance at physical meetings. Because ICANN sees itself as global, its meetings are peripatetic. ${ }^{655}$ This policy, which has the advantage of making it more possible for geographically disparate groups to attend the occasional board meeting, also makes consistent participation by those without substantial expense accounts impossible. People who cannot attend meetings of the board are able to take part in debates in only the most limited and derivative way - the few remote comments read to the meeting are filtered and edited by the readers, as contrasted to attendees, who queue for a microphone and can say whatever they like. The problem is equally pronounced in subsidiary groups such as DNSO functional constituencies and working groups. Indeed, the pay-to-play aspect of ICANN reached its zenith recently when the intellectual property constituency announced that members seeking to participate in its Vienna meeting would have to defray the access fees demanded by the local hosts-a sum it admitted was four times the normal rate. ${ }^{656}$

2. Money. ICANN's financial dependence on low-interest unsecured loans from corporations that have a large interest in ecommerce and the Internet, such as MCI and IBM, creates at least the appearance of a conflict, particularly as during the time ICANN was soliciting and then spending these funds it also worked diligently to minimize the extent to which ordinary domain name users would be able to elect members of the ICANN board. ${ }^{657}$

654. See Judith Oppenheimer, New TLD's at Any Price, Part 2, at http://icbtollfree.com/txt/ release-14Part2.htm (last visited Oct. 1, 2000) (quoting Registrars' Constituency \& Working Group B Chair Michael Palage as saying, "The trademark lobby must be placated because of its potential ability and inclination to bankrupt new registrars and wreck havoc on their registrant databases") (on file with the Duke Law Journal).

655. ICANN meets four times per year, with each meeting on a different continent.

656. See E-mail from Michael K. Kirk, IPC Constituency President, to Members of the IPC (Sept. 13, 2000) (on file with the Duke Law Journal).

657. Some observers have also suggested that the extraordinary extent to which ICANN's expenses have been dominated by payments to its law firm and its supposedly interim CEO also raises questions of conflict of interest. See, e.g., Karl Auerbach, Platform, Reform of ICANNFinancial Reform, at http://www.cavebear.com/ialc/platform.htm\#financial-reform (last updated Aug. 10, 2000) (on file with the Duke Law Journal). 
ICANN has a policy on conflicts of interests, ${ }^{658}$ but it is difficult to have confidence that it is being honored. As the policy provides for no meaningful public review, and requires no public statements as to the extent of conflicts, the public is, in any case, unable to monitor compliance. In March 1999, ICANN adopted a conflicts of interest policy applying to directors and certain other interested persons with "[a]n existing or potential ownership or investment interest in, or compensation arrangement with, any entity whose business or operation has been or will be directly affected by a decision or action of the Corporation." ${ }^{659}$ Directors must disclose conflicts to the Committee on Conflicts of Interest, ${ }^{660}$ currently composed of two members of the ICANN board, ${ }^{661}$ and have a duty to abstain from board votes (but not discussions) relating to matters in which they have a conflict. The committee meets in secret, and, at least as of October 1, 2000, neither the statements (if any) made to the committee nor minutes of its meetings appear on the ICANN website.

Under the ICANN bylaws and the Conflict of Interest Policy, officers of supporting organizations have a duty to observe the supporting organization's rules on conflicts, but ICANN apparently has no duty to monitor whether there are such rules, and whether they are observed. As far as one can tell-some constituencies have not published their rules ${ }^{662}$-none of the constituencies have any rules re-

658. See Meetings of the Initial Board, at http://www.icann.org/minutes/minutes-4mar99.html (Mar. 4, 1999) (adopting a conflicts of interest policy) (on file with the Duke Law Journal).

659. Conflicts of Interest Policy, \$2.3(d), at http://www.icann.org/general/coi-policy.htm (Mar. 4, 1999) (on file with the Duke Law Journal).

660. See ICANN Amended Bylaws, supra note 541, art. V, § 7,:

The Board, through a committee designated for that purpose, shall require a statement from each Director not less frequently than once a year setting forth all business and other affiliations which relate in any way to the business and other affiliations of the Corporation. Each Director shall be responsible for disclosing to the Corporation any matter that could reasonably be considered to make such Director an "interested director" within the meaning of Section 5233 of the California Nonprofit Public Benefit Corporation Law ("CNPBCL"). In addition, each Director shall disclose to the Corporation any relationship or other factor that could reasonably be considered to cause the Director to be considered to be an "interested person" within the meaning of Section 5227 of the CNPBCL. The Board shall adopt policies specifically addressing Director, Officer and Supporting Organization conflicts of interest. No Director shall vote on any matter in which he or she has a material and direct interest that will be affected by the outcome of the vote.

661. See Committee of the Board on Conflicts of Interest, at http://www.icann.org/general/ conflicts-committee.htm (last visited Oct. 1, 2000) (stating that the current members of the committee are Eugenio Triana (Chair) and Rob Blokzijl) (on file with the Duke Law Journal).

662. There do not appear to be published rules for the ASO, the PSO, or the gTLD constituency (which currently has only one member). 
lating to conflict of interest. ${ }^{663}$ Since some functional constituencies of the DNSO, such as the registrars' and registries' constituencies, for example, limit their membership to parties involved in businesses that are highly likely to be affected by ICANN's policies, it is a little difficult to imagine what a meaningful conflicts policy for those bodies would look like.

ICANN's failure to solve the problem of conflicts of interest has understandable causes, but the failure impinges nonetheless on the values against the self-interested regulation that Carter Coal held were the real evil of private regulatory bodies. First, as the example of the registrars' and registries' constituencies demonstrates, a corporatist organization requires self-interested industrial regulation-that is the whole point of it. Second, many of ICANN's directors and supporters come from cultures that lack what they see as an American puritanical insistence on needless inefficiency. Different nations have

The ASO's MoU with ICANN does state: "Selection of the RIR's members of the Address Council will be made via an open and transparent procedure. The individuals selected for the Address Council must not be staff members of any RIR." Memorandum of Understanding, ICANN Address Supporting Organization, § 2 (a)(v), at http://www.aso.icann.org/docs/asomou.html (Oct. 18, 1999) (on file with the Duke Law Journal). There is no similar provision in the PSO's MoU. See Memorandum of Understanding, ICANN Protocol Supporting Organization, at http://www.icann.org/pso/pso-mou.htm (July 14, 1999) (on file with the Duke Law Journal).

663. There are seven constituencies: (1) the ccTLD constituency, see Principles of the ccTLD Constituency of the DNSO, ccTLD Constituency of the DNSO, at http://www.wwtld.org/aboutcctld/history/wwtld1999/const-principlesV4.html (May 25, 1999) (making no mention of conflicts of interest) (on file with the Duke Law Journal); (2) the business constituency, see Commercial and Business Entities Constituency Charter, supra note 222 (setting out the framework for the structure and rules of the business constituency); (3) the gTLD registry constituency, see gTLD Registry Constituency, the gTLD Registry Constituency, at http://www.gltdregistries.org/ (last visited Sept. 30, 2000) (containing no published charter/rules section) (on file with the Duke Law Journal); (4) the ISPCP constituency, see ICANN/DNSO Constituency Groups, Domain Name Server Organization, at http://www.dnso.org/constituency/ispcp/ispcp.html (last visited Sept. 30, 2000) (summarizing ISP's and Connectivity Providers section) (on file with the Duke Law Journal); see also Articles for the ISPs and Connectivity Providers Constituency Group Within the DNSO (ISPCP), Domain Name Server Organization, at http://www.dnso.org/constituency/ispcp/ISPCP. Articles.html (last visited Sept. 30, 2000) (detailing the framework, mission and purpose of this constituency) (on file with the Duke Law Journal); (5) the NCDNH constituency, see NCDNH Constituency Charter, the NCDNH Constituency, at http://www.ncdnhc.isoc.org/docs/charter/ drafts/19990816.html (last visited Oct. 11, 2000) (detailing the goals, membership rules and voting procedures of the Non-Commercial Domain Names Holders Constituency) (on file with the Duke Law Journal); (6) the DNSO registrar constituency, see The DNSO Registrar Constituency, supra note 222 (outlining the structure of the registrar constituency); (7) the intellectual property constituency, see By-Laws of the Intellectual Property Constituency, supra 222 (detailing the goals, membership rules and voting procedures for the Intellectual Property Constituency). 
different standards regarding what constitutes improper conflicts of interest (and what, on the other hand, is better seen as "hands-on knowledge"); few countries go as far as the United States in seeking to avoid even the appearance of a conflict of interest. ${ }^{664}$

Key members of the ICANN staff believed that while corporations deserved to be represented, even those whose only interest was protection of their trademarks, registrants did not deserve to be represented, at least not directly, in what they believed was really a standards body. ${ }^{665}$ As, Joe Sims, who drafted many of the early ICANN policies, put it, the risk that "a determined minority-whether commercial, religious, ethnic, regional or otherwise" might capture control of nine at-large ICANN board seats on the projected nineteenperson board was so threatening that ICANN felt it needed to exclude direct end-user input into ICANN's decisions. ${ }^{666}$ ICANN, therefore, sought on several occasions to find a formula that would limit the role of individuals in electing ICANN board members ${ }^{667}$ while not setting off a political firestorm. The consequence of this policy, however, was to entrench a body run by the very "private persons whose

664. See generally YVES DEZALAY \& BRyANT GARTH, DEAling IN VirTuE: INTERNATIONAL COMMERCIAL ARBITRATION AND THE CONSTRUCTION OF A TRANSNATIONAL LEGAL ORDER (1996) (describing interviews with arbitrators and arbitration practitioners which reveal very different worldviews relating to questions of independence and conflict of interest); Mary C. Daly, The Ethical Implications of the Globalization of the Legal Profession: A Challenge to the Teaching of Professional Responsibility in the Twenty-first Century, 21 FORDHAM INT'L L.J. 1239, 1288-93 (1998) (comparing the strict U.S. conflict of interest rules for lawyers with non-U.S. rules); Robert E. Lutz, Current Developments in the North American Free Trade Agreement: A Guide for Future Economic Integration Efforts, 18 WHITTIER L. REV. 313, 318-19 (1997) (noting the different views between Mexican and American lawyers).

One striking example of this phenomenon was the heated statement by ICANN board member Hans Kraaijenbrink that although he was a member of the executive board of the European Telecommunications Network Operators, an organization that had submitted a DNSO proposal, he would not recuse himself from the board debate considering their application. See ICANN Public Meeting_Meeting Proceedings Archive: Meeting Held in Suntec City, Downtown Singapore, Berkman Center for Internet and Society, at http://cyber.law.harvard.edu/icann/singapore-0399/archive/Domain Name Supporting Organization applications (Mar. 3, 1999) (audio archive of ICANN meeting, with Kraaijenbrink's comments beginning at 1:05:00).

665. See Weinberg, supra note 39, at $245 \&$ n.287 (discussing the limited role of representation in the standards body).

666. Posting of Joe Sims, Joe_Sims@jonesday.com, to comments-bylaws@icann.org (Oct. 23, 1999) (on file with the Duke Law Journal). For the entire dialogue between Sims and Froomkin, see A. Michael Froomkin, Personal Comments on the WIPO/ICANN Process, at http://www.law.miami.edu/ amf (last visited Sept. 30, 2000) (on file with the Duke Law Journal).

667. See supra note 39 . 
interests may be and often are adverse to the interests of others in the same business" ${ }^{, 668}$ - not to mention adverse to other types of interests that were not represented in the process.

\section{REFORMING THE U.S. DNS POLICY}

The Constitution constrains governmental action "by whatever instruments or in whatever modes that action may be taken." ${ }^{669}$

ICANN is a flawed attempt to tackle a genuinely difficult policy problem: what the U.S. government should do with its almost accidental control over the DNS, an essential element of an increasingly global communications network. The DNS problem is complicated because of its significance to e-commerce and expressive rights, its international aspects, its affect on trademark and perhaps other intellectual property rights, and because control over the DNS could be misused if it fell into the wrong hands. Further complicating matters, while the United States currently has de facto control over the DNS, and its direct control of a minority of the root servers makes it difficult to see how anyone else could supplant it, the legal basis and likely permanence of that control are not beyond any imaginable challenge. Last, but not least, Congress has yet to legislate on DNS management other than to pass one bill providing private rights against cybersquatters. ${ }^{670}$

As noted above, opinions differ as to how one should characterize the legal status of the U.S. government's de facto interest in the DNS. The government controls the root file itself, but this data file is small and easily replicated or relocated. The root file matters only because of the convention-not currently reflected in any statute or contract - that the root servers will rely on it. The government's interest is not easily described as either a property interest or an intellectual property interest. Arguably, the government's main legal interest may be as the beneficiary of contracts with NSI and others who manage the DNS for it.

668. Carter v. Carter Coal Co., 298 U.S. 328, 311 (1936); cf. Patrick Greenwell, Despite Our Best Efforts, ICANN Fails in Many Respects, at http://www.icannwatch.org/archives/essays/ 944584730.shtml (Dec. 7, 1999) (accusing ICANN CEO Mike Roberts of conflicts of interest) (on file with the Duke Law Journal).

669. Lebron v. National R.R. Passenger Corp., 513 U.S. 374, 392 (1995) (quoting Ex parte Virginia, 100 U.S. 339, 346-47 (1880)).

670. See Anticybersquatting Consumer Protection Act, 15 U.S.C.A. $§ 1125$ (d) (West Supp. 2000). 
Nevertheless, whichever characterization of the government's legal interest prevails, there is no dispute that the U.S. government, through the Department of Commerce, currently enjoys de facto control of the DNS. Nor is there any dispute that DoC has at least temporarily ceded to ICANN, through a variety of contractual and quasicontractual agreements, almost all the control the United States enjoys. DoC has, however, explicitly reserved a right of review, the power to create new top-level domains, and the contractual right to replace ICANN with another body or take over DNS management directly.

This control imposes legal obligations on the United States which it cannot evade so long as it remains in ultimate control of the DNS and chooses to exercise its power or to allow others to exercise power in its stead. That is as it should be; the government should not be allowed to bob and weave around the Constitution's imposition of duties of due process and equal protection through the creation of formally private intermediaries for policymaking. Nor should government contracts become a means to alter the legal rights of millions of citizens under the guise of technical coordination, even in a relatively peripheral area such as claims of trademark infringement or cybersquatting.

\section{A. The Policy Problem}

In trying to frame a policy for the DNS in 1998, DoC faced a daunting set of problems and conflicting agendas:

- Jon Postel had been forced to abandon his attempt to create hundreds of new TLDs in the face of opposition from trademark owners and Internet first-movers who wished to protect their mnemonic domain names against competitors. Unless something changed, a stalemate on new gTLDs seemed likely to continue just as the e-commerce revolution seem poised for exponential growth.

- The pre-ICANN DNS system-in which Jon Postel and a few others ran the system more or less as they wished, making policy by creating and following a consensus among the technical elite that founded the Internet, subject only to occasional direction by NSF-was proving inadequate to deal with the economically and legally charged environment created by the domain name land rush of the 1990s. The naming of IANA as a nonparty conspirator in a law- 
suit, even one that was ultimately dismissed, signaled that Postel needed reinforcements.

- The U.S. government's control over the DNS was more accidental than anything else, and U.S. officials were receptive to arguments by friendly governments that it was unreasonable for the United States to hold such power over a control point that seemed likely to be bound into the sinews of every developed economy's commercial, social, political, and even artistic life.

- NSI was entrenching itself in its monopoly of gTLD registrar and registry services. Would-be market entrants were clamoring for access, and would-be registrants wanted new gTLDs.

- The criticism that greeted the Green Paper suggested that perhaps DoC was not going to be able forge a consensus itself. DoC genuinely did not know how to resolve all the issues in a mutually satisfactory way-perhaps because that was impossible.

Most of these problems are if anything more real, and more pressing, today.

The menu of possible solutions on offer in 1998 probably did not look appealing. The existing system of DNS governance did not look as if it could be left untouched, as it was ossifying and coming under increased pressure from foreign governments, domestic rights holders, and would-be dot-coms wanting new catchy names. Although it would have been legal for the U.S. government to do nothing-just walk away and hope for true privatized self-organization to manifest itself-policymakers undoubtedly believed, with some reason, that this would have been irresponsible since there was a significant chance that no such market resolution would occur. Yet, the hostile reaction to the Green Paper-a sincere if perhaps flawed attempt to make traditional regulations to sort out the DNS problem-made direct regulation appear to be an unattractive choice. Even if a rule could have been crafted that was within DoC's authority, it seemed certain to be unpopular with one or more of the powerful interest groups weighing in on the issue. In contrast, self-regulation not only seemed to be consistent with the Internet's folkways and a political climate in which the "era of big government" was so notoriously over, but it offered the possibility of taking the administration out of the 
line of increasingly hostile fire into which it had somewhat inadvertently walked.

DoC, or at least Ira Magaziner, found the rhetoric and reality of privatization and "stakeholder" governance congenial. Calling for self-governance seemed a political winner, and it seemed most likely to meet with wide acceptance. In this, at least, it succeeded. Although the DNS wars were already at a high pitch, from my personal observation most of the participants accepted (at least in public) that the White Paper was as close to a statement of community and "stakeholder" consensus as one was likely to get. It only emerged later that different people read quite different things into the White Paper's four principles ${ }^{671}$ and that the faction that came to control ICANN would justify its de-emphasis of representation under the banner of "stability."

\section{B. ICANN Sets a Terrible Precedent}

For all of its problems, ICANN commands substantial support, and not all of it from the stakeholders who dominate it. Many believe that the need for some sort of management of the DNS is so pressing that, until they see a viable alternative, ICANN is the only game in town. (Others, who wish to preserve the status quo as long as possible, may see ICANN as the least bad way of blocking change.) To many of the participants in the DNS wars, especially old Internet hands imbued with the libertarian traditions of the founders of the Internet, anything that takes power away from government is presumptively, and sometimes irrebuttably, better than a governmental solution.

These views are mistaken, if only because there is more at stake here than the Internet. Even if ICANN were thought to be a good thing, a narrow focus on the Internet ignores the pernicious effect of ICANN on the U.S. government itself and on our democracy-for there is a real danger that ICANN will not be a fluke but will be used as a model for additional erosions of responsible government. ${ }^{672}$ DoC's use of ICANN undermines accountability. Every government power must be exercised in accordance with law and with the Constitution. But ICANN is a private nonprofit California corporation; unless it is a government actor or advisory committee, neither the APA

671. See supra notes $188-89$ and accompanying text (listing the four principles).

672. See supra note 36 and accompanying text. 
nor the Constitution apply to it. The APA and the Constitution apply to DoC, however, and this is where the main violation of law is to be found. Allowing DoC to use ICANN to make non-technical policy decisions violates basic norms of governance and accountability. DoC cannot quasi-privatize the DNS in a manner that allows the United States to retain ultimate control of the root zone file but achieve deniability about everything that its agent or delegate does with day-today control.

ICANN is sufficiently dependent on and symbiotic with the government for ICANN to be a government actor. Although the government did not formally incorporate ICANN, and does not directly fund it, the government:

- called for a body like ICANN to be created;

- described in the White Paper what policies this body should enact;

- demanded, and got, specific changes in ICANN's organization;

- recognized ICANN as the "NewCo" called for in the White Paper once it was "spontaneously" incorporated in California;

- transferred to ICANN control over IANA and/or "the IANA function";

- ensured that ICANN's control over the DNS would suffice for it to be able to charge fees from registrars, registries, and applicants for new gTLDs;

- kept ICANN on a short contractual timetable, ensuring that ICANN would have to perform as DoC wished, or lose its source of funding and reason for being;

- recently extended ICANN's lease on the DNS, thus in effect ratifying its actions to date.

If ICANN is a government actor, then DoC's use of ICANN to make what are for all intents and purposes binding rules affecting every registrant of a domain name in .com, .org, or .net amounts to making rules without APA rulemaking. Alternately, if ICANN is not 
a government actor, then DoC's decision to turn over to ICANN the government's control over the DNS is a violation of the Carter Coal doctrine of prohibiting delegations of social policymaking authority to private groups. That doctrine is not violated when the government relies on private groups to set technical standards. And, indeed, whether or not one agrees with ICANN's decisions, a substantial fraction of what ICANN has done to date could fairly be described as technical. But this is clearly not true of the most critical and controversial decision so far, ICANN's mandatory arbitration policy, the UDRP. The UDRP cannot fairly be called "technical coordination" when its sole purpose and effect is to alter the legal rights of domain name registrants in favor of trademark holders.

If ICANN is not a government actor, and if it were to limit itself to a purely technical role, DoC's reliance on it would be legal. In enacting the UDRP, however, ICANN exceeded this limitation, and it seems set to do it again soon. ICANN's plan to choose a small number of new gTLDs seems likely to enmesh it in improper social policy judgments once again. Choosing the number of new gTLDs that would be created might have been a technical rather than social policy issue-if there really were technical limits on the number the DNS can bear. ${ }^{673}$ Prescribing the minimum standards that would make an applicant technically qualified to run a new gTLD registry would be a technical, not a social, choice. Adjudicating which applicants met that standard could be described as technical policy coordination, although it is a bit of a stretch. Doing what ICANN plans to do, which is making this adjudication without first having spelled out the standard to be applied, is an even greater stretch of the concept of "technical coordination," and in theory could, depending on the decisions, rise to the level of "arbitrary and capricious." If, however, there are more technically qualified applicants for new gTLDs than ICANN wishes to create, and ICANN chooses among them based on some idea of the quality or usefulness of the proposed gTLD, or the extent to which the applicant promises to enact social policies such as privacy or trademark protection, then ICANN will have clearly crossed the line into making social rather than technical policy. It cannot seriously be suggested that choosing whether the world is better served

673. In fact, however, if there is a technical limit on the number of additional gTLDs that the DNS can bear, it is likely to be a far larger number than the less than 10 that ICANN currently contemplates creating. See supra note 12 . Recall, for example, that Jon Postel himself proposed creating hundreds of gTLDs. See supra notes 148-50 and accompanying text. 
by .banc, .shop, or .xxx is an issue with any "technical" content whatsoever. This is a question of social and political import only; the technical issues are identical whatever a TLD happens to be called. As such, the selection among technically qualified applicants on social merit is a decision that DoC cannot delegate to ICANN so long as the DNS remains in DoC's ultimate control.

\section{A Better DNS Policy is Within Our Grasp}

If the current quasi-privatization of the DNS is illegal, then DoC needs a new policy to deal with the DNS. DoC has at least four options: (1) design structures that limit ICANN to true technical policy; (2) get out of the DNS business by turning over the DNS to ICANN or another private body; (3) create a new public international body to take over the DNS or recruit an existing one to do the job; or (4) take advantage of the serendipity of U.S. government control of the DNS to make simple and enlightened rules that would help ensure Internet stability and satisfy legitimate foreign concerns as to U.S. dominance, while preserving the Internet's diversity. None of these options is without its costs, but a distinctly superior policy could be crafted by combining the first and the fourth into a hybrid plan.

1. Limit ICANN to Technical Policymaking? So long as DoC wishes to keep its control over the DNS, it must ensure that it and its agents exercise this power according to law. Some sort of narrowing of ICANN's scope is necessary if DoC is to continue to use it as its agent for DNS matters. Closely restricting ICANN to truly technical matters would also reduce the need for a more popular and democratic representation within ICANN itself. There is usually little need to get a popular vote on truly technical issues; the need for enhanced representation in ICANN comes from the combination of the exclusion of some interest groups and the reality that ICANN is currently not at all limited to technical issues.

a. Restriction by fiat. This solution is by far the easiest to initiate, although not perhaps the easiest to monitor. DoC could simply direct ICANN to restrict itself to purely technical questions, either by rulemaking or even as an amendment to its various agreements with ICANN. Of course, the line between "technical" and "policy" matters is not a perfectly bright one, which means that DoC's instruction would have to be drafted with care. Even so, it 
should be possible to come up with a formulation that would, at least in most cases, separate permissible "technical coordination" from impermissible "regulation." We ought to be able to know it when we see it, and matters on the "policy" side of the line would have to be undertaken by DoC itself, via rulemaking, or not done at all.

Karl Auerbach, now an ICANN board member-elect, ${ }^{674}$ has proposed one definition to delineate the technical from the political. In his view, a matter is "technical coordination" of the Internet only if "[a] wrong decision has an immediate and direct impact on the ability of the Internet to deliver its fundamental service, i.e. the end-to-end transport of IP packets. Otherwise it is a policy matter." ${ }^{, 675}$ Although this formula has the attractive property of being clear, it is probably too restrictive to be acceptable to $\mathrm{DoC}$, and, indeed, is probably more restrictive than the law requires. There are some matters that could reasonably be called "technical coordination" which do not have an immediate or direct effect on Internet stability, only a long-term one, or which make incremental improvements in the DNS. Deciding what information belongs in a completed domain name registration, for example, may not be critical to Internet stability immediately, but might not in many cases be anything other than technical. ${ }^{676}$ Dropping the "immediate" would limit ICANN to matters that "directly impact the end-to-end transport of IP packets," which probably gets closer to a practicable rule.

Although this proposal would be relatively simple to initiate, it is not self-enforcing and would require a continuing monitoring effort by DoC.

b. Creating a domain name registrant bill of rights. Alternately, rather than affirmatively defining ICANN to a very narrow role, DoC might impose a users' bill of rights on ICANN, by describing things that ICANN should not do. In this formulation, ICANN would be required to be far more open, give greater advance notice of its plans, and be prohibited from making any rules that limited human rights or reduced the pre-existing legal rights of either

674. See supra note 12 (noting Auerbach's recent election to ICANN Board).

675. E-mail from Karl Auerbach, to ICANN wc-c Mailing List (Dec. 29, 1999), Domain Name Server Organization, http://www.dnso.org/wgroups/wg-c/Arc01/msg00456.html (on file with the Duke Law Journal).

676. Whether there should be a privacy-enhanced TLD or whether all TLDs should allow (or be required) to have "unlisted" personal contact information for registrants would probably be a policy issue, since the Internet would run fine either way. 
party in domain name-related disputes. Unfortunately, crafting the right list might be more difficult than trying to delineate the technical from the political. An overinclusive list might make ICANN's real technical job difficult; an underinclusive list would leave it open to expand into areas that would violate the APA or the Constitution. Furthermore, even a very well-drafted list would not be self-policing and, again, some kind of review or enforcement mechanism would be required.

c. A Contract with the Internet. A third method of limiting ICANN to technical policy would solve the policing problem, but at a substantial potential cost. ICANN often says it operates according to the Internet tradition of consensus. Meanwhile, however, it seeks contracts with key parties that would require them to obey ICANN. ${ }^{677}$ Similar contracts, however, could be used to make ICANN more accountable to the public. DoC itself once suggested that ICANN should contract with key stakeholders to "restrict its policy development" and to act in "accordance with the principles of fairness, transparency and bottom-up decision making." ${ }^{\text {"678 }}$ These agreements, DoC suggested, "give all who enter into agreements with ICANN a contractual right to enforce safeguards that are now contained in the ICANN bylaws and in the antitrust laws of the United States."

Rather than limit enforcement to corporations contracting directly with ICANN, Congress or DoC could insist that ICANN include third-party beneficiary agreements in favor of every holder of a unique domain name in a revised registry and registrar agreement. ${ }^{680}$ ICANN would promise openness, due process, even-handedness, user privacy, protection for noncommercial expressive activities, and agree

\footnotetext{
677. See ICANN-NSI Registry Agreement, supra note 42; Registrar Accreditation Agreement, supra note 42; see also supra notes 89-90 and accompanying text (describing ICANN's attempt to sign contracts with root server operators).

678. Pincus, supra note 43. DoC's General Counsel continued:

There is concern in the Internet community about the possibility of over-regulation, and therefore ICANN should assure all registrars and registries, through contract, that it will restrict its policy development activities to matters that are reasonably necessary to achieve the goals specified in the White Paper and that it will act in accordance with the procedural principles set forth in the White Paper.

679. Id.

680. See A. Michael Froomkin, ICANN Should Sign a Contract with the Internet, at http://www.icannwatch.org/archives/essays/932650853.shtml (July 22, 1999) (on file with the Duke Law Journal).
} 
to avoid facilitating content controls. Making promises for the benefit of registrants would empower the several million people directly affected by ICANN's actions to monitor and enforce the agreements. The large number of beneficiaries makes it an unusual use of this legal device, but so long as the beneficiaries are identifiable registrants, the odds are that most courts would enforce the deal. If ICANN got out of hand, registrants could sue individually or as a class. In one stroke, ICANN would be accountable to the Internet community.

Although this proposal should solve the accountability problem, it also could create a new and unwelcome problem in its stead: ICANN might spend too much time and money in court. ICANN already expends an excessive fraction of its resources on attorneys' fees, ${ }^{681}$ and an ideal solution would reduce this expenditure rather than multiply it.

2. Full Privatization? DoC has repeatedly assured Congress, the GAO, and the public that it has no current plan to relinquish its authority over the DNS. ${ }^{62}$ This is, however, a much weaker formulation than a promise never to do so. The GAO opined that legislation would be required to allow DoC to turn over its authority to ICANN, but it based that conclusion on the understanding that DoC's interest sounds in property; ${ }^{683}$ to the extent that DoC's interest in the DNS is purely contractual, the picture may be less clear.

Full privatization would solve the APA and constitutional issues identified in this Article, but, at least with the ICANN we have today, would do so at an unacceptable cost. As it stands, ICANN is accountable only to DoC, or to the so-far unlikely concerted action of the root server operators. ${ }^{684}$ Although ICANN is allowing a minority of its directors to be elected by a group of "members" (who are, ICANN insists, not members under California nonprofit law), ${ }^{685}$ these directors are to serve on sufferance: unless the other directors affirma-

681. For the 2000-01 fiscal year, ICANN expects that its total budget for professional and technical services, which include "agreements for legal services," will be $\$ 984,000$. ICANN's budget states its total expenditures, capital equipment, and reserve contribution for the 2000-01 fiscal year will be $\$ 5,024,000$. See 2000-01 Budget, supra note 41, tbl. 1 .

682. See supra note 43.

683. See supra note 44 and accompanying text.

684. ICANN is also contractually obligated to registrars and NSI to allow them to challenge claims that future policies are the product of consensus. See supra note 42 and accompanying text.

685. See supra note 39. 
tively act to recreate the elected positions, they will sunset in two years. Thus, accountability to the public remains very limited and contingent.

Were DoC to complete the "transition" to a "privatized" root in ICANN's control, there would be little other than the good sense of ICANN's directors to prevent serious mission creep. Under the banner of "technical standard setting," and using the UDRP as its guide, ICANN might reasonably decide to require that all DNS users agree to a code of conduct that punishes spammers, domains hosting objectionable material such as child pornography, or hosts of hate speech. ${ }^{686}$ Given ICANN's composition and early direction, efforts to further optimize the Internet for the protection of intellectual property rights would be more likely. ${ }^{67}$

Just how negligible the public control over ICANN would be were DoC to give it full control of the root can be seen by imagining what, other than the self-restraint of its officers, would prevent ICANN from turning itself into a for-profit concern, or leasing its power of the DNS to the highest bidder. The answer is: not much. ${ }^{688}$ Already, even while ICANN is accountable to DoC, neither ICANN nor DoC feel accountable to outsiders or the public for ICANN's actions. ${ }^{69}$ There is no reason to believe ICANN is corrupt, and even the

686. There is a strong sentiment in some quarters that "industry self-regulation" should be used to ban hate speech on the Internet. See generally J.M. Balkin et al., Filtering the Internet: A Best Practices Model 2-10 (Sept. 15, 1999) (arguing that self-regulation is the only effective means of controlling Internet content), http://webserver.law.yale.edu/infosociety/Filtering5.rtf (on file with the Duke Law Journal); Self-Regulation of Internet Content, Bertelsmann Foundation, at http://www.stiftung.bertelsmann.de/internetcontent/english/download/Memorandum.pdf (1999) (examining the need for and structure of a self-regulating system for the control of Internet content) (on file with the Duke Law Journal).

687. Early in the ICANN process, rights holders worried about the ease with which the Internet can be used to violate their copyrights were already demanding that "whois"- the DNS function that allows anyone to see who has registered a domain name-be set up in a way that made tracking suspected violators easier-and that was before Napster.

688. The only potential source of limits would be California nonprofit law. But the California law imposes few, if any, meaningful limits on management discretion. For example, the ICANN management could engage a for-profit group to manage the DNS under contract, or it could form a joint venture with a profit-making body. Indeed, nonprofit tax-exempt organizations in California appear to be almost perfect examples of Berle and Means's "managerial firm" in which ownership can be fully separated from control. $C f$. CAL. CORP. CODE $\$ \S 5049$, 5410; Adolph A. Berle, JR. \& Gardiner C. MeAns, the Modern Corporation AND PRIVATE PROPERTY (1932).

689. As one ICANN critic put it:

ICANN is less accountable by far, in terms of how it's being designed, than the WTO is. I mean at least at WTO ... if we want to get change in the WTO, and in fact we do this, we actually talk to governments. We're talking right now to the French, the 
people who have questioned the size of its legal expenditures have not suggested that the billed services were fictitious, only excessive. ${ }^{690}$ Nevertheless, ICANN's structural similarity to the unaccountable International Olympic Committe ${ }^{691}$ is worrying and suggests that the U.S. government should not permanently transfer functions to it until either its role can be limited to purely technical matters or some other form of accountability is built in.

Thus, while it would solve DoC's legal problem, full privatization might require congressional authorization, which might justifiably be difficult to obtain. And given ICANN's performance to date, the case for unshackling it from DoC's oversight seems marginal at best.

3. Give the DNS to an International Body? One of the strongest arguments against continuing control over the DNS by a U.S. federal government agency is that the domain name system has international effects. Why, foreign governments reasonably ask, should the United States be allowed to dominate this increasingly critical element of the international communications infrastructure? In response to the belief that some sort of international public law solution would be most appropriate, some have proposed creating a new treaty-based body or a new intergovernmental or international semi-governmental entity. $^{692}$

\footnotetext{
Norwegians, the Australians, the South Africans, the Thai,... the Pakistanis,... [about] different changes we want to see in negotiations with WTO. I mean, it's pretty hard to do, but in some ways it's easier than dealing with ICANN. See because there's some process, there's some political process.... Governments tend to have a broader set of interests than big companies do, big profit-making companies do. I mean, what do we do, lobby Disney? I don't want to do that. I don't know anybody that does.
}

Gina Paik \& P-R Stark, The Debate Over Internet Governance: Jamie Love IV.g., Berkman Center for Internet and Society, at http://cyber.law.harvard.edu/is99/governance/love.html (2000) (quoting remarks of Director of Consumer Project on Technology James Love) (on file with the Duke Law Journal).

690. See, e.g., Karl Auerbach, Platform: Reform of ICANN-Jones Day Must Go, http://www.cavebear.com/ialc/platform.htm\#reform-jdmg (last modified Aug. 10, 2000) (proposing that Jones, Day be replaced as ICANN's lawyers in part because they are too expensive) (on file with the Duke Law Journal).

691. See generally George J. Mitchell et al., Report of the Special Bid Oversight Commission (Mar. 1, 1999) (reporting that the IOC's governing structure does not provide adequate accountability), Sydney Morning Herald, http://www.smh.com/au/news/content/olyscandal/report. html (on file with the Duke Law Journal).

692. See, e.g., PFIR Statement on Internet Policies, Regulations, and Control, People For Internet Responsibility, at http://www.pfir.org/statements/policies (July 23, 2000) (calling for "a completely new, more formally structured, not-for-profit, internationally-based organization") (on file with the Duke Law Journal). 
While the United States' accession to any such agreement would most likely resolve the domestic law problems discussed earlier, it would not do much to solve the underlying public policy problems that animate those challenges and, in fact, threatens to make them worse. If the greatest problem with ICANN's relationship with DoC is that it is making public policy outside of normal channels of accountability, then placing similar power in a supranational or transnational entity equally insulated from the public hardly seems much of an improvement. Again, the specter of the International Olympic Committee comes to mind. It is hard to see how an undemocratic solution based on the international system in which a tyranny's vote is as valid as a democracy's vote would be a material improvement on ICANN itself. And while it is possible to imagine a body limited to democratic governments, it is unlikely that the United States and other democracies would wish to expend the political capital it would cost to close the door to nations that fail to ensure basic human rights and representative government.

4. True Stewardship? The White Paper's four principles for Internet governance were "stability, competition, private bottom-up coordination, and representation." ${ }^{, 693}$ These are good principles, but only because they are means towards the more fundamental goals of using the Internet to enhance freedom and increase human wealth and well-being around the globe. If the United States is going to retain ultimate control over the root file, it should use this power wisely, in a manner that both furthers those goals and appears sufficiently decentralized and transnationalized to calm foreign concerns regarding U.S. dominance of the Internet.

A decentralized and transnationalized policy is also wise because it is unlikely that any single group is wise enough to craft criteria for domain name policy, given all the diverse interests that have an interest in it. As the freest and most robust communications medium since paper and ink, the Internet offers an enormous potential for enhancing the freedom of expression, and supporting the rise of democracy, around the globe. ${ }^{694}$ It offers new ways of sharing information be-

693. White Paper, supra note 15, at 31,743.

694. See, e.g., Robert H. Anderson et al., Universal Access to E-Mail: Feasibility and Societal Implications, at http://www.rand.org/publications/MR/MR650 (1995) (on file with the Duke Law Journal); Dana Ott, Power to the People: The Role of Electronic Media in Promoting Democracy in Africa, 3 FIRST MONDAY 4 (1998), at http://www.firstmonday.dk/issues/issue3_4/ott/ (on file with the Duke Law Journal). 
tween nations and peoples. It also offers enormous opportunities for increased commercial efficiency, the growth of e-commerce, and the creation of new wealth.

Centralizing control over the creation and naming of TLDs in a single body such as ICANN seems attractive because leaders in the technical community have stated that name collisions must be avoided or the Internet as we know it is in danger. ${ }^{695}$ In their view, "stability" requires a hierarchical root. They are far more concerned about preserving the uniqueness of domains and names than they are about how many new TLDs are created, ${ }^{696}$ although there are also concerns about the orderly creation of new TLDs. But centralization in policy, just as in routing technology, creates a single point of potential failure. ${ }^{697}$ This is unwise. The challenge, therefore, is to find a way to decentralize policy control over TLDs and names while preserving uniqueness and preventing too many new TLDs from being created in a very short space of time.

It turns out that decentralizing yet coordinating TLD policy is within the reach of DoC in a single new rulemaking. DoC should begin by identifying a relatively small number of policy partners, say, somewhere between five and thirty. Each policy partner would get a share of the TLD space to manage, which would give it the opportunity to add an agreed number of TLDs to the root within that space and to design whatever policy regime it thought was appropriate for those TLDs.

The policy partners could be, and should be, diverse. In addition to the United States itself, obvious choices include supra-regional bodies such as the EU and ASEAN. However, in the interest of maximizing diversity, domestic and foreign nongovernmental organizations should also be represented. ${ }^{698}$ Choosing a wide range of policy partners would make for a much greater private and "bottom-up"

695. See supra note 73 and accompanying text.

696. See supra note 12 .

697. That centralized policymaking leads to error-if not tyranny-is perhaps the central insight of the Framers. Both horizontal separation of powers and federalism (vertical separation of powers) are structural responses to this insight. See generally THE FEDERALIST No. 28 (Alexander Hamilton), No. 51 (James Madison).

698. Perhaps by an elected council from those accredited to the UN, see Directory of NGOs Associated with DPI, at http://www.un.org/MoreInfo/ngolink/ngodir/NGODirAlph/ alphabet.htm (last visited Oct. 1, 2000) (maintaining a directory of such organizations) (on file with the Duke Law Journal). 
policy formation process than would be possible with a single centralized organization such as ICANN or DoC itself.

A few prophylactic measures will avoid replicating the due process issues raised by the ICANN experience. In its rulemaking, DoC would need to ensure that its future relationship with its policy partners complies with the Due Process Clause. Selecting participating foreign governments and supra-national associations carefully should allow DoC to declare that the selected partners' procedures comply with due process. Once selected, the governmental partners' decisions would be subject to minimal process, perhaps only publication with a very limited challenge procedure before implementation. Constitutional concerns raised by delegations to private parties do not ordinarily apply to executive agreements with foreign governments, and the existence of countervailing constitutional values, including both comity and the President's foreign affairs powers, also suggests that an abbreviated procedure would be lawful. ${ }^{69}$

In contrast, the legal position of NGOs selected as policy partners would be much the same as ICANN's, and thus require more careful handling. In particular, DoC would have to set up a more thorough review process, perhaps one modeled on the SEC's oversight of self-regulatory exchanges; at a minimum, the NGOs proposed actions would need to be published, a federal official would need to certify that the proposals were fairly arrived at and in the public interest, and comments contesting this determination would need to be considered.

Portions of the TLD space could be delegated alphanumerically or by rota. In the first model, the EU, for example, might be given the right to create TLDs starting with certain letters of the alphabet, or TLDs of a certain length, or some combination of these constraints. Each partner would have a set of letter-length combinations for which it could create up to a defined number of TLDs per year, perhaps with other spacing constraints to ensure that not too many TLDs are created simultaneously. The letter-length combinations might either be assigned with some thought to linguistic appropriateness or simply by lot.

A pure rota scheme is slightly more complex but avoids the potential arbitrariness of giving some policy partners highly unattractive letter-length combinations; the winner of "six-letter-groups-starting-

699. The rulemaking portion of the APA does not apply to foreign affairs. See 5 U.S.C. $\S 553(\mathrm{a})(1)(1994)$. 
with-Z" might otherwise feel justly aggrieved. Once the policy partners have been identified, and perhaps given relative shares if some are to have a greater number of TLDs than others, a lottery is held among the partners, with each winner having as many tickets as they have shares. Tickets are pulled randomly, with the first winner being allowed to choose whatever TLD it wishes and to create it first. Each subsequent player can create any TLD except those already spoken for. In this way, TLD uniqueness is preserved but diversity, subsidiarity, and policy decentralization and internationalization are all enhanced. The total number of new TLDs can be limited by the number of tickets pulled in year, and creation dates can be controlled to prevent the possible chaos of large numbers of new TLDs debuting simultaneously.

An expansion of the name space in this fashion should serve the interests of all but one of the "stakeholder" communities interested in domain name policy. That one exception is, however, significant and powerful: holders of trademarks, especially famous (and perhaps also well-known) marks, usually oppose the creation of new TLDs because they fear the dilutive effects on marks that they have associated (or wish they had associated) with existing second-level domains in .com. Some Internet first-movers using common words in .com that may be too generic to trademark may also wish to prevent competitors from using the same second-level domain in a new TLD. Thus, for example, cars.com might worry about the creation of a cars.biz.

Generally speaking, the interest of holders of ordinary, nonfamous, trademarks should be helped more than harmed by a substantial increase in the number of TLDs. Increasing the number of TLDs certainly creates a risk of confusion, and that is not helpful. But increasing the number of TLDs also holds out the promise of greatly increasing the number of firms that can register names corresponding to their own names. ${ }^{700}$ Both Delta Air and Delta Faucets will be able to be delta.something if they want to be. Furthermore, cybersquatting should quickly decrease as the artificial shortage of attractive names ends-announce an impending increase in the supply of a previously rationed commodity and watch the price drop. The main losers among the holders of ordinary, non-famous, trademarks will be Internet first-movers who will find their rents caused by the scarcity

700. Since trademarks are limited by geography and type of business, many firms commonly have the same trademark either for the same goods in different places, or different goods in the same place. 
of good names to be diminished. All other firms seeking an easy mnemonic tend to be better off.

The combination of famous mark holders and Internet firstmovers constitutes the making of a blocking coalition in any process that relies on consensus. An enlightened legislature, or an agency pursuing an enlightened policy, would be asked to balance these interests against the greater good-note that traditionally a trademark right, even in a famous name, is a right to seek redress for the commercial misuse of that mark, not to preemptively block all possible uses, even noncommercial ones. In my opinion, the balance clearly points towards ending the artificial scarcity of TLDs, preferably by instituting a policy partner program.

Of course, neither Congress nor DoC are necessarily so enlightened at all times. The trademark lobby is politically powerful, and it is quite possible that it could block any proposal that threatened a large number of new TLDs. For example, Congress might act to impose an arbitrary limit on the number of new TLDs in the ICANN-controlled root. If that happens, however, it is still a preferable outcome to having ICANN choose the arbitrary limit (currently set at less than ten). If Congress or the executive make poor policy choices, they can at least in theory be punished at the polls. Against ICANN the citizen currently has no redress at all.

Most Internet users do have one ultimate recourse against overcentralized control of the DNS: They can switch to an alternate root, one that does not rely solely, or at all, on the ICANN-regulated root. Depending on how the new root works, it might supplement or even entirely replace the legacy system. A supplemental root would mirror the legacy root's data, and add extra TLDs of its own. ${ }^{701}$ Given the network effect associated with the dominance of the current DNS, ${ }^{702}$

701. This is the concept behind the "superroot." See The Stable Implementation of New Top Level Domains, The SuperRoot Consortium, at http://www.superroot.net/ (last visited Oct. 13, 2000) ("The SuperRoot Consortium root is not an alternative to the IANA/ICANN legacy root since we use the IANA/ICANN legacy root as our foundation. The SuperRoot Consortium root can be thought of as a 'staging root' for the testing and implementation of new top level domains.") (on file with the Duke Law Journal); supra notes 61, 75 and accompanying text (describing the alternate root run by the Open Root Server Confederation).

702. See Froomkin, A Commentary on WIPO's Management, supra note 13, If 78; Craig McTaggart, Governance of the Internet's Infrastructure: Network Policy for the Global Public Network, § III.A.2.B, Unit for Internet Studies, at http://www.internetstudies.org/members/ craimct/thesis/section3.htm (last updated July 25, 2000) (noting that since the early days of networked computing, "the value of being connected was steadily rising as more and more other networks joined") (on file with the Duke Law Journal). 
this is a difficult, even costly solution. Moreover, changing roots can be complex for the average user, ${ }^{703}$ and can be blocked upstream by an ISP. ${ }^{704}$

DoC and ICANN appear to understand that alternate roots threaten their vision of the Internet, and their control over a critical component of it. Both DoC and ICANN have gone out of their way to disable ICANN's policy competitors. Recall that in the tripartite agreements, DoC required NSI to promise "not to deploy alternative DNS root server systems," to further "the interest of the smooth, reliable and consistent functioning of the Internet." ICANN's solicitation for applications to create and host new TLDS listed a number of its criteria for choosing among applications. First among them-first! - was that the new TLD "should not disrupt current operations, nor should it create alternate root systems.",706

\section{CONCLUSION}

This Article began by repeating the adage that the Internet is notoriously decentralized and unhierarchical. But the ICANN story reminds us of important ways in which that perception was always false: a critical portion of the Internet infrastructure relies on a single hierarchy, one that is subject to capture.

The battle over control of domain name policy is only part of a larger trend in which the centrifugal forces of the Internet war with powerful centralizing tendencies. The long-run trend is increasingly difficult to discern as the two opposing tendencies intensify. On the one hand, new client software continues the trend of decentralizing content and services. The recent progression has gone quickly from a centralized registry that keeps upload/download logs (Napster), to a decentralized registry with logs (Gnutella), to a decentralized, anonymized, redundant distribution of objects (Freenet), and will soon have an encrypted decentralized, anonymized, redundant distri-

703. For example, see the Instructions at http://www.superroot.net/how-to.html (last visited Oct. 10, 2000) (on file with the Duke Law Journal); see also note 75 (explaining how to access the ORSC root).

704. My current provider of DSL services, BellSouth, blocks http calls to non-ICANN domain names. Oddly, all other protocols, including telnet and ftp, work fine.

705. Amendment 19, supra note 301, § I.B.4.E.

706. Criteria for Assessing TLD Proposals, $\S 1$, at http://www.icann.org/tlds/tld-criteria15aug00.htm (Aug. 15, 2000) (on file with the Duke Law Journal). 
bution of objects. ${ }^{707}$ New services promise secure online anonymity. ${ }^{708}$ On the other hand, routing topography has gradually concentrated traffic along a few major thoroughfares, thus drastically concentrating and centralizing the Internet. ${ }^{709}$ Governments around the world are also expressing increasing concern about the anarchic forces they fear the Internet may unleash, ${ }^{710}$ suggesting that the centralizing trend will continue to have powerful promoters.

ICANN is only one battleground in this larger conflict, but it happens to be one that is, or should be, subject to the values of due process, equal protection, openness, and accountability instantiated in U.S. public law. It remains true that "nothing is more certain than that beneficent aims, however great or well directed, can never serve in lieu of constitutional power." reliance on ICANN is not the corporation's secretiveness, or its deci-

707. See, e.g., John Markoff, Cyberspace Programmers Confront Copyright Laws, N.Y. TIMES, May 10, 2000, at A1; Ian Goldberg \& David Wagner, TAZ Servers and the Rewebber Network: Enabling Anonymous Publishing on the World Wide Web, 3 FIRST MONDAY 4 (1998), at http://www.firstmonday.dk/issues/issue3_4/goldberg/index.html (on file with the Duke Law Journal); Andy Oram, Gnutella and Freenet Represent True Technological Innovation, at http://www.oreillynet.com/pub/a/network/2000/05/12/magazine/gnutella.html (May 12, 2000) (on file with the Duke Law Journal).

708. See, for example, the web page for one such company, ZeroKnowledge Systems, at http://www.zeroknowledge.com (last visited Oct. 1, 2000) (on file with the Duke Law Journal).

709. See Réka Albert et al., Error and Attack Tolerance of Complex Networks, 406 NATURE 378 (2000) (suggesting that because the WWW is an "exponential" rather than "scale-free" network, it is vulnerable to failure at key points), available at http://www.nature.com/cgitaf/DynaPage.taf?file=/nature/journal/v406/n6794/full/406378a0_fshtml\&_UserReference=D823 49ED46B4E09D92A99AAF93F139E898C1 (on file with the Duke Law Journal); see also Telegeography, Inc., An Atlas of Cyberspace: Topology Maps of Elements of Cyberspace, UCL Department of Geography, at http://www.geog.ucl.ac.uk/casa/martin/atlas/topology.html (last visited Oct. 15, 2000) (mapping Internet as sets of hubs and spokes and showing fractal, but distinctly centralized, Skitter diagrams of Internet connections) (on file with the Duke Law Journal).

710. See, e.g., Carl S. Kaplan, French Nazi Memorabilia Case Presents Jurisdiction Dilemma, N.Y. TIMES, Aug. 11, 2000 (reporting that states are concerned about cross-border offenses, including hate speech, libel, and fraud), http://www.nytimes.com/library/tech/00/08/cyber/ cyberlaw/11law.html (on file with the Duke Law Journal); Reuters, German Urges Global Rules on Hate on Web, N.Y. TIMES, June 28, 2000 (reporting the German Justice Minister's call for global rules against hate speech), http://www.nytimes.com/library/tech/00/06/biztech/articles/ 28tech-germany.html (on file with the Duke Law Journal); Leonard R. Sussman, Censor Dot Gov, at http://www.freedomhouse.org/pfs2000/sussman.html (last visited Oct. 4, 2000) (surveying countries' domestic content and access control laws); see also A. Michael Froomkin, The Empire Strikes Back, 73 CHI.-KENT L. REV. 1101, 1114-15 (1998) (arguing that reactive antidemocratic supranational agreements by governments frightened by regulatory arbitrage may be "the great looming Internet irony").

711. Carter v. Carter Coal Co., 298 U.S. 238, 238 (1936). 
sions, or its fight against accountability. Rather the problem is that DoC's reliance on ICANN, and endorsement of its activities, undermines basic elements of accountability and due process on which the administrative state is based. By lending ICANN its control over the DNS, DoC created a system in which social policy is made not by due process of law but by something that begins to resemble governmentsponsored extortion. ICANN is able to use its control over the legacy DNS to impose conditions-on domain name registrants, registrars, and registries - that owe nothing to the free market or properly constituted regulation and cannot fairly be called "standard making" or "technical coordination." ICANN's UDRP offers little that a registrant would want, as it creates a third-party benefit potentially available to any aggrieved trademark holder in the world. ICANN's control over the DNS also gives it the leverage to demand fees from other participants in the DNS, especially registrars and registries.

So long as ICANN is making policy decisions, however, DoC's arrangement with ICANN either violates the APA, for ICANN is making rules without APA rulemaking, or it violates the nondelegation to private parties doctrine set out in Carter Coal. Were ICANN's mission to be limited more strictly to technical matters, DoC's reliance on it would not be illegal. An ideal solution to the DNS policy problem would both redefine ICANN's mission more narrowly and share out the responsibility for managing the domain name space with both public and private "policy partners," who would each manage a unique portion of the top-level domain space in order to ensure a more decentralized, competitive, robust, diverse and freedomenhancing approach to the DNS. 